\title{
The combinatorial chemistry revolution : sustaining a superior performance position through technological learning
}

Citation for published version (APA):

Malo, S. (2003). The combinatorial chemistry revolution : sustaining a superior performance position through technological learning. [Doctoral Thesis, Maastricht University]. Universiteit Maastricht. https://doi.org/10.26481/dis.20031015sm

Document status and date:

Published: 01/01/2003

DOI:

10.26481/dis.20031015sm

Document Version:

Publisher's PDF, also known as Version of record

Please check the document version of this publication:

- A submitted manuscript is the version of the article upon submission and before peer-review. There can be important differences between the submitted version and the official published version of record.

People interested in the research are advised to contact the author for the final version of the publication, or visit the DOI to the publisher's website.

- The final author version and the galley proof are versions of the publication after peer review.

- The final published version features the final layout of the paper including the volume, issue and page numbers.

Link to publication

\footnotetext{
General rights rights.

- You may freely distribute the URL identifying the publication in the public portal. please follow below link for the End User Agreement:

www.umlib.nl/taverne-license

Take down policy

If you believe that this document breaches copyright please contact us at:

repository@maastrichtuniversity.nl

providing details and we will investigate your claim.
}

Copyright and moral rights for the publications made accessible in the public portal are retained by the authors and/or other copyright owners and it is a condition of accessing publications that users recognise and abide by the legal requirements associated with these

- Users may download and print one copy of any publication from the public portal for the purpose of private study or research.

- You may not further distribute the material or use it for any profit-making activity or commercial gain

If the publication is distributed under the terms of Article 25fa of the Dutch Copyright Act, indicated by the "Taverne" license above, 


\section{The Combinatorial Chemistry Revolution.}

Sustaining a Superior Performance Position through Technological Learning

\section{PROEFSCHRIFT}

ter verkrijging van de graad van doctor aan

de Universiteit Maastricht,

op gezag van de Rector Magnificus, Prof. dr. A.C. Nieuwenhuijzen Kruseman volgens het besluit van het College van Decanen, in het openbaar te verdedigen

op woensdag 15 oktober 2003 om 14.00 uur

Stéphane Malo 
Promotor

Prof. Dr. Robin Cowan

Beoordelingscommissie:

Prof. Dr. P.A. Mohnen, voorzitter

Prof. Dr. J.G.A.M. Lemmink

Prof. Dr. A-P. de Man, Technische Universiteit Eindhoven

ISBN 90-5681-183-5 
Dedicated to Monique and Gaétan Malo 



\section{Acknowledgment}

I wish to express the greatest thanks to my $\mathrm{PhD}$ director, Robin Cowan, MERIT and supporting staff for their assistance in the preparation of this thesis. It is their support which motivated me all the way to bring this work. I am also very much grateful to the following list of persons for helping me with completing this thesis: Sylvain Dansereau, Pierre Dubé, Geert Duysters Armand Guicherit, Nicolas Jonard, Önder Nomaler, Fabio Pammoli (EPRIS), Alain Rajotte, Andreas Reinstaller, Benoit Simon, Edward Steinmuller and Mario Vendittotli. Last but not least, I must convey my utmost gratitude to Aldo Geuna. Without his support and generosity, this thesis would not have been possible. Thank you.

Hospitality and encouragement from the Centre Interuniversitaire de Recharche sur la Science et Technologie (CIRST) also worked wonders for me. Sincerely, I couldn't have done without the support of Jorge Niosi, Jean-François Auger, Yves Gingras and Raymond Laliberté. The thesis has also benefited from the professional work and mappings of Ard-Pieter de Man at the Centre for Global Corporate Positioning (CGCP) as well as Daniel Malo and Xavier Riotte at the Centre d'intervention pour la revitalisation des quartiers (CIRQ). I also greatly appreciated the ongoing support of Maureen McKelvey and the department of Industrial Dynamics at Chalmers University of Technology.

Finally, it gives me great pleasure to say that I have received great motivation when scientists and entrepreneurs answered back to my information requests. Special thanks are due to Roland Dolle, Ronald Frank, Arpád Furka, Peter Grund, John Hewes, Hugo Kubinyi, Roger Lahana, Morten Meldal and Arno Spatola. Financial support from the Social Sciences and Humanities Research Council of Canada (SSHRC) is also gratefully acknowledged.

Göteborg, May, 2003

Stéphane Malo 



\section{CONTENTS}

List of Figures

List of Tables

1. INTRODUCTION

\section{PART I THE THEORY}

2. TECHNOLOGICAL LEARNING AND SUPERIOR PERFORMANCE

2.1 Introduction

2.2 Preliminary tenets from the resource-based theory of the firm

2.3 Knowledge as the single most important resource of the firm

2.3.1 Taxonomy of knowledge

2.3.2 Knowledge as a semi-public, semi-private good

2.4 Technological learning as the single most important process of the firm

2.4.1 Technological learning

2.4.2 Stock of accumulated knowledge

2.4.3 Path dependence 33

2.5 Technological discontinuities and market structures 34

2.5.1 On discontinuous technological change 35

$\begin{array}{ll}2.5 .2 \text { Structural implications } & 36\end{array}$

2.6 Concluding remarks 38

PART II THE TECHNOLOGY

3. ON THE EMERGENCE AND EXPANDING KNOWLEDGE BASE OF 43 COMBINATORIAL CHEMISTRY

3.1 Introduction 43

3.2 Combinatorial chemistry: origins, methods and principles 44

3.3 The expanding knowledge base of combinatorial synthesis methods 48

3.3.1 The pre-clinical steps of the combinatorial approach to drug discovery 60

$\begin{array}{ll}\text { 3.3.2 Knowledge-based combinatorial chemistry: } & 67\end{array}$ when combinatorial chemistry meets rational drug design

3.3.3 From pharmaceuticals to new materials, catalysts, pesticides, etc. $\quad 67$

$\begin{array}{lll}3.4 & \text { Concluding remarks } & 70\end{array}$

\section{PART III THE ACTORS}

4. COMBINATORIAL CHEMISTRY AND NEW ENTRANTS 75

$\begin{array}{lll}4.1 & \text { Introduction } & 75\end{array}$

$\begin{array}{lll}4.2 & \text { The rise of new entrants } & 76\end{array}$ 
4.3 Technological learning in a turbulent environment 81

4.3.1 Phase 1: The firm as a provider of compound libraries (1988-1995) 81

4.3.2 Phase II: The firm as a provider of chemical-based services and 83 products (1995-2001)

4.3.3 The dynamics of external learning between new entrants and 91 smaller firms

$\begin{array}{ll}4.4 & \text { Learning through acquisitions } \\ & 100\end{array}$

$\begin{array}{ll}4.5 & \text { Concluding remarks } \\ \end{array}$

5. COMBINATORIAL CHEMISTRY AND LARGE INCUMBENTS 107

$\begin{array}{lll}5.1 & 107\end{array}$

$\begin{array}{ll}5.2 & \text { The entry of large pharmaceutical firms } \\ 5.308\end{array}$

5.3 Dynamics complementarities between new entrants and large $\quad 116$

5.4 GlaxoSmithKline: a case study of competence building in combinatorial 122 chemistry

$\begin{array}{lll}5.5 & \text { The entry of (agro) chemical firms } & 127\end{array}$

$\begin{array}{ll}5.6 & 130\end{array}$

6. COMBINATORIAL CHEMISTRY AND SCIENTIFIC ORGANIZATIONS

$\begin{array}{lll}6.1 & 131\end{array}$

6.2 The contribution of scientific organizations to industrial innovation 132

$\begin{array}{ll}\text { 6.3 Tapping into public research } & 137\end{array}$

6.3.1 Formal interorganizational agreements between new entrants and 137 scientific organizations

6.3.2 Informal interorganizational agreements between new entrants and 142 scientific organizations

$\begin{array}{lll}\text { 6.3.3 The provision of vocational skills } & 145\end{array}$

$\begin{array}{lll}\text { 6.3.4 The creation of spin-offs } & 146\end{array}$

$\begin{array}{ll}6.4 & 149\end{array}$

\section{PART IV THE PERFORMANCE}

7. DETERMINANTS OF HIGHER PERFORMANCE IN A TURBULENT ENVIRONMENT 153

$\begin{array}{lll}7.1 & \text { Introduction } & 153\end{array}$

$\begin{array}{lll}7.2 & \text { Hypotheses } & 154\end{array}$

$\begin{array}{ll}7.3 & 159\end{array}$

$\begin{array}{lll}7.4 & \text { Results } & 161\end{array}$

$\begin{array}{ll}7.5 & 165\end{array}$

References $\quad 171$

$\begin{array}{lr}\text { Nederlendse Samenvatting } & 195\end{array}$

$\begin{array}{ll}\text { Curriculum vitae } & 201\end{array}$ 


\section{List of Figures}

Figures Pages

3.1 Nomenclatures of combinatorial synthesis methods 45

3.2 A view of technological trajectories in combinatorial 47 chemistry

3.3 The knowledge plot 63

3.4 Growth in the number of structures in the Protein Data 66 Bank

4.1 De novo entry, entry by diversification and entry following $\quad 78$ merger and acquisition in combinatorial chemistry -by year foundation

4.2 Average size of alliances -in million dollars (1980-2001) 82

4.3 Strategic alliance network -Discovery Partners 85

4.4 Increase in the number of formal interorganizational 92 agreements by new entrants with smaller firms, large incumbents and scientific organizations (1982-2001)

4.5 Increase in the number of mergers and acquisitions 100 (1982-2001)

4.6 Strategic alliance network -Pharmacopeia 102

$5.1 \quad$ Growth of published combinatorial libraries 113

- new entrants versus large incumbents

5.2 Strategic alliance network -Glaxo (1992-1995) 124

5.3 Strategic alliance network -GlaxoWellcome (1995-2000) 124

6.1 Increasing volume of public research in combinatorial 135 chemistry as measured by published libraries -by geographic location (1992-2000)

6.2 Location of new entrants and research output of scientific 148 organizations in combinatorial chemistry as of 2000 


\section{List of Tables}

Tables

3.1 Miniaturization of microtitre plates

3.2 Comparing the parallel synthesis approach with traditional chemistry in the discovery of lead compounds for the treatment of glaucoma

3.3 Comparing the Symyx combinatorial approach with traditional chemistry in the discovery of promising materials

4.1 Selected consolidated financial data of new entrants (1996-2001)

4.2 Formal network: Increase in number of alliances between new entrants aand smaller firms (1984-2001)

5.1 Summary of lead compounds discovered by combinatorial means -by large incumbents

5.2 Top 15 large incumbents for combinatorial libraries (1992-2000) 114

$\begin{array}{lll}5.3 & \text { Mergers and acquisitions (1991-2001) } & 115\end{array}$

5.4 Formal network: Increase in number of alliances between new 120 entrants and large incumbents (1984-2001)

5.5 Top 10 large (agro)chemical firms for number of alliances $\quad 129$

6.1 Summary of lead compounds discovered by combinatorial means 133 -by scientific organizations (1999-2001)

6.2 Top 20 scientific organizations for published libraries 136

6.3 Formal network: Increase in number of alliances between new 139 entrants and scientific organizations (1984-2001)

6.4 Formal network: top 15 scientitic organizations for number of 140 alliances (1984-2001)

6.5 Formal network: alliances between new entrants and scientitic 142 organizations-by geographical location (1988-2001)

6.6 Informal network: co-authorship of scientific papers between new entrants and scientific organizations -by geographical location (1986-1996)

6.7 Informal network: Top 15 scientitic organizations for number of coauthorship of scientific papers

6.8 Scientific organization spin-offs

$7.1 \quad$ Descriptive statistics of new entrants in $2001 \quad 161$

$\begin{array}{lll}7.2 & \text { Intercorrelation matrix } & 164\end{array}$

7.3 Regression model with revenue per employee as the dependent 165 variable 


\section{Introduction}

Economists have, for the most part,

found the whole subject of knowledge too slippery too handle

- Edith Penrose (1957)

A common theme in industrial organization $(\mathrm{I} / \mathrm{O})$ economics is the notion that external forces shape the profit potentials of individual firms. Profits, or the lack thereof, are industry driven, and are largely seen to be determined by market power and industry structure. Early neo-classical perfect competition theory concluded that whatever short-run profit an individual firm is able to reap is eventually eroded by the entrance of more firms, driving prices down and yielding market equilibrium of zero economic profits (Stigler 1957). Conceding that the presence of alternative market structures within which individual firms have the power to influence the price of their products and services, the first wave of $\mathrm{I} / \mathrm{O}$ theorists, led by Mason $(1957,1966)$ and Bain $(1951,1954)$, argued that profits were only possible if oligopolistic and monopolistic firms created entry barriers for the whole industry. Seen through Porter's theory of competitive forces (1979a, 1979b, 1980), a firm's ability to capture economic rents is largely determined strategic group memberships, which involves the erection of different mobility barriers that insulate the strategic group from entry by 
rivals.

These outward-oriented theories turned out to be very fruitful for economic exploration, but they also have drawbacks. In the first place, they have dominated research thinking for so long that it is tempting to suggest that firms could only improve their performance by finding an attractive industry and/or by harnessing or suppressing competition. In Porter's words: "Strategy can be viewed as building defenses against the competitive forces or finding positions in the industry where the forces are weakest" (1979a: 140). ${ }^{1}$ As this statement suggests, a "superior" firm is essentially a firm that operates in an industry with high barriers to entry, and/or formulates a strategy that prevents outsiders from occupying a similar strategic position. In the second place, the $\mathrm{I} / \mathrm{O}$ paradigm fails to explain, or even acknowledge, the phenomenon of interfirm differences in efficiency within industry and strategic group. The critical issue as to why, for instance, ArQule had revenues per employee totaling \$US 152,000 in 2001 while Cortech went out of business remains unanswered. Same industrial group, same barriers to entry, same market (e.g. chemical-based services and products), different performance. Why? In this context, a firm seeking to outperform its rivals will only find limited guidance in the essentially static I/O literature.

To accommodate the problems arising from the $\mathrm{I} / \mathrm{O}$ perspective, the knowledge-based analysis of superior performance developed in this thesis will combine contributions from the resource-based theory of the firm, the emerging knowledge-based theory of the firm, evolutionary economics, economics of innovation, organizational learning and the industry life cycle literature. In particular, the theory subscribes to the resource-based view of the firm that is closely associated with the firm's rare, valuable, non-imitable and non-substitutable bundle of resources and competences. This knowledge-based model, however, posits the need to integrate dynamic considerations and reframes the central principles of the resource-based theory of the firm to highlight knowledge as the single most important resource of the firm. The idea that superior performance depends mainly on this intangible asset is based on the fundamental premise that a firm must repeatedly innovate in order to survive and grow in an environment where customers demand changes rapidly, competition intensifies and technological change is characterized by high complexity, high uncertainty and high velocity. More importantly, it is assumed that knowledge is by no means static, implying that its creation can only reinforce a firm's competences and hence competitive standing in such environment. Learning, therefore, is of

1. Porter (1980) identifies three generic strategies: (1) overall cost leadership (i.e. to produce the same or better quality product at less cost than rivals); (2) differentiation (i.e. to produce a different or better product/service from rivals); and (3) market niche/segmentation (i.e. to service a narrow target more effectively than rivals). 
crucial importance to reach and sustain a high performance position.

This theory also considers the impact of technological discontinuities on market structures. Thus, the thesis examines two kinds of technological discontinuities: (1) competence-destroying discontinuities and (2) competence-enhancing discontinuities. The implication drawn from this distinction is that competence-destroying discontinuities can shift the competitive emphasis in favor of new entrants, whereas competenceenhancing discontinuities give a long-term advantage to large incumbents.

\section{Knowledge-based theory of the firm and combinatorial chemistry}

From a theoretical point of view, combinatorial chemistry (or combichem) provides an interesting background for presenting a knowledgebased theory of the firm. As will later be shown, firms using combinatorial chemistry operate in a turbulent environment, where technology, demand and competition rapidly evolve. Innovations, obviously, occupy center stage. In addition, combinatorial chemistry, which is here defined as "the systematic and repetitive, covalent connection of a set of different "building blocks" of varying structures to each other to yield a large array of diverse molecular entities" (Gallop et al. 1994:1233), presents all the attributes of a competence-enhancing process discontinuity. On the one hand, combinatorial synthesis and combinatorial drug discovery largely rest on a knowledge base that has been around for decades, already known and shared by a large network of universities, public research institutions, large established firms, etc. On the other hand, the days of laborious, expensive and slow organic synthesis are long gone. Where a team of chemists would previously produce one molecule a week at a cost of $\$$ US 7-8000, scientists have now the possibility to synthesize, hundreds, if not thousands of molecules a week at a cost of \$US 8-12 per unit.

This latter point cannot be overstressed, given that the main bottleneck in the therapeutic drug market is no longer biological, but chemical. Almost every drug works through a structural interaction with a target protein that plays key roles in the disease process. Typically, a drug binds to a target, like a key in a lock, and either induces or inhibits the protein's normal function. While all drug discovery programs traditionally aimed at about 500 molecular targets (Drews 1997), the explosion of new targets stemming from the Human Genome Project now puts the burden of innovations on the shoulders of organic chemists. "We're in a very target-rich but lead-poor post-genomics era for drug discovery", explains Raymond Stevens, researcher at the Scripps Research Institute and co-founder of Syrrx (Henry 2001a:69). In summary, chemistry is once again the main driver of technological change in the pharmaceutical industry.

No wonder, then, that The Economist put combinatorial chemistry on its 
list of technologies "to watch" in 1996. Two years later, the scientific journal Science (1998) brought further attention to this technology, recognizing it as one of nine discoveries that transform our ideas about the natural world. In 2000, Time magazine named Peter Schultz, a pioneer scientist-entrepreneur in the field, one of the most important innovators of the century. No study to date, however, has documented what is one of the most important technological achievements to happen in the pharmaceutical industry since the first gene splicing experiment by Cohen and Boyer in 1973. In 1995, the technology has even entered the arena of new materials, polymers, phosphors, catalysts and agrochemicals. Although the ensuing generic technological developments have been unnoticed by students of technological change, they have led to the establishment of new companies and substantial research endeavors by large (agro)chemical firms, some of which being the very same companies that have pulled out, or reduced, their investment in agricultural biotechnology.

What is surprising, therefore, is that combinatorial chemistry is almost entirely missed by economists. If combinatorial chemistry is discussed, it is almost always discussed in terms of a simple technology used by dedicated biotechnology firms (DBFs). The view adopted in this thesis is that, although dozens of DBFs have invested in the radical innovation (i.e. innovations that result in order-of-magnitude improvement in the performance/price ratio), the new breed of new entrants, often founded by scientists from departments of chemistry at universities, made it increasingly difficult to distinguish between pharmaceuticals and biopharmaceuticals.

Although these new entrants share the spotlight with large incumbents and scientific organizations, they will be the main characters of this thesis, for two reasons. The first reason is that new chemical-based entrants, most notably Coselco Mimotopes in Australia and Affymax in the United States, initiated technological change in the field, bringing out the first innovations in the pharmaceutical drug market. By shattering an important barrier to entry -the cost of chemical synthesis, these firms, which now total 393, have entered a technological field that has been the province of large pharmaceutical companies since the industry emerged in the 1880s. Market structures, consequently, have been significantly altered by the technological discontinuity. The second reason is that higher labour absorption can be achieved through small firms. ${ }^{2}$ According to Audretsch (2001), the net

2. According to a study commissioned by the California Healthcare Institute, jobs generated by the emergence of combinatorial chemistry offer good stipends too; thus, employees working in California for the combinatorial synthesis sector earn an average of $\$ 67,000$ per year, as much as in the biotechnology industry but considerably more than those employed in the medical laboratories sector, which make about $\$ 36,900$ annually (Gallagher 1998). 
employment gain during 1990-1995 is greater among small firms than larger firms and while the latter yields a larger number of patents, the former exhibits higher patenting rates when measured on a per employee basis. Hence, it is clear that combinatorial chemistry is a new promising technological area for economic growth and thereby will necessarily command greater attention as far as policy-makers are concerned.

\section{Thesis outline}

This thesis is divided into four parts and seven chapters. In the first part, chapter 2 establishes the foundation of a knowledge-based theory of higher performance. In the resource-based tradition, superior performance is ascribed to the firm's bundle of rare, valuable, non-imitable and nonsubstitutable resources and competences. As these conditions may not be enough to sustain a high performance position in a turbulent environment, the theory presented in this chapter focuses on knowledge and the need to bring new innovations on a continuous basis. More specifically, the theory recognizes that three different features of the firm must be taken into account if one is to shed light on the determinants of superior performance. These three features are: (1) technological learning; (2) the stock of accumulated knowledge; and (3) path dependence. Borrowing from Tushman and Anderson (1986), the chapter also argues that technological discontinuities can affect industry structures by increasing, or decreasing, the entry-exit ratio.

The second part essentially deals with technological change. Chapter 3 provides technical background on the combinatorial synthesis methods, its origins and expanding knowledge base. As will be demonstrated, the technology is best described in terms of a competence-enhancing process innovation leading to a period of incremental improvements representing progress along four trajectories: (1) chemical synthesis, (2) lead discovery and lead optimization, (3) knowledge-based combinatorial chemistry and (4) new materials. Another central lesson that can be drawn from this chapter is that rapid advances in genomic sciences have the effect of fragmenting the demand of chemical-based services and products.

The third part and chapters 4,5 and 6 are devoted to the three main players in the innovation network. Chapter 4 reviews the build up of new entrants. The chapter also demonstrates how these new entrants have been able to cope with the turbulent environment by learning, both internally and externally, about the innovations carried out along the four trajectories. A focus on the process of external learning with smaller firms (i.e. firms with less than 1,000 employees), most notably genomic firms, will also clarify how suppliers of combinatorial libraries have been able to metamorphose into suppliers of pharmaceutical services and products, most importantly small molecule drugs (i.e. pills). For the purpose of this thesis, new entrants 
refer to companies that use the combinatorial techniques and have less than 1,000 employees.

Chapter 5 takes a closer look at the corporate response of large established pharmaceutical and (agro)chemical companies: (1) in-house development, (2) acquisition of new entrants, (3) learning through alliances with new entrants and (4) scientific organizations. Following Rothwell $(1989,1992)$ and Rothwell and Dodgson (1994), it is argued there that these large incumbents have a material advantage (i.e. they can achieve economies of scale and scope in R\&D, they possess the necessary assets to produce and distribute their innovations, etc.). In particular, a larger stock of accumulated knowledge allowed them to catch up with, and even establish their dominance over, their smaller counterparts. However, a perspective is beginning to emerge that challenges the Tushman-Anderson model: new chemical-based entrants might be here to stay. As shown in the chapter, the introduction of combinatorial chemistry appears to stimulate a new division of labour between new entrants and large incumbents in the pharmaceutical industry, the former providing chemical-based innovations while the latter provide funding, complementary technologies and expertise in marketing, distribution and regulatory affairs. More generally, combinatorial chemistry and the firms that have embraced it further change market structures by fostering new inter-organizational relationships on the basis of chemicalbased services and products, especially joint R\&D and licensing of small molecule drugs.

Chapter 6 focuses on scientific organizations. A scientific organization is a term broadly used in this thesis to describe, indiscriminately, universities, public research organization and private, non-profit research organizations. The chapter is oriented towards the contribution of these scientific organizations to industrial innovations and goes on to assess the transfer of technology to new entrants. It also examines the competitive position of USbased firms with respect to new entrants from the European Union and the rest of world, suggesting that United States have a competitive advantage over other countries thanks to a greater dissemination of knowledge into the American economy.

The last part and chapter 7 return to the theory presented in chapter 2 and pick up many of the themes from chapters $3,4,5$ and 6 . The final chapter, therefore, is essentially concerned with one theoretical question, namely, the conditions that separate the winning firms from the losers in a turbulent environment. A correlation and regression analysis is introduced as a means to test whether higher performance is related to the following factors: (1) levels of internal learning, (2) levels of external learning with other organizations, (3) learning through acquisitions, (4) research "openness", (5) localization, (6) size and (7) diversification. The results reveal the importance of (1) external learning with scientific organizations, 
(2) localization in California, (3) number of employees, (4) a competence in combinatorial material and (5) previous experience in drug discovery. The chapter and the thesis will conclude by drawing the following normative prescriptions: firms can increase their revenues by building a multiple technology platform, by increasing levels of internal learning, by fostering "openness" of their research and by establishing close inks with scientific organizations. 

PART I: THE THEORY 



\section{Technological Learning}

\section{and Superior Performance}

Man educated at the expense of much labour and time may be compared to one of those expensive machines

Adam Smith (1776)

\subsection{INTRODUCTION}

The resource-based view of the firm, which is rooted in the pioneering work of Penrose (1959), Chandler (1962), Learned \& al. (1965) and Andrews (1971), may be given credit for shifting the axis of intellectual discussion about the source of superior performance towards the firm's resources and competences. Hence it offers a natural and useful starting point in formulating the foundations of a knowledge-based theory (section 2.2). Besides discussing what is meant by "knowledge" and why it matters (section 2.3 ), the chapter also stipulates that three features of the firm have an important bearing on its performance: (1) technological learning, (2) the stock of accumulated knowledge, and (3) path dependence (section 2.4). The basic purpose of section 2.5 is to examine the impact of technological discontinuities on the long-term performance of new entrants and large 
incumbents. Some brief concluding comments are provided in the final section.

\subsection{Preliminary Tenets from the ResourCe-Based THeORY Of THe Firm}

Resource-based theorists have generated an impressive -and rather heterogeneous- amount of theoretical and empirical work, and the following account can do no more than bring forward and define the main concepts and tenets that are germane to this knowledge-based model. Resources will therefore be defined and categorized as tangible assets such as machines, land, plants, etc., and intangible assets such as knowledge, patents, brand name, entrepreneurial culture, etc. (Penrose 1959; Wernerfelt 1984). Competences will refer to the combination of resources that are held by the firm and help fulfill a particular task or activity (Collis 1991; Grant 1991, 1998). In this thesis, superior performance will describe the extent to which resources and competences provide a firm with the ability to survive and outperform its rivals. Armed with these three basic concepts, it is now possible to examine the four tenets that run through most contributions, as encapsulated in the following fundamental proposition: (1) Superior performance may be achieved and sustained by any given firm (2) if it can leverage its bundle of rare and valuable resources and competences, (3) more specifically, those that are simultaneously difficult to imitate (4) and to substitute. Each one of these four tenets will be considered in turn.

Superior performance may be achieved and sustained by any given firm ...

Underlying the first tenet of the resource-based theory is an idea that is very much questioned by early neo-classical economics theory: a firm, regardless of its industrial or even strategic position, can create, capture and, most importantly, sustain superior performance. Many attempts have nevertheless been made to detect any differences (or consistency) in efficiency and profitability levels among firms. Collectively, these studies concluded that firms within an industry have very different features in terms of job creation and destruction (Davis and Haltiwanger 1992), innovative and imitative capabilities (Dosi 1984; Patel and Pavitt 1997), growth rates (Dunne et al. 1996), productivity levels (Davis and Haltiwanger 1992; Jensen and McGuckin 1997) and profitability (Jacobsen 1988; Gerowski and Jacquemin 1988). Crucially, they have also concluded that such differences can persist over long stretches of time. Sustainability, however, should not be taken to mean that a high performance position is "eternal". For example, Jacobsen (1988), who examined the time-series behavior of return to investment of 2,000 business units over a 20-year period, points to the persistence of within-industry asymmetries in profits rates, though at some 
point also finds that profits appear to move slowly towards competitive levels.

...if it can leverage its bundle of rare and valuable resources and competences...

The resource-based curriculum is best known for explaining the phenomenon of inter-firm differences in performance in terms of heterogeneity of resources and competences. The tenet largely rests on the Ricardian assumption that valuable resources and competences, by definition yielding greater than average productivity gains, are in short supply, in turn implying that inferior resources/competences are also brought into production (Peteraf 1993). In this resource-based view, firms endowed with rare and valuable resources/competences will be able to capture abovenormal profits while firms endowed with resources and competences that are shared with large numbers of competitors should only expect to break even (Barney 1991, 1997; Peteraf 1993; Dollinger 1999). Now, the important question to ask is: What evidence is there that profitability has its source in the firm's internal characteristics rather than in the firm's external environment?

To begin, it is important to recognize that intra-industry variation in profits, as demonstrated in a series of econometric studies, is far greater than inter-industry variation in profits (Schmalensee 1985; Wernerfelt and Montgomery 1988; Rumelt 1982, 1991). For example, Rumelt (1982), in a study examining 1,292 US corporations over a 20-year period, reveals that inter-firm differences in profitability within industry are three to five times bigger than differences in profit rates across industries. But this too raises a question: What causes this variation in profits? Hansen and Wernerfelt's study (1989) suggests that firm characteristics (i.e. communication flow, emphasis on human resources, decision-making practices, etc.) are largely responsible, accounting for far more profitability variance as industry characteristics (i.e. average industry profits, market share, firm size, etc.). Perhaps more importantly, the simple procedure of assuming that profitability derives from strategic group memberships, as set forth in Porter's theory of competitive forces, has also been forcefully criticized. For instance, Cool and Schendel (1988) demonstrated, using longitudinal data from the US pharmaceutical industry between 1963-1982, that firms pursuing similar strategies can nevertheless display significant asymmetries in performance levels.

In line with the econometric studies, an impressive number of case studies covering a wide range of industries underline the significance of idiosyncratic resources cum competences, associating those which are valuable and unique to the superior performance of individual firms. The point is best made with two practical examples. In the bearing industry, 
Collis (1991) convincingly demonstrates that Minebea's success in the market of precision miniature bearing and $256 \mathrm{~K}$ DRAMS owes much to its low cost strategy that exploits its intangible assets and competence in "high quality volume production". In the retailing industry, Stalk et al. (1992) show that Wall Mart's unique inventory-replenishment system, combined with its highly effective human resource system, had transformed the American company from a small niche retailer to the world's largest and most profitable retailing company. Miller and Shamsie (1996) indicate that longterm contracts for movie stars help to explain the superior performance of Hollywood film studios in the period 1936-1950.

...more specifically, those that are simultaneously difficult to imitate...

Resource-based theorists share a common point in advocating that rare and valuable resources cum competences must equally be imperfectly imitable, namely, hard to copy, if they were to create and sustain higher performance. The resource-based argument goes, if resources and competences were to be easily and cheaply duplicated by rivals, the condition of heterogeneity will be violated, driving profits back to competitive rates. In this respect, Rumelt brought forward the concept of the isolating mechanism, described as "the phenomena that limit the ex post equilibration of rents among individual firms" (1984:567). Isolating mechanisms can therefore be compared with the concepts of entry barrier and mobility barrier which, to recycle Rumelt's formula, refer to the phenomena that limit the ex post equilibration of rents among individual industries and strategic groups.

At first sight isolating mechanisms seem to have the attributes of a "catchall" concept. To see this most vividly, consider the fact that Mahoney and Pandian (1992) have identified 37 different isolating mechanisms in the literature, ranging from time compression diseconomies (Dierickx and Cool 1989) and unique combinations of business experience (Prahalad and Bettis 1986) to causal ambiguity (Lippman and Rumelt 1982) and patents (Alchian 1984). Impressive though their list may be, the authors pointedly remarked that most isolating mechanisms exist as a result of causal ambiguity. In other words, isolating mechanisms implicitly underscore the fact that the causality of events leading to superior performance, being very hard to untangle, often hinder the imitative efforts of competing firms (Lippman and Rumelt 1982). Demsetz expresses it this way: "It may be difficult for these firms to understand the reasons for this difference in performance or to know which inputs to attribute the performance of successful firms" (1973:7). This is essentially why the possession of tangible assets, being inherently mobile, easy to purchase and/or "reverse-engineer", seldom represents a source of superior performance (Amit and Schoemaker 1993; Peteraf 1993). 
... and to substitute.

Every theorists of the resource-based perspective have rightly stressed the threat (or opportunity) of imitable resources. Fewer, however, have pondered the substitution of resources (Dierickx and Cool 1989; Barney 1991, 1992, 1997). The apprehension over substitutable resources, embodied by Porter in his "diamond" of competitive forces (1980), is nevertheless a serious matter, the "seriousness" largely depending on the form taken by the substitutability; that is to say, on whether substitutable resources are: (1) equivalent and equally costly; (2) equivalent and cheaper; or (3) superior and equally costly. First, if equivalent and equally costly resources were to be owned by competitors, prices might have to go down and profits shared among sellers. Second, if equivalent and cheaper resources were to be employed, a firm's competitive advantage could be wiped out altogether. Third, if sperior and equally expensive resources were to be used by rivals, the ability to capture super-normal returns and experience higher performance would be moved away from the pioneering firm towards the challengers (Barney 1991, 1992, 1997). An example of this form of substitutability is to be found in the anti-ulcer drug sub-market. Introduced by SmithKline in 1977, the H2-antagonist Tagamet, the first of its kind, was a blockbuster, capturing the whole sub-market, commanding a premium price and providing an important source of super normal returns to the company. However, the UK-based company Glaxo responded 6 years later with Zantac, a slightly modified version of Tagamet that had fewer side effects. As a result, Glaxo, despite charging slightly more than its US counterpart for its ulcer drug, had captured 25 percent of the sub-market within one year and 55 percent by the end of May 1993, whereas SmithKline's market share had decreased from total market to 21 percent in 1993 (Berndt et al. 1994).

\subsection{KNOWLEDGE AS THE SINGLE MOST IMPORTANT RESOURCE OF THE FIRM}

Such as it is, the discussion about the resource-based theory of the firm has expressly moved the source of superior performance away from industrywide and strategic group characteristics and memberships towards the firm's resource endowments and competences. Another fundamental lesson that the resource-based perspective allows one to extract is that a sustained superior performance demands that resources and competences comply with the conditions of (1) heterogeneity; (2) non-imitability; and (3) nonsubstitutability. The key to profitability, here, is not only a matter of being different but also, perhaps as crucially, a matter of protecting this uniqueness (Wernerfelt 1989; Aharoni 1993; Grant 1998). Accordingly, the way forward can only be the formulation of strategies that enable the firm to align the intangible assets that meet the above conditions with the marketplace. 
Following this insight, Teece (1980, 1982), Schoemaker and Amit (1994) and Grant $(1991,1998)$, setting out the first claims on behalf of the resource-based approach to strategy formulation, have devised useful guidelines and procedures for top management to follow and observe. Grant (1991), for instance, suggested that profit seeking firms ought to: (1) identify their unique, non-imitable and non-substitutable resources; (2) identify their unique, non-imitable and non-substitutable competences, otherwise known as core competences; (3) appraise the rent-generating potential of their resources and core competences; (4) select a strategy which best exploits their resources and core competences; and (5) identify the resources gaps that need to be filled. It is useful to note that steps $1,2,3$, and 4 are essentially "static" in nature, involving the management and coordination of the firm's current resources and competences, in contrast to step 5, which involves the "dynamic" replenishment of resources. Admittedly, a one-sided, static emphasis on existing intangible assets would be shortsighted in a turbulent environment, where customers' demand for products and services changes rapidly, competition intensifies and the pace of technological change accelerates. If one accepts the fundamental premise that profit-seeking firms must adapt by moving their competences along such environment, then the presumption that knowledge is the single most important resource of the firm naturally follows. A number of authors have drawn attention in different ways to this dynamic aspect of competition. For example, Aaker (1989), in a survey of 248 businesses, asked 68 managers from high-tech businesses about the source of their competitive advantage. The majority cited technological superiority as the most important factor, much more than managers from services and manufacturing businesses. Another example is a study situated within the pharmaceutical industry by Roberts (1999), which shows that a firm can only maintain a high performance position if it repeatedly introduces innovations that service previously unmet consumer demands.

However, a knowledge-based theory of superior performance should be regarded as more than just a resource-based theory of the firm with special emphasis on knowledge as the ultimate resource. At least in today's world, knowledge sets apart from other tangibles in being dynamic and difficult, if not impossible, to monopolize. As a result, a shift towards a knowledgebased theory of the firm, which seems natural for the study of a high-tech industry, demands a treatment of knowledge to be realistic and useful. Because of the inherent complexity of such model, the arguments will be built piece-by-piece, beginning with a thorough examination of what is meant by the term "knowledge" and why it matters. A classification of knowledge and some comments about its attributes will therefore be proposed in the next few pages, followed by theoretical propositions that are broadly consistent with the discussion on knowledge. 


\subsubsection{Taxonomy of knowledge}

The idea that knowledge has important economic value perhaps dates back to the eighteen century when Adam Smith (1776:8) brought attention to the power of specialization and division of labor. Henceforward, contemporary economists have pondered in many different ways its economic significance, glimpses of which may be caught by reading the history of economic thought. Preceding the national systems of innovation literature by hundred years, List's appreciation (1841) of England's industrial leadership was one that relates the wealth of that nation to its larger stock of accumulated knowledge assets. Breaking fresh theoretical ground, Marx suggested in the late eighteen century that inventions and innovations were the outcome of interactions between social classes and institutions. More recently, Marshall (1952:115) boldly stated that "knowledge is our most powerful engine of production; it enables us to subdue Nature and forces her to satisfy our wants." Finally, Schumpeter (1942:1954) introduces the notion that innovation as an engine of growth is the driving force of the evolution of capitalist societies.

In spite of all this, the very idea of formalizing these arguments into practical models had largely been overlooked, if not completely ignored by mainstream economics. By all accounts, conceptualizing and operationalizing knowledge has always been a difficult task. To see this, one only has to note that "neo-classical production functions" had traditionally emphasized the relationships between the maximum output that can be produced by every possible combination of labor, capital, material and energy. The issue of knowledge and technologies had conveniently been subsumed into the production function. Economists would simply assume that these two intangible assets were in the public domain, suggesting that many parties could benefit from their production by virtue of the fact that they are considered to be inexpensive to teach and learn compared with the cost of invention or innovation (Nelson 1959; Arrow 1962a).

Nevertheless, this simple, materialist conception of knowledge and technologies is not unassailable. Since Machlup (1962), a score of academics have criticized this conception on epistemological grounds; thus, they pointedly remarked that knowledge has multiple dimensions and attributes, suggesting that focus on an isolated aspect would only represent a fraction of what is necessary to capture its true nature. Winter, for instance, decries "the paucity of language useful for discussing the subject" (1987:180). In this context, scholars of technological change have argued that taxonomies of knowledge highlighting its multifaceted nature would actually be more helpful than attempts to conceptualize it. ${ }^{3}$ Although several classifications of

3. Other critics and/or taxonomies can be found in Winter (1987), Nelson (1989), 
knowledge have been proposed, the typology of Lundvall and Johnson (1994) offers the advantage of stressing the properties of knowledge in terms of transferability across time, space and people. Subsequently adopted by the OECD $(1996,2000)$, this typology draws a clear and useful distinction between: (1) know-what; (2) know-why; (3) know-how; and (4) know-who.

Know-what denotes knowledge about facts and is, quite simply, related to information that can be transmitted in the form of data and messages to decision agents. Examples of know-what includes the facts that Edwin Merrifield synthesized the first enzyme, that Zeneca was awarded the patent EP 0820591-A1 for an affinity chromatographic method for screening combinatorial libraries, that a radio-ligand experiment gives a certain percent inhibition, etc. This form of know-what is commonly traded by independent companies specialized in law and medicine.

Know-why is most commonly known as scientific knowledge of the principles and laws of nature, in the human mind and in society. The discovery that 2 ' substituted phenethylamines bind with $\alpha$ receptors, thus activating the production of proteins, is one instance. Another one is the discovery that the deficits caused by Parkinson's disease are associated with nicotinic acetylcholine receptor subtypes, which regulate the release of dopamine and acetylcholine. Know-why offers great opportunities for industrial innovations, though its contribution varies widely across industries and technologies (Godin 1996). The creation of know-why is mainly organized in universities, government laboratories, private, non-for profit research institutes and firms in high-technology sectors like genetics, pharmaceuticals and chemistry are also known to invest in its production.

Know-how is to the individual what competences are to the firm: the accumulated skills and abilities that allow him/her to achieve something smoothly and efficiently (von Hippel 1988; Lundvall and Johnson 1994). As economists have come to appreciate, this form of disembodied knowledge as a strategic resource is paramount: technological success, akin to sports and music, cannot simply be achieved by understanding physical laws or by reading books. Manuals may provide great insights and guidance as to how to perform well, but success without painstaking and repeated practice would elude even the most well red scientist.

Know-who refers to a combination of social skills and information about who knows what, why and how. Know-who is built on trust and is gained through

Nonaka (1991), Spender (1993), Kwavnicki (1994), Gibbons et al. (1994), Den Hertog and Huizenga (2000), Garud (1997) and $\operatorname{OECD~(1996,~2000).~}$ 
day-to-day dealings with costumers, sub-contractors, universities, rivals, etc. As will be shown, know-who is particularly important for technological systems, since the know-how necessary to devise complex innovation is usually widely dispersed in a network of innovators.

More than just mere semantics, this taxonomy of knowledge allows one to draw an overview of the four attributes that affect the process of knowledge creation, accumulation and diffusion. The first attribute is that know-what and know-why have many of the characteristics that are otherwise associated with non-rival, durable public goods. They may be absorbed and used jointly by many players without losing their value in the course of repeated use (Dasgupta and David 1994). The second attribute is that knowwhat and know-why are generally easy to codify, their main vehicles ranging from manuals, textbooks, scientific and technical journals to computer programs and operating manuals for commercial process plant and research equipment. The third attribute is that know-how and know-who are typically more "tacit" than know-what and know-why. The concept of tacit knowledge, first described by Polanyi in his book Personal Knowledge: Towards a Post-Critical Philosophy (1958), refers to the idea that people know much more than they are able to describe. Paraphrasing Polanyi's classical illustration of bicycle riding or swimming, these activities might be practiced successfully, but full awareness of how they are done -the elementary facts that constitute them- can never really be achieved. The fourth and final attribute is that know-why may possess generic attributes that allow it to be used as a shared input in the search for closely related products and services. For instance, know-why that has been used to discover pharmaceutical products has proven to be applicable to the development of new pesticides, but not the design of motor cars (Pavitt 1992).

\subsubsection{Knowledge as a semi-public, semi-private good}

Thus described, it is obvious that knowledge represents a resource that has little resemblance to other assets, its particularity resting on the fact that knowledge is neither completely public nor completely private. On the one hand, there is a public aspect attached to codified know-what and know-why because educated people may simply learned them by reading manuals, textbooks, etc. (Nonaka 1991; Dasgupta and David 1994; Lundvall and Johnson 1994). This possibility, of course, is influenced by the amount of knowledge being codified, which varies greatly depending on how costly it is to do and the extent to which rewards can be captured from the extra effort involved (David 1993). In this respect, information and communication technologies (ICT) in general and the Internet in particular have reduced substantially the transmission costs of know-what and know-why among 
economic agents, thus altering radically the knowledge production and distribution chain. The fact that codified know-why and know-what have non-rival and durable public features is also noteworthy, since the ease with which it can be reduced, transmitted, stored and reproduced raises a problem of appropriability -the classical "free rider" problem. While the buyer of knowledge has no idea about the value of the know-why and knowwhat she or he wants to acquire, the seller has little incentives to reveal her or his knowledge for evaluation for fear of losing it. Such knowledge is also typically generic and widely used by professionals in the field, which generally means that other specialists can ferret out the generic aspects of a rival's technology (Nelson 1989).

Unless, of course, its access is restricted through expensive measures such as patent laws and "codes" or "languages" designed to ensure secrecy (i.e. not known to external agents) (Cowan and Foray 1997). The essence of patent protection is that an invention cannot be commercially made, used, distributed or sold without the patent owner's consent. In theory, the patent owner has the monopoly right to decide who may use the patented invention for a 20 year-period. In practice, the legal system through which know-what and know-why is shielded from competition needs careful consideration. This is due to the fact that patents have different protective value across industries, their effectiveness varying greatly according to the type of innovation the firm is trying to safeguard and the industry it operates. Thus, the survey questionnaires conducted by Levin et al. (1987) and Cohen et al. (2000) on appropriability conditions strongly suggest that patents are generally better suited to products than processes. The surveys also show that patents are highly effective for a small number of industries, most notably in the pharmaceutical sector, but ineffective for most innovations in other sectors. So ineffective, in fact, that firms often choose not to patent, especially processes, the ease of inventing around and information disclosure being adduced as the main reason for keeping the innovation as trade secret. Also, it needs to be insisted that know-why is never "free" as major investments in learning must be made before know-what and know-why have any meaning (OECD 2000). ${ }^{4}$

On the other hand, knowledge may be seen as a private good in that know-who and know-how have tacit and specific elements preventing them from being easily traded in the market (Lundvall and Johnson 1994). In fact, markets as a governance structure are only efficient when know-how is

4. Sociologist of science Michel Callon presents the case clearly: "You might print thousands of copies of an article or a book and air-drop copies in Lapland or in BosniaHerzegovina. You might similarly send well-trained students or well-calibrated instruments to the far corners of the earth. However, if all these elements do not come together in a single place at the same time, the dissemination will have been a waste of time" (1989:402). 
embodied in a product and the product efficiently used without having to grasp the nuts and bolts of its production (Demsetz 1988; Grant 1996a). Scientists do not need to know how a piece of automated instrumentation has been constructed in order to use it; they may simply purchase the item from a supplier. In contrast, know-who is socially embedded knowledge that cannot be communicated through formal channels of information, and it cannot be bought: "you cannot buy trust and, if you could, it would have no value whatsoever", writes Arrows (1971). ${ }^{5}$ Likewise, know-how possesses distinguishing features that impinge on its transferability across boundaries. That is, its difficult-to-verbalize property makes it difficult to transmit from individual to individual (Polanyi 1958, 1966), from firm to firm (Nelson and Winter 1982; Spender 1996) and from country to country (Teece 1981; Westphal et al. 1985).

There should therefore be no mistake in casting tacit know-how and tacit know-who in terms of causal ambiguity and, consequently, isolating mechanisms. Inherently hard to articulate, tacit knowledge generates, in the words of Reed and DeFillipi: "ambiguity through the skilled operator's own level of unawareness of the actions that he or she undertakes. Consequently, the causal relationships between action and results remains less than apparent or is not understandable to rivals" (1990:91). Because of this property, duplicative efforts can be a costly enterprise. Mansfield et al. (1981), for instance, estimated that the imitation costs of innovations remain close to 70 percent of innovation costs. One must also reckon with the fact that knowhow is seldom completely used efficiently outside the firm that has generated it. The explanation is that that much learning is "localized", specific to particular contexts, to the experience of the user, the producer or both (Atkinson and Stiglitz 1969; Dosi 1988). Nonetheless, the proprietary nature of know-how and know-who is not watertight. For one thing, tacit knowhow can be learned if demonstrations, personal instruction and the provision of expert services by those who possess it are involved (David 1993). For another thing, technologies tend to display lower levels of tacitness in the course of their life cycle, since the degree of codification often increases as innovations mature (Saviotti 1998). Consequently, the potency of causal ambiguity regarding tacit knowledge eventually declines over time, and the cost and difficulties associated with the transfer of know-how is reduced in due course. Take the example of genetic engineering. Born in 1973, the radical innovation caught the scientific community by storm, and yet, the basic principles became widely accessible to scientists and students alike in 1982, when Cold Spring Harbor Laboratory published Molecular Cloning: A Laboratory Manual (Fujimura 1988). Yet another thing is that firms seeking to gain access to tacit know-how and know-who can hire a top scientist or top

5. As quoted in OECD (2000:17). 
manager away from a competing firm, though firms have particular institutional arrangements that may help protect these intangible assets. For example, employment contacts containing a restriction clause and a noncompete clause could help reduce the mobility of the know-how and knowwho employees possess (Liebeskind 1996). ${ }^{6}$

\subsection{TECHNOLOGICAL LEARNING AS THE SINGLE MOST IMPORTANT PROCESS OF THE} FIRM

A key element in this knowledge-based theory, as reflected in the previous section, is that public and private knowledge cannot be easily dichotomized, suggesting that knowledge remains a very difficult resource to protect against imitation, let alone substitution. Hence, if the goal is to assess the conditions which separate the technological leaders from the technological laggards in a turbulent environment, a knowledge-based analysis of superior performance must accept the notion that, because knowledge eventually leaks out to industry, firms must maintain -and even speed up- their innovative momentum to keep abreast of the technological race. Thus, resource-based theorists, by simply assuming that the firm's valuable resources are those that cannot be imitated or substituted by rivals, have often neglected the disequilibrium process, and even sympathizers like Foss, Knudsen and Montgomery (1995) recognize that issues such as technology and entrepreneurship should be getting more attention.

By contrast, the evolutionary framework, being largely concerned with the survival and growth of industries, has largely eschewed the firm as a unit of analysis, but incorporates more realistic assumptions with respect to innovations and technological change. In an evolutionary setting, the knowledge-based economy leaps in and out of equilibrium, and Schumpeterian competition occupies center stage: "The fundamental impulse that sets and keeps the capitalist engine in motion comes from the new consumer's goods, the new methods of production and transportation, the new markets, the new forms of industrial organization that capitalist creates..." (Schumpeter 1942:82).

Assuredly, evolutionary economics and resource-based theory have much to gain from borrowing concepts and assumptions from each other. After all, they both take an efficiency approach to firm performance, and both depend on the claim that resource/knowledge asymmetry is the essence of performance differences among firms since, without this claim, superior performance would not be possible (Foss and Foss 1998). Mindful of this

6. In a restriction clause, an employee must exclusively work for the employee in question, whereas in non-compete clause employees are forbidden from working for a competitor for some time after quitting the job (Liebeskind 1996). 
potential, authors such as Dierickkx and Cool (1989), Collis (1991, Conner (1991), Lado et al. (1992), Grant (1996a, 1996b), Teece et al. (1997) and Mathews (2002) have gone some way towards meeting theoretical integration.

One of the most interesting and well-known examples of "crossfertilization" is to be found in the dynamic capability theory of Teece, Pisano and Shuen (1997). Combining elements from the theories of Penrose (1959) and Barney (1986) on the one hand, and Schumpeter (1934) and Nelson and Winter (1982) on the other, the dynamic capability framework predicts that accumulating valuable technology assets will not be enough for wealth creation in a turbulent setting. Rather, the dynamic capability theory made an important point stipulating that "the competitive advantage of firms lies with its managerial and organizational processes, shaped by its (specific) asset position, and the paths available to it" (Teece et al. 1997:518). This latter argument concerning the three dimensions of the firm as a determinant of superior performance provides a great opportunity for the development of a model that will focus more closely on the attributes of knowledge, its creation and accumulation. Specifically, the theory states that the firm's fortunes: (1) are intimately tied to the process of technological learning, (2) which is conditioned by its stock of accumulated knowledge, and (3) determined by path dependence.

\subsubsection{Technological learning}

To sustain a superior performance, a firm is compelled to generate knowledge in an endless race with its rivals. To accomplish this, the firm must develop and upgrade its competences to match with the turbulent environment: volatile customers demand, increasing competition and rapidly changing technologies. According to this view therefore, a firm must pursue a strategy requiring technological learning, which is here defined as the process that allows firms to create and accumulate knowledge and purposefully enhance, expand and renew their competences as a response to changes in technology, demand and competition. ${ }^{7}$ To comprehend the ramification of this definition, it is useful to think about technological learning as a dual, yet overlapping set of learning mechanisms and consider the following discussion on internal learning, which focus on the creation and accumulation of knowledge within the firm, and external learning, which concerns on the absorption of knowledge from upstream and downstream sources such as universities, suppliers, subsidiaries, rivals, customers, etc.

7. This definition of technological learning is largely consistent with the definitions proposed by Dodgson (1991), Carayannis (1999) and Figueirido (2002). 


\section{Internal learning}

Following Huber (1991), the firm can learn by grafting new employees, that is, it can reinforce and develop its competences by hiring new members who possess know-how not previously available within the firm. This is surely why the movement of skilled graduates to industry is often regarded as the single most important technology transfer mechanism of universities (Gibbons and Johnston 1974; Abramson et al. 1997). While science and engineering graduates must be taught about the lessons of "history" through formal and informal training (Levitt and March 1988), this new personnel brings into industry new knowledge and an ability to solve complex problems, perform research and develop new ideas (Salter and Martin 2001).

However, if a firm is to increase its chances of survival in a turbulent environment, it must also commit significant resources to in-house R\&D. This is because strong commitment to R\&D is one of the surest ways to produce innovations (Cohen 1995), generate firm profits, especially in complex resource contexts (McEvily and Chakravarthy 1999), create shareholder value (Kelm et al. 1995) and raise capital in an initial public offering (Deeds et al. 1997). The firm must also think strategically about long-term outcome and hence promote changes or explore new alternatives, especially in science-based industries which, by definition, rely heavily on know-why (March 1991; Lei et al. 1996) ${ }^{8}$ Although the outputs of knowwhy creation deemed economically valuable remain the exception, "they are critically important inputs to other investment processes that yield further research findings, and sometimes yield innovation..." (David et al. 1992:68). Thus, the process of know-why creation may not yield new products and processes per se, but the interaction between this process and applied research can play an important role in increasing the productivity of both activities. This process does not come free of cost, however. As Klevorick and colleagues (1995) have shown empirically, R\&D intensity in an industry is strongly related to the industry's connection with know-why created, and opportunities generated, by scientific organizations.

Yet it would be a serious mistake to think of R\&D as involving know-why for the sole purpose of disrupting the status quo. This is due to the fact that R\&D generally aims at solving a broad range of technological problems in the near term. According to the National Science Foundation (1998), more than \$US 160 billion were allocated was spent by the US industry on development and applied research in 1998, but only \$US 12 billion to basic

8. This is amply confirmed by scientometric studies, where patents in industries/technologies such as pharmaceutical, genetics and chemistry cite journals dedicated to basic research more than those of applied research (Collins and Wyatt 1988; Narin and Olivastro (1992). 
research (i.e. know-why creation). ${ }^{9}$ Emphasizing the "D" of R\&D, Rosenberg wrote that:

Even where technological change does clearly depend upon previously existing science, it often turns out that the purely scientific part of the research is the easy part: the real difficulty is converting that newly acquired scientific knowledge into useful products and services. We commonly attach very high status and prestige to scientific accomplishments. But, if our primary concern is with business activity and productivity improvements, it is the technological achievements and their translation that really counts (1992:65).

Relatedly, it would be mistaken to underestimate the importance of learning by doing and incremental innovations. The concept of learning by doing captures the essence of the fact that workers improve the efficiency of production through the accumulation of know-how over time. ${ }^{10}$ Thus, learning by doing creates changes in the way the product is manufactured without alterations in physical capital, which have the effect of increasing productivity levels. It also creates opportunities for communicating knowhow and know-what between workers/technicians and scientists, which may be conducive to yet more innovations (David 1975; Rosenberg 1976). In fact, taken together, the tacit know-how born of experience and small, gradual improvements of innovations generate productivity gains greater than those generated by the introduction of major technological innovations (Enos 1962; Hollander 1963; Lieberman 1984; Rosenberg 1982, 1994). An oft-cited example is Enos's long-term study on the petroleum refining industry, which shows that cost reductions taking place during the production stage were three times as significant as those associated with the initial implementation of several radical innovations (Enos 1962).

Notice that incremental innovations often occur, not so much as the result of any deliberate $R \& D$ activity but as the outcome of inventions and improvements suggested by users or other persons engaged in the innovation process. Take, for instance, oral contraceptive pills. Epidemiological studies revealed that estrogen could increase the risk of thromboembolic disorders,

9. In the pharmaceutical industry, estimates for financial year 2000 show that companies spent only 36 percent of R\&D expenditures to pre-clinical functions, the rest being allocated to human clinical trials ( 40.8 percent), development and quality-control functions (11.7 percent), etc. (PHRMA 2001).

10. Wright (1936), an American engineer working for the aircraft industry, was the first to make the observation that a firm's efficiency depends positively on the extent of its previous productive activity, and the idea was taken up by economists such as Arrow (1962b), Hollander (1965) and Lieberman (1984). 
some patients even voicing concerns over weight gain and symptoms of nausea. In that event, feedback loops motivated the search for a better pill, leading to the discovery oral contraceptives with lower concentrations of estrogen and fewer side effects (Gelijns and Rosenberg 1994). Anyone familiar with the economics of innovation literature would see a connection between this latter example and the process learning by using. As pointed by Rosenberg (1982), von Hippel (1988) and Lundvall (1992), a great deal of disembodied knowledge may be accumulated in the course of using a new scientific instrument, software product, piece of equipment and so on, namely, through learning by using. Undergirding this view is the assumption that users may gain know-how while using the innovation, since the cumulative experience enables them to improve the execution of particular tasks and thereby lower costs and increase efficiency. There is, of course, more to this story. Another noteworthy feature of learning by using is that feedback loops from users to producers can motivate the search for minor and even major improvements. Thus, users can inform scientific actors about the innovation's shortcomings or strengths, and the resulting information used as basis for further research. ${ }^{11}$

The reason why the process of internal learning is paramount for success is simple: first, consider that knowledge is the single most important output (innovation) and input (competence) in the innovative process. Thus the innovative process contributes to both the genesis of innovations and the enhancement, expansion and renewal of competences, the impact of which being felt long after a research program has been brought to fruition. Second, consider that the creation of knowledge and strong competences remain crucial to evaluate, absorb and assimilate external knowledge produced outside the firm (Cohen and Levinthal 1989, 1990). Arora and Gambardella (1990) stress this point most of all; thus, they observed that large pharmaceutical firms pursuing higher levels of $R \& D$ in biotechnology were also those that exploit the most the opportunities of external learning with new biotechnology firms and scientific organizations.

\section{External learning}

There are at least six reasons why firms may wish to collaborate with other organizations: improving market power (Hagedoorn 1993), sharing risks (Hamel 1989 et al.) and costs through scale and scope economies (Kogut 1988; Ebers 1993), obtaining external legitimation (Baum and

11. For instance, the first generation of polymerase chain reaction (PCR) machines had been impaired by the use of a DNA polymerase that tended to break down at high temperature, compelling the addition of polymerase after each cycle of the reaction. Noticing this glitch, an inspired technician suggested using a polymerase extracted from the hotspring bacterium Thermus aquatticus, which copes better with heat (Mullis 1990). 
Oliver 1991), and speeding up products to market (Rothwell 1992). Gaining access to complementary assets can also be an important motive, especially for smaller companies lacking the necessary manufacturing, distribution and marketing skills to commercialize their products. This is especially true for the field of biotechnology, where dynamic complementarities between new entrants and large incumbents benefit both players (Pisano et al. 1988; Rothwell and Dodgson 1994; Barbanti et al. 1999). More often than not, biotechnology firms have products but not the funds to bring them beyond the first stage of clinical trials, large pharmaceuticals need new drugs to fill their innovation gap but have the money to carry out all the complementary tasks.

However, an alternative explanation for collaboration could be the following. In consonance with Hamel et al. (1989), Dodgson (1991), Mody (1993), Hagedoorn (1993), Inkpen (1996) and many others, the decision of a firm to collaborate may also stem from the motivation to access knowledge from other organizations and learn, that is, to purposefully enhance, expand and renew its competences as a response to changes in the external environment. This explanation cannot be underestimated. According to innovation studies, knowledge contributing to the development of innovations is often obtained from suppliers, customers, subsidiaries, competing firms, universities and public research organizations (Jewkes et al. 1969; Langrish et al. 1972; Gibbons and Johnston 1974; Rothwell et al. 1974; Mansfield 1991, 1995; Arundel et al. 1995). ${ }^{12}$

In this latter explanation, interorganizational collaboration is often regarded as involving bilateral arrangements or clusters of autonomous, yet interdependent organizations connected by bilateral arrangements. If more than two organizations are connected through such arrangements, including those across industries and countries, they form a network of innovators (Grant and Baden-Fuller 1996; Ebers 1997; Gulati et al. 2000; Kogut 2000). By and large, these network members engage in relationships characterized by recurring exchange of knowledge over a longer period of time and trust (Freeman 1991). One explanation is that tacit know-how cannot be transferred efficiently in the absence of repeated face-to-face interactions (Teece 1992; Grant and Baden-Fuller 1996; Ebers 1997). Another explanation is that codified know-why is best transferred if opportunism is reduced by repeated and durable relationships between people who share norms of trustworthy behavior (Powell 1990; Liebeskind et al. 1996; Lütz 1997).

These network relationships can take the form of either formal or

12. Mansfield (1991), for instance, estimated that 11 percent of new product innovations and 9 percent of process innovations could not have been developed had academic research not been performed within 15 years of the first introduction of an innovation. 
informal arrangements. Whereas formal arrangements support the exchange of knowledge by using legal contracts (i.e. licensing, equity participation, etc.), informal arrangements circumvent the need to use the legal system. This is largely because partners in these informal network not only share norms of reciprocity (i.e. mutual exchange of knowledge, resources, favors, etc.), honesty and respect for other's people intellectual property rights but also a mutual interest in each other's success (Saxenian 1991; Liebeskind et al. 1996). In fact, most members of the informal network admit that they consider most of their transfer partners to be good acquaintances or even friends (Schrader 1991). Yet even if trust is not completely funded meaning that codified know-why and know-what spill over to other playersthe knowledge is likely to enlarge the informal and formal network's knowledge pool, further stimulating the synergistic creation of innovations through joint learning. As argued by DeBresson and Amesse: "Networks involve a positive sum game, where some members may be losers some of the time, but most members are winners, to some extent, most of the time" (1991: 364).

Following the insights of Marshall (1920), a number of authors have documented the notion that proximity facilitates the transmission of tacit know-how among network members (e.g. Audretsch and Feldman 1996; Lawson and Lorenz 1999; Desrochers 2001). Others have also argued that trust and the exchange of know-why necessitate repeated interaction that is easier to achieve over short distance (e.g. Saxenian 1991). Going one step further, Jaffe (1986, 1989), Jaffe et al. (1993), Mansfield (1995), Prevezer (1995) and Audretsch and Feldman (1996) argue that the ability to capture knowledge spillovers is one of the major reasons behind the decision of firms to cluster nearby universities and other publicly funded research bodies. Jaffe's work is particularly interesting in this regard. Using state-level R\&D, patent and patent citations data, Jaffe (1989) demonstrated in one particular study that firms, especially in the drug sector, located nearby universities had more chances of capturing external knowledge spillovers through informal conversations than those located far away.

These arguments are an important part of the jigsaw, provided they are seen in the context of a turbulent environment. Distinct from innovation studies, but consistent with their main indings, the management literature shows that firms are choosing to place less emphasis on total integration of activities in technological fields such as biotechnology, new material, telecommunication, semiconductor and computer (Hegert and Morris 1988; Pisano et al. 1988; Hagedoorn and Schakenraad 1990; Duysters 1996). The complexity, velocity and uncertainty of technological change in these fields may shed light as to why firms choose a strategy focusing external learning, rather than solely relying on internal learning: 
Complexity. As demonstrated by Bertrand Gille (1978) in his seminal book, Histoire des Techniques, technologies, to various degrees, are interrelated to one another, constituting what he refers to as a technological system. ${ }^{13}$ The relationships between technologies, noted Gille, also grow over time, so the nature of a technological system becomes more complex during the course of its life cycle. ${ }^{14}$ Because the success of complex innovations requires a wide range of knowledge, and because there are limits to the range of things a firm can do well, few firms have a perfect match between its knowledge base and the evolving knowledge base of technological systems. Firms can therefore benefit from a strategy focused on external learning, given that collaboration provides a means with which firms can access knowledge components or competences that would otherwise be too prohibitive to develop independently.

Velocity: In high-velocity environments, there is a general agreement that the advantage goes to those that act quickly (Stalk 1988; Smith et al. 1992). The ability to outpace competition may therefore offer a good explanation for prefering external learning, especially with scientific organizations, over internal learning. Partnering with an oganization that already possess the necessary knowledge and competences can, in effect, reduce the interval between know-why creation and commercialization and thereby provide a first mover's advantage, given that firms often target the same market segment. Doz and Hamel would agree with this proposition by stating that: "companies often turn to alliances to win the learning race. These are often faster and more effective than alternative approaches to learning. Internal development, for instance, is often slow and uncertain" (1998: 52).

Uncertainty. The very business of developing new products and processes internally is indeed fraught with uncertainty, with the majority of innovative attempts floundering for both technical and economic reasons (Freeman and Soete 1997).${ }^{15}$ Consequently, no one can predict if any particular $R \& D$

13. Interestingly, Kodama (1986), in a survey of 3,803 Japanese companies, found that firms allocate a significant percentage of their resources outside their principal product field (i.e. chemical products, electronic equipment, etc.) and that the trend gained momentum between 1970 and 1982, suggesting that companies are increasingly fusing technologies in their research portfolio.

14. For Wang and von Tunzelmann (2000), the concept of complexity can be assessed along two dimensions: "breath" (i.e. range of areas that has to be investigated to develop a particular subject) and "depth" (i.e. analytical sophistication of the subject). This thesis is essentially concerned with the breath of technologies.

15. This is, however, only the most obvious source of uncertainty. One must also take into consideration the ex ante uncertainty associated with predicting the future uses of successful technologies and the impact of improvements that take place in complementary inventions (Rosenberg 1998). 
project, especially when know-why creation is involved, will translate into viable and profitable products. The nagging doubt that firms might not do so may therefore provide powerful reasons to collaborate. Three reasons are apparent. One is that the cost sharing and risk pooling afforded by external learning can buffer potential technological and commercial downturns. A second reason is that collaboration may provide a window on promising, yet unproven technologies. A third reason is that external learning with an expert in the field can provide the necessary flexibility with which to access knowledge assets without dealing with the irreversible sunk costs of internal learning (Mody 1993). If the outcome of an alliance is poor, which happens in 30 to 70 percent of the time (Kogut 1989; Bleeke and Ernst 1995), the firm can just terminate the relationships with its partner on short notice.

If the outcome of collaboration is good, the firm may decide to put more money into it or merge with its partner (Roberts and Mizouchi 1986; Mody 1993; Doz and Hamel 1998). Or so most people assume. Hagedoorn and Sadowski (1999) argue that alliances and M\&As are not part of a smooth continuum where the former strategy leads to the latter. ${ }^{16}$ This is not to suggest that alliances and M\&As have nothing in common; both modes of governance can be used as a vehicle enabling firms to broaden their knowledge base and competences. Following Vermeulen and Barkema (2001), learning through acquisitions can break the rigidities of acquiring firms and foster their long-term survival. Other related advantages usually considered in discussing M\&As are the synergies created by bringing different competences together (e.g. the exploitation of economies of scale and scope) and the financial rewards (e.g. higher stock price; cost of capital) associated with being a larger and more diversified company.

Paradoxically, past empirical and theoretical contributions found M\&A activity to be a mixed blessing. A peculiar lacuna found in the resourcebased literature is that the bidder faces many difficulties in investigating: (1) what intangible assets the targeted firm possesses; (2) which of those the firm can actually benefit from; (3) what the costs of doing so will be; and (4) what the firm could pay (Wernerfelt 1984). As a result, the acquirer must either have better information or be lucky to capture a competitive advantage (Barney 1986). The most obvious downturn, however, is that this form of learning is the most costly of all, not least because the acquiring company would not automatically assimilate and adapt the acquired resources. Integration of new technical staff, consequently, is an important organizational issue (Keil and Laamanen 1995). Therefore, the acquiring firm wishing to transfer knowledge and technologies from its subsidiary is

16. In examining 6,425 strategic technology alliances, Hagedoorn and Sadowski (1999) only find 168 cases (2.6 percent of total) where an alliance preceded a merger or acquisition (M\&As). 
often obliged to stimulate interactions between the two entities if it wants the acquisition/merger to bear fruit. In addition, there is always the risk, especially if the entrepreneurial culture is replaced by a bureaucratic organization, that key personnel leaves as a result of the take-over. The impact can be damaging to the acquiring firm. According to Grandstrand and Sjölander (1990), based on empirical studies of Swedish industry, in all cases where a large firm could not retain $R \& D$ key personnel, and in 60 percent of the cases where the general manager left the firm, the take-over led to a failure.

\subsubsection{Stock of accumulated knowledge}

An important proposition circulating in the emerging knowledge-based literature has it that the creation of knowledge requires that individuals specialized in specific knowledge domains, while the application of knowledge demands that several knowledge specialists be integrated within the organization (Demsetz 1988; Spender 1993; Grant 1996a, 1996b; Hodgson 1998). Two additional assumptions must therefore be introduced in this section. First, it must be assumed that an individual is limited by "bounded rationality", namely, his or her behavior is constrained in principal by the limits of the human mind, and hence, he or she is likely to specialize in a particular area of know-why, know-how and so on (Simon 1955). A firm equipped with a larger stock of human capital may therefore be better positioned to exploit economies of scale, given that a larger firm can benefit from increased specialization (Scherer 1980). Additionally, a larger stock of accumulated knowledge enables firms to assess, transfer and learn more efficiently and more cheaply knowledge outside its boundaries (Teece 1977. 1981; Cohen and Levinthal 1989). ${ }^{17}$ Furthermore, although levels of spending on technological learning can be adjusted instantaneously, knowledge stocks cannot. To the extent that setting a given rate of R\&D expenditures over, say, 10 years, yields a larger increment to the stock of accumulated knowledge than setting twice this rate over 5 years, a firm endowed with a larger stock of accumulated knowledge can erect an isolating mechanism through time compression diseconomies (Dierickx and Cool 1989). Time, and thus the age of the firm, can be a double-edge sword, however. On the one hand, older firms can learn from experience and innovate more frequently than younger firms. On the other hand, older firms tend to build on their previous innovative activity and generate less

17. These costs can be substantial, as demonstrated by Teece (1977) who estimated that the non-codified part of costs of transferring and absorbing technology between plants range from 2 percent to 59 percent of the total projects costs. As a rule, the larger the stock of knowledge a firm accumulates, the smaller the anticipated costs of transferring tacit knowledge. 
influential innovations than those of their younger counterparts (Sørensen and Stuart 2000).

The second assumption is that, since technological problems often defy easy analysis, individuals have much to gain from pooling their specialized knowledge together under the same organization. This is precisely the point Adam Smith was trying to convey in his famous story of the "pin factory", though the nineteenth century economist was mainly concerned with productivity gains stemming from specialization rather than those arising from the coordination of different skills (Demsetz 1988). Yet firms are, to put it succinctly, integrators of specialized knowledge (Grant and BadenFuller 1996). One powerful reason is that a broad knowledge base creates synergies from scope economies, which exist when the productivity of conducting two or more activities together are higher than if they are conducted separately (Grant 1996a). Another reason is that a firm can also increase flexibility with a broad knowledge base, enabling it to reconfigure related technologies into technological systems (Bierly and Chakrabarty 1996a, 1996b; Henderson and Cockburn 1994). In turn, the reconfiguration of different knowledge assets and their integration into organizational routines may shield firms from duplication, providing a source of enduring superior performance (Reed and DeFillipi 1990). Yet another reason is that additional knowledge in marketing, manufacturing and after sales support, also known as complementary assets, provides a basis upon which learning by doing and learning by using and helps safeguard knowledge spillovers that might otherwise benefit competing companies (Teece 1987).

This is not taken to mean, however, that the integration of specialized knowledge is a deus ex machina. To integrate specialized knowledge, top management must implement direction and built routines (Demsetz 1988; Grant 1996a, 1996b; Grant and Baden-Fuller 1996; Hitt et al. 2000). Direction implies the codification of tacit knowledge and encompasses a wide variety rules, directives and guidelines for organizational members. Their main advantage is that they allow knowledge to be communicated at low cost between specialists and non-specialists. Thus, American technicians producing and testing drugs at a pharmaceutical company do not have to know everything about quality control. Instead, they rely heavily on Good Manufacturing Practice regulations of the Food and Drug Agency (FDA) and the firm's own directives.

Routines, on the other hand, are "an executable capability for repeated performance in some context that has been learned by an organization in response to selective pressures" (Cohen et al. 1996:683). The firm's repertoire of organizational routines is often regarded as the firm's organizational memory (Levitt and March 1988) or repository of knowledge (Nelson and Winter 1982). Despite the turnover of personal and the passage of time, routines can be maintained through systems of socialization and 
control, as for example systems of formal and informal apprenticeships (Levitt and March 1988). Routines are also highly tacit, and hence, do not involve the communication of knowledge in explicit form. Nor do they require each organizational member to acquire the specialized knowledge of the others. For example, a screener knows what to do when a combinatorial chemist brings in new compounds, but not a molecular biologist. Their main advantage, therefore, is that they economize on communication and offer wide variety of responses to a broad range of circumstances (Grant 1996a; Hitt et al. 2000).

On the other hand, direction and routines require the existence of a common language. Indeed, a common language known to all members is essential as "it permits individuals to share and integrate aspects which are not common between them" (Grant 1996b: 115-116). The key point is that a common language is necessary for organizational members to be able to communicate with one-another and to orchestrate their tasks in view of possible technological difficulties (Kogut and Zander 1992; Lawson and Lorenz 1999).

\subsubsection{Path dependence}

Devoid of historical considerations, a knowledge-based theory of the firm would necessarily flounder in its attempt to explain how firms manage to differentiate themselves and protect their uniqueness from their rivals over long period of time. To fill this void, and to pin down precisely what may cause firms to diversify in one line of business and not another, it is necessary to introduce a third dimension: path dependence. The evolutionary path the firm has followed in the course of its existence is highly significant, for it determines what it can do today and in the future (i.e. "history matters").

A defining moment in the life of a firm should therefore be its founding year. Firms do not start their existence with clean states, but inherit the congenital knowledge of the founding entrepreneurs (Boeker 1989; Huber 1991). This congenital knowledge has the technological implication of circumscribing the creation of future knowledge and competences along a narrow corridor of incremental innovations and learning domains. A major reason why firms would "stick to their knitting" is that the switching costs associated with implementing a new set of organizational routines are often too high to justify against the backdrop of a successful performance. Another reason is that uncertainty is extremely costly to reduce, imposing restrictions on what is likely to be profitable (Rosenberg 1990). Thus, success nurtures success; economically, it would seem unwarranted for a firm to create knowledge far from the stock of specific knowledge it has accumulated since its inception (Nelson and Winter 1982; Arthur 1989; Lei 
et al. 1996; Dosi et al. 1992). ${ }^{18}$ To the extent that for different firms that narrow corridor differs, the knowledge created and accumulated by the firm will be specific in nature. This property and the tacit lessons of experience that are maintained within the firm's organizational routines combine in various ways to differentiate firms and protect their uniqueness over a long period of time. For example, Ely Lilly has been remarkably productive in the field of diabetic therapy for over one hundred years, largely because much of the knowledge created and accumulated about a particular disease area is highly specific and tacit in nature, making it difficult for its rivals to understand and duplicate (Henderson and Cockburn 1994).

To say that the firm's present knowledge constrains its future behavior, obviously, is not the same as saying that firms never change. Following Cohen and Levinthal (1990) and Dosi et al. (1992), the accumulation of knowledge in one period allows further absorption of external, though closely related, knowledge that may become available in the next period. The point is noteworthy. Consistently, the technical and managerial competence of the firm and the extent to which it understands the new technology determine the ease with which it will absorb the technology (Teece 1977). In this connection, the concept of path dependence may provide some clues as to why firms decide to move in one line of business, rather than another one (Teece 1980, 1982; Dosi et al. 1992). In the same vein, the concept may shed light as to why firms following a diversification strategy into related businesses exhibit higher levels of profitability than firms diversifying into unrelated ones (Rumelt 1982; Montgomery and Wernerfelt 1988; Chatterjee and Wernerfelt 1991).

\subsection{TECHNOLOGICAL DISCONTINUITIES AND MARKET STRUCTURES}

The discussion to this point has been concerned with the firm as the main unit of analysis; thus, issues proper to market structures were set aside. Yet firms can be confronted with the emergence of technological discontinuities at some time in the course of their life cycle. Characteristically, these technological discontinuities may have an important effect on the performance of these business organizations: they may either destroy or enhance their knowledge base, competences and thereby competitive position. This section draws this theoretical consideration together with those already discussed.

18. This is particularity evident in the pharmaceutical industry, where the cost of moving from a new disease area to another one that is unrelated can be too prohibitive to consider. To see this, one only has to note that the most important determinant of investment in any given disease area is the previous year's investment (Cockburn and Henderson 1994). 


\subsubsection{On Discontinuous technological change}

Insofar as firms turn to the existing knowledge base for clues as to what to do next and how to achieve it, the stock of public and private knowledge accumulates in the economy, building endlessly on prior achievements. Therefore, the process of technological change is by no means random, without references to knowledge and competences already in use. Just like learning, technological change has irreversible, path-dependent features. It would be inclined to follow a relatively ordered and distinctive pattern of continuous incremental improvements, proceeding along what Nelson and Winter $(1977,1982)$ referred to as technological trajectories. However, technological progress is sometimes punctuated by a technological discontinuity. That is, the economic and technological potentials of a single product (i.e. electric calculators, compact disks, etc.) or process (i.e. genetic engineering, catalytic cracking, etc.) are such that this innovation alone displaces an old one, triggering a wave of incremental innovations along one or several new trajectories in the process. Indeed, a new technology is initially crude and expensive: only when improvements are carried out and thereby the technical feasibility and economic viability of the innovation demonstrated would its diffusion actually take off throughout the economy (Rosenberg 1976, 1982). ${ }^{19}$

This technological shift often brings about a change in the set of knowledge and competences necessary for designing and producing a given product. Yet, as pointed out by Ehrnberg (1995), technological change can be assessed in different ways, often leading to confusion. ${ }^{20}$ In addition to changes in knowledge and competences, a technological discontinuity can also be used to describe physical change in the product itself and changes in price and technical performance. This latter dimension of change comes from Tushman and Anderson, who also make a clear distinction between competence-destroying innovations, those entailing the use of "new skills, abilities and knowledge in both the development and production of the product", and competence-enhancing innovations, which "built on existing know-how within a product class" (1986:441-442). The distinction is an important one, since it may help forecast the long-term performance of new entrants and large incumbents in a new industry or new line of business. It is

19. Hence sales or uses of the old product/process may continue for years and even decades. For example, steamships began replacing sailing ships only when technological change lowered substantially the costs of transportation by steam as compared to the relative cost of transportation by sail. The process took nearly 40 years, spanning from 1850 until 1890 (Harley 1971).

20. Inevitably, the terminology used in the literature varies greatly. Concepts such as radical, drastic, basic, replacement, major and revolutionary innovations are thus usually taken to counter the concepts of minor, improvement, routine, add-on, evolutionary and incremental innovations. 
treated more extensively below.

\subsubsection{Structural implications}

As a first cut to the issue of technological change and market structures, one should conjecture that new entrants have a learning-based advantage. Or, as Rothwell $(1989,1992)$ and Rothwell and Dodgson (1994) point out, smaller firms have a behavioral advantage over large incumbents. These entrepreneurial firms, among other things, are more willing to accept risks, have less organizational rigidity, react more quickly to change in the external environment and have better informal communication networks than their large counterparts. For all these reasons, it does seem likely that entrepreneurial firms frequently serve as a powerful catalyst for competence-destroying innovations, in line with the predictions of the early Schumpeter of The Theory of Economic Development (1934). ${ }^{21}$ For instance, in the emergence of radical innovations such as diesel engines, the float-glass process in glass manufacturing or mechanical ice-making new industries were created or old industries were reformulated by new entrants (Tushman and Anderson 1986).

Conversely, the literature identifies a set of explanation as to why large established firms are often loath or slow to venture into radical innovations. For Hannan and Freeman (1984), large firms are less inclined to invest in radical innovations because potential members, investors and clients value reliability more than efficiency; thus, the fact that large firms are more accountable for their actions becomes a source of structural inertia. The study of Henderson (1993) on photolithographic alignment equipment pointed to both underinvestment and incompetence as responses to radical innovation. Rosenbloom and Christensen's (1994) results on the computer disk drive industry suggest that the incumbent's disadvantage rests on their inability to change strategies, not technologies. Katz and Allen (1982) propose that $\mathrm{R} \& \mathrm{D}$ professionals of large corporate companies suffer from the "Not-Invented-Here syndrome"; thus, they tend to think that they possess a monopoly of knowledge in their field, leading them to underestimate innovations from their competitors. Bet it implicit or explicit, a recurrent theme across these explanations is that large established organizations tend to be constrained by the evolutionary path they have followed in the course of their history. Thus in each explanation, large firms, unwilling or unable to alter their organizational routines, are often victims of their own past success. In the tradition of Schumpeter (1934), a competence-destroying discontinuity breaks the grip of large established companies, since they are

21. See Mansfield (1981), Pavitt et al. (1987), Scherer (1990), Henderson and Clark (1990), Henderson (1993) and Christensen (1997) for a discussion of this in different industrial settings. 
locked-in with the wrong type of knowledge and competences. Thus, the innovation blows path dependence asunder, providing the best opportunity for smaller firms and outsiders to gain market share at the expense of large incumbents.

On the other hand, large established companies already possess the necessary knowledge and competences to initiate a competence-enhancing discontinuity, as put forward by Schumpeter in Capitalism, Socialism and Democracy (1942). Large incumbents have introduced important competence-enhancing innovations into industry, as for example the turbofan, the electric typewriter, the Edison kiln and catalytic reforming. As Tushman and Anderson (1986) tell the story, a competence-enhancing discontinuity ushers in an era of ferment: uncertainty and munificence (i.e. the extent to which an environment can sustain growth) prevail as many different versions of the product or process innovation compete in the marketplace and annual sales grow significantly. Only when a standard version (or dominant design) emerges and is no more questioned by users would an era of incremental technological change begin. To the extent that the quantity of products being manufactured increases, large firms can enjoy the benefits of scale economies, which rise barriers to entry and propel the exit of smaller players. Summing up the discussion Tushman and Anderson argue: "The rich are likely to get richer" (1986:443). The intuition here is that large incumbents have a material advantage (Rothwell 1989, 1992; Rothwell and Dodgson 1994) and can use their greater financial and technological resources to consolidate their leaderships in a product class. Besides scale economies, large established companies can benefit from scope economies, can spread risks over larger portfolios and are better positioned to deal with distribution, marketing and manufacturing.

The Tushman and Anderson model, however, does not seem to hold in the cases of several technological discontinuities. ${ }^{22}$ Examples can be found in the markets for organic chemical products, pharmaceuticals, medical devices (Nelson 1996), cameras, road vehicle amplification systems and personal computers (Windrum and Birchenshall 1998). There are, of course, many different explanations for this, which are beyond the scope of this knowledge-based theory of the firm. Hence this thesis will confine itself to two central, closely knitted, reservations.

The first reservation flows directly from the observation that technology life cycle theories largely emphasize "supply-side" over "demand-side" dynamics (Adner and Levinthal 2001). In many cases, customer needs can be so heterogeneous that an industry differentiates into a number of distinct market niches (Windrum and Birchenshall 1998). In this event, economies of

22. See, for instance, Rosenbloom and Christensen 1994; McKelvey 1996; Tripsas 1996; Nelson 1996. 
scale play a lesser role in affecting market structures, in large part because large incumbents lose their cost spreading advantage. Moreover, the relationships between technological activities and customers demand can open opportunities to firms of all size, thus weakening concentration ratios in a given industry. ${ }^{23}$

The second reservation lies within the focus of this chapter in that firms can confront a technological discontinuity by implementing knowledgebased strategies involving internal and external learning. This plausible argument has already been made by Carayannis and Stokes (1997), who showed that continued good performance at the German chemical/pharmaceutical firm BASF may be traced back to its capacity to maintain a corporate culture fostering technological learning, enabling the firm to adapt and thrive despite encountering watershed events such as two major wars, a worldwide depression and the conversion from coal to oilbased feedstock. Another example is provided by McKelvey (1996), who demonstrated that Kabi (now Pharmacia) and Eli Lilly, far from being displaced by new biotechnology companies, have been able to "jump" over to the new technological trajectory by linking their absorptive capabilities with access to external agents with complementary knowledge.

\subsection{CONCLUDING REMARKS}

Insofar as the first wave of resource-based theorists have often paid lip service to dynamic considerations, the contributions of these scholars could only be viewed as a staging step towards the development of a knowledge-based model of superior performance. The resulting model treats knowledge as a dynamic asset and, because of its semi-private, semi-public good characteristics, difficult to monopolize. The problem of firms is compounded by the fact that they often operate in a turbulent environment, compelling them to innovate in a ceaseless technological race with their competitors. Accordingly, the crucial objective to pursue is less the development of innovations as the matching of knowledge and competences with the ever-changing technology, demand and competition. Technological learning, therefore, becomes paramount. Yet, firms differ from one another in terms of learning-based strategies, knowledge assets and historical paths, so one should expect these heterogeneous organizations to perform differently.

The Tushman-Anderson model presented in this chapter also showed that

23. In a way this reservation is consistent with that of Edith Penrose: "The productive opportunities of small firms are composed of those interstices left open by the large firms which the small firms see and believe they can take advantage of. The nature of the interstices is determined by the kind of activity in which the larger firms specialize, leaving other opportunities open" (1959:222-223). 
for large firms, little would come easily as far as competence-destroying discontinuities are concerned. On the other hand, the emergence of competence-enhancing discontinuities would reinforce their competitive position at the expense of smaller firms. Yet another possibility that cannot be dismissed is that firms can confront both types of technological discontinuities through technological learning. More specifically, the implementation of strategies involving internal and external learning and the fragmentation of an industry into different submarkets could be conducive to a division of innovative labor. Given the behavioral advantage of new entrants and material advantage of large incumbents, dynamic complementarities could be established between these organizations (Rothwell 1989, 1992). 

PART II: THE TECHNOLOGY 



\section{On the Emergence and Expanding Knowledge Base of

\author{
Combinatorial Chemistry
}

Combinatorial chemistry is not just a numbers game. ${ }^{24}$ - Mario Geysen, co-inventor of a parallel synthesis method

\subsection{INTRODUCTION}

This chapter deals with technological change and the ways in which combinatorial chemistry introduced a technological discontinuity and provided a foundation for a large number of subsequent incremental innovations along four technological trajectories. Its principal methodology is historical, with emphasis placed on the dynamic pattern of knowledge creation in combinatorial drug and, to a lesser extent, new material discovery. Only four questions will be addressed:

- What are the origins of combinatorial chemistry?

- What is the underlying (and expanding) knowledge base of

24. As quoted in Thayer (1996). 
combinatorial synthesis methods?

- Is combinatorial chemistry a competence-enhancing discontinuity, as opposed to competence-destroying discontinuity?

- Is the demand for combinatorial-based services and products heterogeneous, as opposed to homogenous?

The chapter is set as follows. Section 3.2 takes up the challenge of identifying the origins, methods and underlying principles of combinatorial chemistry. Section 3.3 is in three parts, each highlighting the dynamics of technological change in the field. Section 3.3 .1 breaks down the combinatorial approach to drug discovery into 5 pre-clinical steps as an attempt to assess the first two technological trajectories: incremental innovations concerning: (1) the synthesis of combinatorial libraries and (2) the discovery and optimization of leads. Section 3.3.2 focuses on a summary of research carried out under the umbrella of knowledge based combinatorial chemistry as a means to highlight the third technological trajectory and further integration with the rational drug design approach. Section 3.3.3 describes the fourth trajectory, that is, the recent changes that combinatorial chemistry, together with recent developments in software and hardware technologies brought about in new materials, catalysts, pesticides, etc. Section 3.4 concludes with some remarks about the characteristics of technological change.

\subsection{COMBINATORIAL CHEMISTRY: ORIGINS, METHODS AND PRINCIPLES}

Chronicling the history of combinatorial chemistry is bound to be a difficult, subjective task. This is largely because the pharmaceutical industry actually exploits dozens of combinatorial synthesis methods, the diversity of which reflects a broad choice of methodologies, building blocks, synthesis and screening strategies, software packages, targets, instrumentation levels and so on. Such is its complexity that an historical account is likely to overestimate the contributions of a handful of inventors and innovators while underestimating the inputs of hundreds, if not thousands of known and unknown chemists of all backgrounds, mechanical engineers, molecular biologists, $\mathrm{x}$-crystallographers and so on. Bearing these caveats firmly in mind, one may nevertheless introduce combinatorial chemistry and trace back its origins if one establishes a simple dichotomy between the methods and nomenclatures of "simultaneous parallel synthesis" and "simultaneous multiple synthesis".

Ronald Frank (1983) at the German National Research Center for Biotechnology (GBF) may be credited with laying the first principles of simultaneous parallel synthesis, having invented a method with which 


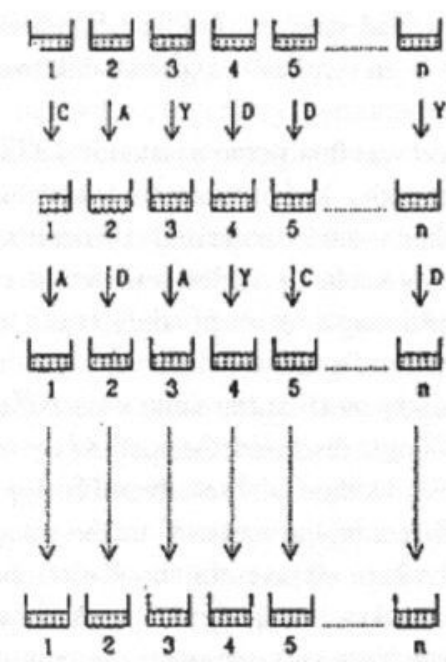

a) Simultaneous parallel synthesis
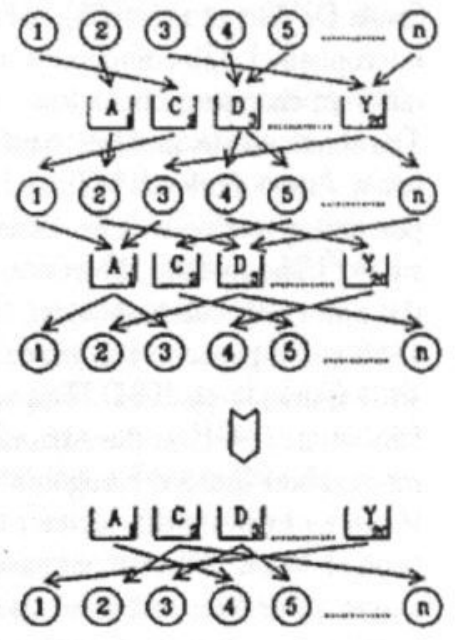

\section{Figure 3.1}

Nomenclatures of Combinatorial Synthesis Methods Source: Ronald Frank (1993)

thousands of different oligonucleotides (i.e. short strand of DNA or RNA) could be rapidly synthesized for systematic functional screening through simple fragment exchange. While Frank's method was a radical departure from previous work in the field, contributing to construct thousands of "synthetic genes", it was soon being overtaken by polymerase chain reaction (PCR) machines as well as better and faster automated DNA synthesizers. ${ }^{25}$ Hence it is probably Mario Geysen, Rob Meloen and Simon Barteling at the Central Veterinary Institute (now called ID-Lelystad) in the Netherlands who presented the most influential parallel synthesis method. Published in the journal Proceedings in National Academy of Science USA in 1984, this method was initially used to synthesize peptides simultaneously by assembling different building blocks (as represented by C, A, Y and D in figure 3.1a) in parallel fashion. Parallel synthesis was first carried out on pin-shaped solid-support, then on microtitre plates (i.e. a molded plastic sheet of wells filled with a few millilitres of reagents) and compound arrays such as those invented by Stephen Fodor (1991) at Affymetrix, Ronald Frank (1992) at the GBF and

25. Personal communication, Prof. Ronald Frank, German National Research Center for Biotechnology (October 2000). 
Sheila DeWitt et al. (1993) at Parke-Davis. Had scientists used a 1,536-well microplate, 1,536 compounds would have been synthesized, each exhibiting different chemical properties.

The simultaneous multiple synthesis method was first demonstrated in 1982 , when Árpád Furka (1982) at Eötvös University in Hungary described his portioning-mixing process in an unpublished -albeit notarized- theoretical study. ${ }^{26}$ The method, however, seemed impossible to publish and patent at the time, only reaching wider audience following a series of conferences in 1988 and a paper in the International Journal of Peptide and Protein Research in 1991 (Furka et al. 1991). This was done pretty much at the same time as Kit Lam et al. (1991) at the Arizona Cancer Center disclosed the split synthesis method and Richard Houghten et al. (1991) at the California-based Scripps Research Institute the "divide, couple and recombine method" in the same issue of Nature. These three methods, which have all been the foundation for a number of later variations, would be carried out on polymer beads, "teabags" or filer disks in movable combined synthesis compartments containing mixtures of building blocks (i.e. A-C-D in figure 3.1b). Had a combinatorial project used 20 building blocks and involved a four-fold reproduction, $20^{4}$ different chemical combinations, or 160,000 new compounds, would have been synthesized, each exhibiting different chemical properties.

\subsection{THE EXPANDING KNOWLEDGE BASE OF COMBINATORIAL CHEMISTRY}

Insofar as combinatorial chemistry is akin to major innovations in being introduced in a crude form, it became clear that the impact of simultaneous parallel synthesis and simultaneous multiple synthesis upon drug discovery would have been minimal had several clusters of incremental innovations not followed its appearance in Hungarian, Dutch, American and German laboratories. This is not unheard of in the history of technology literature. Important inventions and innovations hardly ever work in isolation, and productivity gains can often only be achieved by drawing on small gradual refinements and improvements (Enos 1962; Hollander 1963; Lieberman 1984; Rosenberg 1982, 1994). In this respect, the emergence of combichem methods should not be regarded as a culminating point in the history of drug discovery processes. This should not be taken to trivialize the work of Furka, Geysen, Houghten, Frank and two or three dozen more pioneers. On the contrary, the reality is far more interesting: the emergence of combinatorial chemistry signaled a technological discontinuity, triggering a period of numerous incremental, improvement innovations along four distinct technological trajectories: (1) chemical synthesis; (2) lead discovery and lead

26. Personal communication, Prof. Árpád Furka, Eötvös University (October 2000). 
optimization;(3) knowledge-based combinatorial chemistry; and (4) new materials (see figure 3.2).

In the first trajectory, synthetic organic chemists would progressively shift their efforts and imagination away from "traditional synthesis methods" towards the production of large collections of molecular compounds, also known as combinatorial libraries. The preparation of these libraries did not come without strings attached: automation devices for synthesis had to be developed; chemical synthesis had to be performed in smaller volumes; software for data handling improved; etc. Yet, judged from the vantage point of about 20 years, it is apparent that much of the research performed along this first technological trajectory contributed to the success of multiple and parallel synthesis as a provider of fresh and low costs compounds, once an important bottleneck and a high barrier to entry in the pharmaceutical industry. As will be shown in the following chapter, this first technological trajectory led to the development of a first phase of industrial development: the firm as a provider of combinatorial libraries.

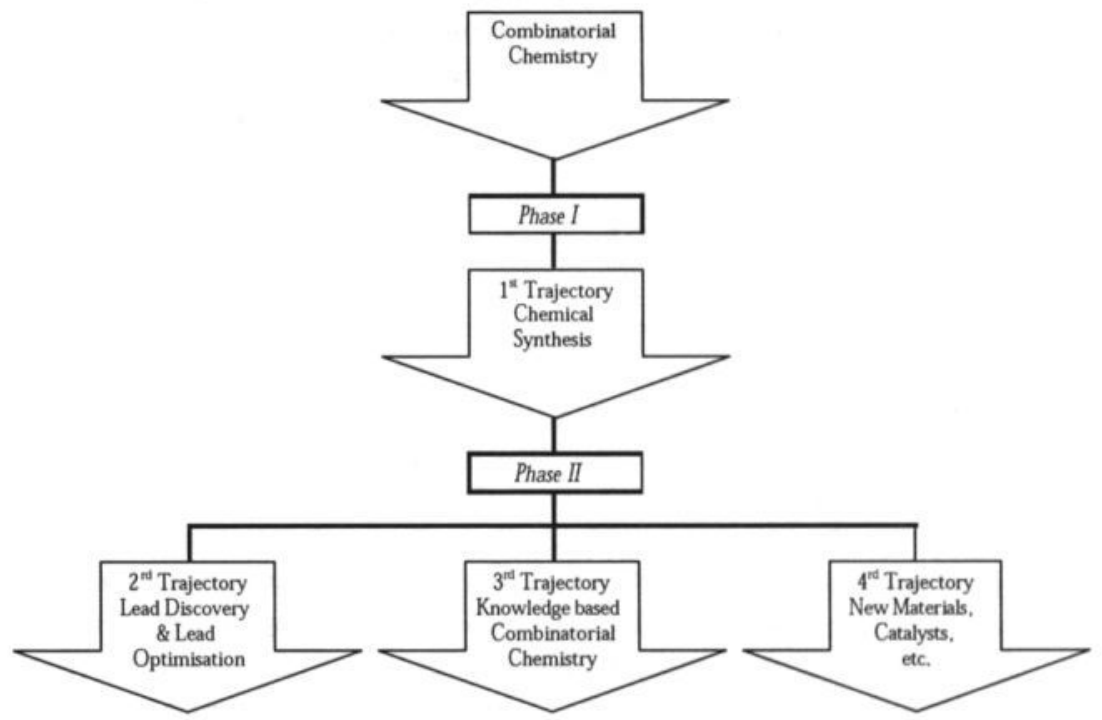

Figure 3.2

A View of Technological Trajectories in Combinatorial Chemistry

The next three technological trajectories have been critical to the establishment of a new phase of industrial development: the firm as a supplier of chemical-based services and products, most notably small molecule drugs. In the second trajectory, technological progress headed upstream towards lead identification techniques, high-throughput screening equipment 
purification tools, quantitative structure-activity relationships and ADMEtoxicology software. ${ }^{27}$ The intent was to improve the process of lead discovery (i.e. the process of generating and identifying an active compound) and lead optimization (i.e. the process of modifying an active compound to fulfill all stereophonic, physicochemical, pharmacokinetic and toxicological tests required for clinical usefulness).

In the third trajectory, technological change is rapidly moving downstream towards the experimental design of focused libraries (i.e. "libraries using a limited number of building blocks chosen on the basis of pre-existing knowledge or hypothesis which defines the type of functionalities deemed important to obtain a particular activity") (MaClean et al. 1999: 2352-53). The rationale behind this move is that the initial combinatorial libraries often yielded disappointing results, leading to a marriage of convenience between combinatorial chemistry and rational drug design. In the fourth trajectory, the achievements of combichem in drug discovery set the stage for exploration into new market segments; thus, knowledge initially created for pharmaceuticals is now being increasingly used to create phosphors, catalysts, zeolites, pesticides and other products. Diversification into new materials, however, has given rise to yet other challenging problems and hence a focal point of further scientific and technological developments.

\subsubsection{The combinatorial approach to drug discovery}

The following description segregates a combinatorial drug discovery project into five pre-clinical steps: (1) the slection and design of a discovery or targeted library; (2) the synthesis of a discovery or targeted library; (3) the establishment of germane screening tests for lead validation; (4) the actual screening of libraries and validation of lead compounds; and (5) the optimization of lead compounds. Admittedly, this technical account is not exhaustive, and one should keep in mind that each pre-clinical step necessitates a complex set of scientific and technical interactions (Augen 2002). Nonetheless, the section should provide a basis for understanding how the emergence of combinatorial chemistry formed the basis upon which two technological trajectories were initiated: (1) chemical synthesis, and (2) lead discovery and

27. The exact wording of research leader Andrew Merritt at GlaxoWellcome is instructive: "Once the realization that the combinatorial and parallel route was an opportunity to obtain, for example, SAR data far more rapidly than previously possible, and that the handle-turning aspects were mostly taken care of by either the machinery itself or support mechanisms, the avenues for project advancement using the new approaches were wide open. Moreover, newer technical and scientific challenges became the driving forces to enthuse and interest the chemist -such as how to select a good set of compounds or how to optimize a piece of chemistry for genetic reactants" (1998:507). 
lead optimization.

First step: select and design discovery or targeted library

During the late eighties and the first half of the nineties, combinatorial libraries could be conveniently divided into two categories: discovery libraries, which are prepared with building blocks and scaffold chosen without bias toward a particular target; and targeted libraries, which are geared towards a particular protein class such as a kinase, an ion channel, etc. (MacLean et al. 1999). For the former, the reasoning is that with large random libraries containing thousands and thousands of compounds, medicinal chemists will be able to cover more chemical space in the search for new classes of compounds. For the latter, the reasoning is that with smaller libraries containing building blocks that are known to interact with target receptors, medicinal chemists will be able to cover more diversity (i.e. the "unrelatedness" of a set of, for example, building blocks or members of a combinatorial library, as measured by their properties such as atom connectivity, physical properties, computational measurements, or bioactivity) (MacLean et al. 1999:2352) within a given conformational space, thereby prioritizing compounds for screening and accelerate the lead discovery process. Yet both libraries attempt to maximize diversity in their own way, since it is axiomatic for all combichem projects that the more diverse the compounds, the better the odds of finding "hits" (Fauchère et al. 1998)..$^{28}$

Anxious to maximize their chance of success and minimize uncertainty, for-profit firms would carefully plan these libraries by exploiting the potential of information technologies in general and the burgeoning field of chemoinformatics in particular. Chemoinformatics has been recently defined as the "mixing of [information technology and management] resources to transform data into information and information into knowledge for the intended purpose of making better decisions faster in the arena of drug identification and optimization" (Brown 1998:375). In an all-encompassing fashion, the latest buzzword in the combichem field embraces "compound registration into databases, including library enumeration; access to primary and secondary scientific literature; QSAR (quantitative structure-activity relationships) and similar tools for relating activity to structure; physical and chemical property calculations; chemical structure and property databases, chemical library design and analysis; structured-based design, and statistical methods" (Hann and Green 1999:379). Stated differently, chemoinformatics

28. Robert Pearlman at University of Texas expresses the concept of diversity this way: "It is like shooting a shotgun in the dark. You want to shoot in as many places as you can to maximize your chance of hitting something. Once you hit something, you can train the gun in that one area to see if you hit more" (Wilson 1998). 
takes in most of the information resources the combinatorial chemist needs to perform his or her job before and within the process of lead discovery and optimization (Brown 1998).

Responding to this pressing demand, software companies and database suppliers have developed text-based information systems, software programs and databases aimed at evaluating proactively existing data, know-what and know-why on the inventory and commercially available building blocks (Can starting materials be obtained at reasonable price?), the related chemical reaction literature (How can the optimal synthetic route be achieved?), the existing drugs (Are there any potentials for patent infringement?), the company's own libraries (How much of this library overlaps with previous ones?) and the availability of bioassays (Can the newly synthesized compounds be efficiently tested?) (Krieger 1996; Pavia 1996; Polinsky 1999; Grethe 1999; Calvert et al. 1999). Hundreds of new websites have also been created to provide not only the now familiar access to the organization's home pages but also an effective channel through which the above knowledge is freely disseminated, licensed or sold to a widespread group of users (Krieger 1997; Sullivan 1997; Güner and Casher 1999).

\section{Second step: synthesize discovery or targeted library}

Prior to 1992, discovery and targeted libraries exclusively contained small stretches of proteins called peptides and oligonucleotides. ${ }^{29}$ Such libraries, however, began to lose some of their appeal when Barry Bunin and Jonathan Ellman (1992) at University of Berkeley in California, preceding Sheila DeWitt et al. (1993) at Parke-Davis by a few months, set up a library made of small chemical molecules (i.e. compounds weighing about 500 daltons). The idea clearly caught fire (Borman 1996). Roland Dolle's surveys of combinatorial libraries best captured its diffusion (Dolle 1998a, 1998b, 2000; Dolle and Nelson 1999). Of the 154 biological active libraries identified by Dolle during 1998-1999, 31 (20 percent) compound collections were peptide-based and 123 (80 percent) had low-molecular weight diversity elements, a reversal of fortune considering that peptide libraries represented 50 percent of total combinatorial libraries synthesized during 1992-1997.

Technological change in the discipline of organic chemistry must be understood in the light of delivery problems arising from using DNA and

29. One reason for this early preference is that peptides and oligonucleotides were well suited to the medium of solid phase chemistry, a synthesis method invented by Nobel Laureate Edwin Merrifield (1965). Another reason is that automated $\mathrm{DNA} /$ peptide/protein synthesizers and sequencers widely available, making routine the task of producing and identifying newly assembled peptides and oligonucleotides (Thayer 1996). 
amino acid as building blocks. Proteins and peptides, which become seriously vulnerable to digestive enzymes when taken orally, often have to be administered through intravenous injections. Small molecular weight compounds, by contrast, can often -but not always- be delivered without needles. These orally active medications cause less discomfort and less inconvenience, increase patient compliance and thus wider use, a human reflex that may lead to larger markets and larger profits (Damms and Bains 1995). In other words, Ellman's breakthrough discovery and the strong demand for pills had been pushing and pulling combinatorial synthesis into the field of organic chemistry.

However, the opportunity to commercialize small molecule drugs had been restricted by the limited number of solid phase reactions that have been optimized since Merrifield invented the method in 1963. An important advantage of solid phase chemistry is that the medium allows more complex reactions to be completed by use of excess of reagents, which reduces the risk of losing compounds during the extraction procedures. On the other hand, solution phase chemistry (i.e. without the use of beads or solid support) had been used by synthetic chemists since the end of the $19^{\text {th }}$ century, permitting the use of a greater variety of reagents and reactions, but had disadvantages with respect to purification (Coe and Storer 1999). To redress many of these shortcomings, substantial efforts have been made to develop compatible organic reactions for both solution phase and solid phase synthesis in conjunction with new supports, methods, etc. (Sucholeiki 1999; Van Hijte et al. 1999). However, Dolle's surveys are proof of higher activity with regard to solid phase chemistry. Of the 284 biological active and nonactive libraries reported in the scientific literature in 2000, 82 percent were generated on solid support (Dolle 2001).

At first, these libraries were synthesized manually. Combinatorial chemists using parallel synthesis employed pins that were mounted onto a plate, and synthesis had to be carried out on the tip of each pin by dipping them into a machine tray with reagents. Similarly, the nitial emphasis for producing complex mixtures of compounds focused on manual synthesis. It was carried out in 20 independent flasks, which were then empty into a separate mixing container from which they were redistributed. ${ }^{30}$ Proposed by Arne Holm and Morten Meldal (1989) at the Carlsberg Laboratory (DK), the first multiple-column synthesizer for simultaneous parallel synthesis was patented and presented at a conference in Tübingen, Germany, in 1988. The potential for automating the multiple synthesis method was also recognized, and Zuckerman et al. (1992) at the US-based biotech firm Chiron built the first equimolar mixture synthesizer in 1990.

30. Personal communication, Dr. Morten Meldal, Carlsberg Laboratory June 2001) 
This was followed by the commercialization of dozens of automated devices by manufacturers of scientific instrumentations. In addition to increased efficiency, which can be measured by increased throughput, a broader range of chemistry, increased in the product quality, reliability and reproducibility of the process, these suppliers have given careful considerations to make synthesizers accessible to most chemists, rather than expert programmers (Hird 1999; Coates et al. 2000). While the price of these fully automated synthesizers can be steep, manufacturers have also brought to market semi-automated or manual synthesizers, making the technology affordable to every chemist. ${ }^{31}$

One thing is sure, however; the emergence of combinatorial synthesis methods marked a technological discontinuity, providing the framework upon which a swarming of incremental innovations would allow the scope of synthesis to be extended and a reduction in the price of individual compounds. One needs only to look at the changes in price and performance of chemical synthesis to appreciate the importance of this technology. It previously took, on average, one month for a medicinal chemist to generate four compounds directed towards a given target -at a cost of approximately \$US 30,000 , or $\$$ US 7,500 per compound. By 1996 , a chemist could generate 3,300 compounds for \$US 40,000 , or approximately \$US 12 per compound. Calculated differently, combinatorial chemistry allows 1,000 times more compounds to be synthesized than the conventional methods for at least 600 times less cost per compound (Persidis 1998). ${ }^{32}$

\section{Third step: establish screen on assay for lead validation}

A goal that all drug discovery programs have in common is the need to determine whether any of the newly formed compounds elicit a particular physiological activity. While yesterday's drug hunters would have met this requirement by injecting the novel compounds into animals, today's scientists are more likely to perform their primary screens on a bioassay that is germane to a specific disease. This is not surprising considering that in vitro and in vivo assays are unmistakably less cumbersome, ethically much less controversial, clearly much faster to implement, much cheaper (i.e. \$US 0.10 to \$US 1.00 per unit) and more effective than animal models (Beese 1996). In addition, large investments in basic research in biotechnology have

31. In fact, some chemists even prefer working with these semi-automated and even manual synthesizers due to the complex nature of conducting many types of chemistry on a single robot Personal communication. Dr. Morten Meldal, Carlsberg Laboratory (February 2001).

32. These estimates were taken from the Booz, Allen \& Hamilton 1996 Survey. It is safe to say that today's methods permit greater reduction in costs because they are ceaselessly being improved, evolving towards more sophisticated forms. 
made possible the identification and cloning of drug targets, which then can be grown into cultured cells and deposited in a screening assay. Besides cellbased lines, other molecular drug targets have been developed, including factors and hormones, enzymes, ion channels, nuclear receptors and DNA. In 1996, compounds could be screened against about 500 targets cum genetic diseases (Drews 1997).

Nonetheless, firms face difficulties producing in a cost effective manner the quantities of molecular targets needed for current screening capabilities. Therefore, large number of compounds may also demand that assays have to be adapted to run in smaller volume, prompting a shift of detection mode away from radioactive methods towards methods based on fluorescence (Oldenburg 1998).$^{33}$ Moreover, the distribution of these targets is heavily skewed, reflecting the opportunism stemming from past medical research experience. For example, almost 30 percent of total targets aim at drugs affecting synaptic, neuroeffector junction sites and the central nervous system (Drews and Ryser 1997). Despite these limitations, the years to come should bring a growth in the number of drug therapy targets -estimated about 5,000-10,000 - as a result of the Human Genome Project (Drews 1997). As a consequence, wrote Jürgen Drews: "the potential of drugs to interfere with physiological or pathophysiological processes would increase by at least one order of magnitude as compared with the present situation" (1997:77).

This potential should demand a rising number of newly synthesized compounds, thereby unleashing synergetic forces resulting in a stream of new innovations and the creation of new sub-markets for firms of all size to occupy. In the words of Riccardo Pigliucci, chief executive officer at Discovery Partners International: "It is hard to imagine two drug discovery technologies that could be more reinforcing and complimentary. Genomics will provide a wealth of new targets. Combinatorial chemistry is providing a wealth of new chemical diversity, and high throughput screening is providing the machinery to test this chemical diversity against these targets" (Parle 1999).

\section{Fourth step: screen library and validate lead candidates}

If the innovations listed above were to have a truly significant impact on the pharmaceutical industry, another major issue had to be addressed: how can the most active compounds be rapidly singled out and identified from the new-found ability to create small quantities of many compounds cheaply and rapidly? Finding the needle in the haystack required innovations to be

33. Suppliers have striven to do achieve these goals, and fluorescence-based assays for parallel synthesis methods are now becoming prevalent (Burbaum 1998; Hetzberg and Pope 2000). 
developed, but again the parallel synthesis and multiple synthesis methods posed different sets of problems to which there were many viable technical solutions. ${ }^{34}$

Consider first parallel synthesis methods. Parallel synthesis on solid support (or in solution) allows molecules to be tested individually in a spatially differentiated manner. This basically means that investigators, having kept track of the building blocks used for each reaction in each well of a microtitre plate, may use specially designed software to locally derive the structure of compounds that appear to be reacting against the set target. Parallel synthesis also lends itself well to high-throughput screening methods (HTS), which refers to the techniques by which vast populations of compounds are screened simultaneously via automated instrumentation. However, no typical HTS strategy actually exists, and levels of automation and robotization vary greatly from firm to firm. In some companies, the purchase of a complex robotic system capable of screening large collections of compounds without requiring shift work is the solution of choice (Houston and Banks 1997). In some others, HTS are limited to simple automated dilution devices. Yet other firms would prefer buying off-theshelf components and cobble them into an integrated screening system (Dove 1999).

However, most firms are prone to purchase HTS instrumentation that is becoming increasingly automated and miniaturized. On the one hand, the automation of repetitive tasks like pipetting, àssay reading and sample storage pushes screening rates to higher levels as well as being less labor intensive and more reproducible. The recent introduction of ultra high-throughput screening (UHTS), which can handle 100,000 samples or more a day, fits this mould (Hertzberg and Pope 2000). These robotic systems are "walk-away" devices in the sense that the operator can walk away until the screening is completed (Oldenburg 1998). On the other hand, miniaturization allows scientists to pack more compounds/vessels into a microtitre plate, which increases the number of compounds being screened in a given time and keeps reagents, compound and target quantities -and cost- to a minimum. For this reason, technological endeavors got underway to develop smaller microtitre plates, as shown in table 3.1. Economies of scale can be substantial. For instance, the new entrant Selectide recently synthesized 300,000 compounds in 1,536-well plates. Whereas the price of the required reagents amounted to \$US 12,867 , the same test carried out in a 96 -well plate would have cost the firm \$US 321,610 (Hadlington 1999).

34. For further references to the extensive literature, one should see, for instance, Gallop (1994). Wilson and Czarnik (1997). Venton and Woodbury (1999) and Barnes and Balasbramanian (2000). 


\section{Table 3.1}

Miniaturization of microtitre plates

\begin{tabular}{lccc}
\hline Format & Assay volume & Reagent savings & Year of introduction \\
\hline 96-well plates & $100 \mu \mathrm{l}$ & - & $1980 \mathrm{~s}$ \\
384-well plates & $50 \mu \mathrm{l}$ & 4-fold & 1994 \\
864-well plates & $20 \mu \mathrm{l}$ & 10-fold & 1996 \\
1,536-well plates & $2-5 \mu \mathrm{l}$ & 20 to 50 -fold & 1997 \\
6,144-well plates & $0.2-0.9 \mu \mathrm{l}$ & 250- to 1000-fold & 1997 \\
9,600-well plates & $0.2 \mu \mathrm{l}$ & $>1000$-fold & 1998 \\
\hline
\end{tabular}

Sources: Houston and Banks 1997; Oldenburg 1998; Dove 1999; Sundberg 2000.

In light of these benefits, the infant microfluidic technologies should only be attracting more attention in the future. These miniaturized devices are designed to control the flow, reactions and measurements of tiny amounts of chemicals and biochemicals on a chip made of glass, plastic and/or silicon (Kricka 1998; Freemantle 1999) ${ }^{35}$ Many microfluidic technologies are not directly connected to combichem, but the start-up company Orchid Biocomputers continues to experiment with the concept of synthesizing more than 10,000 molecules on a credit-card sized glass chip ${ }^{36}$ while Caliper Technologies broke fresh technological grounds by introducing the first microfabricated devices for high-throughput drug screening in 1999. The Caliper 100, 110 and 220 are capable of performing thousands of screening experiments per day on a single chip while reducing reagent consumption up to 100,000 -folds. These lab-on-chips compete directly with microtitre plates and HTS instrumentations. But the dynamics of substitution may be hampered by the fact that the Calipers are only sold through a technology access program involving license fees and subscriptions fees, and these command premium price. In addition, screeners typically work in a manufacturing mode, and they have less time than other industry scientists to allocate to technology exploration. ${ }^{37}$

Multiple synthesis methods produce much larger libraries in complex mixtures of compounds, most of which do not work well with HTS methods and do not allow for direct identification (Venton and Woodbury 1999) ${ }^{38}$

35 . The term microfluidic technology is used quite loosely and may include a variety of products and thereby applications such as DNA sequencing for genomic projects. diagnostics/prognostics, forensics, analytical systems for use in defense against biological and chemical warfare, high-throughput screening and even synthetic chemistry (Pharmaceutical Business News 1997).

36. It is estimated that a library of 10,000 compounds would cost less than $\$$ US 100 with a Orchid microchip, as opposed to \$US 200,000 (Borman 1998).

37. Personal communication, Dr. Mike Knapp, Caliper Technologies (April 2001).

38. The exception is the portioning-mixing synthesis method, wherein one bead contains one compound. This characteristic allows researchers to elucidate the compound's structure by mass spectrometry (Venton and Woodbury 1999). 
Nevertheless, solutions to the screening bottleneck were eventually brought forward: (1) deconvolution methods and (2) tag-encoding technologies. Pioneered by Richard Houghten et al. (1991) at the Scripps Research Institute, the iterative deconvolution procedures involve the creation and screening of sub-libraries in which the building blocks at one position are identified. If a strong pharmacological activity were observed in a particular sub-library, medicinal chemists would resynthesize the whole mixture, divide it into even smaller sub-libraries, and retest each one separately. The iterative process is then repeated until the active compound ends up isolated. Various deconvolution methods since 1993, which provide direct validation without iterative resynthesis, have since been developed, including the positional scanning method by Colette Dooley and Richard Houghten (1993) at the Torrey Pines Institute for Molecular Studies in California and the "orthogonal" library approach by Benoit Deprez et al. (1995) at CEREP, France's largest new entrant in the field.

A second solution involves developing tag-encoding technologies in which compounds are screened still tethered to polymer beads and identified by "chemical markers". While there is no single best tagging method, most innovations have in common the synthesis of a second compound on the bead, each one representing a readable tag that defines the synthetic history of the compound. The first of these, invented by Steven Brenner and Richard Lerner (1992) at the Scripps Research Institute used biochemical tags made of small stretches of nucleotides, which act a bit like bar codes on products in supermarkets. Other scientists followed suit, and other tagmaking technologies have been successfully tested. ${ }^{39}$ Recently, K.C. Nicolaou at the Scripps Research Institute and Xiao-Yi Xiao and colleagues at the new entrant Irori also proposed radiofrequency encoding (Nicolaou et al. 1995). This encoding strategy involves tethering beads with microchips containing detailed information about the compound's specific synthetic pathway, namely, its structure, the reagents used and the reaction conditions such as temperature and $\mathrm{pH}$. As these chips emit radio waves, researchers would retrieve the required information with the help of a receiver via radiofrequency transmission.

Innovative though deconvolution and encoding technologies may be, their laborious and time-consuming nature, combined with the lack of analytical control, the lack of accurate structure elucidation and a tendency to yield reveal "ghost" activity, can play down multiple synthesis methods as far as computing methods are concerned (Plunkett and Ellman 1997; Antel 1999; Van Hijte et al. 1999). ${ }^{40}$ Yet, if the demise of multiple synthesis has

39. Examples include tags made of peptides (Kerr et al. 1993), halogenated aromatic compounds (Ohlmeyer et al. 1993), fluorescent labeled enzymes (Lowe and Quarell 1994) and chromatographically resolvable organic (Still 1996).

40. "Ghost" activity may arise when a combination of many low-affinity compounds 
sometimes been heralded, it is by no means sure that firms using this process have become "locked-in" to an inferior technology, since deconvolution methods and encoding technologies are constantly being upgraded (Barnes and Balasubramanian 2000), lead compounds are still regularly found in mixture-based libraries (Golebiowski et al. 2001) and new materials have just begun being synthesized along this trajectory (Borchardt 1998). In addition, because some properties may be impossible to predict with smaller libraries, several organizations still believe that large mixture-based libraries will be more successful in disclosing entire new classes of compounds, especially when no knowledge about the target is available (Karet 1999).

\section{Fifth step: optimize lead compounds}

It is important to bear in mind that drug candidates do not come out directly from combinatorial libraries and screening activities. In fact, combinatorial chemistry does not produce higher quality compounds; only more compounds -and data. The quality of compounds will never depend on a specific synthesis method, screening strategy, software product or automated piece of equipment, however sophisticated or miniaturized the technological platform may be. Rather, the quality of compounds -and ultimately drugs- will always depend on the intuition and care which the medicinal chemist has put into their design. ${ }^{41}$ Nevertheless, taking a lead compound through the lead optimization process may take 24 to 36 month, the longest and most unpredictable pre-clinical step to drug discovery (Andersen 1998), and increasing pressures to speed up and enhance the whole combinatorial drug discovery process pointed to more innovations along the second technological trajectory.

Before considering the bottlenecks tackled by scientists in greater detail, it needs to be insisted that a lead compound is not a ligand and a ligand is not a drug candidate! To qualify as a ligand a lead compound must fulfill the requirement of potency (i.e. the molecule must interact with a receptor protein and bring about a physiological change), and to qualify as a drug candidate a ligand must be optimized with respect to its absorption, distribution, metabolism and excretion (ADME) properties (i.e. the molecule must be absorbed efficiently by the body, accumulated in sensible quantities and persist for a sensible period of time), toxicity (i.e. the molecule must have a minimum of negative side effects), freedom to operate, acceptable cost of synthesis, accessibility, stability (chemical and metabolic), color, odor, formulability, etc. (Kubinyi 1997a, 1998a; Fecik et

sometimes reveals as much activity as a few high-affinity compounds, producing complex mixtures of molecules with equivocal and even false screening results (Gordon et al. 1994).

41. Personal communication, Prof. Dr. Hugo Kubinyi, BASF (DE) (April 2001). 
al. 1998).

From this standpoint, the enhanced role of combinatorial chemistry finds its expression in the ability to generate large quantities of low cost analogues and data for quantitative structure-activity relationships studies, or QSAR for short; thus, a medicinal or computational chemist who wishes to anticipate the binding affinities of ligands may harness the power of numbers far more rapidly and effectively than previously achieved. First demonstrated by Gorwin Hansch and Toshio Fujita (1964) at Pomona College, QSAR models are chemoinformatics methods that enable chemists to predict the likely potency of analogues not yet synthesized, all from knowledge of chemical structures and properties. The central assumption is the similarity-property principle: structurally similar compounds tend to exhibit similar biological activities (Kubinyi 1997a; 1998b). The main challenge is to quantify the structures or physical property (i.e. hydrophobicity, electronic properties, steric effects, topology, etc.) of a set of compounds into a number and compared them to the numerical value of a biological activity (i.e. the yes or no answers of bioassays). The principal task is to craft mathematical models and use correlation techniques to convert data into know-what and knowwhat into know-why of which interactions are important to biological activity (Brown 1998). And, finally, the crucial objective is to provide working hypotheses for the synthesis of similar but more potent compounds, which will be validated by screening these analogues in an assay and the best ones refined in a follow-up process until the medicinal chemist is satisfied with the characteristics of a particular ligand (Kubinyi 1997b).

However, it is apparent that the economies of scale created by combinatorial chemistry came at a price: the more compounds being synthesized, the more difficult it became for analytical chemists to guarantee the purity of compounds -and thereby the validity of QSAR calculations. ${ }^{42}$ The recognition that combinatorial chemistry is not always up to the task led instrumentation companies to develop high-throughput purification instruments. These manufacturers and many others have constructed reliable and sensitive devices for infrared and gel-phase nuclear magnetic resonance spectroscopies and liquid and gas chromatography mass spectrometries. The success of these purification tools, reflected in their ability to rapidly, reliably and effectively purify and assess the quality of multiple and parallel synthesis libraries, suggests that quality assurance and quality control is fast becoming a reality (Fitch 1999; Weller 1999; Coates et al. 2000; Papac and

42. As pointed out by Sheila H. Dewitt, inventor of the Diversomer method and senior director of business development at Orchid Biocomputer: "As the bottleneck moves from lead generation to lead optimization, the need for quality compounds becomes critical. The current capabilities of analytical instrumentation cannot address the emerging needs for quality assurance and quality control or large numbers of compounds" (Kane 1999). 
Shahrokh 2001). ${ }^{43}$

Medicinal and computational chemists also felt the burden of numbers. In the early nineties, synthesis and screening efforts were commonly designed for 10 to 20 assays and 10,000 compounds per assay, per year, yielding 100,000 to 200,000 data points. By the mid-nineties, the number of assays had increased on average to 25 to 50 , with 200,000 compounds being tested in each assay, resulting in 2.5 million to 10 million data points per year. By the late nineties, scientists tested 500,000 compounds annually in 100 different assays, resulting in roughly 50 million data points per year (Kane 1999). While the flood of new compounds and data made it more difficult with traditional property descriptors to characterize adequately what distinguishes an active compound from an inactive one (Connolly Martin 1996), software programs encompassing a wider range of property descriptors have been and continue to be developed in-house and commercialized by suppliers of chemoinformatic tools. A prime example is the introduction and improvement of CoMFA, or Comparative Molecular Field Analysis, by Richard Cramer et al. (1988) at Tripos. Much of the early work focused on 2D descriptors, but CoMFA made it possible to consider the $3 \mathrm{D}$ representation of molecular structures, enabling correlations to be established between properties of molecules and their shapes (Connolly Martin 1998). Another prime example is QuaSAR-Binary, a new technology for HTS and UHTS data analysis. Developed by Paul Labute (2000) at Chemical Computing Group (CA), the software incorporates new mathematical principles and error-prone binary measurements as input and is capable of predicting the biological activity of untested compounds even when large numbers of compounds and data are considered.

Another important bottleneck arising from rapid synthesis comes from the realization that medicinal chemists and pharmacologists could not keep up with the number of compounds being supplied for pharmacokinetics and toxicity studies, propelling the development of in silico testing as a way to reduce to a minimum the use of animal models and/or standard metabolic screens (Sanson 1999). Examples include software products that have been marketed the solubility prediction software by Advanced Chemical Development and the toxicity software package by Accelrys. Simple rules of thumbs have also been developed to reduce the uncertainty of the innovative process and help identify compounds with ADME and toxicological problems (Lipinski et al. 1997; Fecik et al. 1998; Ekins et al. 2000; Watt and Morrison 2000). Lipinski's rule of five, in spite of its simplicity, is assuredly the most well known of combinatorial filters. By studying the physiochemical properties of over 2000 drugs that are on the market,

43. Purification tools, however, are not costless: sophisticated instruments may reach the six digits number, raising the sunk costs associated with the lead optimization process. 
Christopher Lipinski and colleagues at Pfizer suggested that easy-to-calculate parameters could be of assistance in the prediction of a compound's poor absorption. ${ }^{44}$ Lipinsky may well have a point: only 4 out of the 100 best selling drugs in 1998 fell outside the rule of 5 (Blake 1998). Although software for QSAR and ADME and simple rules of thumbs may boost the chance that the selected drug candidate does not end up being rejected, or withdrawn, by regulatory authorities for unforeseen negative side effects, they only produce working hypothesis which, albeit supported by statistical parameters, need to be proved (or disproved) by iterative feedback cycles of synthesis and testing of analogues (Kubinyi 1997b). The lead optimization process is therefore evolutionary, as opposed to "finding a needle in a haystack". 45

\subsubsection{Knowledge-based combinatorial chemistry: when combinatorial chemistry meets rational drug design}

The core of this section is to highlight the strengths and weaknesses of discovery and targeted libraries and systematize what has been done along the third technological trajectory: knowledge-based combinatorial chemistry, also known as mechanism-based or structure-based library design. Such trajectory contrasts with the first and even second trajectory in that, like biotechnology and the rational drug design approach (Gambardella 1995), it generated greater incentives to invest in frontier scientific research. Consequently, the underlying methodology of combinatorial chemistry has swung from a semi-empirical approach towards a knowledgebased approach to drug discovery.

\section{From discovery library to focused library}

The best thing that can be said about the innovations mentioned in the previous section is that they have combined together to improve chemical synthesis, lead discovery and lead optimization. An illuminating illustration of these benefits have been presented by Stefan Thomke, Eric von Hippel and Ronald Frank (1998) in a case study involving the construction of a targeted library (see table 3.2). Using data by New Jersey-based Pharmacopeia, a leader in the industry, the authors weighed the development cost and time of synthesizing and screening compounds in the hope of finding one that can act against an eye disease (glaucoma). In all respects, the combinatorial approach wins hands down, allowing the firm to

44. Thus, if a compound has more than 5 hydrogen-bond donors, 10 hydrogen-bond acceptors, a calculated log of octonol/water partition coefficient greater than 5 and a molecular mass over 500 daltons, the medicinal chemist would simply not synthesize it.

45. Personal communication, Prof. Dr. Hugo Kubinyi, BASF (April 2001). 
move to clinical trials much faster and cheaper than the traditional approach. The scholars have also conducted a series of interviews with experts in the field, who estimated that combinatorial chemistry projects reduce the cost and time devoted to lead optimization by a range of 10 percent to 80 percent.

The worst thing that can be said about combinatorial chemistry is that large random discovery libraries and therefore pure chance discoveries are passé. By the mid-nineties, evidence began trickling out of laboratories that these libraries did not necessarily deliver pharmacologically active compounds (Lahana 1998; Dolle 2000; Leach and Hann 2000). While large libraries using diversity-driven sample screening have a share in the discovery of lead compounds (Golebiowski et al. 2001), these leads are much more likely to be derived from corporate collections of compounds, reflecting more the history of each incumbent than actual chemical diversity. This underscores the fact that discovery libraries are usually constructed around a single or few scaffolds (i.e. core portion of a molecule common to all members of a library) -if the theme is biologically irrelevant, no leads can be found. ${ }^{46}$ In this respect, skeptical medicinal chemists have wasted no time remarking that $10^{40}$ molecules or so would have to be screened if every conceivable drug-like molecule were to be synthesized. To put this into perspective, the number of seconds since the Big Bang is $10^{17}$. Therefore, even if a company were to synthesize and screen 100 million compounds, the sampling would still be hopelessly inadequate (Valler and Green 2000).

\section{Table 3.2}

Comparing the parallel synthesis approach with traditional chemistry in the discovery of lead compounds for the treatment of glaucoma

\begin{tabular}{lcc}
\hline Project variable & $\begin{array}{c}\text { Combinatorial } \\
\text { approach }\end{array}$ & $\begin{array}{c}\text { Traditional } \\
\text { approach }\end{array}$ \\
\hline (1) Total development time & 3.5 months & 5 years \\
(2) No. of chemists needed & 4 & 15 \\
(3) No. of compounds tested & $\sim 9000$ & 3750 \\
(4) No. of (serial) rounds & 1 & $100(250$ max $)$ \\
(5) No. of compounds per round & $\sim 9000$ & $\sim 38$ \\
(6) Cost of screen per round & $\$ U S 10,000$ & $\$ U S 10,000$ \\
(7) Total cost (chemists only) & \$U 167,000 & \$US 18.75 million \\
(8) Total cost per compound & $\$ U S 19$ & $\$ U S 5,000$ \\
\hline
\end{tabular}

Source: Thomke et al. (1998)

To address this huge bottleneck, scientists from both public and private sectors have turned to rational drug design for solutions. In a few words, the

46. Personal communication, Dr. Roland Dolle, Adolor Corporation (June 2001). 
ultimate objective of the rational drug design method was to construct a drug, atom by atom, on a basis of knowledge about the target (Blundell 1996). Yet, as is often the case with new drug discovery methods, the impact of rational drug design had been less than envisioned (Gambardella 1995; Bailey and Brown 2001). ${ }^{47}$ One reason is that protein structures are dynamic, making it difficult for nuclear magnetic resonance (NMR) and $x$ crystallography to predict how a protein might change shape to conform to a not yet synthesized ligand. Another reason is that even supercomputer level calculations of enzyme-ligand complexes have difficulties œping with force field inaccuracies, poor modelling of solvation and counter-ion effects, bondmaking/breaking processes, dynamics of binding/reaction, etc. ${ }^{48}$ Peter L. Myers, chief scientific officer at the new entrant CombiChem, explains that:

...the problem with [rational drug design] was that it had to be a hole in one. You took the combination of features that looked perhaps the most relevant and then you tried to express them all in one molecule. Then you'd go make that molecule, and if it was a lemon, you kind of were no wiser. We use libraries, so we're automatically looking at larger numbers of compounds and we're not expecting to get an exact match. We're just expecting to see some marginal improvement in activity of some of those compounds as the focused libraries are synthesized, screened, and analyzed in an iterative manner (Borman 1999:38).

Since the combinatorial chemistry could be criticized for relying to excess on numbers rather than design and rational drug design disparaged for the opposite reason, the two technologies were set for a marriage of convenience (Bailey and Brown 2001). Spurred on by the hope of revitalizing both technologies, scientists of all backgrounds took to improve and merge both research methods with a wave of incremental innovations. As charted in figure 3.3, this close intermeshing of process innovations triggered a conceptual division of combinatorial libraries from discovery to focused library and focused library into pharmacophore based and structured based library, ench exhibiting less diversity and more knowledge about the receptor target than the last (Hann and Green 1999). To add complexion to an already intricate situation, pharmacophore based, targeted and optimization libraries can be designed based on 3D information of the target, blurring all distinctions between libraries. In this context, any typology of

47. Only a handful of "rationally designed drugs" exist, including Dorzolamid by Merck, AG85 by Agouron as well as Saquinavir and Ro466240 by Roche (Bailey and Brown 2001).

48. Personal communication, Dr. Peter Grund, Pharmacopeia, June (2001). 
combinatorial libraries is necessarily imperfect. ${ }^{49}$

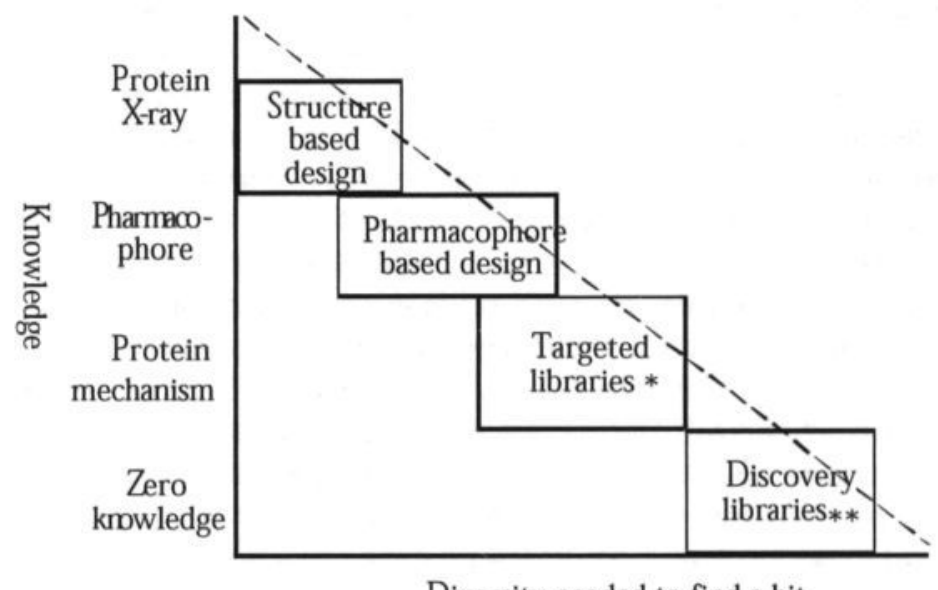

Diversity needed to find a hit

\section{Figure 3.3}

The knowledge plot

${ }^{*}$ Focused sets and ${ }^{* *}$ Primary screening libraries in authors' terminology Source: Hann and Green (1999:380)

Confronted with a huge chemical universe, scientists have learned that the similarity-property principle could prove useful in situation in which the list of compounds to be synthesized needs to be pared down, libraries need to be compared one another and/or libraries need to be purchased. $h$ the course of time, this recognition became the catalyst that fuelled the in-house and/or commercial development of software for diversity analysis and the basis upon which focused libraries will be synthesized. ${ }^{50}$ In concrete terms, diversity analysis involves the construction of a virtual combinatorial library containing, in electronic form, all the compound structures that would be possible to make given the constraints of specific problems, the chemistry being involved and the reagents that are commercially available or synthetically accessible (Brown et al. 2000; Leach and Hann 2000).

Hereafter, the limiting step involves making difficult decisions, since computational chemists must choose among hundreds of descriptors (i.e. molecular properties, 2-D fingerprints, BCUT descriptors, 3-D structural

49. Personal communication, Dr. Adam Golebiowski, Procter \& Gamble Uune 2001).

50. Examples of diversity software include DiverseSolution by Tripos, C2Diversity by Accelrys and Fingerprint Toolkit by Daylight Chemical Information Systems. 
descriptors, etc.), each capable of converting the physical property of the whole molecule or pieces of the structure into data. They must also choose a selection method, as for example cluster-based selection (Down and Willett 1995), genetic algorithm (Sheridan and Kearlsey 1995), partioning techniques-based (Pearlman 1996), stochastic algorithm (Agrafiotis 1997) and dissimilarity-based selection (Lajiness 1997). Each method is capable of converting data into know-what and know-what building blocks or members of a combinatorial library are the most "unrelated".

While every chemist agrees on the need to select a representative sampling of compounds, no one seems to agree as how best to define, let alone to measure, diversity (Agrafiotis et al. 1999; Gorse and Lahana 2000; Connolly Martin 2000). Nor does a consensus exist as to the best selection method (Willett 2000). This uncertainty stems from the fact that diversity largely depends on multiple factors that are beyond the scope of isolated molecular descriptors, compelling scientists to take decisions on the basis of imprecise and vague feedback (Ramesha 2000; Villar and Koehler 2000) ${ }^{51}$ While diversity software can avoid the necessity for a large library, it can do little to ensure that libraries contain molecules that have drug-like properties (Oprea et al. 2000). Filtering procedures such as Lipinsky's rule of five are therefore added to omputer programs, which enable computational and medicinal chemists avoid molecules from undesirable groups (i.e. alkyl halides, acid chlorides, etc.) or classes of compounds known to cause ADME or toxicological problems (Lipinski et al. 1997; Walters et al. 1998; Leach and Hann 2000; Ekins et al. 2000; Watt et al. 2000).

However, diversity analysis may not be enough to uncover lead compounds. To paraphrase a scientist, diversity is only serendipity in disguise (Agrafiotis et al. 1999:22). To add value to their synthesis efforts, computational chemists would often design a pharmacophore based library, countering the false notion that "rational design" is all about protein structures. A pharmacophore is a binding hypothesis as to the minimum functionality a molecule requires to exhibit biological activity, which is described in terms of a $3 \mathrm{D}$ geometric pattern recognized by a target macromolecule: only molecules that act at the same receptor site in the same way will share a pharmacophore (Davies and Upton 1995; Ghose and Wendoloski 1998, Drewry and Young 1999). Specifically, scientists may use information provided by a ligand known to interact with a target to construct a pharmacophore, which can be used for 3D pharmacophore searching (Valler and Green 2000). This operation allows them to use the pharmacophore profile to screen a database, as for example the public database of the National Cancer Institute, to check whether the

51. The "old" debate as to whether 2D descriptors outperform 3D descriptors exemplifies this uncertainty (Brown and Martin 1996; Patterson et al. 1996). 
pharmacophore embedded in the compounds of their virtual library meet the geometric constraints specified in the query definition. Only then will they synthesize by combinatorial means the compounds that meet the pharmacophore requirements.

Alternatively, scientists may focus combinatorial libraries by incorporating 3D structure information of the protein target into the virtual library design process (Salemme et al. 1997; Li et al. 1998; Kubinyi 1998c; Antel 1999; Böhm and Stahl 2000). In the few years since the first public presentations of structured based libraries were made circa 1993-1994, several methods using combinatorial chemistry in tandem with rational drug design have appeared in the literature, all of which involves selecting compounds which fit the cavity of the target receptor by in silico screening (i.e. computer simulation). The steps of the structured based procedures generally entail choosing one or a few scaffolds based on their complementarity to the macromolecular target. Then computational chemists would attach synthetically accessible side chains (or branch) on the scaffold to form a virtual library and "dock" the compounds into the 3D structure of the target by means of a computational algorithm (Drewry and Young 1999; Böhm and Stahl 2000). ${ }^{52}$ Given that only virtual compounds that match specific geometrical criteria will be kept for actual synthesis, a macromolecular target may act as a powerful combinatorial filter in the design process, providing the means to weed out molecules with unsuitable structures and speed out the innovative process.

Missing in this account is the fact that today's chemistry and computer scientists can freely navigate the websites of the Brookhaven's Protein Data Bank (PDB) database, the HIV protease Database, the Cambridge Structural Database or many other sources in the hope of finding some useful, yet public knowledge (Berman 1999; Berman et al. 2000). This strategy is likely to gain in acceptance, since important advances in NMR and $\mathrm{x}$ crystallography technologies, themselves triggered by important advances in hardware and software technologies, have radically streamlined the supply of 3D structures of proteins (Gambardella 1995). At Cambridge University in the UK, Max Perutz and his colleagues took 22 years to complete the 3D structures of hemoglobin in the late 1950s, which could be now accomplished in a matter of days (Augen 2002). The pace of development is well illustrated by the escalating number of biological macromolecular crystal structures being archived by the Brookhaven's Protein Data Bank, as figure 3.3 shows. ${ }^{53}$ By July 2002, the number of available structures had

52. "Docking" refers "to the physical fit between a macromolecular target and a pharmaceutical compound, whether it is a substrate, inhibitor, or activator" (Smith 2002).

53. However impressive the pace of development may seem, it is important to remark that any knowledge that helps reduce the chemical space to be explored needs to 
reached 18,294, many of which drug targets.

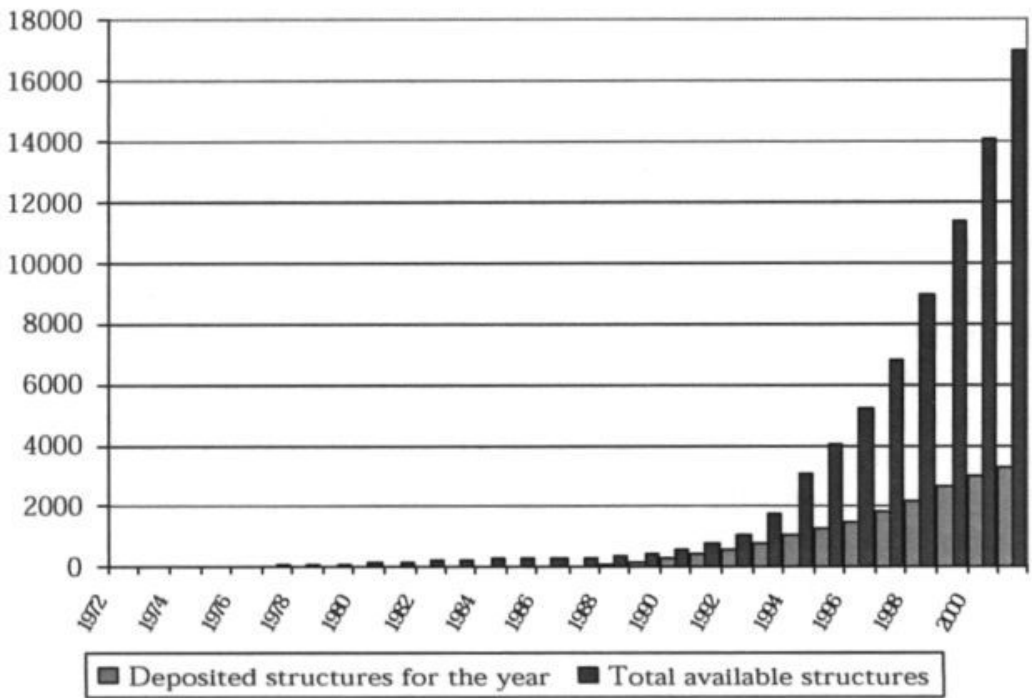

\section{Figure 3.4}

Growth in the number of structures in the PDB (1972-2001)

Source: PDB's Website (www.rcsb.org/pdb/).

If large random libraries are characterized by sheer unrestricted diversity, focused libraries designed to incorporate knowledge about the target reduce the amount of diversity to be tapped and thereby redundancy of information and sample, reagents and handling costs (Valler and Green 2000). If discovery libraries were not up to expectations, yielding hit rates of only about 0.01 percent, focused libraries often provide rates of about 10 percent (Augen 2002). It is therefore telling that Dolle's results regarding 240 biological active libraries show that 49 ( 57 percent) discovery libraries, 26 (30 percent) targeted and focused libraries and 11 (13 percent) optimization libraries had been designed during 1992-1997, whereas the period 1997-1999 saw the construction of 42 (27 percent) discovery libraries, 76 (49 percent) targeted-focused libraries and 36 (23 percent) optimization libraries (Dolle 2000). ${ }^{54}$ Besides Web-based 3D-databases,

be taken into account, irrespective of its origins: patents, diversity analysis, structureactivity relationships studies, target receptors, chemical structures of known drugs, etc. Scientists at Vertex Pharmaceuticals, in a recent review of virtual screening, nicely encapsulate this notion: "There is no dichotomy between HTS and [virtual screening]. Information drives drug discovery -the more of it, the sooner, the better" (Walters et al. 1998:181).

54. Data for 2000 are not available. 
scientists can now use software for pharmacophore-based and structurebased design, which have been developed in-house and licensed on a yearly basis by specialized, chemoinformatic firms. ${ }^{55}$ Both types of software products take aim at converting data into know-what and know-what into know-why of which geometric relationships are important to biological activity.

Despite the appeal of knowledge-based combinatorial chemistry, a number of problems still need to be solved if the full benefits of previous innovations were to be fully achieved. Examples of bottlenecks facing today's pharmaceutical companies include poor scoring functions, imprecise understanding of the properties of drug-like molecules, inability to map 3D properties onto 2D structures, incorrect assessment of existing SAR data, poor docking strategies, poorly selected targets and incorrect synthetic assessment (Walters et al. 1998). No doubt further innovations in the field of chemoinformatics will circumvent many of these bottlenecks, but these tools remain expensive. ${ }^{56}$ Moreover, computing tools are rooted in different scientific domains, implying that incompatible computers systems, standards and terminology may hinder the interface between medicinal chemists and scientists from other disciplines (Hann and Green 1999). In doing so, the implementation of drug discovery services increases the likelihood that different "codes" impaired effective communication across scientists. "This is probably the single most challenging problem that chemoinformatics must solve", argued Hann and Green (1999:379). While commercial information management systems (IMS) have been touted as tool for bringing together interdisciplinary teams, these systems often fail to address some of the tasks that are intrinsic to the firm, compelling drug makers to purchase software programs and write in-house programs to complement commercial ones (Brown 1998; Hann and Green 1999).

\subsubsection{The combinatorial approach to new materials, catalysts, pesticides, etc.}

Earlier in this chapter the idea of discovering new materials by combinatorial means was dismissed in a few lines. Nonetheless, the fourth technological trajectory deserves a little more attention because the generalpurpose technology will continue to grow steadily as a result of significant technology-push and market-pull factors. The following review, however, can do no more than briefly cover the infant applications of combinatorial

55. Like PRO_SELECT (Proteus Molecular Design; GB) and DREAM++ (UBSF;

US) for the former and the CHEM-X (Chemical Design; GB) and Catalyst (Accelrys;

US) for the latter.

56. If you want good tools to derive and use knowledge" wrote Hann and Green, "you must be prepared to commit significant resources to this area, in terms of hardware, software and people-ware (i.e. effective creators and users of software" (1999:382). 
chemistry into new market segments. $^{57}$

From pharmaceuticals to new materials, catalysts, pesticides, etc.

If Furka, Geysen and colleagues could see their ideas unfolding into the knowledge-based economy before their eyes, Joseph Hanak (1970) at RCA Laboratories had to wait 25 years before witnessing a revival of his "multiplesample concept", a combinatorial-like approach that yielded a variety of new materials, a series of publications and even patents (Dagani 1999). Hanak's ideas lay dormant due to the inefficiencies of computers of the time, but the synthesis of new high-temperature superconductors and magnetoresistive materials on cobalt oxide by Xiang et al. (1995) at Lawrence Berkeley National Laboratory (LBNL) and Briceno et al. (1995) at LBNL and UBC led to a revival of his ideas. Unfortunately, a major difficulty in discussing state of the art combinatorial research in new materials emanates "from the highly confidential aspects of the progress accomplished by industrial research" (Holzwart et al. 2001:310).

On the other hand, examples of successful experiments are not too difficult to find. Danielson et al. (1997) at Symyx discovered a red light-emitting phosphor in a library of 25,000 different phosphors, which could be used in the fabrication of computer and TV screens. Brocchini et al. (1997) at Rutgers University synthesized by combinatorial means a small library of 114 structurally related copolymers, which are biodegradable and potentially useful as medical implant materials. New classes of dielectric materials have also been created, like thin-film materials by van Dover et al. (1998) at Lucent Technologies, which hold promises in the fabrication of dynamic randomaccess memory (DRAM) computer chips. The work of Akporiaye et al. (1998) at Sintef Applied Chemistry in Norway opens the gate for the combinatorial synthesis of zeolites, which can end up as catalysts in oil refineries or as ingredients in the making of laundry detergents, absorbents, etc. It is also instructive that knowledge originally created to discover new drug candidates is being used by scientists to discover new pesticides, herbidices, etc. The generic nature of chemical knowledge knows no border: "A compound is a compound. Once it's synthesized it doesn't know whether it's supposed to be a pesticide or a drug", says pointedly Russell Bellina, DuPont director/agricultural chemical synthesis (Chemical Week 2000a).

Echoing the story of combinatorial chemistry in pharmaceuticals, the first impact of material R\&D most certainly came from productivity gains achieved through the generation of large quantities of low costs molecules. Yet, according to John D. Hewes, program manager at the chemistry and life science office at the US Commerce Department's Advanced Technology

57. For a review of literature, see Jandeleit et al. (1999). 
Program, the probability of success in the discovery phase of new materials has already increased from 20 percent to more than 50 percent (Wood 2001). One can get a glimpse of these overall potentials by examining the estimates of table 3.3. This table, taken from the website of the start-up Symyx, shows some of changes in the price-performance ratio that combinatorial chemistry brought about in the area of new materials, catalysts, etc.

\section{Table 3.3}

Comparing the Symyx combinatorial approach with traditional chemistry in the discovery of promising new materials

\begin{tabular}{lll}
\hline Project variable & \multicolumn{1}{c}{$\begin{array}{c}\text { Combinatorial } \\
\text { approach }\end{array}$} & \multicolumn{1}{c}{$\begin{array}{c}\text { Traditional } \\
\text { approach }\end{array}$} \\
\hline (1) Team & $\begin{array}{l}\text { 1 chemist }+1 \\
\text { technician }\end{array}$ & $\begin{array}{l}\text { 1 chemist }+1 \\
\text { technician }\end{array}$ \\
(2) Cost/year & \$US 500,000 & \$US 500,000 \\
(3) Experiments/year & $20,000-50,000$ & $500-1,000$ \\
(4) Cost/experiment & \$US $10-\$ U S 25$ & \$US $500-\$ U S ~ 1,000$ \\
(5) Timeline to discovery & $0.5-2$ years & Many years \\
\hline
\end{tabular}

Source: www.symyx.com

That data handling should prove difficult is not surprising since combinatorial methods applied to new materials feature the same ability to generate thousands of molecules than those applied to pharmaceuticals (Dagani 1999). However, their main bottleneck is of a different nature because new materials require performance-based characterizations that are application-specific, and this can only be done by adapting "old" or developing "new" analytical techniques (Hewes 2000). A good example of new high-throughput screening tools is the technique of infrared thermography. Initially employed by police departments and the military for surveillance purposes, infrared thermography technology has been successfully used by Moates et al. (1996) at University of Houston and Holzwarth et al. (1998) at the University of North Carolina to measure heat coming out of catalytic reactions and thus assess catalyst activity. Another good example is the development of resonance-enhanced multiphoton ionization (REMPI) by Senkan (1998) at University of California in Los Angeles. REMPI is a laser-based method that enables the detection of the product molecule in the gas stream containing the starting material that flows through the catalyst sites (Dagani 1999). Other scientists have taken the challenge of devising yet more screening methods, and the new scanning mass spectrometer device (Cong et al. 1998) by Symyx, the xray microprobe technique (Isaacs et al. 1998) by LBML and the scanning evanescent microwave microscope (Wei et al. 1996) by NEC Research Institute may be added to the list of practical high-throughput screening tools. 


\subsection{Concluding remarks}

Seen through the lens of economic history, the introduction of combinatorial chemistry by Furka, Geysen, Houghten, Ellman and others signaled fundamental changes in the price and technical performance of chemical synthesis, and laid the foundation upon which a whole series of incremental innovations were made by scientific organizations, new entrants and large (agro)pharmaceutical firms along four technological trajectories. In the first technological trajectory, new knowledge was, and continues to be, created in the fields of solid and solution phase chemistry, chemoinformatics and automated synthesis instrumentation. In the second trajectory, R\&D targets identification methods, 2D and 3D QSAR software, "bioware", HTS workstations and purification tools as a mean to improve the process of lead optimization. In the third trajectory, the necessity to sample a much smaller portion of chemical space and improve the process of lead discovery has been adduced as a reason to develop diversity analysis tools and to incorporate elements from the rational drug design approach, giving the powerful, yet faulty technology a second lease of life. In the last trajectory, one that pushes and pulls combinatorial chemistry into new material territory, the future points to the development of sophisticated highthroughput screening tools as a mean to overcome very specific testing problems.

As technological change goes, it is apparent that the emergence of combinatorial chemistry was not the most disruptive innovation as far as knowledge and competences are concerned. Furka, Geysen and other pioneers largely stood on the shoulders of Edwin Merrified (1965) by virtue of their dependence on solid phase chemistry. Chemoinformatics covers applications that can be traced back to Justus Liebig's Annalen der Pharmacie (1832) and the creation of the Chemical Abstracts in 1907 (Smith 2002), prompting two scientists to call it "a new name for an old problem" (Hann and Green 1999: 379). More recently, Cramer's CoMFA grew from traditional QSAR methods, structural chemistry and quantum chemistry; 3D pharmacophore searching in database had been proposed by Peter Grund as early as 1977; Kier's work on pharmacophores was inspired by Paul Elrich (1909); etc. Even Xiang's work on combinatorial material built on the achievements made by Hanak in the early seventies. What's most important, the profession of medicinal chemistry had not become obsolete as a result of combinatorial chemistry, and good old-fashioned synthesis know-how remains one, if not the most important competence of the firm.

In this sense, although combinatorial chemistry is either spoken of as a simple problem-solving process (Thomke et al. 1998), a technological platform (Persidis 1998; Poste 2000), a general-purpose technology (Pammoli and Riccaboni 2000) or a mass-production technology 
(Nightinghale 2000), it is also a competence-enhancing process discontinuity as defined by Tushman and Anderson (1986). This finding implies that large pharmaceutical companies should rapidly learn the new synthesis methods and even dominate the field of combinatorial synthesis. This is the hypothesis that will be tested in chapter 5 . Yet, as the following chapter will demonstrate, new entrants reacted quickly to enhance, expand and/or renew their competences along the evolving environment through internal and external learning. More specifically, the implementation of learningbased strategies by new entrants and the increasing fragmentation of the pharmaceutical industry resulting from the genomic revolution contributed to their success in terms of firm formation, growth, revenues and research output. 

PART III: THE ACTORS 



\section{Combinatorial Chemistry and New Entrants}

Knowledge is power, but pills are profit

Stephan Herrera, industry analyst (2001)

\subsection{INTRODUCTION}

From chapter 3 , it emerged that combinatorial chemistry has all the attributes of a competence-enhancing process discontinuity as described by Tushman and Anderson (1986), implying that large pharmaceutical and (agro)chemical companies should initiate innovations in the field and later on gain competitive advantage over smaller or newer firms. This chapter, however, questions these predictions on both empirical and theoretical grounds. The first companies using combinatorial chemistry were overwhelmingly new entrants, not large incumbents. In addition, although large pharmaceutical corporations have rapidly absorbed the new synthesis methods, new entrants continue to demonstrate their success in terms of firm formation, growth, revenues and research output. The key to unlocking this mystery is to be found in the behavioral advantage of new entrants. Rather than exiting the industry, these firms have been able to adapt by moving their 
knowledge base and competences along the second, third and/or fourth technological trajectories through technological learning, with many if not the majority becoming fully integrated drug discovery firms.

The chapter has four sections. Section 4.2 is mainly designed to illustrate how the conditions of entry in the pharmaceutical and (agro) chemical industries had been altered by the emergence of combinatorial chemistry, propelling de novo entry, entry by diversification and entry following merger and acquisition of about 393 companies. Section 4.3 focuses on two fundamental phases of industrial development: (1) the firm as a provider of compound libraries; (2) the firm as a provider of chemical-based services and products, most notably small molecule drugs. It goes on to assess the special relationships between these new chemical-based entrants and other smaller companies, especially genomic firms. Section 4.4 maintains that the recent upsurge of mergers and acquisitions, rather than signaling the beginning of a "shake-out", could be interpreted as the logical outcome of the realization that rigidities can be broken and economies of scale and scope achieved if knowledge specialists with complementary skills were brought together under the same organization. Section 4.5 closes the discussion by suggesting that the survival of new entrants remains possible in the backdrop of a competence-enhancing discontinuity.

\subsection{THE RISE OF NEW ENTRANTS}

On the face of it, the younger Schumpeter of The Theory of Economic Development (1934) better depicts the infant combichem subsector than Schumpeter's later work Capitalism, Socialism and Democracy (1942). While the former stressed the role of small firms in initiating technological discontinuities, the latter postulated that large established firms would preempt the role of small firms in innovations. In this respect, the TushmanAnderson hypothesis stipulating that existing firms initiate competenceenhancing changes appears to fail the test of empirical validation: the firms that introduced combinatorial chemistry into industry were new entrepreneurial start-ups, rather than large pharmaceutical companies.

Indeed, the concept of synthesizing dozens, if not hundreds or thousands of molecular compounds simultaneously had been first imported in industrial setting in 1988, when entrepreneur Dr. Alejandro Zaffaroni launched California-based Affymax and Coselco Mimotopes spun out of Commonwealth Serum Laboratories, Australia's largest investor in pharmaceutical research and development, to exploit the potentials of combinatorial chemistry. From then on, a significant number of earlyadopters began populating the pharmaceutical industry. ${ }^{58}$ The founding

58. These include Houghten Pharmaceuticals, Selectide, Gilead Sciences, NeXstar, 
scientists of these new entrants were from the chemistry discipline, unlike biopharmaceutical companies where biologists often acted as entrepreneurs. To quote Barry Toyonaga, president of Ontogen: "This is the first wave of chemistry-based companies that hopefully will become places where chemists can take their talents and really create something both professionally and personally" (Thayer 1996:64).

Also, the striking intersection of chemistry, automated instrumentation, biology and information technology provided dozens of (usually older) small and medium sized companies from different, yet related lines of business with an opportunity to diversify their technology portfolios into combinatorial chemistry. In the early and mid-nineties, manufacturers of scientific instrumentation, dedicated biotechnology firms, rational drug design companies and suppliers of chemoinformatic tools, far from being restrained by their previous investments and repertoire of organizational routines, begun using existing knowledge to "jump" on the bandwagon of combinatorial chemistry.

Take the examples of Advanced ChemTech, Oxford Glycosciences, Vertex Pharmaceuticals and Tripos. Born in 1985, privately owned Advanced ChemTech established a solid reputation selling an extensive range of fine chemicals (i.e. amino acids, resin supports) and instruments for peptide libraries and small organic compounds, but resolved to offer synthesis services to biotechnology and large pharmaceutical companies. Citing Mark Peterson, manager of commercial operations: "Adding combinatorial chemistry as a service is a certainly something that you have to be able to do" (Kreeger 1996:19). Oxford Glycosciences was established in 1988 to develop and commercialize products that would support research in the areas of protein analysis and glycobiology. However, the firm decided to become a fully integrated drug discovery company in 1995. To achieve its goal, the Oxford University spin-off undertook to internally build a competence in combinatorial chemistry, enabling the firm to screen its own compounds against target proteins discovered via its genomics and proteomics platforms. Vertex Pharmaceuticals was founded in 1989 to become a rational drug design company, though the firm pointedly concluded in the mid-nineties that combinatorial chemistry complemented, rather than supplemented, its structure-based design platform. Tripos, set up in 1979 , was a supplier of discovery research software to pharmaceutical and life sciences companies. In early 1995, the chemoinformatics firm began an aggressive effort to expand its range of products and services, including screening libraries and contract discovery research.

What's more, a second, much larger wave of new chemical-based

Isis Pharmaceuticals, Pharmacopeia, Ontogen and Sphinx Pharmaceuticals in the United States, ComGenex in Hungary, Oxford Asymmetry and Cambridge Combinatorial in Great Britain as well as Auda Pharmaceuticals in Denmark. 
entrants has been sweeping the therapeutic drug market since the midnineties, and de novo entrants, often bypassing the bottlenecks of the first and second technological trajectories, have been formed on the basis of competences together forming a fully-integrated drug discovery platform. ${ }^{59}$ While these entrants exclusively pursued applications in the human healthcare sector in the early years of the technology life cycle, the technological and economic landscape characterizing this line of business changed with the foundation of Symyx in 1995. Symyx became the first entrepreneurial startup to focus on new materials, catalysts and polymers agrochemicals, a technological trajectory that has been subsequently pursued by 11 other new entrants.

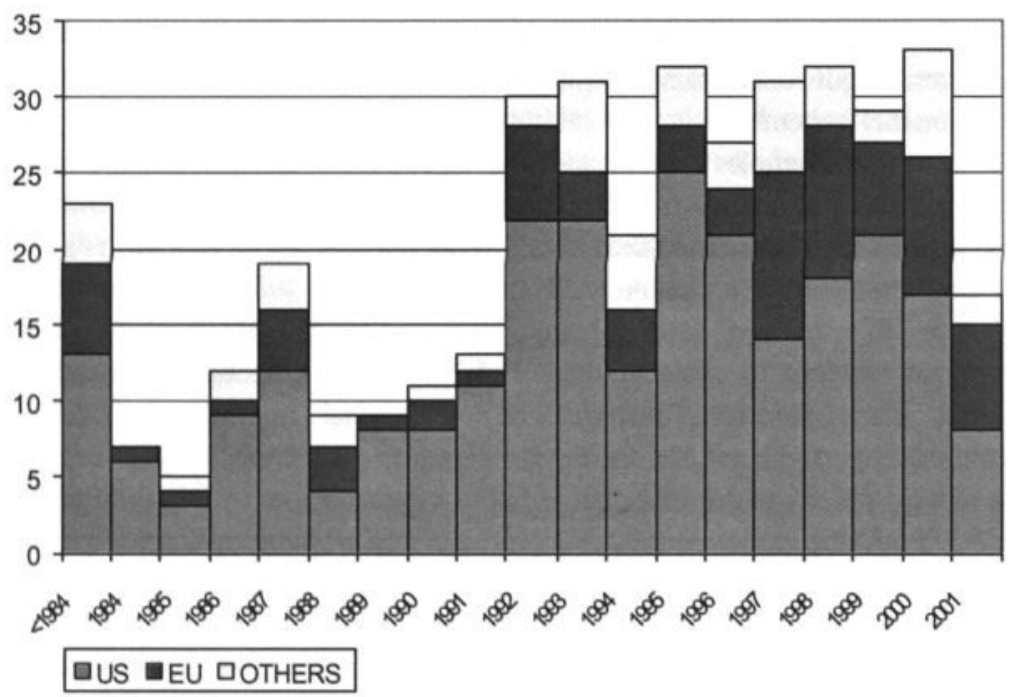

\section{Figure 4.1}

De novo entry, entry by diversification entry following merger and acquisition in combinatorial chemistry in combinatorial chemistry -by year of foundation

Source: Compiled by author

To date, at least 393 companies, de novo entrants, entrants by diversification and entrants following merger and acquisition, have integrated combinatorial chemistry into their technology portfolios (see figure 4.1). That the market of combinatorial-based products and services is still in its infancy can be seen by noting that 285 (72.5 percent of total) have

59. Examples of de novo entrants include BioFocus, CombinatoRx, Combio A/S, Libreria, Mixture Sciences, Néokimia, Personal Chemistry and Synt:em. 
been formed in 1992 onwards. Therefore, it seems certain that the emergence of combinatorial chemistry in general and Ellman's 1992 breakthrough discovery (i.e. the first library made of small chemical molecules) in particular triggered the largest influx of de novo entrants in the pharmaceutical industry since genetic engineering became a spawning ground for biological-based entrants in 1976 -the year Genentech was founded to exploit the technology.

While the swarming of new entrants is an international phenomenon, the rise of combinatorial chemistry is most clearly pronounced in the United States, where 256 new entrants have adopted the technology. With 82 and 55 firms, EU-15 and the rest of the world place a distant second and third, respectively. For the former, efforts to use combinatorial chemistry in industrial settings are especially strong in Great Britain (36 new entrants), Germany (21), Sweden (8), France (4) and the Netherlands (4). For the former, competition is most likely to be mounted by new entrants in Canada (20), Israel (9), Australia (7), Russia (5), Switzerland (4) and China (3).

This burst of new entrants and the diffusion of combinatorial chemistry must be understood from a number of perspectives. First, and closest to what Winter (1984), Audretsch (1991), Malerba and Orsenigo (1996) describe as an entrepreneurial regime, are the conditions of high opportunity and "tight" appropriability. The tread of the argument is that the potential of generating innovations for any given investment, combined with the ability to appropriate the returns of this investment, can provide entrepreneurs and venture capitalists with a powerful incentive for setting up new companies. The condition of high opportunity is clearly met, given that the chemical space yet to be explored is enormous. Specifically, the chemical space offers an almost infinite set of possibilities for the synthesis of combinatorial libraries not only in pharmaceuticals but also in the fields of new materials, catalysts, polymers and pesticides. These possibilities should also be enriched by the introduction of better scientific instrumentation and, most importantly, the likely generation of thousands of new target diseases for actual and virtual screening, which open up ample technological and economic opportunities for occupying and exploiting new market niches.

The condition of "tight" appropriability might seem more questionable. It stands to reason that combinatorial synthesis methods, unlike genetic engineering and PCR technology, are characterized by a diffuse lineage of intellectual property, shared by several individuals and companies (Persidis 2001). Even so, firms involved in combinatorial chemistry can patent libraries, lead compounds, scaffolds and structures for diversification thereof, mechanisms and machines (i.e. synthesizers, purification tolls, etc.), specialized chemistry directed to combinatorials (i.e. reaction protocols, etc.) and so on (Caldwell 1998). Survey questionnaires also lend support to the view that patent protection is strong for product innovations, especially 
drugs, in the pharmaceutical industry (Mansfield et al. 1981; Levin et al. 1987; Cohen et al. 2000).

Therefore, it seems reasonable to assert that entrepreneurs and holders of capital are not being deterred by current appropriability conditions while being encouraged by the opportunities presented by the technology. The confidence shown by the financial community in combinatorial chemistry and the new entrants that have embraced it is best put into evidence in a recent study by the consulting firm BioVista. ${ }^{60}$ If their estimates are correct, the market capitalization of the 10 principal combinatorial chemistry firms in the United States was \$US 1.7 billion in 2001. BioVista also estimated that firms using combinatorial chemistry succeeded in raising about 23 percent of the total public offerings and private placements raised by new entrants in the life sciences industry between 1996 and 2001 and that market capitalization has grown by 28 percent per year since 1991 .

Thanks to combinatorial chemistry, these companies have also been free to enter an industry that had long been protected by the big, expensive costs of organic chemical synthesis. As combinatorial synthesis methods have become available to anyone for a modest capital investment, largely because automated instrumentation can be purchased at relatively low price, the large collection of compounds that had been assembled by large pharmaceutical companies were no longer preventing the entry of new companies. "That's no longer a huge advantage when you can make and purchased diversity libraries for screening", says Nicholas B. Lydon, vicepresident for small-molecule discovery at Amgen (Henry 2001b:82). "Combinatorial chemistry has been a godsend for the smaller companies because it allows you to develop a sample bank competitive in numbers to those of large pharmaceutical companies, which in some cases have been amassing their banks for decades" adds Theodore Jones, the lab head of the lead discovery program at the same company (Timpane 1996:7).

It is, of course, clear that combinatorial procedures remained tacit in the early days of industrial development, hindering their diffusion throughout the economy. This knowledge barrier, however, had been somehow lowered when "cookbooks" of combinatorial "recipes" began to surface in private and public libraries across the world in $1995 .^{61}$ The publication of these manuals was followed by the appearance of scientific journals dedicated to the new chemical discipline. Molecular Diversity (Kluwer Academic Publisher) opened the fray in 1995, followed by Combinatorial Chemistry \& High Throughput Screening (Bentham Science Publishers) and Combinatorial Chemistry (John Wiley \& Sons) in 1998 and the Journal of Combinatorial Chemistry (American

60. See www. biovista.com.

61. The first manuals were probably Chemical Diversity: The Synthetic Techniques of Combinatorial Chemistry by Mario Geysen et al. and Combinatorial Libraries: The Theory and Practice of Combinatorial Chemistry by Richard Houghten. 
Chemical Society) in 1999. These scientific journals as well as articles in the traditional organic and non-organic chemistry literature e.g. Tethrahedron Letters, Tethrahedron, Proceedings of the National Academy of Sciences, Analytical Biochemistry, etc.) have been instrumental in the diffusion and transfer of public knowledge to graduate students and scientists of new entrants and large incumbents alike. In fact, the number of papers related to combinatorial chemistry published each year has rapidly risen since the early nineties, one estimate showing that such articles grew from less than one hundred in 1990 to more than 2,300 in 2000 (Barnett 2002).

\subsection{TECHNOLOGICAL LEARNING IN A TURBULENT ENVIRONMENT}

The preceding section implied that combinatorial chemistry, for the most part because it has disrupted the conditions of entry to the pharmaceutical and (agro) chemical industries, has been conducive to the de novo entry, entry by diversification and entry following merger and acquisition of about 393 new companies. This section examines how these new entrants adapted in parallel to the external environment through internal and external learning. These companies will be analysed in terms of two phases of development: (1) the firm as a provider of compound libraries, and (2) the firm as a provider of chemical-based services and products. The first and second phases of development differ in at least three respects. In the first phase of development, combinatorial chemistry firms (1) focus on innovations made along the first technological trajectory, (2) face competition from similar chemical-based companies and (3) target the market of combinatorial libraries. In the second phase of development, new entrants (1) are mainly concerned about innovations created along the second, third and fourth trajectories, (2) confront competition from a broader front, most notably scientific organizations, and (3) target the wider markets of chemical-based services and products, which include small molecule drugs.

\subsubsection{Phase 1: The firm as a provider of compound libraries (1988-1995)}

The first phase of industrial development roughly covers the period between 1988 and 1995. Much of the early commercial impetus was aimed at supplying large pharmaceutical companies and biopharmaceutical firms with discovery and targeted libraries, with new entrants striving to improve the methods and/or absorb some of the interlocking innovations made along the first trajectory. Clearly, these early-adopters also struggled to find and/or integrate scientific and technicians, since combinatorial chemistry was such a novel technology that few, if any students graduated with a solid expertise in the field. Hence they often resolved to convert synthetic organic 
chemists into combinatorial chemists, integrating them in the laboratory through formal apprenticeships. "It's a really new field and there are very few people who have done this sort of work. So the company by and large will recruit $\mathrm{Ph} . \mathrm{D}$. chemists and teach them much the same way the pharmaceutical companies have hired organic chemists and taught them the medicinal chemistry they need", said John C. Chabala, President and chief scientific officer at Pharmacopeia (Brennan 1995).

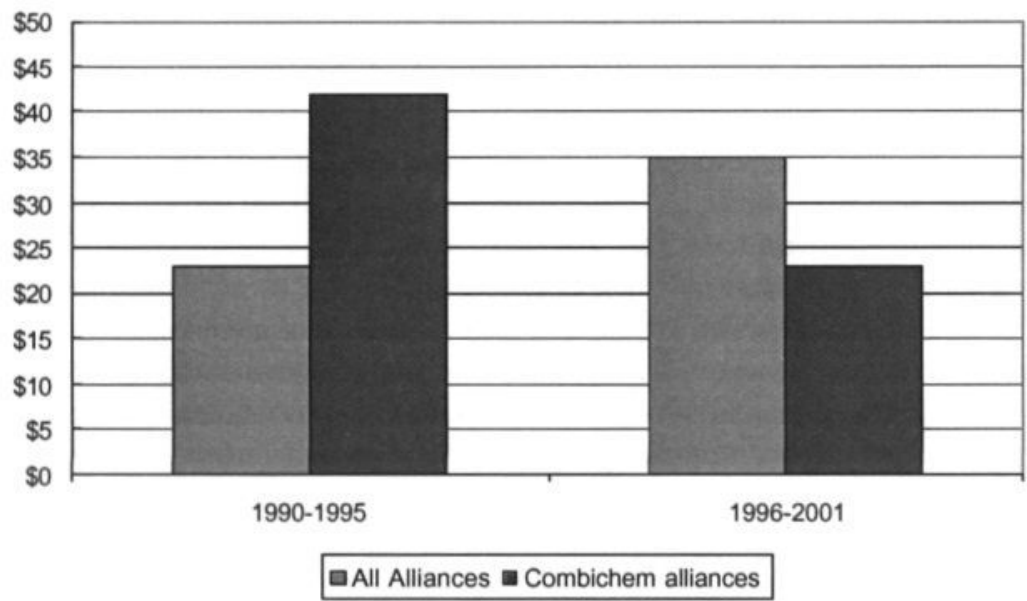

\section{Figure 4.2}

Average size of alliances -in million 2001 dollars (1990-2001)

Source: Compiled by author

According to TechKnowledge Associates (1997), the pharmaceutical industry spent \$US 3 billion to synthesize, study and test combinatorial libraries in 1995. In dynamic terms, this translated into combinatorial chemistry firms competing about market share in the business of compound libraries, giving rise to "platform technology deals". Specifically, combinatorial chemistry firms have been busy developing innovative collaborative strategies for granting non-exclusive licenses to multiple large pharmaceutical companies simultaneously, thus giving various degrees of access to their discovery libraries. ArQule and Pharmacopeia, for example, have offered the same library to multiple corporate partners, each paying an upfront fee (i.e. also known as an access fee) for screening the same compounds. If the deal resulted into a "hit", a hit into a drug candidate and a drug candidate into a drug, the firm would usually receive success fees such as milestones payments and royalties (Lytton 1997). Nonetheless, the viability of this business model was to be questioned in the mid- and late nineties. Then, it became apparent that large pharmaceutical companies and 
smaller firms with different history developed their own competences in the field. As chapter 6 will demonstrate, even universities and non-for-profit research organizations began offering services in combinatorial library synthesis, with a growing number of scientific organizations selling or licensing targeted and focused libraries to large incumbents and life science companies alike.

Competition not only intensified, but customer desire for products and services rapidly evolved. Thus, it became clear that large discovery libraries, seldom backed by biologically active compounds, were simple commodities with little value added, hardly a source of competitive power. ${ }^{62}$ It also became apparent that large pharmaceutical companies were less willing to pay downstream royalties for non-exclusive compound libraries, with contracts often going to the lowest bidder (Thiel 1999; Studt 1999; Boswell 2000). ${ }^{63}$ Consequently, combinatorial chemistry firms came to acknowledge the obvious: a superior performance could not be sustained by only supplying compounds to large pharmaceutical firms and other organizations. This can be seen by noting that the price tag attached to "platform technology deals" significantly dropped over the first and second phase of industrial development. Although the figure, which is based upon 276 partnership deals for which financial data and technological information are available, is likely to overestimate the value of alliances, the average size of alliances involving the synthesis of combinatorial libraries dramatically decreased. Such alliances amounted, on average, to \$US 42 million between 1991 and 1995, but only \$US 23 million during the period 1996-2001. At the same time, the value of alliances involving other stages of the drug discovery value-chain (i.e. lead optimization, etc.) rose from \$US 23 million to \$US 35 million.

3.2 Phase II: The firm as a provider of chemical-based services and products (19962001)

With the value of alliances related to "technology platform deals" dimming the prospect for a big pay off and competition increasing from all sides, combinatorial chemistry firms had no other choice but to adapt with the external environment -or exit the industry. Using their competences in

62. "The days of the multimillion dollar combinatorial chemistry deals are done", argued Michael Grey, CEO at Trega Biosciences (formerly Houghten Pharmaceuticals, now part of Lion Biosciences). "Simply providing a large numbers of compounds is not enough" (Thiel 1999:2).

63. A comment by Richard Brown, vice president of business development at ChemRx, exemplifies this awareness: "There simply is no interest in royalty-based chemistry deals. The pharmaceutical industry is not willing to mortgage its future" (Chemical Week 1999). 
combinatorial synthesis as a natural starting point for developing downstream competences in lead discovery and lead optimization and upstream competences in the design of focused libraries, these new entrants responded by offering a better, broader range of products and services for improving and accelerating pharmaceutical research and development. These products and services may include: (1) the development of equipment (i.e. synthesizers, etc.) and consumables (i.e. solid supports, building blocks, etc) for the creation of combinatorial libraries; (2) assay development; (3) the computational design and analysis of targets; (4) the sourcing of targeted and focused libraries; (5) the creation of new leads against specific targets; and (6) the optimization of already identified leads for particular targets. In addition, 28 new entrants began to diversify from only offering pharmaceutical products and services in the late nineties, when they subsequently outsource combinatorial libraries to agrochemical companies for applications in pesticides, herbicides, etc.

Take the example of Discovery Partners International, which comprises 7 subsidiaries (Irori, ChemRx, Axys Advanced Technologies, Discovery Technology, Stuctural Proteomics, SIDDCO, and Xenometix). The firm offers a wide array of integrated drug discovery services focused from the point immediately following identification of a drug target through when a drug candidate is ready for clinical trials. A few examples, some of which displayed in figure 4.3, may illustrate this business thinking. SIDDCO created an 800,000-compound library for Aurora BioSciences and licensed miniaturized screening technologies to NPS Pharmaceuticals; Irori installed an ultra high throughput system allowing synthesis of up to one million new compounds per year at Aventis and Bristol-Myers Squibb; Discovery Partners International identified drug leads for the treatment of colon cancer for the Genetics Company; Xenometrix licensed its gene expression profiling technology to Rosetta Inpharmatics; Axys Advanced Technologies provided Bristol Myers Squidd with screening compounds and related technologies; etc. Together, these value-added services created a strong business, growing at a 15 percent-20 percent annual clip (Saftlas 2001).$^{64}$

There is little doubt that a multiple technology platform has potential problems. To begin, new entrants operate amid far more competition; thus, if new entrants continue to penetrate the industry, markets could become

64. Recently, Discovery Partners reorganized into five operational centers: (1) Discovery Instrumentation, which develops, manufactures, and markets equipment and consumables for the generation of chemical libraries. (2) ChemRx; which offers drug discovery chemistry services by providing chemical libraries and lead-optimization and medicinal chemistry services. (3) Discovery Biology; which provides assay development and ultra-high throughput screening services; (4) Computational Discovery; which offers informatics services for drug discovery; and (5) Xenometrix; which provides gene expression analysis. 


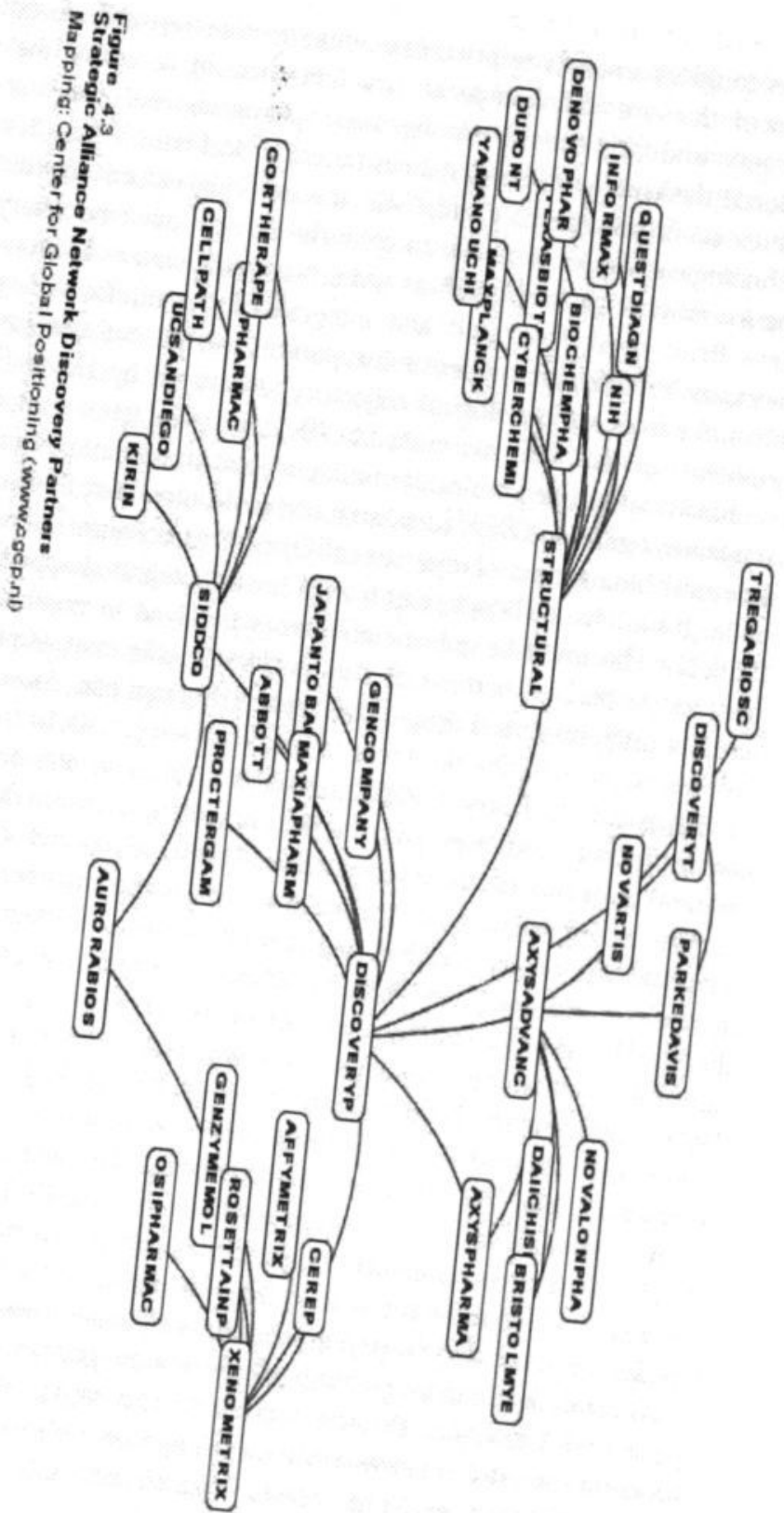


saturated with their products and services. With more competition, large firms could also negotiate price discounts or other terms for products and services that are unfavorable to new entrants. In addition, the spate of mergers and acquisitions among large pharmaceutical giants may have reduced the number of potential customers to deal with. ${ }^{65}$ Another problem relates to organizational change and the evolving nature of scientific and technological work. In order to gain the critical mass necessary to srve opportunities in the new markets and achieve economies of scope and scale, these firms needed to graft and integrate the multidisciplinary personal necessary to create and monitor innovations carried out along the second, third and fourth technological trajectory. As stated by David Ecker, vice president of Isis Pharmaceuticals: "Beyond chemists, companies need combinatorial-minded molecular biologists and computational modelers. As companies figure out ways to make more molecules, they'll need to explore structural biology and computational chemistry to figure out what they've made. It's a new challenge, and it calls for an integrated approach" (Brown 1996:1). The multidisciplinary endeavors involved in combinatorial drug discovery is perhaps better reflected in the scientific management profile of Syrrx, a fully integrated drug discovery start-up company launched in 1999 . Syrrx brought together directors of lead discovery, cellular pharmacology, combinatorial chemistry, computational biology, molecular biology, protein chemistry and crystallography. In the case of new materials, a successful operation can require the intermeshing of chemical, electrical, software and mechanical engineers, analytical chemists, physicists, materials and catalyst scientists as well as modeling and database experts. In fact, about half of Symyx's workforce doesn't come from the chemistry discipline (Henry 2000). However, recruiting these scientists is by no means easy, for their demand has been exceeding their supply since the early nineties (Brennan 1997, 2000; Henry 2000, 2001b; Mooney 2001). Physical and analytical chemists, in particular, have been in increasing demand for the past couple of years, in large part because new chemical-based entrants are gearing up for an increasing number of lead compounds entering clinical trials (Brennan 1997). Therefore, competition to attract the best professionals is intense, often compelling new entrants to "steal" experienced scientists away from big pharma R\&D units by paying them princely salaries (Brennan 2000).

Not only learning by grafting calls for the integration of different types of specialized knowledge through the creation of organizational routines and direction, but also requires a common language with which these specialists can interact and exchange ideas, information, etc. Bruce Eaton, vice

65. These include Pfizer (Pfizer + Warner Lambert + Parke-Davis), GlaxoSmithKline (Glaxo + BurroughsWellcome + SmithKline Beecham), AstraZeneca (Astra + Zeneca), Novartis (Sandoz + Ciba-Geiby), Pharmacia (G.D. Searle + Pharmacia \& Upjohn), Aventis (Rhône-Poulenc Rorer + Hoechsts + Marion Merrel Dow). 
president of research chemistry at $\mathrm{NeXstar}$ Pharmaceuticals, expresses it this way: "Written and spoken communication is the key, as being able to communicate in the language of different disciplines. We have molecular biologists here who can discuss reaction mechanisms and transition states and care about it, and we have chemists who understand the interplay between different biological targets" (Timpane 1996:9). Underscoring further the importance of knowledge specialists and common language, Eaton adds: "If you can't work in a team, you are going to fail. There is no way a lone scientist can do it all" (Ibid 1996:9).

Despite these challenges, a multiple technology platform does have advantages; first among them is that a broader knowledge base allows firms to adopt a "one-stop shopping" model, enabling them to offer different services simultaneously under the umbrella of a single company. A well-known example of such high-value deal is the legendary \$US 800 million agreement between Vertex Pharmaceutical and Novartis in which the new entrant is responsible for drug discovery and clinical-proof-of-concept testing of 8 drug candidates over a six-year period. The second advantage for a firm of having a multiple technology platform is that firms can create synergies through economies of scope. The third advantage is that the firm can reallocate cash from one business that has positive cash flow to one business with negative cash flow (Amit and Livnat 1988; Teece 1996). The fourth advantage is that while the provision of non-exclusive discovery libraries can be characterized as a commodity business, a "me-too" service than can be duplicated by rivals, the new business model is based on highly specialized, hard-to-copy drug discovery services that may become "core competences". Following Henderson and Cockburn (1994), this is because the necessary competences to perform these tasks are deeply embedded in the organizational routines of the firm, which may become the basis for sustaining a superior performance taken into account the unique knowledge or mode of working together that makes the team particularly effective.

The last advantage is that new entrants can use their multiple technology platforms to develop their own small molecule drug pipeline. Motivated by the expectation of a temporary monopoly, these new entrants would not only use their bioassay-to-lead optimization platform to support pharmaceutical companies in their research efforts but also often translate these knowledge assets into in-house drug discovery programs. Therefore, the end-users (i.e. physicians and patients), as opposed to large pharmaceutical companies, become the actual costumers. Concerned about long-range outcome, the most forward-looking firms even rethought their business model with an eye on focused library design, which saves time and money and offers, at least potentially, higher hit rates (Boswell 2000; Flanagan 2001). More generally, an alternative business strategy combining inter-organizational collaborations with internal product development has 
emerged to capitalize on the opportunities presented by the thousands of new targets for drugs being revealed from the sequencing of the human genome project and the knowledge created along the second and third technological trajectories.

Attempting to look at it pragmatically one can say that many if not the majority of new entrants have been looking beyond an R\&D boutique strategy and are focused on becoming fully integrated drug discovery companies. In a sense this is surprising. Very few new entrants possess the complementary assets necessary to bring a drug to market, implying that large incumbents usually end up being responsible for marketing and sales of any therapeutic products. However, new entrants become much less dependent on the timing of milestone payments and get to keep a much larger percentage of the revenues and profits if they build their own portfolio of drug candidates and carry them out as late a stage of pre-clinical and clinical development as possible. The later the stage, the more revenues and profits these firms will capture from future sales. This is essentially because the risk of a compound not being the right type of drug candidate should be remarkably reduced as it passes through the pre-clinical and clinical phases (Fitzgerlad 1992). Therefore, it is not uncommon for deals involving later-stage drug candidates to provide royalties in the range of 10 to 15 percent, whereas arrangements involving molecules with early stage clinical data give royalties in the range of 5 to 8 percent (Lytton 1997).

To be sure, product-oriented companies face a higher level of uncertainty than service-oriented companies. On one recent estimate, the R\&D costs of bringing a new drug to market is $\$$ US 803 million (DiMasi et al. 2003). Yet firms cannot expect any of their active compounds to be profitable for a number of years, if at all. This is because the process of drug discovery and development is long -up to 15 years- and prone to regulatory and economic failure. Not only 75 percent of drug candidates typically fail the test of clinical trials (Bienz-Tadmor 1993), but also 70 percent of marketed drugs do not generate enough revenues to cover average $R \& D$ costs (Graboswki and Vernon 1994) ${ }^{66}$ Still, earnings can be substantial. Consider the example of Agouron Pharmaceuticals. The structured-based design company hit it big in 1997 with the approval of the HIV drug Viracept, allowing the firm to post profits in 1998 (Copeland 2001).

Unsurprisingly, these new entrants struggle to find the long-term financing they need to support future operations and capital expenditures for additional tangibles such as purification tools, chemoinformatics software, etc. and intangibles such as highly skilled personnel. Information about private firms is, obviously, almost impossible to obtain, but data on 70

66. Isis Pharmaceutical learned first-hand how much the business of drug discovery is uncertain in 2003. After its experimental cancer drug failed the test of regulatory approval, the company cut its work force by 9 percent (NYT 2003). 
public firms in the United States were collected from the website of the Security and Exchange Currency (SEC) or their annual reports, showing that only 8 companies turned a profit in 2001. Despite sales revenues increasing from \$US 2 million in 1996 to \$US 13.5 million in 2001, and despite service revenues stemming for collaborative agreements rising from \$US 9.5 million in 1996 to about \$US 15 million in 2001, the average net loss for a public firm operation amounted to about \$US 34 million in 2001, considerably more than 1996 losses (i.e. \$US 10 million) (see table 4.1) ${ }^{67}$ Because of and/or in spite of these losses, the firms tracked herein continue to grow and accumulate innovations: they had, on average, 116 employees in 1996, which rose to 250 in 2001, 130 of whom are engaged in research development, including 66 scientists holding doctorate degrees, and the number of their patents applications accumulated from 9 to $24{ }^{68}$

\section{Table 4.1}

Selected consolidated financial data (1996-2001) Average in thousands of real dollars (Standard Error)

\begin{tabular}{ccccccc}
\hline & Product & Service & Total & \multicolumn{3}{c}{ Total } \\
Year & Revenues & Revenues & Revenues & R\&D & Expenses & Loss \\
\hline 2001 & 13,533 & 14,797 & 31,793 & 39,847 & 67,033 & $-34,403$ \\
& $(4,497)$ & $(2,555)$ & $(5,909)$ & $(4,825)$ & $(8,581)$ & $(4,238)$ \\
2000 & 10,026 & 12,019 & 24,756 & 28,088 & 53,804 & $-28,813$ \\
& $(3,706)$ & $(2,245)$ & $(5,026)$ & $(3,543)$ & $(8,094)$ & $(6,032)$ \\
1999 & 6,850 & 9,395 & 17,570 & 23,013 & 35,690 & $-18,317$ \\
& $(2,838)$ & $(1,791)$ & $(3,744)$ & $(2,995)$ & $(5,203)$ & $(3,217)$ \\
1998 & 2,641 & 8,953 & 12,566 & 19,311 & 29,544 & $-15,975$ \\
& $(979)$ & $(1,815)$ & $(2,170)$ & $(2,294)$ & $(3,578)$ & $(2,557)$ \\
1997 & 2,345 & 10,102 & 13,495 & 18,359 & 28,597 & $-12,340$ \\
& $(1,031)$ & $(2,039)$ & $(2,406)$ & $(2,323)$ & $(3,853)$ & $(2,506)$ \\
1996 & 2,050 & 9,475 & 11,963 & 13,949 & 21,405 & $-10,354$ \\
& $(1,072)$ & $(1,798)$ & $(2,037)$ & $(1,920)$ & $(2,710)$ & $(2,113)$ \\
\hline
\end{tabular}

Source: Form 10Ks and annual reports

Clearly reflecting a shift towards a product-oriented model, their commitments to R\&D have also increased, escalating from \$US 14 million to \$US 40 million over 1996 and 2001. At the same time, combinatorial drug discovery swung from a semi-empirical approach (i.e. discovery libraries) towards a scientific approach (i.e. focused libraries), which exercised a significant effect on research intensity. In 2001, new entrants spent, on

67. Taken together, these 70 firms earned $\$$ US $1,035,859,000$ through their services and \$US $947,373,000$ by selling pharmaceutical products in 2001, but their net lost amounted to $\$$ US $2,408,251,000$.

68. Patent data are from the European Patent Office. 
average, \$US 159,000 per employee (implying a growth of 32 percent compared to 1996), thus showing an upward trend in basic research funding. Such trend did not arise automatically. Rather, it reflects the conscious and deliberate pro-active decision of strategic leaders. 3-Dimensionnal Pharmaceuticals is a prime example. Dr. F. Raymond Salemme, founder, president and dief scientific officer of the Pennylvania-based company is quoted as saying: "We recognized that specific knowledge of the target could guide the power of combinatorial chemistry to rapidly make compounds eight or nine years ago and built the entire architecture of our company around that idea" (Henry 2001:71).

In addition to being among the most research intensive, the emerging combinatorial drug market is one of the most "know-why intensive". Using the classification of journals and methodology of $\mathrm{CHI}$ Research Inc., Geuna and I have also examined the citations in 816 combinatorial patents to the scientific literature to assess the scientific content of combinatorial chemistry. Of the cited papers, 80.7 percent belong to basic research literature (e.g. Nature, Journal of the Chemical Society), 17.6 percent were in the applied research literature (e.g. Journal of Chromatography) and the rest (1.7 percent) in the engineering/technological sciences (e.g. Chemical \& Engineering News) and applied technology (e.g. Journal of Urology) literature. Breaking down the patent data and the citations in scientific journals by type of innovation and scientific discipline, the role played by science in the creation of process innovations ( 86 percent) appear to be even more predominant than product innovations (77.8 percent). Therefore, it is very difficult to distinguish between basic and applied research in combinatorial drug discovery, implying that know-why creation can rapidly lead to industrial innovations (Malo and Geuna 2000).

While only 8 firms turned a profit in 2001, the number will certainly increase, judging by the fact that 152 new entrants reported having 978 compounds in the pipeline. Of these, 261 were active compounds at the discovery stage, 356 lead compounds at the lead optimization stage and 341 drug candidates at the clinical stage. Although it is difficult to determine whether compounds moving along these stages of drug development come out of a combinatorial chemistry program, one knows for sure that Isis Pharmaceuticals identified by combinatorial mean a lead compound against HIV infection and Selectide an anticoagulant agent (Hughes 1996); Corvas International identified an orally active thrombin inhibitor and Trega Biosciences a drug candidate for pain and asthma (Persidis 1998); Magainin Pharmaceuticals has a novel antibacterial drug lead in the regulatory pipeline (Borman 1998); Signal Pharmaceuticals, Acadia Pharmaceuticals, Ontogen and Ariad Pharmaceuticals discovered lead compounds from focused libraries (Golebiowski et al. 2001); etc. 
The discussion, however, misses an important point: it takes higher levels of internal learning and accumulated know-why to be a member of the innovation network. To illustrate this point, consider the synthesis of focused libraries. The fact that macromolecular crystal structures and pharmacophores can be downloaded, freely or not, from the Internet is irrelevant: spending more in R\&D in general and know-why creation in particular is necessary to assess, collect, reduce, store and analyze gigabyte data. Following de Valle and Gambardella (1993), the organizational implication of shifting from a service platform to a product platform could be that new entrants may be compelled to accept more openness of their research and hire scientists who internalized some values of the scientific community. More generally, an absorptive capacity is needed to monitor, understand, evaluate and exploit external knowledge. The bottom line may well be that the process of external learning could play its full part only if underpinned by strong internal knowledge and competences in both chemistry and biology.

\subsubsection{The dynamics of external learning between new entrants and smaller firms}

Why would new entrants monitor, understand, evaluate and learn external knowledge, with whom, when, what and how? To answer these questions, a database for formal contractual, interorganizational agreements was built from the web pages and press releases of new entrants with a competence in combinatorial chemistry. The sample is composed of 273 firms and covers their subsidiaries and/or parent company if the latter had less than 1,000 employees. The search unearthed 3,035 different agreements, many of which involve multiple modes of collaboration. For example, a typical agreement would include an initial equity investment, research and development funding and licenses on certain products developed through the collaboration. Hence the database, which covers the period between 1984 and 2001, includes 4,390 alliances.

Whereas new entrants with a competence in combinatorial chemistry signed 2,194 and 795 formal contractual, interorganizational agreements, respectively, with large incumbents and scientific organizations, they collaborated 1,401 times with other smaller firms (i.e. companies with less than 1,000 employees) (see figure 4.4). On one estimate, these interorganizational agreements are designed to last on average 3 years, with a 0.5-5 year range (Persidis 1998). If anything, they illustrate first and foremost that the locus of chemical-based innovations is to be found in a network of innovators. The root of this argument is, of course, a knowledgebased division of labor between large incumbents, scientific organizations and new entrants in the market of chemical-based innovations. Empirical evidence about collaborative activities with large incumbents and scientific 
organizations, which deserves to be discussed at greater length, is deferred in chapter 5 and 6 . However, it seems expedient to mention in this chapter that the share of alliances with large incumbents rose from 33 percent $(722$ alliances) to 67 percent (1472) and with scientific organizations from 45 percent (358 alliances) to 55 percent (437) over the first and second phase of development. By comparison, the share of strategic alliances implemented between new entrants and smaller firms grew from 18.3 percent (256 alliances) to 81.7 percent (1145) over the periods 1984-1995 and 19962001 (see table 4.2).

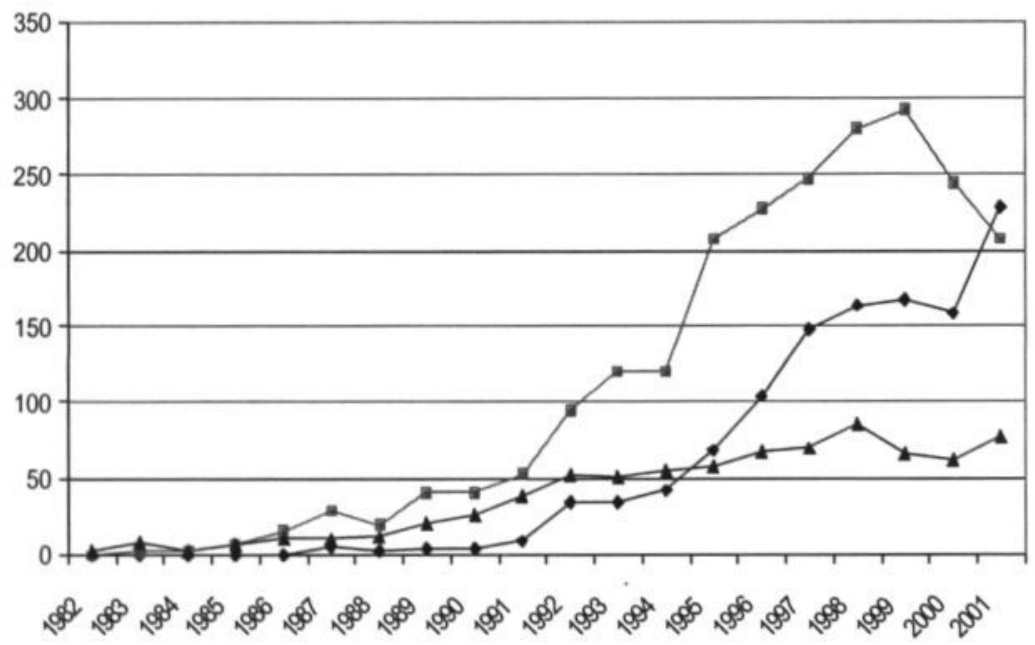

$\rightarrow-$ Smaller firm $\rightarrow-$ Large incumbent $₫$ Scientific organization

\section{Figure 4.4}

Increase in the number of formal interorganizational agreements by new entrants with smaller firms, large incumbents and scientific organizations (1982-2001)

Source: Compiled by author

While formal interorganizational agreements with large incumbents provide opportunities for access to complementary assets and financial support and linkages with scientific organizations provide a means to explore scientific and technological alternatives, the greater propensity to collaborate with smaller firms largely reflects the desire of new entrants to capture a share of the lucrative market of chemical-based services and products, most notably orally acting pills. In parallel with their collaborative activities with big pharma and scientific organizations, new entrants are 
counting on formal alliances with genomic firms, high-throughput screening firms, suppliers of chemoinformatics tools, manufacturers of scientific instrumentations and other smaller players to access the information, knowledge and existing technologies necessary to enhance, develop and/or renew one or several competences along the drug discovery value-chain. Explanation for choosing this learning-based strategy over internal learning is quite straightforward: three attributes of technological change stimulate collaboration among heterogenous companies. These three attributes are:

Complexity. The knowledge base of combinatorial chemistry has been evolving into a technological system wherein a myriad of scientific disciplines such as structural biology, information technologies, engineering and many more disciplines play a crucial part. Therefore, the combinatorial approach to drug discovery is composed of knowledge components that are so tightly intermeshed that the absence of any component would impair the development of drug (new material) discovery projects. As observed by Fred Fox at University of California in Los Angeles: "It is important to look at the whole picture -the chemistry, the screen, the biology that drives the screen, and the informatics that holds these things together. The parts aren't worth much without the whole" (Borman 1999:34).

Uncertainty. To the possibilities of clinical and commercial failures one must add up the rising popularity of focused libraries, which suggests that knowwhy creation will play a far more active role in impending combinatorial drug discovery projects. Yet, despite the come back of scientific inquiry, new entrants are still trying to skin the diversity cat to the best of their knowledge. In fact, they are still struggling with a highly hazardous environment; the bulk of R\&D remains one of trial and error, involving the use of "fuzzy" scientific principles and even simple rules of thumb as means to minimize uncertainty.

Velocity. The knowledge frontier of combinatorial chemistry is moving very rapidly, making it difficult for firms, large or small, to keep up. "Combinatorial chemistry synthesis and screening technologies are developing so fast that requirements for a library design a year ago compared to what they are today are totally different" says Rob Brown at Molecular Simulations, San Diego (Studt 1999:49). This is corroborated by a recent scientometric study, wherein Geuna and I calculated that the peak time for papers cited in combinatorial patents is 2 years prior to patent application (Malo and Geuna 2000). This represents an extremely short time lag; in comparison, Narin et al. (1997), using US patents, estimated that the peak time of papers cited in drugs and medicine patents is 46 years prior to patent grant. In addition, the number of new targets and protein structures 
is increasing rapidly, making it difficult for new entrants to keep up with advances in genomic sciences.

It follows that few new entrants have the breadth of knowledge necessary and the financial capacity to perform all the tasks along the pre-clinical steps of a research program, given the complexity of the combinatorial drug discovery process. This is largely why collaboration among smaller firms with complementary skills is so appealing. By facilitating the transfer of tacit know-how, and by facilitating economies of scale and scope, collaboration with smaller firms can provide the means to access knowledge that would be impossible to purchase in the market or too expensive to produce internally.

\section{Table 4.2}

Formal network

Increase in number of strategic alliances between new entrants and smaller firms -by mode of cooperation (absolute number and percentage of total)

\begin{tabular}{lccc}
\hline Mode of Cooperation & $1984-1995$ & $1996-2001$ & TOTAL \\
\hline R\&D & $45(24.7)$ & $137(74.2)$ & $182(100)$ \\
& $(17.6)$ & $(11.9)$ & $(12.9)$ \\
Licensing & $95(20)$ & $370(79.5)$ & $465(100)$ \\
& $(37.1)$ & $(32.3)$ & $(33.1)$ \\
Equity Participation & $22(20)$ & $88(80)$ & $110(100)$ \\
& $(8.6)$ & $(7.7)$ & $(7.8)$ \\
Manufacturing & $3(20)$ & $12(80)$ & $15(100)$ \\
& $(0.1)$ & $(0.1)$ & $(1)$ \\
Distribution/Marketing & $13(36)$ & $23(64)$ & $36(100)$ \\
& $(0.5)$ & $(0.2)$ & $(2.5)$ \\
R\&D Consortia & $0(0)$ & $20(100)$ & $20(100)$ \\
& $(0)$ & $(1.7)$ & $(1.0)$ \\
Joint R\&D & $41(10.8)$ & $338(89.1)$ & $379(100)$ \\
& $(16.0)$ & $(29.5)$ & $(27.1)$ \\
Joint Venture & $11(34.3)$ & $21(65.6)$ & $32(100)$ \\
& $(0.4)$ & $(1.8)$ & $(2.2)$ \\
Merger/Acquisition & $20(15.7)$ & $107(84.2)$ & $127(100)$ \\
& $(7.8)$ & $(9.3)$ & $(9.0)$ \\
Asset trading & $6(17.1)$ & $29(82.8)$ & $35(100)$ \\
& $(2.3)$ & $(27.1)$ & $(2.4)$ \\
\hline TOTAL & $256(18.3)$ & $1145(81.7)$ & $1401(100)$ \\
& $(100)$ & $(100)$ & $(100)$ \\
\hline
\end{tabular}

Source: Compiled by author

Formal contractual, interorganizational agreements with genomic firms engaged in identifying genes and drug targets are particularly noteworthy because these firms remain the most important source of technological opportunities for chemical-based innovations. In times of rapid technological 
change, collaboration with these firms can also save valuable time. Thus for those new chemical-based entrants seeking to occupy a niche position in market of small molecule drugs, collaboration with genomic firms can offer a way to pre-empt competition in the patent race, thus providing a first mover's advantage. In fact, even when a patent expires, a pioneer product often dominates a sub-market due to successful marketing and prescribers' familiarity with the drug (Caves et al. 1991). Savings can also be significant, since the full cost of bringing a drug to market not only include the cash outlays spent to discover and develop the product but also the opportunity cost of capital (OTA 1993).

There are also ample reasons to believe that formal contractual, interorganizational agreements can preserve flexibility in the face of uncertainty. Indeed, a product-oriented model, though generating much more revenues if the drug under development ends up being a blockbuster, is much more risky and costly than a single or even a multiple technology platform model. Hence firms with complementary skills have good reasons to share the risks of drug discovery and keep the collaboration as flexible as possible. In the event of a "hit", they may choose to invest more capital and perhaps even establish a joint venture to develop the lead compound into a drug candidate. If, on the other hand, the joint research program fails to delivers on its promises, it can be terminated at much lesser costs on short notice. As mentioned earlier, the attrition rate between lead discovery and commercialization remains unacceptably high, and far too many compounds still fail relatively late in the development process at huge cost. Thus the uncertainty pertaining to the process of combinatorial drug discovery has, in the pharmaceutical industry, made the firm's performance something of a lottery, making it impossible to predict the outcome of innovative activities. Yet the process of external learning enables new entrants to minimize uncertainty; and it thereby provides a basis upon which value is created and effectiveness boosted.

This is not to imply that sweeping generalizations can be made about external learning. To begin, the needs of start-up companies have evolved along the changing environment in general and the life cycle of the combinatorial approach to drug (and new material) discovery in particular. The network is therefore subject to dynamic evolution. In addition, the level at which knowledge and technology is actually absorbed depends on the mode of cooperative arrangement (Hagedoorn 1990; Steensma 1996). Thus the knowledge rooting of external learning increases as start-up companies shift from R\&D contracts, licensing agreements, equity participation, manufacturing/distribution/marketing agreements, R\&D consortium, joint $\mathrm{R} \& \mathrm{D}$ contracts and joint ventures. An examination of these modes of collaboration is presented below. 
$R \& D$ contracts are agreements where, in exchange for capital, an organization contracts another one to perform a particular task without losing its rights to any development made (Steensma 1996). For most part, these agreements are of a unilateral technology transfer type (Hagedoorn (1990). New entrants increased the number of these R\&D contracts from 45 to 137 between the periods 1984-1995 and 1996-2001. By and large, such customer-supplier agreements bypass face-to-face interactions and thus limit the transfer of tacit know-how, which is probably why their share decreased from 17.6 percent to 11.9 percent over the first and second phase of development. Yet R\&D contracts are a relatively low risk strategy and may help determine the potential of a new, uncertain technology (Steensma 1996). For example, Sugen participated in Caliper's Value-Added Screening Collaboration program, which serves as an in-house testing facility for the path breaking microfluid high throughput technology. Under the agreement, Sugen paid Caliper Technologies to screen its compound library and target in exchange for data. While Caliper received screening fees on a data point basis, Sugen retained all proprietary rights to develop drug leads that emerge from screening. ${ }^{69}$

Licensing agreement is a contractual arrangement by which a company receive the rights to use another organization's drug, lead compound, combinatorial library, process innovation, software product or, most commonly, a receptor target for a lump sum payment and future royalties. There is a body of literature suggesting that licensing contributes little to knowledge accumulation (Roberts and Mizouchi 1989; Hagedoorn 1990; Anand and Khanna 2000), yet the new research climate promises to be different for two reasons. One reason is that the combination of licensed targets and genomic technologies with combinatorial synthesis methods enable firms to generate more chemical and biological data than ever before. New entrants can transform these data into information and information into knowledge, which, in turn, can establish a foundation for generating and sustaining the expertise required to occupy a niche market. Aurora Biosciences, for example, obtained a non-exclusive license to Microcide Pharmaceuticals' U.S. Patent Number $6,020,121$, related to a specific non-traditional bacterial target. ${ }^{70}$ The licensing deal does not directly enhance competences, but will subsequently lead to the creation of knowledge about bacterial, fungal and viral infections and further the development of new classes of antibiotics, antifungal agents and antiviral drugs. Second, a licensing agreement does not preclude firms from using another mode of collaboration. In fact, if the number of licensing agreements reached 370 (32

69. Interestingly, Caliper moved away from a fee-based technology access program model to a commercial product business in 2001.

70. Microcide Pharmaceuticals recently changed its name to Essential Therapeutics. 
percent of total) in the period 1996-2001, up from 95 (37 percent) in the period 1984-1995, it is essentially because chemical-based firms and biological-based firms signed an increasing number of joint R\&D agreement in tandem with licensing rights.

Equity participation, or minority holding, takes place when a firm buys capital stock into another firm. Minority investment alliances were taken 22 times (8.6 percent of total) in the first phase of development, as compared to 88 times (7.7 percent) between 1996 and 2001. It its simplest form, equity participation gives an exclusive right to buy resources in exchange for capital (Lewis 1990). For instance, Ligand Pharmaceuticals acquired a minority equity stake in X-Ceptor Therapeutics for \$US 3.2 million. The minority investment provides Ligand with an exclusive right to use targets for cardiovascular disease and metabolic/neurological disorders. In the words of Ligand Chairman, President and CEO David E. Robinson: "It allows Ligand to develop our long-term technology base and share the risk as well as the potential upside of a leading orphan nuclear receptor venture without the direct management, financing or full profit and loss responsibility. ${ }^{71}$ Anticipation of profits in the event of future buy-out may be another motive. When Marion Merrell Dow purchased Selectide in 1995, for example, USbased Sugen was well rewarded for committing funds to an early financing round of the American combinatorial chemistry firm. Indeed, Sugen received approximately $\$ 3$ million in proceeds from the sale.

Manufacturing/Distribution/Marketing. Although arrangements related to manufacturing, distribution and marketing involve sharing a great deal of technical information, these modes of collaboration remain marginal and merely rose from 16 ( 0.6 percent of total) to 35 ( 0.3 percent) over the first and second phase of development. This is in line with the observation that few new entrants have the financial means to develop complementary assets, with perhaps the exception of scientific instrumentation suppliers, as for example Argonaut Technologies. Argonaut Technologies and Symyx Technologies initiated a collaboration wherein the former will commercialize improve, manufacture, and distribute worldwide certain of the latter's proprietary instrument for high-throughput synthesis and screening of chemical materials.

$R \& D$ consortium is an arrangement wherein two or more organizations share resources to create a new legal order to conduct cooperative research and development activities (Olk and Young 1997). Since combinatorial chemistry made its debut in the industrial setting, new entrants, large

71. See X-Ceptor's website (www.x-ceptor.com). 
incumbents and scientific organizations have participated in at least 20 consortia. Mindful of the fact that consortia can further the development of innovations, the European Union helped set up COMBICAT, a consortium comprising 2 start-ups, 3 large companies, 5 scientific organizations that aims at developing innovative methods for high-speed catalyst preparation, testing and selection; ComGenex launched EMIL with 17 Japanese pharmaceutical and biotechnological companies to design software for library-building purposes; Accelrys, a subsidiary of Pharmacopeia, established 7 different consortia dedicated to development of software for computation, simulation and the management and mining of scientific data used by biologists, chemists and materials scientists; etc. ${ }^{72}$ One of the most representative example is that of Argonaut Technologies, which formed 7 consortia to define product requirements and perform validation and testing of its state-of-the-art parallel synthesizers. While each participating company can achieve a nine-month to one-year competitive advantage by receiving one or more of the advanced process tools before it becomes available to non-members, Argonaut Technologies receives non-refundable participation fees and gets to incorporate the member's feedback into the final product. "We listen to our customers and solicited input from process chemists throughout the world," said David P. Binkley, Argonaut's president and chief executive officer. "We then present a concept to consortium members who review it and are able to either validate or change product features and specifications by consensus" (PRNewswire 1999). Thus one of the purest forms of learning by using can be found in consortia, for good reason. Consortia members can identify unanticipated problems related to a new synthesizer, software or any other pharmaceutical input and share their ideas and experience with the group, leading to the better design of future products.

Joint $R \& D$ occurs when two firms collaborate on a particular process or product through research or development and share future profits. The number of joint $R \& D$ contracts increased from 41 (16 percent of total) to 338 (29.5 percent) over the periods 1984-1995 and 1996-2001. Most of this increase reflects firms' shifting emphasis away from just offering combinatorial libraries as a service towards developing small molecular weight drugs. To buy this logic is to accept the idea that while $R \& D$ and joint

72. Thierry Jean, CEO of Cerep, sums up the benefits of the MSI's consortium: "As a member of the Phase I Consortium, we recognize the positive impact that the synergy of MSI and other members of the consortium brought to our internal computational chemistry efforts. In the field of molecular modeling, as for the rest of our drug discovery platform, we want to both keep abreast of the latest innovations and keep adding the most useful technologies to our portfolio. Staying in the consortium is part of this strategy" (www.pharmacopeia.com). 
R\&D agreements bring together complementary strengths and help achieve economies of scale and scope, the latter is much better in transferring the tacit know-how necessary to complete a research program. Thus combinatorial drug discovery cuts into more disciplines than mere chemical synthesis, compounding transactional difficulties in the intermediate market of know-how and requiring face-to face interaction between scientists. It needs to be emphasized that these arrangements are often cashless, wth chemical-based firms bartering expertise in lead discovery and lead optimization for know-how in assay development from biological-based firms. The joint R\&D agreement between Nanoscale Combinatorial Synthesis and Euroscreen is a representative example. Besides giving them the opportunity to share and accumulate know-what about the general interaction between types of chemistries and types of drug targets, the joint R\&D project bringing together Nanoscale Combinatorial Synthesis's knowhow in small molecule libraries with Euroscreen's expertise in cloned G protein coupled receptors.

Joint Venture involves the creation of a subsidiary by a firm and at least one more partner to achieve a specific objective. Often, a joint venture not only involves capital from its partners but also employees (Roberts and Mizouchi 1989). This is a mode of collaboration that has gained some ground in recent years, from 11 joint ventures in the first phase to 21 in the second phase of industrial development. A joint venture makes sense when two companies endowed with different yet complementary knowledge assets seek to develop a new technology requiring the transfer of tacit knowledge (Kogut 1988). Take the example of ChiroChem Discovery Services, a joint venture which was established in 1998 by Chirotech Technology, a eader in chiral technologies, and CombiChem, a leader in computational drug design and synthesis, to develop and sell specifically designed chemical libraries. Under the agreement, ChiroTech provides novel, multi-functional chiral templates to CombiChem scientists as an information base to design and synthesize information-rich chiral compound libraries. Joint ventures may also speed up a firm's acquaintance with the human resource management practices and problems of the host country (Pisano et al. 1988; Sachwald 1999). One example will suffice: the joint venture between BioFocus, a UK-based company, and Australian Cancer Technologies (AustCancer), which has been formed with the aim to discover new small molecule drugs against breast cancer and circumvent barriers to entry (i.e. regulatory procedures, prospective clients, etc.) in the Australian market. ${ }^{73}$

73. As pointed out by Dr David Stone, Chief Executive at BioFocus: "The collaboration will continue to build on BioFocus' expanding market presence in the AsiaPacific Rim and will also allow us to capitalize on AustCancer's experienced clinical team in developing novel therapeutics for breast cancer." (See Biofocus's website: 


\subsection{LEARNING THROUGH ACQUISITIONS}

The picture on the behavior of new entrants would only be partial if one did not give place to mergers and acquisitions (M\&A). Since the late 1980s, when the technology appeared in industrial settings, 183 new entrants have been acquired by, or merged with, another organization, as figure 4.5 shows. These findings, combined with the 7 new entrants that have dissolved their operations, sold their assets or folded for lack of funding, are not trivial and play to the Tushman-Anderson model. Most of them "exited" the industry in times of increasing combinatorial output and declining price.

But there are important observations to be made. To begin, the acquiring organizations were large incumbents in 25 cases, often with no previous experience in the field (see next chapter). In line with Acs and Audretsch (1989), one should acknowledge that the entry of one large firm can more than offset the entry of dozens smaller firms. One should also take into account the fact that 37 chemical-based entrants have been bought up by small biotechnology companies with no expertise in combinatorial chemistry.

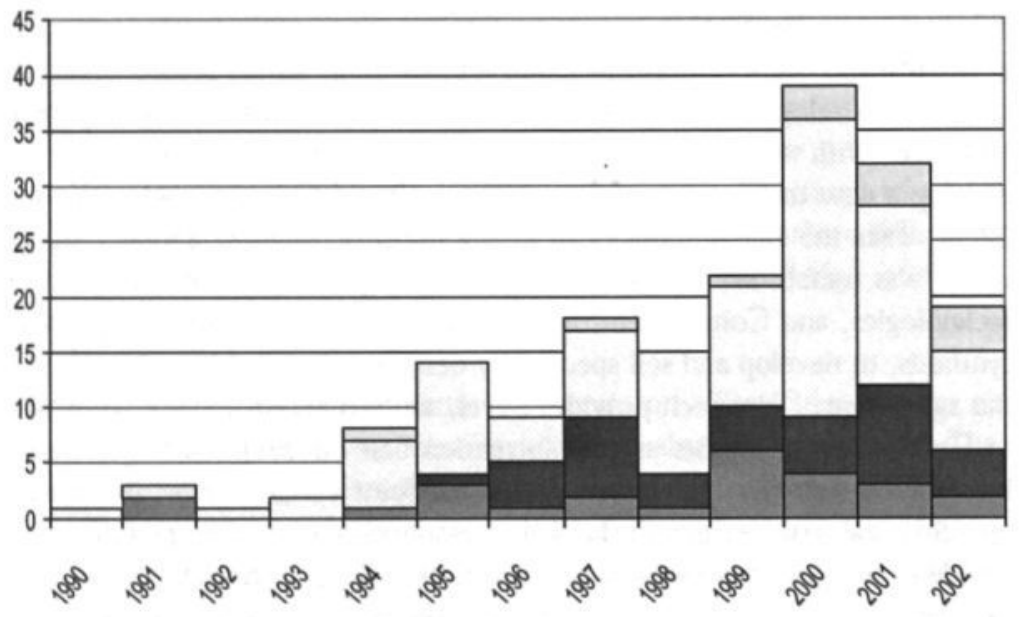

Q Acquired by large fim Acquired by smaller fim $\square$ Acquired smaller fim $\square$ Merged with smaller fim

\section{Figure 4.5}

Increase in the number of mergers and acquisitions (1990-2002)

Source: Compiled by author 
It is telling that genomic firms, which typically sell analytical data, software and hardware to large pharmaceutical companies, were among the most aggressive buyers. This is because biological-based firms, akin to combinatorial chemistry firms, have been trying to avoid the trapping of a commodity market (Herrera 2001; Thayer 2002). In the words of William Haseltine, chairman and CEO of Human Genome Sciences: "I think the challenges we face are not on the research end, not in generating these wonderful ideas, but in the proper coupling of those to the market, to the customer and to the most efficient use of those technologies. A lot of these splendid new tools and ideas are being applied to old ends. The key research/development challenge is fitting yet another small molecule drug into our complex body" (Jarvis 2002). Thus genomic firms are buying up new entrants in combinatorial chemistry in the hope of penetrating the market of small molecule drugs. Learning through acquisition, therefore, allows them to break rigidities, to metamorphose into fully-integrated drug discovery firms. ${ }^{74}$

Not only does this weaken the relation between M\&A activity and concentration, but this also implies that new chemical-based entrants do not play second violin as far as learning through acquisitions is concerned: they initiated 14 mergers and 107 acquisitions of smaller firms with complementary technologies. ${ }^{75}$ Rather than falling into a competency trap, 71 firms reason that this learning-based strategy provides a fast, effective albeit expensive- way to enrich their knowledge base cum competences. Concomitantly, the mushrooming of M\&As may have been triggered by the belief that the combined value of technology platforms are greater than the sum of their parts, first because the very business of conducting innovative activities in combinatorial chemistry, genomics, computational chemistry and scientific instrumentation can synergize to achieve economies of scope and scale, and second because the newly-integrated drug discovery company can potentially deliver small-molecule drugs, rather than just libraries, target receptors, etc.

The example of Pharmacopeia can convey the basic idea. Since its foundation in March 1993, Pharmacopeia acquired 5 different start-ups, enabling the New Jersey-based company to move its position of supplier of

74. Examples include the acquisition of Aptein by Cambridge Antibody Technology for \$US 11 million in 1998, the take over of Trega Biosciences by Lion Biosciences for \$US 35 million in 2000, the acquisition of Coelacanth by Lexicon Genetics for \$US 32 million in 2001, the purchase of Medichem Life Sciences by deCode for $\$ 83.6$ million in 2002; etc.

75. Examples include the acquisitions of Structural Proteomics in 2000 and Xenometrix in 2001by Discovery Partners International; the take over of Triangle Pharmaceuticals by Gilead Sciences for $\$ 464$ million in 2002, the acquisitions of Molecular Simulations in 1998 and Synopsys Scientific Systems, Oxford Molecular and GCG in 2000 by Pharmacopeia; etc. 

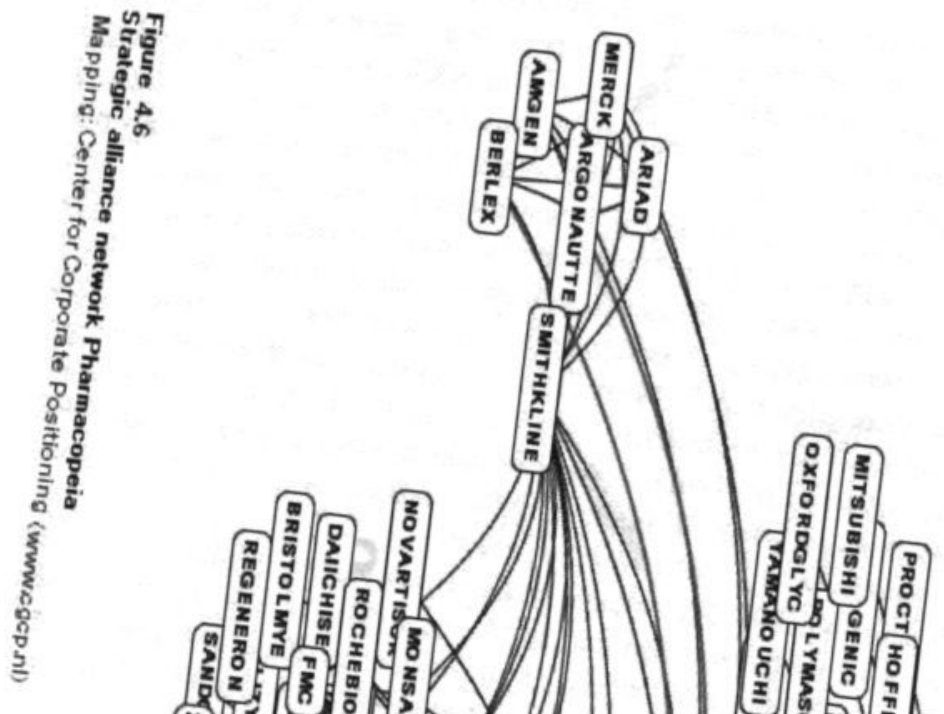

年

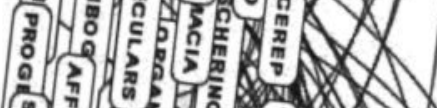

ร)

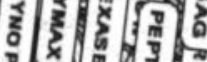

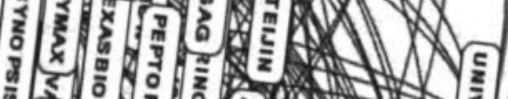

ด

ริ

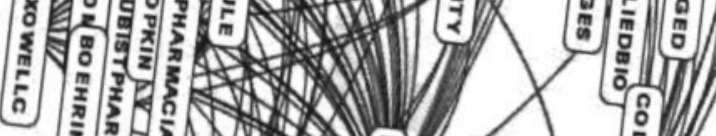

业

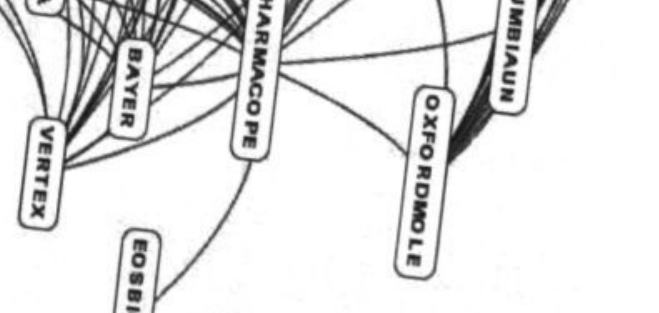


combinatorial libraries towards a position of fully integrated drug discovery and development firm. Pharmacopeia's mission statement is to "provide experimental, computational, and informatics products and services to accelerate and improve the design, discovery and development of new pharmaceuticals and chemicals to identify compounds active against collaborators' targets and improve potency and other partner-defined criteria of lead compounds. ${ }^{-76}$ The acquisitions of Molecular Simulations Inc. (MSI) in 1998 and Synopsys Scientific Systems, Oxford Molecular, and GCG in 2000, which were grouped and incorporated into Accelrys in 2001, are therefore strategically significant. Accelrys provides Pharmacopeia with four key assets: a broad line of cheminformatics products that complement its existing chemical database tools, an industry leading position in the large and growing field of bioinformatics, a group of more than 120 talented employees, including highly skilled scientific software developers and an instant access to a network of collaborating firms, etc., as figure 4.6 shows. Joseph A. Mollica, Pharmacopeia's chairman, president and chief executive officer explained the company's acquisition strategy: “...the critical mass we will achieve from [Accelrys] cheminformatics products will benefit our customers as they seek to leverage the important chemical data emerging from today's drug discovery efforts. This acquisition should serve to fuel Pharmacopeia's continued growth."

In addition, Pharmacopeia spent \$US 197 million in 2001 to buy Eos Biotechnology, which built an integrated platform of custom genomicsbased tools to discover and validate targets. In this way, the company hopes to benefit from technological opportunities stemming from the genomic revolution by securing its own source of high-quality disease technology, expertise and resources. In this way, the company hopes to benefit from technological opportunities stemming from the genomic revolution by securing its own source of high-quality disease technology, expertise and resources. Joseph A. Mollica was quoted as saying:

By combining Eos' skills and assets with Pharmacopeia's leadership in experimentation, computation, and informatics products, our combined company will have the full spectrum of drug discovery capabilities from target discovery and validation, through lead discovery, enhancement and optimization. The combination will also create many new scientific and business opportunities not currently available to either company. ...we will now be able to set our own objectives and, importantly, move up the 'value chain' in our drug discovery business. In short, our combined company will have all the science,

76. See Pharmacopeia's website: www.pcop.com. 
technology, partnerships, and management in place to create a full-fledged drug discovery company (PR Newswire 2001a).

Consolidating complementary competences and technologies to create synergies through economies of scale and scope is an explanation, although logically one cannot rule out that the possibility that an acquisition or merger is motivated by the hope of raising the profile of the firm. Consider the example of NeXstar. NeXstar, a liposome company with an expertise in combichem, came into existence after the merger of NeXagen and Vestar in 1995. NeXagen's stock was about \$US 8 per share prior to the merger but \$US 27 a year later (Persidis 1999). Four years later the share price of NeXstar rose again significantly when it merged with Gilead Sciences, a combinatorial chemistry firm specializing in anti-viral therapies. It may be impossible to assess whether the firm would have survived without merger, but NeXstar, now Gilead Sciences, has enjoyed steady growth (The Economist 1999b).

\subsection{CONCLUDING REMARKS}

This chapter was intended to show that the discovery of simultaneous parallel synthesis and simultaneous multiple synthesis signaled watershed structural changes in the pharmaceutical industry. Indeed, the emergence of combinatorial chemistry has clearly democratized the process of organic compound synthesis. More specifically, the pioneering work of Furka, Geysen, Frank, Ellman and colleagues lowered an important barrier to entry in the market of chemical-based services and products, allowing at least 393 new entrants to venture into a territory that had traditionally been the province of large pharmaceutical companies. Not only did new entrants initiate the competence-enhancing discontinuity, but also the number of entrants remains relatively stable, despite the creeping "commodization" of combinatorial libraries. The chief reason is that new entrants did not make the mistake to wait until the price of combinatorial libraries went down before adapting to the external environment. Using their behavior advantage, most notably their formal networks, these firms reacted quickly to enhance and/or expand their competences along the second, third and fourth trajectory through technological learning. Some repackaged their service and product offerings to help large pharmaceutical firms in their drug discovery endeavours. Some have diversified into catalysts, pesticides, etc. Less obvious, but probably more important in the longer term, others became fully-integrated drug discovery firms. A general theme, however, prevails throughout. Smaller firms have been increasingly joining forces to learn about the complementary knowledge of the other. The structural implications can be far-reaching, as the following chapter will demonstrate: a 
new division of labor on the basis of chemical-based innovations is taking place between new entrants and large established companies in the pharmaceutical industry. 



\section{Combinatorial Chemistry and Large Incumbents}

If you are lost in the forest and stand still for two years, moss will gather on one leg. This is the north.

Pierre Légaré, Québecois humorist

\subsection{INTRODUCTION}

Chapter 4 has described how new entrants created value in different ways through internal and external learning. However, one is also confronted with the fact that these firms operate in the context of a competenceenhancing process discontinuity. Lending credence to the predictions of Tushman and Anderson (1986), the gap between smaller and larger firms was never so great as to leave the latter far behind on the learning curve, and today's large pharmaceutical firms largely surpass new entrants in terms of combinatorial library output.

In theory, this should cloud the outlook for the long-term development of the new entrants. The key argument should be that large pharmaceutical companies, having rapidly learned the skills required to master combinatorial chemistry, will take advantage of their size to achieve economies of scale and 
drive smaller firms out of business. In practice, large pharmaceutical and large (jgro)chemical firms, while enjoying a material advantage over new entrants, remain far from being self-sufficient: large incumbents need new entrants as much as the latter need the former. The idea, of course, is not entirely new. For example, Jewkes, Sawers and Stillerman stated more than three decades ago: "It may well be that there is no optimum size of firm but merely an optimal pattern for an industry, such a distribution of firms by size, character and outlook as to guarantee the most effective gathering together and commercially perfecting the flow of ideas" (1958; 2nd edn, 1969:168). What is new, however, is that the emergence of combinatorial chemistry may be leading to a restructuring of the relations between smaller and larger firms on the basis of chemical-based innovations: the technology is giving rise to a new division of labor in the pharmaceutical industry.

The chapter is structured as follows. Section 5.2 examines the motives behind the decision to adopt combinatorial chemistry, describes the implementation of corporate learning-based strategies and inquires into the impact of the technological discontinuity on their competitive standing. Section 5.3 turns to formal interorganizational agreements between new entrants and large incumbents and explores what light they can shed on the new division of labor in the drug industry. Section 5.4 draws many of the threads of this overall assessment together with a case study of GlaxoSmithKline. The subject matter of section 5.5 is the entry of large (agro)chemical companies into combinatorial material. Section 5.6 concludes by returning to the question of how new entrants and large incumbents are playing different, yet complementary functions in the dynamics of combinatorial innovations.

\subsection{THe Entry of Large Pharmaceutical Firms}

Established by the German firms Bayer and Hoechst in the 1880s, the first pharmaceutical $R \& D$ laboratories had initially searched for therapeutic drugs by screening, with little or no preselection, thousand of different compounds (Liebenau 1985). However, the use of pure random exploration declined from the mid-fifties-on, giving way to more empirically oriented research programs. Thus, medicinal chemists would increasingly tap into bits of know-what, know-how and know-why that had been acquired and provided by pharmacologists, clinical researchers, marketing personal and others (Schwartzman 1976). Such semi-empirical search strategy may have been successful in the early post-war period, but the number of newly introduced compounds slowly declined during the sixties and seventies. In the United States, for example, an average of 50 new chemical entities (i.e. drugs whose ingredient has never been approved by regulatory authorities) per year had been introduced between 1955 and 1960, but only 17 had 
been launched yearly during the 1965-1976 period (Grabowski and Vernon 1982). Most analysts had associated this decline to the effects of regulation in general and the Kefauver-Harris amendments of 1962 in particular, ${ }^{77}$ but a few others suspected that the depletion of research opportunities, at least in a few therapeutic classes, had also played a detrimental role (Wiggins 1981; Comanor 1986).

In this context, one might have justifiably wondered whether the rise of rational drug design and biotechnology would solve the innovation deficit of the human health care industry. While it is true that these radical innovations gave new ways to understand the mechanisms of disease and thereby placed frontier scientific research at the center of the drug discovery process, it is also true that these technologies did little to increase the flow of new molecular entities containing new active ingredients (NMEs). According to the National Institute for Health Care Management Research and Educational Foundation (NIHCM 2002), only one-third (361) of 1,035 drugs approved in the in the United States by the Food and Drug Agency between 1989 and 2000 were NMEs. Of the 361 NMEs, less than half (153) were given "priority" status, which is reserved for drugs the agency believes could provide significant clinical improvement over existing medications. This implies that a total of 674 drugs, or 65 percent of FDA-approved medications, contained active ingredients that were already available in marketed products.

Critics of big pharma often dismiss such drugs as "copycat" or "me-too" drugs. Yet these drugs, which results from the process of incremental innovations, can offer advantages in terms of improvement in efficacy, better patient satisfaction and compliance, and in some cases, potency. ${ }^{78}$ Nonetheless, launch price for priority NMEs can be two to three times higher than incrementally modified drugs (Lu and Comanor 1998), and pharmaceutical innovations, despite the wave of acquisitions and mergers among large pharmaceutical companies, have become less concentrated over time (DiMasi 2000).

In spite of this, few large pharmaceutical companies showed interests in combinatorial chemistry in its early days, with many disregarding its potentials (Brown 1996; Glaser 1996; Merritt 1998; Lebl 1998). Whether industry incumbents had fallen prey to structural inertia (Hannan and

77. In a nutshell, the 1962 Kefauver-Harris amendments to the Food, Drug, and Cosmetic Act in the US increased the authority of the Food and Drug Administration by requiring drug manufacturers to show that their drugs were safe.

78. Take the case of beta-blockers. Contrary to first-generation agents, the secondgeneration beta-blockers are selective for beta- 1 receptors and hence are less likely to cause systemic vasoconstriction. They also offer differences in potency, cardioselectivity, effects on the nervous system, pharmacokinetic properties, additional pharmacological effects, potential for interaction with other drugs, efficacy in specific racial groups and complexity of dosage regimen (Wertheimer et al. 2001). 
Freeman 1984), myopic learning (Levinthal and March 1993), underinvestment and incompetence (Henderson 1993) or the "Not-InventedHere syndrome" (Katz and Allen 1982) remains open to question, though it is apparent that the early days of combinatorial chemistry, as with so many other important innovations, had been characterized by widespread skepticism. To observe this, one only has to note that medicinal chemists, who were accustomed to synthesize one or two pure compounds once a week, were often loath to employ the new technology. As Andrew Merritt, research leader at GlaxoWellcome, puts it: "For most chemists, the automation synthesis approach was an example of increased mindless handle turning, not appropriate to the craftsman style of medicinal chemistry" (1998:506). By all accounts, the initial impression was essentially that combichem methods were completely ugly, too empirical, disappointing, not reproducible, not practical, inelegant and unscientific (Service 1998; Lebl 1998).

In retrospect, large pharmaceutical companies had every reason to adopt a "wait and see" strategy. After all, no one knew for sure if the process innovation would someday be economically viable and technically feasible: Will combinatorial chemistry help increase research productivity? Was the new technology just a hype? Nonetheless, it is clear that the diffusion of combinatorial chemistry took off once its relative backwardness had been overcome by hundreds of incremental improvements, setting the stage for making the competence-enhancing process innovation much less uncertain and much more attractive to larger competitors. Remember that the first synthesizers appeared in the market 6 to 8 years after Frank' and Furka's experiment, that HTS instrumentation and bioassays had to be miniaturized, that deconvolution and tagging methods only surfaced in the early nineties, etc. In particular, recall that chemists were constrained in the type of structures or organic reaction amenable to combinatorial chemistry, since the combinatorial synthesis methods could only be applied to construct peptides and oligonucleotides libraries before the synthesis of a benzodiazepine library by Ellman's group at UBC in 1992. As pointed out by it Plunkett and Ellman: "Once we and others demonstrated that combinatorial chemistry could be used to assemble drug-like molecules, the pharmaceutical industry began pursuing more projects in the area" (1997:58).

Therefore, the successful synthesis of small molecule libraries might have been an eye-opener, contributing $\mathbf{b}$ turn the modus operandi of medicinal chemists upside-down and forcing them to change, to quote one scientist, "the thinking about numbers of compounds from hundreds to millions and billions" (Lebl 1998:5). At the same time, newly founded firms and early adopters represented a real competitive challenge, providing an additional factor which influenced their resolution to invest in the new technology platform. Clearly, large pharmaceutical companies could neither perpetually 
ignore the investment made by new entrants nor the potentials of the new methods for increasing efficiency. Suffice here to mention that Merck had synthesized and screened 250,000 compounds between 1934 and $1994^{79}$ while new entrants such as ChemRx, Pharmacopeia, Cerep or Evotech OAI can now synthesize libraries containing thousands of compounds at a fraction of the price the pharmaceutical giant used to pay.

To counter this threat, and to boost research productivity, all large pharmaceutical firms without exception strove to develop in-house competences in the arena. In accordance with Tushman and Anderson (1986) and Cohen and Levinthal (1990), the simple fact that combinatorial chemistry rests on a knowledge base large incumbents already owned suggests that past investments and organizational routines did not inhibit the process of competence building. In fact, the crucial matching of skills between the old screening approach to drug discovery and the new technological discontinuity was not too difficult to achieve. In spite of lagging behind combinatorial chemistry firms by at least 2 years, large incumbents have been able to use their absorptive capacity and existing know-how in chemistry, biology and information technology to build efficiently and rapidly an expertise in the field. In the words of David J. Ecker, vice president of Isis Pharmaceuticals:

It's a technology that is much more widely accepted, at least by the major pharmaceutical companies, than most new technologies. The reason is that it's not that much different from mainstream drug discovery in the pharmaceutical industry for 100 years. It's just a technical advance that allows you to do things much more quickly, but it's not breaking away that much from a tried-and-true approach. In that regard, it seems to require much less justification than something like gene therapy, something that's new and never existed before and people don't know what all the hurdles are going to be (Thayer 1996:60).

By 1997, Eli Lilly already used combinatorial technologies in over 75 percent of its cardiovascular, cancer, central nervous system, endocrine and infectious-disease research programs (Service 1997); Abbott had set out to master combinatorial chemistry in 1994 but could already employ the methods in 80 percent of its drug discovery programs in 1998 (Karet 1998); Bayer only started to build a competence in combinatorial chemistry in 1995, yet there were groups to perform the synthesis techniques in all its laboratories worldwide in 1999 (Gwynne 1999); SmithKline Beecham filed its first cmbinatorial patent with University of Pennsylvannia in 1992 but

79. See www. merck.com. 


\section{Table 5.1}

Summary of lead compounds discovered by combinatorial means by large pharmaceutical firms (Dec. 1999-Jan 2001).

\begin{tabular}{|c|c|c|c|}
\hline Organization & Country & Target & Library \\
\hline Abbott Laboratories & US & LFA-1/ICAM & Discovery ${ }^{*}$ \\
\hline Abbott Laboratories & US & IL-2 & Discovery* \\
\hline Abbott Laboratories & US & Ftase & Focused $^{* *}$ \\
\hline Amgen & US & Human Y5 & Discovery* \\
\hline Amgen & US & $A B$ peptide & Focused $^{* * *}$ \\
\hline Astra Zeneca & GB & Janus kinase 3 & Discovery* \\
\hline Bayer & $\mathrm{DE}$ & P38 & Discovery* \\
\hline Bayer & $\mathrm{DE}$ & PKC & Targeted** \\
\hline Bristol Myers Squibb & US & Bacterial MurB & Focused ${ }^{* * *}$ \\
\hline Hoffman LaRoche & $\mathrm{CH}$ & Opiod & Discovery* \\
\hline Hoffman LaRoche & $\mathrm{CH}$ & VLA-4 & Focused $^{* * *}$ \\
\hline Hoffman LaRoche & $\mathrm{CH}$ & DNA gyrase & Focused ${ }^{* * * *}$ \\
\hline Glaxo & GB & FXR & Discovery* \\
\hline Glaxo & GB & cRAF1 kinase & Focused $^{* * *}$ \\
\hline Janssen & BEL & Yeast & Discovery* \\
\hline Lilly & US & Fxa & Discovery* \\
\hline Lilly & US & AMPA & Discovery* \\
\hline Merck & US & HIV-1 integrase & Discovery* \\
\hline Merck & US & H5-HT24 & Discovery* \\
\hline Merck & US & Human sst & Focused $* * *$ \\
\hline Pfizer & US & Fxa & Discovery* \\
\hline Pfizer & US & F16Bpase & Focused ${ }^{* *}$ \\
\hline Pharmacia \& UpJohn & US & cdc25b & Discovery* \\
\hline RW Johnson & US & Human Y5 & Discovery* \\
\hline RW Johnson & US & B-Lactamase & Discovery* \\
\hline RW Johnson & US & GPIIb/IIIa & Focused ${ }^{* * *}$ \\
\hline SmithKlineBeecham & US & Human 5-HT6 & Discovery* \\
\hline SmithKlineBeecham & US & Lp-PLA2 & Discovery* \\
\hline SmithKlineBeecham & US & CCR2B & Discovery* \\
\hline Shionogi & $\mathrm{J}$ & CPLA2 & Discovery* \\
\hline
\end{tabular}

${ }^{*}$ Diversity-driven ${ }^{* *}$ Thematic libraries ${ }^{* * * *}$ Project-directed, knowledge-based or focused libraries **** Libraries using virtual synthesis and virtual screening in author's methodology Source: Golebiowski et al. (2001)

had accumulated a total of 24 such publications in 1998 (Current Patents 1999); Bristol-Myers increased the number of drug candidates from 6 a year in the early nineties to 14 a year at the end of the decade after spending heavily in its synthesis and screening capacities (Pollack 2002); etc. Table 5.1 gives other examples of lead compounds discovered through combinatorial methods by large established companies; thus, 15 different drug makers discovered at least 30 lead compounds, though the majority of hits are most likely to be derived from the historical collections of compounds of these large incumbents. Additional evidence is indicated in greater details in figure 5.1. The figure depicts the research output of large incumbents and new entrants as measured by published combinatorial libraries between 1992 and 


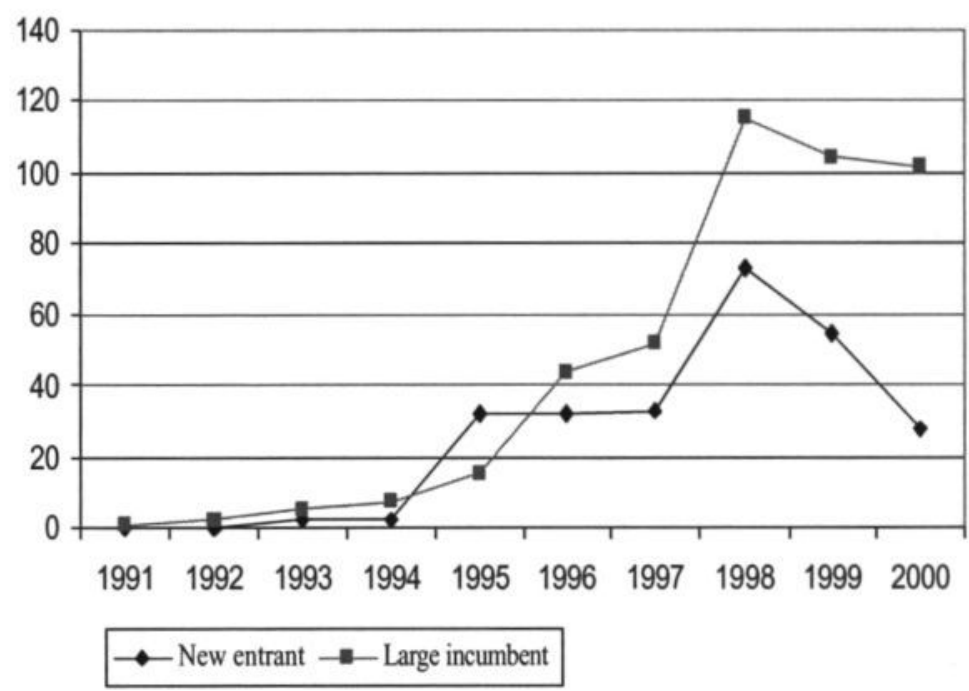

\section{Figure 5.1}

Growth of published combinatorial libraries -new entrants versus large incumbents (1991-2000)

Source: Extracted from Dolle (1998a, 1998b, 2000, 2001) and Dolle and Nelson (1999).

2000. The data have been extracted from the annual surveys of Dr. Roland Dole and sorted by firm size. ${ }^{80}$ Having said this, it is apparent that large incumbents had been trailing new entrants in terms of research output in the early days of the technological life cycle. In the first half of the nineties, 72 percent of published libraries came from new entrants, whereas only Eli Lilly, Chiron, Merck, Bristol Myers Squibb and Parke-Davis (now part of Pfizer) had published their results in academic journals. Thus, large incumbents and new entrants had synthesized 18 and 45 libraries, respectively, in the first phase of industrial development. Yet, by 2000, large pharmaceutical firms could be accounted for 65.5 percent of all combinatorial libraries synthesized by industrial players, or for 76.3 percent

80. To be sure, no measure is perfect; not only one must take into account a 1-2 year time lag between actual synthesis and publication but also a statistical discrepancy that may arise from firms wishing to keep their libraries as trade secret. Nonetheless, Dolle, author or co-author of over 80 scientific publications and 30 patents, is much better positioned to monitor the latest developments in the field than any social scientist, and hence, provide one of the most reliable sources of scientific, technological and economic information. 
if one takes into account those that were subsequently obtained via the acquisition of new entrants. These figures, however, hide a high concentration rate. Thus, the top 15 library holders had been responsible for the synthesis of 351 libraries -436 libraries thanks to their acquisitions of new entrants (see table 5.2).

Table 5.2

Top 15 large incumbents for combinatorial libraries (1992-2000)

\begin{tabular}{lcccc}
\hline Firm & Country & Firm & \multicolumn{2}{c}{ Sumber of Libraries } \\
\hline GlaxoSmithKline & GB/US & 43 & 38 & 81 \\
Aventis & FR/DE & 35 & 24 & 59 \\
Merck & US & 40 & 4 & 44 \\
Chiron & US & 28 & $0(2)^{1}$ & $28(30)^{1}$ \\
Pfizer & US & 24 & 4 & 28 \\
Johnson \& Johnson & US & 25 & 1 & 26 \\
Bristol Myers Squibb & US & 24 & 2 & 26 \\
Novo Nordisk & DK & 23 & 0 & 23 \\
Lilly & US & 18 & 5 & 23 \\
Hoffman LaRoche & CH & 21 & 1 & 22 \\
Amgen & US & 21 & 0 & 21 \\
Pharmacia & US & 15 & 3 & 18 \\
Organon & NL & 12 & 0 & 12 \\
Novartis & CH & 12 & $0(28)^{2}$ & $12(40)^{2}$ \\
Abbott Laboratories & US & 10 & 0 & 10 \\
\hline TOTAL & & 351 & 82 & 436 \\
\hline - & & & &
\end{tabular}

$1=$ Including Coselco Mimotopes; 2 = Including Chiron

Source: Extracted from Dolle (1998a, 1998b, 2000, 2001) and Dolle and Nelson (1999).

How did large pharmaceutical achieve this feat of strength? To build inhouse competences in combinatorial chemistry, all large incumbents without exception have hired key scientists and spend heavily in automated instrumentation and R\&D. Yet, typically for new technologies, recruiting scientists with know-how in combinatorial chemistry was not an easy job. ${ }^{81}$ However, given the costs of highly specialized scientific personnel, their idiosyncratic routines and the type of discontinuity involved, large firms preferred to rain their researchers where possible, rather than hire new employees. "Pharmaceutical companies are not bottomless wells of money," says Stephen Kaldor, head of the combinatorial chemistry effort at Eli Lilly. "We want to retrain and educate scientists internally so they can stay current

81. In the words of Thomas Sowin, project leader for combinatorial chemistry at Abbott Laboratories: "Combinatorial chemists are rare commodities indeed. So what I look for is, first, good skills in synthetic organic chemistry. Beyond that, recruits have to have an interest in doing combinatorial chemistry, and maybe an aptitude for using automation" (Gwynne 1999:2). 
and leverage the tools we find promising. So at Lilly, we make sure flexibility in adopting technologies such as combinatorial chemistry is rewarded" (Brown 1996:2).

\section{Table 5.3}

Mergers and acquisitions (1991-2001)

\begin{tabular}{|c|c|c|c|c|c|}
\hline Acquiring Firm & & Target Firm & & Year & Cost (1) \\
\hline Chiron & US & Coselco Mimotopes & AUS & 1991 & 3.3 \\
\hline Eli Lilly & US & Sphinx Pharmaceuticals & US & 1994 & 76 \\
\hline Glaxo & GB & Affymax & US & 1995 & 539 \\
\hline Marion Merrell Dow & US & Selectide & US & 1995 & 58 \\
\hline Genzyme & US & PharmaGenics & US & 1997 & 112 \\
\hline Perkin-E llmer & US & Perspective Biosystems & US & 1998 & 360 \\
\hline Pharmacia \& Upjohn & US & Sugen & US & 1998 & 650 \\
\hline Merck & US & CN Biosciences & US & 1998 & 150 \\
\hline Warner-Lambert & US & Agouron Pharmaceuticals & US & 1999 & 2.100 \\
\hline Dupont & US & Combichem & US & 1999 & 95 \\
\hline Merck & US & Sibia NeuroSciences & US & 1999 & 87 \\
\hline Celltech Chiroscience & GB & Medeva 82 & GB & 1999 & 915 \\
\hline Ascot & GB & ChiroTech & GB & 1999 & 87 \\
\hline Sigma-Aldrich & US & Genosys Biotechnologies & US & 1999 & 39.5 \\
\hline Millennium & US & Leukosite & US & 1999 & 600 \\
\hline Millennium & US & Cambridge Discovery Chemistry & GB & 2000 & 50 \\
\hline Amgen & US & Kinetix & US & 2000 & 170 \\
\hline Johnson Matthey & GB & Pharm-Eco Lab & US & 2001 & 70 \\
\hline Celera Genomics & US & Axys Pharmaceuticals & US & 2001 & 174 \\
\hline Merck & US & Rosetta Inpharmatics 83 & US & 2001 & 620 \\
\hline
\end{tabular}

(1) In million US dollars

Source: Compiled by author

This policy, however, did not prevent Eli Lilly from acquiring Sphinx Pharmaceuticals for \$US 76 million in 1994. Table 5.3 shows other cases of acquisition by large pharmaceutical companies (e.g. Merck, Marion Merrell Dow, etc.), large chemical firms (Dupont), large biotechnology companies (e.g. Amgen, Genzyme) and large-cap genomic players (e.g. Millennium, Celera Genomics). The total value of these acquisitions amounts to \$US 4.8 billion. To some extent this is the result of attempts to transfer tacit know-

82. Celltech Chiroscience, which only had 400 employees, gave Medeva shareholders 34 new Celltech Chiroscience shares for every 100 Medeva shares. This values Medeva at around $£ 563 \mathrm{~m}$ (\$US $915 \mathrm{~m}$ ) and produced a new company with a market capitalization of around $f 1.3 \mathrm{bn}$ (\$US 2.1bn), making it Britain's fourth largest pharmaceutical company.

83. Rosetta Inpharmatics is a genomic firm but acquired Acacia Biosciences in 1999. Acacia is a company conducting drug discovery utilizing recent advances in genome science and combinatorial chemistry. 
how in combinatorial chemistry, as in the cases of Coselco Mimotopes, Affymax, Selectide and Sphinx Pharmaceuticals, but the decision to buy a small company gets much more driven by the need to expand product portfolios and pipelines and reinforce strongholds in specific disease category as the technology is becoming more mature. For example, it is clear that Warnert-Lambert benefited from Agouron's expertise in structure-based drug design, though the acquisition of Agouron Pharmaceuticals primarily aimed at expanding the presence of the pharmaceutical giant in the AIDS, anti-virals and oncology sub-markets. But this strategy carries an important risk, since that there can be no assurance that the acquired firm will actually deliver on its scientific, technological and commercial promise. It is simply not possible, ex ante, to know the outcome of a firm's drug research efforts.

In addition, the best scientists are inherently mobile and, in spite of confidentiality agreements, may leave with crucial know-how, trade secrets or other proprietary information. The impact can be detrimental to the firm's performance. Hence large pharmaceutical companies must go at great lengths to preserve the incentive structure necessary to keep the best scientists on board. Nothing illustrates more clearly these efforts than the acquisition of Agouron Pharmaceuticals by Warnert-Lambert. The latter increased almost immediately the R\&D budget on Agouron's lead project, and both the commercial and $R \& D$ units were left independent from Warner-Lambert's groups. In addition, only Agouron's two top managers reported to the parent company, and Agouron Pharmaceuticals even kept its name in the hope that its best scientists stay with the firm (Copeland 2001).

That remains to be seen, for the number of key scientists who leaves targeted firms can be considerable. Although the question is beyond the scope of this thesis, it is perhaps not without significance that Xiao-Yi Xiao, director of research chemistry at ChemRx, was a staff scientist at Affymax from 1993 to 1995; Ronald Barrett, Mark Gallop and Bill Dower, also exemployees of Affymax, founded XenoPort in 1999; Michal Lebl, senior director of automation at Illumina, was formerly of Selectide; Peter Myers, previously chief scientific officer of CombiChem, is now chief executive officer at Libraria; Barry A. Bunin, Libraria's founder and chief executive officer, was formerly a senior scientist at Axys Pharmaceuticals; Tim Powers, who serves as Libraria's director of discovery chemistry, was a scientist at Sphinx before its acquisition by Lilly, etc.

\subsection{DYNAMIC COMPLEMENTARITIES BETWEEN NEW ENTRANTS AND LARGE PHARMACEUTICAL FIRMS}

From the point of view of new entrants, the bad news contained in section 5.2 is that large pharmaceutical firms have been able $\mathbf{b}$ rapidly learn the combinatorial synthesis methods. Other troublesome aspects can be inferred 
from their material advantage. The frst material advantage concerns scale economies. Examining the relationships between firm size and productivity in R\&D in the pharmaceutical industry, Comanor (1965) and Grabowski (1976) found that for smaller firms economies of scale exist while large firms display diseconomies of scale. On the other hand, Schwartzman (1976), Vernon and Gusen (1974), Grabowski and Vernon (1994), DiMasi et al. (1995), Simmons (1995) and Sornette (2000) argue in different ways that larger firms are more productive in pharmaceutical research than smaller competitors. While these studies do not address the use of combinatorial chemistry per se, it should be noted that larger players may be able to spread the fixed costs of chemoinformatics software and databases, robotic systems, synthesizers and so on over more $R \& D$ projects and a larger customer's base than smaller companies. Likewise, large companies can benefit from their large historical collections of compounds and combinatorial libraries, whose costs are partially fixed and can be screened in a number of current and future research programs for a less-than-proportionate increase in costs. Finally, large pharmaceutical companies can support the establishment of one or even several large R\&D laboratories and are better positioned to benefit from the ability to support more specialized personnel. In particular, a large firm could take advantage of its deep-seated expertise in chemistry as well as in x-crystallography, NMR and structural biology, enabling it to venture deeper into the analysis of protein structures. In terms of appropriation, this ability is important because large pharmaceutical companies can bypass the use of government grants and hence are not required to deposit structural data into public databases, as for example the Protein Data Bank. Thus, large firms can keep important know-why as trade secret, allowing them to erect isolating mechanisms around important therapeutic categories.

A second advantage concerns the ability of large companies to achieve scope economies. Following Henderson and Cockburn (1996) and Cockburn and Henderson (2001), large pharmaceutical firms can benefit from economies of scope in both drug discovery and development. ${ }^{84}$ Specifically, larger companies, which can afford running simultaneously more research programs than smaller firms, can benefit from their greater access to target receptors, given than scope economies may occur in screening operations when many targets are considered in parallel rather than in linear target-by-target fashion. More importantly, data, information and knowledge stemming from combinatorial projects can be stored into flexible, accessible and expandable chemical data systems, all of which can

84. The fact that a broader knowledge base can speed up the innovative process must also be underscored. For example, Bierly and Chakrabarti (1996a), in their study of organizational learning in the pharmaceutical industry, revealed that firms with a broader knowledge base took less time to use a new technology in a manner that is beneficial to the firm, after the technology is initially developed. 
guide synthesis in future and/or related projects. Since all major drug companies have enormous and cumulative databases that relate chemical structure to receptor activity (Spencer 1998), and since knowledge created in one research program can be reused in a different, yet related, program, it may be assumed that these companies have an advantage in reaping the benefits of scope economies. It might also be conjectured that large pharmaceutical companies can benefit from internal knowledge spillovers due to their investments in a larger number of research programs. This is clearly happening when serendipitous results are exploited in related therapeutic areas, as the example of the antimigraine compound Y334370 illustrates. Acting on a hunch, scientists working on antidepressant drugs at Eli Lilly hypothesized that migraines were linked to particular serotonin receptors protein docking ports on nerve cells that accommodate the brain chemical serotonin. This hypothesis led them to (1) screen a huge library of Prozac-era drug candidates, (2) identify a series of drug candidates, (3) optimize the most promising ones and (4) select Y334370. Y334370 made the pre-clinical journey in a mere two years, half the usual time, and may become the first ever drug discovered via combinatorial means (Moukheiber 1998).

A third advantage lies in the ability of large companies to spread risk over a larger portfolio of projects, providing them with a larger margin for error than new entrants. For instance, Chiron, a biotechnology company with 3,700 employees and a strong presence in combinatorial chemistry, recently announced that a drug designed to treat the blood infection syndrome sepsis proved ineffective in a clinical trial, sending its stock down more than 8 percent. Despite this downturn, analysts expect Chiron to post solid earnings growth in coming years due to its sales of therapeutic drugs, vaccines, blood tests and other products.

A final advantage deals with complementary assets. With 10 new entrants having in-house manufacturing capability and 8 firms an adequate sales force, full-fledged companies made up less than 3 percent of total companies. One important implication is that most entrants depend on large pharmaceutical companies for the commercialization of their products. Another one is that large pharmaceutical companies can create value through learning by using and learning by doing and prevent knowledge spillovers from leaking to competitors.

The goods news for new entrants is that large pharmaceutical firms face considerable challenges preventing them from being truly independent. To begin, big pharma is losing patent protection on its best-selling products, exposing it to generic competition. According to The Economist (2002), major drug companies will be hit with \$US 6 billion in patent expiration in 2003, up from \$US 2.8 billion in 2002. Perhaps just as alarming, the costs of introducing a new drug to market grew from \$US 259 million in the 1970 - 
1982 period (Di Masi et al. 1991) to \$US 480 million in the 1990-1994 period (Grabowski et al. 2002). ${ }^{85}$ These problems are compounded by an innovation deficit. Large pharmaceutical companies had only commercialized, on average, 0.45 new molecular entities per year during 1990 and 1994, of which only 8 percent became blockbusters per se (i.e. sales of greater $\$ 350$ million/year). Yet, for the pace of growth to continue, these companies have to launch at least 5 blockbusters per year (Andersen Consulting 1998).

\section{Formal interorganizational agreements between large incumbents and new entrants}

Owing to the culmination of these challenges, and because large pharmaceutical firms may certainly master many but certainly not all technological fields and therapeutic classes, the proportion of NCE approvals that were self-originated, as opposed to licensed-in, has declined from 71.6 percent in the sixties to 60.9 percent in the nineties (DiMasi 2000). Large firms would also outsource 10 to 40 percent of their research investment (Andersen Consulting 1998). While the trend towards formal interorganizational agreements with new entrants seems to be abating since 1999, the contract revenues of these entrants increased from \$US 9.5 million in 1996 to about \$US 15 million in 2001.

Clearly, the relationship between new entrants and large incumbents has been in a constant flux. In the first phase of industrial development, which can be seen as a monitoring phase, large firms had been mainly interested in testing the early combinatorial synthesis methods and replenishing their laboratories with combinatorial compounds. This is reflected in the fact that equity stakes were relatively more important prior to 1996 . Thus, equity participation was used in 19.1 percent (138 times) of all partnership agreements in the period 1984-1995, as compared to 9.6 percent (142 times) between 1996 and 2001 (see table 5.4). Often, enough equity is purchased to get a seat on the board of directors, which provides the investing firm with a window on technologies at relatively low costs (Kenney 1986). Explaining why large pharmaceutical companies take equity positions in new entrants, Barry Ross, CEO and scientific director of Affymax says: "It's not necessarily to get a financial return. It's also a mean of getting a technology return. And it's technology return that drives the pharma corporate strategy. If there is a financial return through an equity holding, that's all very well. But I don't think that has ever driven the relationships" (Arthur D. Little 2001: 7).

85. The rising costs of $R \& D$ in this industry have been associated with the increasing difficulty in recruiting patients into clinical trials and the increased focus on developing drugs to treat chronic and degenerative diseases, rather than acute diseases. 
At the same time, $R \& D$ contracts accounted for 23.2 percent (168 times) of all agreements in the period 1984-1995, as compared to 20.5 percent (302 times) between 1996 and 2001. This relative decline is a perhaps a demonstration that large pharmaceutical companies initially perceived the early methods to be a risky investment. As few drug companies wanted to make irreversible investments in combinatorial chemistry in its early, uncertain days, outsourcing a combinatorial library provided a safe and inexpensive way to assess the new technology.

\section{Table 5.4}

Formal network

Increase in number of alliances between large incumbents and new entrants -by mode of cooperation (absolute number and percentage of total)

\begin{tabular}{lccc}
\hline Mode of Cooperation & $1984-1995$ & $1996-2001$ & TOTAL \\
\hline R\&D contract & $168(35.7)$ & $302(64.2)$ & $470(100)$ \\
& $(23.2)$ & $(20.5)$ & $(21.4)$ \\
Licensing & $255(31.0)$ & $565(68.9)$ & $820(100)$ \\
& $(35.3)$ & $(38.3)$ & $(37.3)$ \\
Equity Participation & $138(49.2)$ & $142(50.7)$ & $280(100)$ \\
& $(19.1)$ & $(9.6)$ & $(12.7)$ \\
Manufacturing, Distribution & $35(37.6)$ & $58(62.3)$ & $93(100)$ \\
and Marketing & $(4.8)$ & $(3.9)$ & $(4.2)$ \\
Joint R\&D & $110(35.7)$ & $376(77.3)$ & $486(100)$ \\
& $(15.2)$ & $(25.5)$ & $(22.1)$ \\
Joint Venture & $16(35.5)$ & $29(64.4)$ & $45(100)$ \\
& $(2.2)$ & $(1.9)$ & $(2.0)$ \\
\hline TOTAL & $722(32.9)$ & $1472(67.0)$ & $2194(100)$ \\
& $(100)$ & $(100)$ & $(100)$ \\
\hline Sol & \multicolumn{3}{c}{}
\end{tabular}

Source: Compiled by author

In the second phase of industrial development, large drug makers generally became much more concerned about outsourcing services along the drug discovery value chain. First on the list come targeted and focused libraries, as illustrated by the 2001 joint $R \& D$ agreement signed between Merck and ChemBridge to design and produce pharmacophore-based libraries. Second on the list comes the creation of new leads against specific targets. One agreement signed in 2001 between Array BioPharma and Takeda Chemical Industries exemplifies this: the new entrant will create a series of small molecule drug lead compound against a proprietary Takeda target. Third on the list comes the optimization of already identified leads for particular targets. For example, ArQule entered into a five-year collaboration and license agreement in 2000 to identify, optimize and deliver drug candidates for SmithKline Beecham's drug discovery programs. ArQule will optimize a lead compound provided by SmithKline Beecham and another one identified from its own combinatorial library. As shown in 
table 5.4, these joint R\&D agreements grew from 110 (15.2 percent of total) to 376 ( 25.5 percent) over the 1984-1995 and 1996-2001 periods.

As many combinatorial chemistry companies transform themselves into fully-integrated drug discovery companies, it is also clear that complementary assets became increasingly important in the second phase of industrial development, prompting an increase in the number of licensing agreements. Licensing deals occurred 255 times in 35 percent of all cooperative agreements prior to 1996, but they occur 565 times in 38 percent of total agreement in 1996 henceforward. The importance of licensing agreements may be seen as a sign of a high barrier to vertical integration. On the one hand, large incumbents need to find the drug candidate that will make them profitable, but have all the complementary assets necessary to bring them to market. On the other hand, smaller firms are getting richer in chemical-based innovations but often lack the cash flow and complementary assets necessary to commercialize their products. Therefore, there can be little doubt that those that do not own these assets are willing to broker knowledge and a share in future profits in exchange for their access. For example, Centocor, a wholly owned subsidiary of Johnson \& Johnson, acquired worldwide rights to the orally active direct thrombin inhibitor program of 3-Dimensional Pharmaceuticals. While fully integrated Johnson \& Johnson needs new therapeutic products, 3-Dimensional Pharmaceuticals, a structured-based company, is highly innovative but needs financing and possesses no manufacturing and marketing expertise.

Joint venture is another mode of collaboration that gained some grounds over the years, from 16 joint ventures in the period 1984-1995 to 29 between 1996 and 2001 . That 23 joint ventures had been formed between companies of different countries is not surprising. International collaborations are often stimulated by the fact that domestic-based firms are confronted with higher barriers to entry (i.e. the regulatory procedures, prospective customers, etc.) in foreign markets than foreign-based firms (Pisano et al. 1988). One example will suffice: Texas-based BioNumerik Pharmaceuticals formed KI Pharmaceutical, a joint venture with Japan-based Grelan Pharmaceutical. The joint venture focuses on developing new anticancer compounds for the Japanese marketplace. KI Pharmaceutical marries Grelan's Japanese development and marketing expertise with BioNumerik's mechanism-based approach to drug discovery.

Formal interorganizational agreements between large incumbents and scientific organizations

It is should finally be noted, however, that large incumbents do not solely learn from new entrants. Industry-university collaboration has a long history in the pharmaceutical industry (Swann 1988) and remains an important 
strategy among the major players. Rhône-Poulenc Rorer, now part of Aventis, is a case in point. In 1997, the company signed two mega-deals with Cambridge University/Imperial College of Science, Technology and Medicine in Great Britain and Stanford University in the United States. The first agreement, worth 4 million pounds and spread over three years, allows corporate scientists at Rhône-Poulenc Rorer, to interact with academic specialists from the disciplines of computer assisted drug design and combinatorial chemistry. The first group of specialists, led by Dr. Dean at Cambridge University, has to create a series of virtual drugs, which the second group, led by Professor Barrett at Imperial College, would turn into actual compounds by combinatorial means.

The second agreement, potentially worth US\$ 5 million, is one of Stanford University's largest sponsored research awards. Rhône-Poulenc Rorer's research agreement concentrates on the firm's core therapeutic areas of cancer, cardiovascular disease and central nervous system disorders and involves drug discovery programs such as functional genomics, combinatorial chemistry and high throughput screening. Research grants, for US\$ 250,000 each, are being given to Stanford's scientists, and RhônePoulenc Rorer would receive, at its option, either an exclusive or nonexclusive license to the technology. Aventis, Amersham Pharmacia Biotech, AstraZeneca, GlaxoSmithKline, Eli Lilly, Nycomed Amersham, Organon Laboratories, Pfizer and Roche Discovery are another case in point. These firms invested more than 2.5 million pounds into a research consortium developed by Professor Mark Bradley at the University of Southampton. Professor Bradley provides strong clues as to why these firms signed this collaborative deal with his organization: "Pharmaceutical companies want to have large libraries of compounds, but they don't have the time to develop the new tools necessary to make them. At Southampton we will be developing the methodology to make the compounds and the industrial partners will have royalty-free licenses to them" (New Reporter 2000).

\subsection{GlaxoSmithKline: A Case Study of Competence Building in COMBINATORIAL CHEMISTRY}

To see in greater detail how large pharmaceutical companies have been able to use their absorptive capacity to acquire their competence in combinatorial chemistry and why they still need new entrants to fill their innovation gap, let us look at the example of GlaxoSmithKline. GlaxoSmithKline is the international giant resulting from the merger of GlaxoWellcome and SmithKline Beecham in 2000, and combine sales of approximately $\$ 24.9$ billion and an estimated 7.3 percent share of the global pharmaceutical market. GlaxoSmithKline's commitment in combinatorial chemistry is often associated with the purchase of the Affymax by 
GlaxoWellcome. This acquisition remains, without doubt, the cornerstone of the firms's strategy in the field.

Naturally, the story of Affymax invites comparison with the experience of Genentech, the first firm dedicated to genetic engineering. Both firms are the brainchild of a "visionary" entrepreneur in the Schumpeterian tradition: Dr. Alejandro Zaffaroni set up Affymax in 1988, whereas Robert A. Swanson established Genentech in $1976 .{ }^{86}$ Like Genentech whose stock offering set off a buying frenzy, Affymax made the headlines when it went public, raising 92 million in December 1991 -the fourth largest in the life science sector (Ernst \& Young 1995). Both firms are located in California. Both firms also fetched high price when they were acquired by a large incumbent: Hoffman LaRoche purchased Genentech for \$US 2.1 billion in 1990 while GlaxoWellcome paid \$US 539 million for Affymax in 1995.

Above all, both frms had served as a useful knowledge intermediary between the large incumbent and the scientific community. As figure 5.3 demonstrates, Affymax was well positioned to capture external knowledge and external knowledge spillovers in the network of innovators, having established a series of formal, non-market linkages with firms, small or large, and scientific organizations in both the United States and Europe. To quote Dr Ringold, the chief executive officer and scientific director at Affymax: "We can serve as GlaxoWellcome's eyes and ears to California's academic and biotech community and provide the company with a technology magnet that attracts people with interesting ideas to us" (Annual Report of GlaxoWellcome 1997). For example, Affymax was able to absorb the catalytic antibody technology of University of California, Berkeley by striking a joint $R \& D$ agreement with this scientific organization. Another example is a license granted to the firm by Dyax about a patented phage display technology (i.e. otherwise known as combinatorial biology).

But there the similarity between Affymax and Genentech ends. Hoffman LaRoche had grown from the science base of chemistry but had no strong competence in biology. As a result, the Swiss firm simply could not mobilize the molecular biologists necessary to learn the skills of Genentech. While the transfer of knowledge from Affymax to GlaxoWellcome was by no means free, the British giant was able to rapidly absorb the unique Affymax approach to drug discovery by sending its chemists to Palo Alto for training sessions. A scientist from GlaxoWellcome in Verona in Italy spent some time at Affymax making libraries against anti-bacterial agents while another from a division in Madrid visited the facilities in order to make compounds for antifungal screening. The training program was repeated on a larger scale with

86. Dr. Zaffaroni is perhaps the most well known entrepreneur in the life sciences business, having launched in his long career 11 entrepreneurial companies, including as Syntex, Alza, Affymetrix, Symyx and Maxigen. All but one is still in business (The Economist 1999a). 


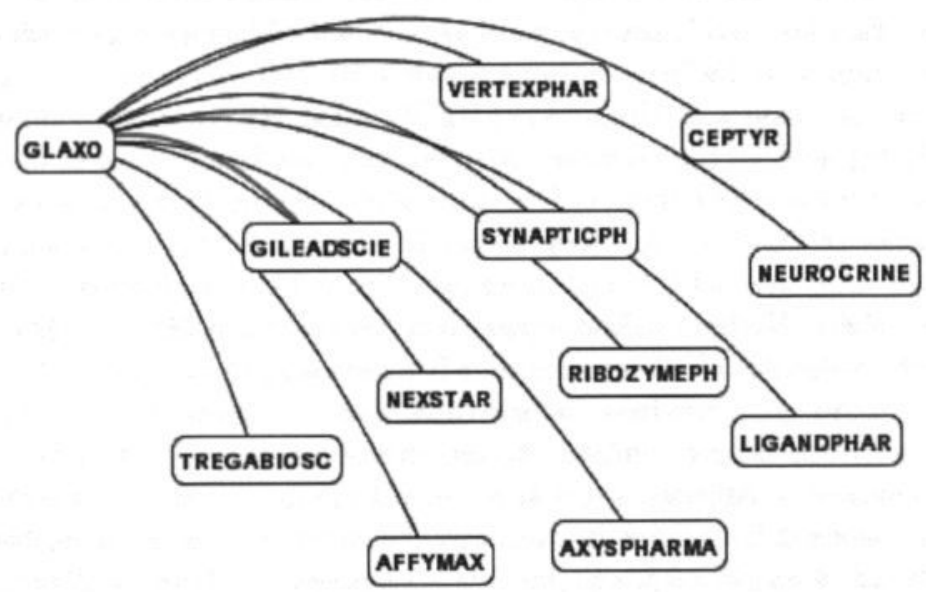

Figure 5.2

Strategic alliance network Glaxo (1992-1995)

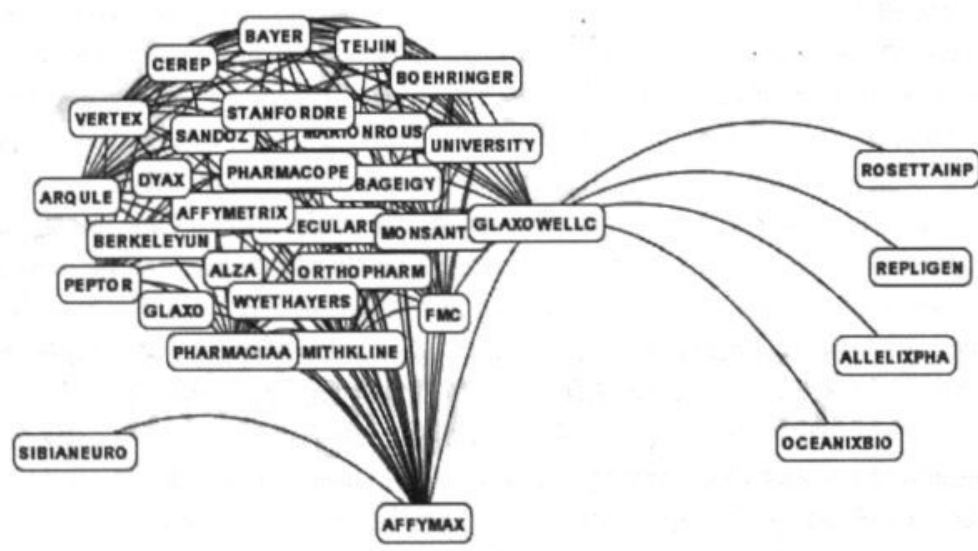

\section{Figure 5.3}

Strategic alliance network GlaxoWellcome (1995-2000)

Mapping: Centre for Global Corporate Positioning (www.cgcp,nl) 
scientists at GlaxoWellcome's research center at Stevenage in Great Britain, where 90 percent of its 400 chemists could use some form of parallel synthesis in their R\&D endeavors by the end of the nineties. Efforts were also made to teach these scientists how to make the technology relevant to their particular needs, since much of the accumulated know-how at Affymax was specific in the context of its use. The words of the president and scientific director of Affymax deserve to be cited at great length:

An important aspect of the GlaxoWellcome acquisition is the transfer of Affymax technology to the rest of the company. In a formal program technology transfer, five scientists from GlaxoWellcome in the UK have spent several months at Affymax to learn the techniques of combinatorial chemistry. The scientists' agenda included learning how to build and dismantle the equipment, proving they could use it effectively. By building their own equipment we're convinced that they'll be able to trouble-shoot any problems that arise if it breaks down at their base [...] An additional advantage is that by fully understanding the equipment they will also be able to adapt it to meet their own needs (Annual Report of GlaxoWellcome 1997).

Another demarcating point between Affymax and Genentech is the sell out of the former by GlaxoWellcome. With GlaxoWellcome having established combinatorial techniques across its laboratories around the world, Affymax has stopped to be a key asset in the pharma company's portfolio. As a result, GlaxoSmithKline sold Affymax to a venture syndicate led by Patricof \& Co. for \$US 51 million in the summer of 2001, and planned to invest the resultant savings in the next innovative steps it intends to take. Meanwhile, Affymax had transformed itself from a combinatorial chemistry firm to a drug discovery company, and is now set to develop medicine independently.

In retrospect, it is almost certain that this strategic move paid off. Between 1995 and 1997, the firm witnessed a ten-fold increase in the number of compounds available for bioassay and a 100 -fold increase in its screening capacity. GlaxoWellcome had made 350,000 molecular entities before combinatorial chemistry was brought into the picture; now, it can easily make that number in a year. In fact, the company had synthesized 81 libraries between 1992 and 2000, and claims it has doubled its drug discovery success rate from 10 to $20-25$ percent. In addition, more than 50 percent of drug leads discovered in 2000 came from combinatorial endeavors -more than twice as many as in 1999 (Borman 2001). Set apart the two leads displayed in table 5.1, GlaxoSmithKline has at least 4 combinatorial drugs in the pipeline: 
- GW405212, a molecule useful in the treatment of dysmenorrhoea and premature labor, was recently discovered by combinatorial means. A team of researchers needed only two scientist weeks for identifying the potency of GW405212, which would have taken 1500 scientists weeks to discover the same compound via traditional methods.

- Having tailored its screening assay for detecting molecules with antimycobacterial activity, the company was also able to screen 17 libraries and capable of identifying several active compounds for further testing. Initial screening of a large combinatorial library against a TB target led to the selection of a molecule that may have potential against obesity.

- GW409890, the molecules' appellation, is already been sent for pharmacokinetics, a process that took 40 chemist and 4 biologist weeks as compared to 600 chemist weeks, half the previous required time.

- The stomach bacterium Helicobacter pylori has been targeted against 500,000 entities, yielding a ranitidine bismuth citrate, which is about to be commercialized for use with an antibiotic to eradicate the bacterium.

It is interesting to note, however, that external learning at Glaxo did not start with Affymax's acquisition. Indeed, the pharmaceutical company did not "jump" on the combinatorial bandwagon right away. Instead, Glaxo signed a series of partnership deals with new entrants as a way to assess the potentials of both combinatorial chemistry and the firms that had been using it (see figure 5.2). The first one, a joint research and development partnership deal involving patented peptide screening technology, was signed with Trega Biosciences in 1992. In 1993, GlaxoWellcome also lured Mario Geysen, the co-inventor of the first parallel synthesis method, away from Coselco Mimotopes, appointing him drug discovery chief of the Diversity Science Department at their North Carolina facility in the United States.

Nor did Glaxo's experience with combinatorial chemistry and relations with new entrants end with Affymax's purchase. As David Langley, compound acquisition manager at Glaxo Wellcome R\&D in Great Britain, puts it: "The simple fact is that none of us have all the answers on our shelves. We've got to go outside looking for compounds. These companies won't all survive -there must be a finite limit to how many deals are out there. But I don't see any immediate rationalizing. For the next five years at least, there is scope for most of the compound suppliers and library companies" (Boswell 2000). In fact, the firm had synthesized in-house 80 percent of its compounds, but its chemical diversity remains limited. A 
significant portion of its collection, judged inappropriate for screening, was even eliminated. Hence GlaxoSmithKline elected to tap the newly accessible universities and research organizations of Hungary and Russia. By one count, 6,000 chemists in the former Soviet Union are active in the business of synthesizing drug-like compounds for screening, which are sold for just \$US 10 to \$US 50 for 10 to 20 milligrams. These hand-made compounds, which are produced by conventional means, offer much greater chemical diversity than those synthesized by GlaxoSmithKline through combinatorial chemistry, which offer greater potential for lead development (Boswell 2000). Glaxo Wellcome R\&D would also continue to outsource part of the " $R$ " side of $R \& D$, as figure 5.3 demonstrates. For example, the company and Repligen have been collaborating on evaluating the potential of blocking the action of certain proteins by interfering with their binding to carbohydrates on the cell surface.

\subsection{THE ENTRY OF LARGE (AGRO)CHEMICAL FIRMS}

Large agrochemical and chemical companies are also entering a new technological era that holds great promise. However, these firms have mirrored large pharmaceutical companies in being cautious with their efforts to develop in-house competences in combinatorial chemistry. As in the case of pharmaceuticals, doubts about the economic viability and technological feasibility of combinatorial innovations in new materials and other markets persisted. As remarked by Klaus Kulien, director/operative research for Aventis: "When we started out this collaboration [with Symyx] I was skeptical. Now I'm convinced that combinatorial chemistry will have quite an important impact on the improvement of catalysts as well as on the discovery of new catalysts" (Fairley 1999). Scientists were also reluctant to switch to the new technology. "They can't understand the need for change", says Daniel Bellus, chairman of Ciba's research board (Wood 2000).

The potentials for productivity growth, being too important too ignored, became nonetheless a powerful incentive to invest in combinatorial materials. Technological and commercial opportunities in the field are far from being trivial. Thanks to combinatorial chemistry, large chemical companies expect to screen 700 compounds a week in 2003, as compared to 10 or 12 in the mid-nineties. In fact, combinatorial chemistry already yields substantial time and cost savings in the search for new or improved polymers, catalysts, etc. Using this process, Dow's Combinatorial Chemistry Lab has increased its research capabilities from just 8-16 experiments per day to 192 (PR newswire 2001b), and Shell said its investment in the field led to an increase in the development of new catalysts from 3 in 1994 to 10 in 1999 (Wood 2000). The need to pre-empt rivals and the fear of being left behind the technological race therefore may have something to do with the 
current spending frenzy in the field. According to a recent study from Business Communication Co. (2001), the chemical industry spent $\$$ US 230 million on combinatorial chemistry in 2000. Rising at at an annual rate of 10.2 percent, these expenditures are expected to reach \$US 374 million in 2005.

Bayer reportedly spent close to \$US 30 million into combichem, with particular emphasis on catalysts. Ciba (now Novartis) spent about \$US 5 to $\$ 7$ million in 2000, and intended to increase this amount more than 20 percent percent/year in the future (Wood 2000). As argued by Clyde Payn, $\mathrm{CEO}$ of the Catalyst group: "As long as two competing companies have combinatorial chemistry they will bounce each other off. But if only one parry of a given technology domain invests and the other doesn't then it is likely [the former] will end up capturing market share" (Chemical Week 2000b: 52).

The use of combinatorial chemistry in new materials does not come cheap, however. By and large, investments in the order of \$US 10-20 million are required in order to achieve interesting results (Ibid 2000b). In addition, assembling the necessary manpower is more complex than pharmaceuticals, involving expertise in robotics, data management, engineering and analytical chemistry ${ }^{87}$ In spite of this, Hoechsts, BASF, Dow, Dupont, General Electric, Ciba Geiby, Rhodia, UOP, British Petroleum, W.R. Grace, DSM, Rohm and Haas, Shell and others have all been busy building competences in the field. But how? Dupont choose to buy Combichem for \$US 95 million in 1999. Others preferred to go with universities for reasons of appropriability. For example, UOP, headquartered in Illinois, judged the new field too important for collaboration with new entrants and chose instead to develop its own technology with the help of scientific organizations. Thus, the company announced a joint $R \& D$ agreement with the research foundation Sintef in Norway to use combinatorial chemistry in the development of zeolites (Fairley 1999). In 2002, UOP also formed a wholly owned subsidiary, named Tonal, which develops and provides combinatorial chemistry tools and services for the materials-oriented industries (Chemical Market Reporter 2002).

Given the generic nature of chemical compounds, it should hardly be surprising that agrochemicals hitherto ranks second only to pharmaceuticals among combinatorial applications (see table 5.5). Indeed, large agrochemical companies like Monsanto, Dow Chemical, DuPont and Novartis have been routinely outsourcing combinatorial libraries ever since Monsanto signed an

87. The same common language is necessary to communicate in the field. As pointed out by James M. Meyer, vice-president of Dupont Central Research and Development: "We look for people who have fundamental skills, but we don't expect that they're going to spend their whole career in the discipline they got their degree in or did their research in graduate schools (Henry 2000:74). 
R\&D contract with Cubist Pharmaceuticals in 1995. The 1999 collaborative agreement between Novartis CropProtection and Pharmacopeia better exemplifies this trend. Under the terms of this collaboration, Pharmacopeia uses its patented ECLIPS technology to provide collections of small molecule compounds for screening by Novartis CropProtection, the world's leading supplier of crop protection products. Pharmacopeia receives payments for each library provided and is entitled to milestone and royalty payments as compounds progress through development and commercialization.

\section{Table 5.5}

Top 10 large (agro)chemical firms for number of alliances (1995-2001)

\begin{tabular}{|c|c|c|c|}
\hline Firm & $\begin{array}{c}\text { Countr } \\
y\end{array}$ & $\begin{array}{c}\text { Alliance } \\
s\end{array}$ & Applications \\
\hline Novartis & $\mathrm{CH}$ & 8 & $\begin{array}{l}\text { Agrochemicals and process development } \\
\text { for additives }\end{array}$ \\
\hline Dow & US & 4 & $\begin{array}{l}\text { Agrochemicals, polyolefins and } \\
\text { pharmaceutical intermediates }\end{array}$ \\
\hline Dupont & US & 4 & Agrochemicals \\
\hline Aventis & FR/DE & 3 & $\begin{array}{l}\text { Agrochemicals and instrument for catalyst } \\
\text { research }\end{array}$ \\
\hline BASF & $\mathrm{DE}$ & 3 & $\begin{array}{l}\text { Catalysts research and instrument for } \\
\text { catalyst research }\end{array}$ \\
\hline Bayer & $\mathrm{DE}$ & 3 & $\begin{array}{l}\text { Catalysts, polymers and electronics } \\
\text { materials }\end{array}$ \\
\hline Celanese & $\mathrm{DE}$ & 3 & Catalysts \\
\hline Monsanto & US & 3 & Agrochemicals \\
\hline Degussa & DE & 3 & Catalysts \\
\hline AstraZeneca & GB & 2 & Agrochemicals \\
\hline
\end{tabular}

Source: Compiled by author

The first large chemical company to test the water in combinatorial catalysts was Germany's Hoechsts, which backed Symyx with a $\$ 43$ million joint R\&D contract in 1997. According to Arthur D. Little, demands for better catalysts in the polymer, specialty chemical and environmental markets are driving growth by 5 percent/year in the $\$$ US 10 billion/year global catalyst market (Caruana 2000). Accordingly, the largest market to be tapped apart from pharmaceuticals is expected to be in this area, and large chemical companies are increasingly striving to learn the technological know-how of new entrants for a head start in the combinatorial race. The collaborative agreement between DSM and Cambridge Combinatorial, which combines DSM's expertise in catalysis, materials and process development with Cambridge Combinatorial's extensive know-how in the area of automation, combinatorial chemistry and software development, is a 
case in point (Chemical Reporter 1998).

The majority, however, turned to "pure" combinatorial material start-up companies (e.g. Symyx, HTE, Avantium) and multiple platform companies (e.g. Discovery Partners, Pharmacopeia) for technological know-how and scientific instrumentation. As pointed out by Klaus Kuhlien from Aventis: "At the moment I don't see that we have the capabilities, personnel, or money to do it all our own" (Fairley 1998). In total, 85 alliances have been formed with these start-ups, with agrochemicals accounting for 25 alliances, catalysts (13), polymers (11), instruments (9) and phosphors (4). In addition, 8 equity stakes have been taken by large chemical companies, chiefly as a means to monitor developments in this fast-changing technology. For example, BASF took equity stakes into Chemspeed, a global leader in the field of parallel reactors, which play an important part in combinatorial materials research. BASF is also entitled to nominate a member of Chempeed's Board of Directors.

\subsection{CONCLUDING REMARKS}

All things considered, and contrary to the predictions of the TushmanAnderson model (1986), it is possible that the most favorable population for industrial innovations has been achieved: new entrants with a behavioral advantage living side by side with a few pharmaceutical giants with a material advantage. Indeed, most of the evidence presented in this chapter suggests that both types of organization enjoy a number of complementary relationships in their innovative activities. Compound-poor large companies provide money and/or complementary assets, whereas cash-poor new entrants full of imaginative ideas provide chemical-based services and products, most notably small molecule drugs. This crucially provides large pharmaceutical firms with a means to fill their innovation gaps, and new chemical-based entrants with a means to generate the necessary cash flow to carry out further research activities, to survive in an environment characterized by fast technological change, changing demand and stiff competition. In fact, given that only 7 new entrants went out of business and only 25 were bought up by large incumbents, the majority of new entrants continue to exist independently. In summary, the introduction of combinatorial chemistry has been fostering a new type of relationship between new entrants and large incumbents, altering the structures of the pharmaceutical industry in the process. One may therefore have a situation where big pharma and new entrants collaborate in a complementary relationship, instead of incumbents displacing entrants. 


\section{Combinatorial Chemistry and Scientific Organizations}

That the University can, actually and practically, forward the progress of industry is seen in the consideration of two facts. First, is the application of new knowledge. [Second, is] the furnishing of men.

Robert Kennedy Duncan, Professor of chemistry, Kansas University (1907)

\subsection{INTRODUCTION}

The dual objective of this chapter is to underscore the contribution of public research to industrial innovation and to solve the following puzzle. The first combinatorial synthesis methods appeared in a Hungarian University and a Dutch public research institute. The combinatorial research output of scientific organizations from the European Union (EU-15) compares well with that of US-based ones. The foundation of EU-15 entrants, on average, only lagged behind their US counterparts by a few months, as opposed to five years in the biotech sector (Saviotti et al. 1998).

Yet, despite these observations, the American entrepreneurial sector appears to be much healthier than elsewhere. US-based entrants remain preeminent in the field by all measures: (1) firm formation; (2) combinatorial library output; (3) compounds under pre-clinical stage; and 
(4) compounds under clinical stage. As previously mentioned, there are 285 US-based, 82 EU-15 and 55 non-US, non-EU-15 new entrants. Whereas US-based entrants held 218 combinatorial libraries and uncovered 659 compounds, of which 256 begun clinical testing, EU-15 firms and the rest of the world place a distant second and third with, respectively, 11 libraries and 191 compounds (i.e. 63 under clinical testing) and 4 libraries and 128 compounds (i.e. 22 under clinical testing).

The predominance and strengths of the US entrepreneurial sector probably owe to several different interrelated factors, including the existence of a sophisticated venture capital system, larger companies, etc. This chapter sets forth a narrower view focused on the relationships between scientific organizations and new entrants. It is divided into three sections. Section 6.2 describes the role of "public" research in combinatorial drug discovery and compares the position of American scientific organizations with the position of similar organizations in EU-15 and the rest of world in terms of library share. In section 6.3 the main question being asked is whether technology transfer from public organizations to the private sector plays an active role in enhancing the competitive standing of new entrants and competitive advantage of nations. Four technology transfer mechanisms are examined: formal networking (section 6.3.1); informal networking (6.3.2); university-based training (6.6.3); and the creation of entrepreneurial spin-offs (6.3.4). Section 6.4 concludes with a summary of the main findings.

\subsection{THE CONTRIBUtIONS OF SCIENTIFIC ORgaNIZATIONS TO COMBINATORIAL DRUG DISCOVERY}

A number of authors have testified in different ways to the positive influence of public and private, non-profit research endeavors on the creation of industrial innovations in the therapeutic drug market. Based on data obtained from top R\&D executives, Mansfield (1991) estimated that 27 percent of pharmaceutical firm's products and 29 percent of their new processes could not have been developed or would have been developed much later in the absence of recent academic research. Much in the same spirit, Maxwell and Eckardt (1990), in a study of 32 different drugs, suggested that 19 of them would not have been discovered or would have marketed with substantial delay without the contributions of scientific organizations. Also, as Gambardella (1992) has demonstrated by correlating company patents with scientific publications, pharmaceutical companies with better in-house scientific capabilities have been able to avail themselves more effectively of external science. Using data from the FDA, the NIH and the Pharmaceutical Research and Manufacturers Association, Toole (2000) calculated that a 1 percent increase in public basic research resulted in a 2.0 
percent to 2.4 percent increase in the number of commercially available drugs. Finally, McMillan et al. (2000) showed that 72 percent of scientific papers cited by the 2,334 patents of 220 US biotech companies originated solely at scientific organizations.

\section{Table 6.1}

Summary of lead compounds discovered by combinatorial means by scientific organizations (Dec. 1999- Jan. 2001)

\begin{tabular}{lccc}
\hline Scientific Organization & Country & Target & Library \\
\hline Scripps Research Institute & US & Poly [dA]-poly [dT] & Targeted* $^{*}$ \\
Max Planck, U. Mainz & DE & PKC & Targeted* $^{*}$ \\
Scripps Research Institute & US & Broad application & Targeted* $^{*}$ \\
Scripps Research Institute & US & Anti-infective & Targeted* $^{*}$ \\
UC -Berkeley & US & Anti-infective & Targeted* $^{*}$ \\
UC -Berkeley & US & Human sst & Targeted* $^{*}$ \\
U. Amsterdam & NL & BCRP & Targeted* $^{*}$ \\
Scripps Research Institute & US & HGH & Focused $^{* *}$ \\
UC -Berkeley & US & Sulfotransferase & Focused** $^{* *}$ \\
U. Pittsburgh & US & Cdc25 & Focused $^{* *}$ \\
Mayo Clinic & US & FT & Focused $^{* * *}$ \\
Yeshiva U., Jefferson U. & US & PTP1B & Focused \\
Texas U, Georgetown U & US & DAT & Focused \\
UC -San Francisco & US & HGXPRT & Focused \\
UC**
\end{tabular}

${ }^{*}$ Thematic libraries ${ }^{* *}$ Project-directed, knowledge-based or focused libraries ${ }^{* * *}$ Libraries using virtual synthesis and virtual screening in author's terminology

Source: Golebiowski et al. (2001)

Certainly, most would agree that scientific organizations are an important source of technological opportunities for new entrants, if only because the history of combinatorial chemistry is strewn with inventions made by scientists from universities, public and private non-profit organizations. Eötvös Lorand University, the Central Veterinary Institute, the Arizona Cancer Center, the Scripps Research Institute, the German National Research Center for Biotechnology and University of California, Berkeley provided the pharmaceutical industry's first combinatorial synthesis methods, thereby taking an important part in the growth of new entrants and large incumbents alike. Scientific organizations are also the source of many instruments (e.g. Carlsberg Laboratory), identification techniques (e.g. Scripps Research Institute) and computational methods (e.g. Pomona College), and their contributions to combinatorial material (e.g. Lawrence Berkeley National Laboratory) only begin to surface in the scientific literature. Above all, these scientific organizations remain the main locus of knowledge production in physiology, pharmacology, enzymology, cell biology and molecular biology -the absence of which would thwart the success of chemical experiments (Cockburn et al. 1999). Researchers at the 
US National Cancer Institute, for instance, have been isolating receptor targets since 1975, which may now be used to test lead compounds against 60 different human cancer cell lines -all major malignancies (Nature Biotechnology 2000). All these contributions enlarged the existing pool of knowledge about many diseases, providing insightful clues to firms as to what to search next and how to achieve their objectives.

The scientific literature also reported that scientific organizations were behind the isolation and identification of at least 14 leads compounds (table 6.1). More often than not, however, these leads have been identified by academic and private, non-profit research organizations that were generously sponsored by nonacademic organizations, primarily from industry and federal agencies. The financial support granted by the German pharmaceutical giant Bayer to the Max Planck Institute and the University of Mainz is a case in point. The grants and contracts given to the Scripps Research Institute by the National Institutes of Health, the American Cancer Society, the American Heart Association, the American Lung Association, the Juvenile Diabetes Association and Novartis Pharmaceuticals and many others is another one. Yet, if industrial sponsorship is removed from the equation, few scientific organizations have the ability to initiate a large, expensive and instrument-intensive pre-clinical research endeavor, given the full cost of lead discovery and lead optimization. Consequently, most of the leads and eventually drugs derived from combinatorial-based research will spring from industry. In the words of scientist-entrepreneur Richard Houghten:

To make 100,000 individual compounds and screen them in a high throughput array format is typically prohibitive for most academic organizations. If you need to look at 100,000 individual data points in triplicate, that will almost short-circuit academic organizations. They just can't get it (Borman 1998:7).

One relevant contribution is clear, however. While it is right in presupposing that universities and public research organizations do not possess the financial strength needed to steer a new pharmaceutical product through the entire drug discovery, development and clinical process, their expertise in solid phase and solution organic synthesis has become a resource upon which hundreds combinatorial libraries have been developed as well as sold or licensed to pharmaceutical and biopharmaceutical companies ${ }^{88}$ With 65 percent of all published libraries coming from academia, government laboratories, private and non-for profit research institutes in 2000, these

88. Personal communication, Prof. Arno Spatola, Louisville University (US) (October 2000). 
organizations now outpaced industry in combinatorial research output (Dolle 2001). Interestingly, the locus of knowledge creation is highly diversified: universities account for approximately three-quarters of total published combinatorial libraries, the rest being shared among government laboratories and private, non-for-profit research organizations.

The creation of these libraries is not undertaken without any particular use in mind. Given the gradual shift from discovery libraries towards targeted and focused libraries, it has become increasingly apparent that chemists at scientific organizations prepare carefully the type of combinatorial combinations they want to synthesize. It is fair to assume that interesting new leads compounds and thereby therapeutic drugs will be discovered in these collections of molecules, though commercialization will require considerable optimization work on the part of companies. What all this adds up is the presumption that technology platform companies face intense competition from unexpected quarters. Indeed, an increasing number of scientific organizations are now playing a role that was previously the province of new entrants: suppliers of compound libraries to large pharmaceutical companies and large biopharmaceutical companies.

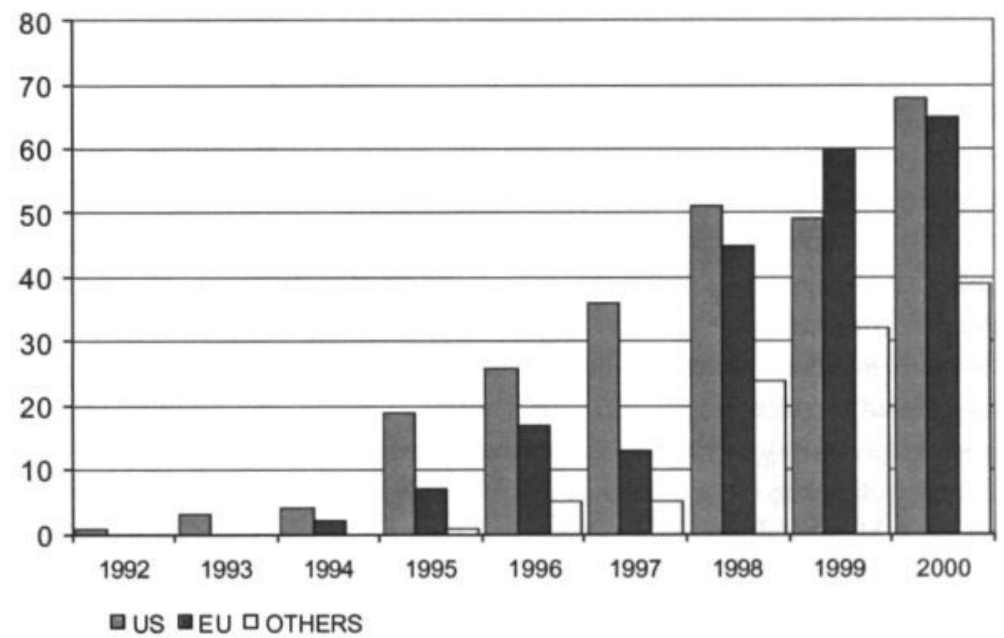

\section{Figure 6.1}

Increasing volume of public research in combinatorial chemistry as measured by published libraries -by geographical location (1992-2000)

Source: Extracted from Dolle (1998a, 1998b, 2000, 2001) and Dolle and Nelson (1999).

Of additional interest, the drive to spend public monies on combinatorial chemistry did not spread simultaneously and equally across countries. 
Through the period 1992-1997, 89 libraries had been synthesized by American organizations, far more than any other country (see figure 6.1). Early contributions mainly originated at UBC, Torrey Pines Institute for Molecular Studies, University of California, Davis, and the Scripps Research Institute. During the same period, only 39 collections of compounds had their source in scientific organizations from the European Union. These include Tubingen University (DE), Dortmund University (DE), Catholic University at Leuven (BEL), Carlsberg Laboratories (DK), Commissariat à l'Energie Atomique (FR), Cambridge University (GB) and Stockholm University (SE). However, as figure 6.1 demonstrates, the American margin of leadership had been eroded in 1999, with EU-15 rapidly catching up and challengers appearing in countries as diverse as Canada, Singapore, Taiwan and India.

Table 6.2

Top 20 scientific organizations for published libraries (1989-2001)

\begin{tabular}{lcc}
\hline Scientific Organization & Country & No. of Libraries \\
\hline Scripps Research Institute & US & 40 \\
University of California - Berkeley & US & 37 \\
Torrey Pines Institute for Molecular & US & 31 \\
Studies & FR & 24 \\
CNRS & SING & 16 \\
National University of Singapore & US & 16 \\
University of California - Davis & US & 13 \\
University of California - Los Angeles & GB & 12 \\
University of Southampton & GB & 11 \\
Cambridge University & DE & 11 \\
Tubingen University & TAIWAN & 10 \\
National Dong Hwa University & DE & 7 \\
University of Gottingen & DK & 7 \\
Technical University of Denmark & J & 6 \\
University of Tokyo & US & 6 \\
Texas A \& M University & DE & 6 \\
Technical University -Munich & GB & 6 \\
University Chemical Laboratory & US & 6 \\
University of Pennsylvania & US & 5 \\
Harvard University & DE & 5 \\
Technical University -Berlin & L &
\end{tabular}

Source: Extracted from Dolle (1998a, 1998b, 2000, 2001) and Dolle and Nelson (1999).

The United States regained their leadership in 2000, its research output expanding at a higher pace than other locations, but the growth of 
combinatorial libraries from the European Union does not seem to be slowing down either. To date, American scientific organizations had synthesized 257 combinatorial libraries and EU-15 ones 209, with Germany (38) being the most prolific country, followed by Great Britain (35), France (28), Italy (11) and the Netherlands (8). The relatively strong publication performance of EU-15 is not surprising, given that European academia has had a long history of excellence in the discipline of chemistry. This is borne out by publication statistics produced by the National Science Foundation (2000), which showed that EU-15 and the United States generated, respectively, 32.8 percent and 20.9 percent of the world's articles published in chemistry over 1995-1997.

Table 6.2 shows the most productive scientific organizations in terms of published libraries, which acount for about 48 percent of all published libraries in the world. The top organization in the United States is the Scripps Research Institute, followed by University of California, Berkeley, Torrey Pines Institute for Molecular Studies, University of California, Davis, and University of California, Los Angeles -all located in California. Interestingly, Torrey Pines Institute for Molecular Studies spun out of another scientific organization. Indeed, its founder, Richard A. Houghten, was a former scientist at the Scripps Research Institute before establishing the organization in 1988. What is also noticeable in table 6.2 is that the response of Asian countries to the technological discontinuity is significant. National University of Singapore (with 16 libraries), National Dong Hwa University (7) and University of Tokyo (6) are now among the most important producers of combinatorial libraries.

\subsection{TAPPING INTO PUBLIC RESEARCH}

It is evident from the previous section that scientific organizations in the United States only slightly outperformed EU-based universities, public research organization and private, non-profit research organizations. Yet one should mention that the population of the former is 40 percent lower that that of the latter. Even more alarming for EU-15 is that EU-based firms have been lagging behind their American counterparts in terms of technology transfer from scientific organizations. Of the numerous technology transfer mechanisms available to the firm, this section will consider: (1) formal interorganizational agreements, (2) informal interorganizational agreements, (3) the provision of vocational skills and (4) entrepreneurial spin-offs.

\subsubsection{Formal interorganizational agreements between new entrants and scientific organizations}

The success of scientific organization in generating new knowledge has 
not been lost on new entrants. Research in scientific organizations is supported by rearly two thirds of these firms, which signed 795 alliances with universities and public research organizations from 1988 to 2001, as table 6.4 illustrates. However, the table also provides the first indication that scientific organizations help finance both $R \& D$ and the foundation of new entrants. This is, first, because these companies often receive outside funding from government agencies and laboratories, most notably the National Institute on Health $(\mathrm{NIH})$ and its agencies. These government agencies had given 10 grants to new entrants in the period 1984-1995, which increased to 67 in the period 1995-2001. For instance Phylos, was able to evaluate protein scaffolds for the design of novel anti-cancer agents thanks to a $\$$ US 550,000 grant by the National Cancer Institute (NCI). Also, it is worth remarking that Scripps Research Institute had organized 9 research contracts and licensing agreements with Cytel, Trega Biosciences, Ixsys, CN Biosciences and Tripos. Second, equity investments occurred 57 times, probably reflecting a concern by universities to not only ensure that the results of their research are exploited but also bring reward to their researchers and themselves. This is exemplified by the equity position taken by Oxford University into Oxford Asymmetry, which was meant to market chiral chemical synthesis technology developed by Professor Stephen Davies and his research group at the Dyson Perrins Laboratory. The equity stakes taken by John Hopkins University into Lion Pharmaceuticals and by Cambridge and Oxford University into Cambridge Combinatorial are other examples.

Likewise, the data reveal a few cases of new entrants whose existence owe to combinatorial technology licensed from universities and government research organizations. Auda Pharmaceuticals started with a combinatorial synthesis methodology developed at the Technical University of Denmark; Jerini Bio Tools was launched to exploit the SPOT technology discovered at German National Research Center for Biotechnology; Synsorb Biotech uses technologies based on discoveries done by the chemistry department at the University of Alberta, which were subsequently transferred to the Alberta Research Council and then licensed to Synsorb; Pharmacopeia started out with an exclusive license agreement with Columbia University and Cold Spring Harbor covering technology related to tagged combinatorial chemical libraries and methods of preparing and utilizing such libraries; etc. Of course, there are also license agreements that transfer technologies other than combinatorial synthesis processes. Scientific instrumentation for medical and new material research can also be targeted, as when Symyx acquired an exclusive license to a portfolio of patents focusing on infrared thermal imaging. The technology was developed at the University of Houston to improve the speed and efficiency of screening and optimizing new catalysts. 


\section{Table 6.3}

Formal network

Increase in number of alliances between new entrants and scientific organizations -by mode of cooperation (1984-2001) (absolute number and percent)

\begin{tabular}{lccc}
\hline Mode of Cooperation & $1984-1995$ & $1996-2001$ & TOTAL \\
\hline Grant & $10(13)$ & $67(87)$ & $77(100)$ \\
& $(2.7)$ & $(15.3)$ & $(9.6)$ \\
R\&D contract & $98(64)$ & $55(36)$ & $153(100)$ \\
& $(27.3)$ & $(12.6)$ & $(19.2)$ \\
Licensing & $194(54.8)$ & $160(45.2)$ & $354(100)$ \\
& $(54.1)$ & $(36.6)$ & $(44.5)$ \\
Equity Participation & $29(50.8)$ & $28(49.2)$ & $57(100)$ \\
& $(8.1)$ & $(6.4)$ & $(7.1)$ \\
Joint R\&D & $23(16.4)$ & $117(83.6)$ & $140(100)$ \\
& $(6.4)$ & $(26.7)$ & $(17.6)$ \\
Others & $4(28.6)$ & $10(71.4)$ & $14(100)$ \\
& $(1.1)$ & $(2.2)$ & $(1.7)$ \\
\hline TOTAL & $358(45)$ & $437(54.6)$ & $795(100)$ \\
& $(100)$ & $(100)$ & $(100)$ \\
\hline Sol & & &
\end{tabular}

Source: Compiled by author

However, there is little doubt that the strongest reason to obtain a license from a scientific organization is to get access to advanced genomics products and technologies. This is probably what top management at Senomyx had in mind when the firm entered into three different license agreements with Rockefeller University, John Hopkins University and University of California, San Diego. In 1999, Senomyx signed an exclusive license with the Rockefeller University regarding the discovery of molecules involved in the human biology of olfaction and the Johns Hopkins University regarding assay technologies and receptor genes related to taste and olfaction. In 2000, the company entered into a license agreement with the University of California, San Diego, under which it obtained exclusive rights to technologies involved in the biology of taste, including two taste receptor gene families, T1Rs and T2Rs. The licensing of such targets is particularly frequent and important because these products and technologies can provide the means to develop screens for specific combinatorial programs. Despite this, the interest in both licensing and R\&D outsourcing has been declining, respectively, from 54.8 percent to 45.2 percent and from 27.3 percent to 12.6 percent over the periods 1984-1995 and 1996-2001.

By comparison, the share of joint $R \& D$ agreements rose from 6.4 percent to 26.7 percent over the same interval. New entrants have been collaborating with scientific organization for a variety of overlapping reasons. As part of their strategy of being integrated drug discovery companies, most new entrants are seeking to branch into a wider spectrum of new 


\section{Table 6.4}

Formal network

Top 15 scientific organizations for number of alliances (1980-2001)

\begin{tabular}{lccccc}
\hline Scientific organization & Country & No. & US Firm & EU Firm & Others \\
\hline NIH & US & 79 & 77 & 2 & 0 \\
John Hopkins University & US & 24 & 23 & 1 & 0 \\
U. of North Carolina & US & 21 & 21 & 0 & 0 \\
Stanford University & US & 16 & 16 & 0 & 0 \\
Harvard University & US & 16 & 16 & 0 & 0 \\
UC-San Diego & US & 14 & 14 & 0 & 0 \\
MIT & US & 13 & 12 & 1 & 0 \\
Washington University & US & 12 & 11 & 1 & 0 \\
UC -Berkeley & US & 12 & 12 & 0 & 0 \\
UC -San Francisco & US & 12 & 12 & 0 & 0 \\
University of Alabama & US & 11 & 11 & 0 & 0 \\
Hebrew University & IS & 10 & 10 & 0 & 0 \\
University of Texas & US & 9 & 9 & 0 & 0 \\
Max Planck & DE & 9 & 0 & 9 & 0 \\
Scripps Research Institute & US & 9 & 9 & 0 & 0 \\
\hline Source: Compiled by author & & & & &
\end{tabular}

Source: Compiled by author

knowledge, though the transfer of know-how and know-why in genomic sciences is again to be the main motivation behind collaborative R\&D. Thus, joint R\&D can represent a cost-effective vehicle not only for experimenting with uncertain technologies but also for developing or reinforcing competences in genomics and related technologies. Whereas licensing and $\mathrm{R} \& D$ contracts do not allow for learning by doing and open-ended learning, joint $R \& D$ arrangements permit interactions among scientists, thereby enabling new entrants to learn the tacit elements of technologies. Thus when Pharmacopeia wanted to learn about leading-edge research in chemical genetics, ${ }^{89}$ the New Jersey-based firm signed a joint collaborative agreement with Harvard University and its Institute of Chemistry and Cell Biology (ICCB). ${ }^{90}$ In view of the fact that technological change is blurring all distinction between basic and applied research, collaborations with scientific organizations can also increase the likelihood that a firm will be the first to use the new knowledge for commercial purposes. Thus, a joint R\&D

89. Chemical genetics is the process of using chemistry to understand biological systems and unlock the function of the vast numbers of new proteins being discovered through genomic research.

90. In the words of Joseph A. Mollica, Pharmacopeia's Chairman, President and CEO: "By having our scientists conduct research at the ICCB, Pharmacopeia will be able to participate in research at the forefront of chemical genetics and potentially apply new advances to our internal efforts, thus complementing Pharmacopeia's own drug discovery efforts". (Press release of Pharmacopeia, see www.pharmacopeia.com). 
agreement enables new entrants to pre-empt rivals in generating innovation within specific therapeutic fields and can establish the basis for forging a privileged relationship with a specific organization (Gambardella 1995). More generally, the faster new entrants move to develop or access novel screens and/or new classes of compounds, the faster they can identify and erect isolating mechanisms around the therapeutic category.

Unsurprisingly, as table 6.4 shows, it is the National Institute of Health, with 79 grants, licensing and research agreements, which carries the palm with respect to the number of awards and alliances. This should not come as a major surprise. The NIH is the single most important source of funding for basic research in the United States. ${ }^{91}$ The table also has something to say about the origins of the partners involved, suggesting that scientific organizations are much more likely to sign on new entrants from their home country, though the data cannot provide a comprehensive picture of international and national trends. Better insights can be gained by examining table 6.5. As expected, scientific organization-new entrant relationships are mainly an American phenomenon. New entrants in the US entered into 678 agreements (85.3 percent of total), whereas new entrants in EU-15 only engaged in 80 alliances ( 10 percent). This is a manifestation that EU-based entrants are less numerous, and their scientists and scientific organizations perhaps less commercially oriented, than their US-based counterparts. With 82 new entrants (21 percent of total), EU-15 trailed the American entrepreneurial sector (72.5 percent of total).

It is also telling that American new entrants collaborated 598 times with scientific organizations from their home country, 47 times with EU-based ones and 33 times with other ones. By comparison, firms from the European Union established 58 alliances with EU-15 scientific organizations, 18 with American ones and 6 with non-US, non-EU-15 ones. As US-based firms seem to benefit almost as much as EU-based firms from European public science, it would be tempting to assert that EU-15 underestimates the value of its own public research. This does not, however, completely explain why 22.5 percent of EU-15 firm alliances are with American scientific organizations while only 6.8 percent of US firm alliances are with EU-15 scientific organizations. One possible reason is that chemical-based companies in EU-15 turn to the American network for innovations in biotechnology in general and genomic technologies in particular. For EU-15 lags behind the US in these technological and scientific areas (Orsenigo 1989; Senker 1998), EU-based entrants are compelled to license technologies or partner with American scientific organizations for biological targets.

91. Take only the case of the National Cancer Institute (NCI). In 2001, the NCI had a budget of \$US 3,754 million, enough money to support 4,695 external research projects and 400 researchers performing intramural research. 


\section{Table 6.5}

Formal network

Alliances between new entrants and scientific organizations

-by geographic location (1988-2001) (percentage of the total)

\begin{tabular}{|c|c|c|c|c|}
\hline & US Firm & EU Firm & Others & TOTAL \\
\hline Scientific & $598(95.9)$ & $18(2.8)$ & $7(1.1)$ & $623(100)$ \\
\hline Organization & (88.2) & (22.5) & (20) & (78.3) \\
\hline EU Scientific Organization & $\begin{array}{c}47(43.5) \\
(6.8)\end{array}$ & $\begin{array}{c}58(53.7) \\
(77.2)\end{array}$ & $\begin{array}{c}3(2.7) \\
(8.5)\end{array}$ & $\begin{array}{c}108(100) \\
(13.5)\end{array}$ \\
\hline Others & $\begin{array}{c}33(51.5) \\
(4.8)\end{array}$ & $\begin{array}{c}6(9.3) \\
(7.5)\end{array}$ & $\begin{array}{c}25(39) \\
(71.4)\end{array}$ & $\begin{array}{c}64(100) \\
(8.0)\end{array}$ \\
\hline TOTAL & $\begin{array}{c}678(85.3) \\
(100) \\
\end{array}$ & $\begin{array}{c}80(10) \\
(100)\end{array}$ & $\begin{array}{c}35(4.4) \\
(100)\end{array}$ & $\begin{array}{c}795(100) \\
(100)\end{array}$ \\
\hline
\end{tabular}

Source: Compiled by author

\subsubsection{Informal interorganizational agreements between new entrants and scientific organizations}

Tables 6.6 and 6.7 present a different, albeit complementary, picture from formal network: informal network. While the phenomenon of informal interorganizational agreements is more difficult to observe, gauge and analyze, Liebeskind and colleagues (1996) took on the challenge by looking at scholarly publications on which scientists of different organizations were named as authors. Multi-addressed papers are an interesting proxy for measuring knowledge transfer because co-authorship provides an opportunity for extensive discussion, debate, exchange of ideas, and joint problem solving (Cockburn and Henderson 1998). Accordingly, the results of Liebeskind et al. (1996) suggest that informal networks increase the learning and flexibility of new biotechnology firms in ways that could not have been possible via formal networks.

The data used here have been extracted from a publication database comprising 2,570 papers focusing on combinatorial chemistry, of which 755 papers had been written by one or several scientists from at least two different organizations. ${ }^{92}$ Several trends can be observed from the resulting

92. The database was built using the CD-roms of the Institute for Scientific Information (ISI). Such an enterprise was fraught with difficulties. The most important one is that the term "combinatorial" spread only very slowly. For example, the first article referring to combinatorial chemistry in Chemical \& Engineering News, the official newsmagazine of the American Chemical Society (ACS), only appeared in 1993, when Jonathan A. Ellman and coworkers at the University of California, Berkeley, described their small molecule benzodiazepines library. To circumvent this problem, a series of keywords such as "parallel synthesis", "library", etc. had to be used. However, a netsite entirely dedicated to combinatorial chemistry (www. $5 z$.com) proved to be helpful as it lists combinatorial papers since the technology appeared in 1982. 
statistics (see table 6.6). First, as one may have expected from scientometric analysis, scientific organizations, rather than firms, constitute the core of the informal network. The informal network encompasses 516 different scientific organizations, considerably less than new entrants (85). Universities, public and pivate, non-profit research organizations therefore seem to be more interested in exchanging knowledge with other scientific organizations than with industry. Only 356 papers ( 47 percent of total) had been written between scientific organizations and new entrants.

\section{Table 6.6}

Informal network

Co-authorship of scientific papers between new entrants and scientific organizations -by geographical location (1986-1996) (percentage of the total)

\begin{tabular}{lcccc}
\hline & US firm & EU firm & Others & TOTAL \\
\hline US scientific organization & $189(86.3)$ & $6(2.7)$ & $27(12.3)$ & 219 \\
& $(82)$ & $(11)$ & $(34.6)$ & $(100)$ \\
& & & & $(61.5)$ \\
EU scientific organization & $26(31.3)$ & $44(53)$ & $14(16.8)$ & $83(100)$ \\
& $(11)$ & $(84)$ & $(17.9)$ & $(23.3)$ \\
Others & $15(27.7)$ & $2(3.7)$ & $37(68.5)$ & $54(100)$ \\
& $(6.5)$ & $(3.8)$ & $(47.4)$ & $(15.1)$ \\
\hline TOTAL & $230(64)$ & $52(14.6)$ & $78(21.9)$ & 356 \\
& $(100)$ & $(100)$ & $(100)$ & $(100)$ \\
& & & & $(100)$ \\
\hline
\end{tabular}

Source: Compiled by author

Second, it is clear that informal interorganizational agreements are akin to formal linkages in that new entrants from the US (64 percent of all cases) are much more effective in linkink with scientific organizations than EU-15 companies (15 percent) and firms from the rest of the world (22 percent). American firms had written 189 papers with US scientific organizations, 26 with European ones and 15 with scientific organizations from other countries. By contrast, new entrants from EU-15 had co-authored papers with 6 American scientific organizations, 44 with EU-15-based ones and 2 with non-US, non-EU-15 ones. Third, some scientific organizations, especially in the US, are more likely to collaborate with new entrants than are others (see table 6.7). For example, Medical Research Council, Edinburgh University and University of Nottingham produced 8, 6 and 4 scientific papers, respectively, with other firms, but their combined contribution appear to be no match for the Scripps Research Institute (33 papers) and Arizona University, which alone wrote 32 papers with the Arizona-based combinatorial company Selectide. 
Table 6.7

Informal network

Top 20 scientific organizations for number of papers written with a new entrant (1986-1996)

\begin{tabular}{lccccc}
\hline Scientific Organization & C'ntry & Number & US Firm & EU Firm & Others \\
\hline Scripps Research Institute & US & 33 & 23 & 2 & 8 \\
University of Arizona & US & 32 & 32 & 0 & 0 \\
Torrey Pines Institute & US & 14 & 14 & 0 & 0 \\
UC - Los Angeles & US & 12 & 9 & 1 & 2 \\
Queensland Inst. Med. Res. & AUS & 14 & 0 & 0 & 14 \\
U. of North Carolina & US & 8 & 8 & 0 & 0 \\
Medical Research Council & GB & 8 & 6 & 1 & 1 \\
UC-Berkeley & US & 7 & 0 & 0 & 0 \\
University of Minnesota & US & 6 & 6 & 0 & 0 \\
Edinburgh University & GB & 6 & 6 & 0 & 0 \\
Penn State University & US & 8 & 3 & 0 & 0 \\
Eötvös University & HU & 6 & 6 & 0 & 0 \\
Harvard University & US & 5 & 5 & 0 & 0 \\
University of Colorado & US & 5 & 5 & 0 & 0 \\
University of Nottingham & GB & 4 & 0 & 4 & 0 \\
University of Virginia & US & 4 & 4 & 0 & 0 \\
Imperial College & GB & 4 & 0 & 4 & 0 \\
UC -San Francisco & US & 4 & 4 & 0 & 0 \\
NCI & US & 4 & 4 & 0 & 0 \\
Max Planck & DE & 4 & 2 & 2 & 0 \\
Duke University & US & 4 & 4 & 0 & 0 \\
\hline So C
\end{tabular}

Source: Compiled by author

A final remark must be made about informal interorganizational agreements with pioneer scientists. As the early combinatorial synthesis methods have important roots in a Hungarian University, a Dutch government laboratory and a new chemical-based entrant from Australia, this absence of informal linkages between EU-15-based entrants and these organizations suggests that new American entrants have been able to access directly the know-how of the inventors of the parallel synthesis and multiple synthesis methods. Thus US-based firms and scientific organizations did not hesitate to establish contacts with some of the original inventors. For instance, Advanced Chemtech and Árpád Furka, the inventor of the first simultaneous multiple synthesis, at Eötvös University in Budapest collaborated in 6 different papers between 1994 and 1996, a collaboration that may have reinforced the firm's position in multiple synthesis method and instrumentation. Most important is the series of papers written by Mario Geysen, a co-inventor of an important parallel synthesis technique. Geysen, then at Common Serum Laboratories (CSL)/Coselco Mimotopes in Australia, co-authored articles with the Scripps Research Institute as early as 
1987 and University of California, Los Angeles, in the early nineties. This informal collaboration may have been a turning point in the dissemination of "combinatorial" knowledge in the United States. As reported in table 6.2, Scripps Research Institute, America's largest not-for-profit biomedical research center, ${ }^{93}$ and University of California, Los Angeles, subsequently became leading contributors of combinatorial libraries in the country.

\subsubsection{The provision of vocational skills}

There is a general consensus that the recruitment of skilled graduates by companies is one if not the most important technology transfer mechanism from university to industry (Salter and Martin 2001). It is therefore instructive to note that combinatorial chemistry is now part of the academic curriculum. In 1996, University of Louisville was the first to teach the ABCs of combinatorial chemistry in Academia in the United States, followed by University of Pittsburgh, Harvard University, University at Buffalo, University of Utah, Ohio State University and Cold Spring Harbor University. Northeastern University, for example, offers a lecture course, Chemistry 4388, as an introduction to the subject. The course covers: (1) peptide chemistry and its application to the discovery of ligands for biological receptors; (2) combinatorial chemistry in drug discovery, materials science and catalysis; (3) methods of solid-phase synthesis; (4) automation in synthesis, analysis, and purification; (5) data handling; (6) design of diverse screening libraries; and (7) drug design (Borchardt 2001). In EU-15, Leeds University, University of Manchester, Cambridge University and Newcastle University in Great Britain, Lund University (SE), the Technical University of Denmark (DK), Barcelona University (SP), Trinity College University (IR), Milan University (IT) and Marburg University (DE) are also known to give some form of training in the field. Few universities have courses that focused solely on combinatorial chemistry, however. Most of them include combinatorial chemistry into a bioorganic chemistry or drug discovery course.

Nonetheless, combinatorial chemists are not born, but made. Put alternatively, the idiosyncratic nature of companies' knowledge base implies that industry would often choose to hire scientists who possess know-how in synthetic organic chemistry, yet are familiar with the combinatorial synthesis methods, and then train them with the specific needs of the firm in mind. This is why universities should make students active participants in the field, as for example by engaging them in the construction of libraries. This could foster problem-solving abilities that can prove valuable once they reach the

93. The Institute's staff includes more than 270 professors, 800 postdoctoral fellows, 1500 laboratory technicians, administrative and support personnel, and $126 \mathrm{Ph} . \mathrm{D}$. students. 
marketplace. ${ }^{94}$ Yet, despite the growing body of evidence suggesting that universities are slowly getting to grips with the emergence of combinatorial chemistry, there is still an acute shortage of skilled graduates with expertise in the field in both the US and EU-15 (Kelly 2000). According to the recruiting pages of the Chemical \& Enginerring News, the US industry regularly suffers a short supply of specialists in this technological area (Brennan 1995, 1997, 2000). Echoing this concern, a survey by the European Federation for Pharmaceutical Sciences (EUFEPS) indicates a potential lack of qualified personnel in QSAR and chemical synthesis in EU-15 (Mooney 2001). If it transpires that the pharmaceutical industry truly suffered shortages of welltrained researchers in combinatorial chemistry, thereby setting limits to the development of the industry, government intervention will be necessary.

\subsubsection{The creation of spin-offs}

Scientific organizations also create spin-offs when an employee leaves the parent organization with a core technology to form a company of his/her own (Lindholm Dahlstrand 1997). Of the numerous possible examples of technology transfer, the creation of spin-offs appear to be one of the most effective in terms of job and wealth creation (Rogers et al. 2001). For example, BankBoston (1997) estimated that 1,065 MIT-related firms headquarter in Massachusetts employ 125,000 people in the state.

In view of the fact that 393 new entrants have been using the tools of combinatorial chemistry, the information provided in table 6.8 only covers a small fraction of the firms using combinatorial chemisty. However, examples of university scientists playing the role of entrepreneurs, as opposed to exemployees of smaller and larger companies, are so numerous that links between public research and industry cannot be ignored. In fact, it is much more difficult to unravel corporate spin-offs than academic and institutional spin-offs. Coselco Mimotopes (spun off from Commonwealth Serum Laboratories), Chemspeed (Roche), Basilea Pharmaceutica (Roche), Origenix (Hybridon), Guilford Pharmaceuticals (Scios Nova), Diversomer Technologies (Parke-Davis), Tularik (Genentech), Sarco (Glaxo), XenoPort (GlaxoSmithKline), HTE (BASF) and Locus Discovery (Sarnoff Corporation) are perhaps the only examples of corporate spin-offs in the sample. By contrast, faculty members and scientists working for government

94. In the words of Jörg Setter, head of the life science department in central research at Bayer: "We are not really looking for combinatorial chemists. Normally, we prefer to hire synthetic organic chemists with broad experience in different types of synthesis, and then educate them here in the company to become combinatorial chemists. Normally, we don't need to have people who have specialized only in combinatorial chemistry, though we look at chemists who have experienced it during their Ph.D.s" (Gwynne 1999:4). 
Table 6.8

Scientific organization spin-offs

\begin{tabular}{|c|c|c|c|c|}
\hline \multirow{2}{*}{$\begin{array}{l}\text { Scientific Organization } \\
\text { Cambridge University }\end{array}$} & \multicolumn{2}{|r|}{ Founding scientist } & \multicolumn{2}{|l|}{ New entrants } \\
\hline & GB & Steven Ley & Cambridge Combinatorial & GB \\
\hline Columbia University & US & Clark Still & Pharmacopia & US \\
\hline Columbia University & US & K. P. Mullinix & Synaptic Pharmaceutical & US \\
\hline Hans-Knöll Insitute & $\mathrm{DE}$ & H-Ulrich Demuth & Probiodrug & $\mathrm{DE}$ \\
\hline Hebrew U. of Jerusalem & IS & Bernard Green & Semorex & IS \\
\hline Harvard University & US & Stuart Schreiber & Ariad Pharmaceuticals & US \\
\hline Harvard Medical School & US & Randall B. Lauffer & EPIX Medical & US \\
\hline Harvard Medical School & US & Barbara Cordell & Scios & US \\
\hline Johns Hopkins University & US & S. H. Snyder & Guilford Pharmaceuticals & US \\
\hline Max Planck Institute & $\mathrm{DE}$ & Dr. Axel Ullrich & Sugen & us \\
\hline NASA & US & David Noever & CyberChemics & US \\
\hline $\mathrm{NIH}$ & US & K. Xanthopoulos & Anadys & US \\
\hline National Cancer Institute & US & F. H. Hausheer & Bionumerik & US \\
\hline New York University & US & Joseph Schlessinger & Sugen & US \\
\hline Northwestern University & US & Byron E. Anderson & Immtech International & US \\
\hline Oxford University & GB & Stephen Davis & Oxford Asymmetry & GB \\
\hline Oxford University & GB & Raj Parekh & Oxford GlycaSciences & GB \\
\hline Oxford University & GB & Alan Fersht & Cambridge Combinatorial & GB \\
\hline Salk Institute & US & Baldomero Olivera & Cognetix & US \\
\hline Salk Institute & US & Wylie W. Vale & Neurocrine Biosciences & US \\
\hline Scripps Research Institute & US & Chi-Huey Wong & Combichem & US \\
\hline Scripps Research Institute & US & Raymond Stevens & Syrrx & US \\
\hline Scripps Research Institute & US & Stephen Kent & Gryphon Sciences & US \\
\hline Scripps Research Institute & US & Richard Lemer & Prolifaron & US \\
\hline Scripps Research Institute & US & K. Barry Sharpless & Coelacanth & US \\
\hline Scripps Research Institute & US & William D. Huse & Applied Molecular Evolution & US \\
\hline Scripps Research Institute & US & Richard Houghten & Multiple Peptide Systems & US \\
\hline Torrey Pines Institute & US & Richard Houghten & Trega Biosciences & IS \\
\hline University of Alabama & US & Charles E. Bugg & BioCryst Pharmaceuticals & US \\
\hline University of Birmingham & GB & John Fox & Alta Bioscience & GB \\
\hline University of Cal. - Berkele & US & Douglas Clark & Enzymed & US \\
\hline University of Cal. -Berkeley & US & Peter Schultz & Symyx & us \\
\hline University of Cal-San Diego & US & Janusz Sowadski & Kinetix & US \\
\hline University of Cal -San Diego & US & Michael Karin & Signal Pharmaceuticals & US \\
\hline Univ. of Cal -San Francisco & US & Jonathan Ellman & Sunesis Pharmaceuticals & uS \\
\hline Univ. of Cal -San Francisco & US & Shaun Coughlin & COR Therapeutics & US \\
\hline University of Colorado & US & Larry Gold & NeXstar & US \\
\hline University of Edinburgh & GB & R. Ramage & Albachem & GB \\
\hline University of Florida & US & Steven Benner & Sulfonics & US \\
\hline University of Glasgow & GB & N. La Thangue & Prolifix & GB \\
\hline University of Pennsylvania & US & Michael Zasloff & Genaera & US \\
\hline Université de Sherbrooke & $\mathrm{CA}$ & P. Deslongchamps & Néokimia & CA \\
\hline University of Tubingen & $\mathrm{DE}$ & G. Jung et al. & EMC Microcollections & $\mathrm{DE}$ \\
\hline University of Vermont & US & Mark R. Brann & Acadia Pharmaceuticals & US \\
\hline Yale University & US & Leonard Bell & Alexion Pharmaceuticals & US \\
\hline Virginia Commonwealth $\mathrm{U}$. & US & Richard J. Freer & Commonwealth Biotech. & US \\
\hline Weizmann Inst. of Science & IS & Haim Aviv & Pharmos & IS \\
\hline
\end{tabular}

Source: Compiled by author 


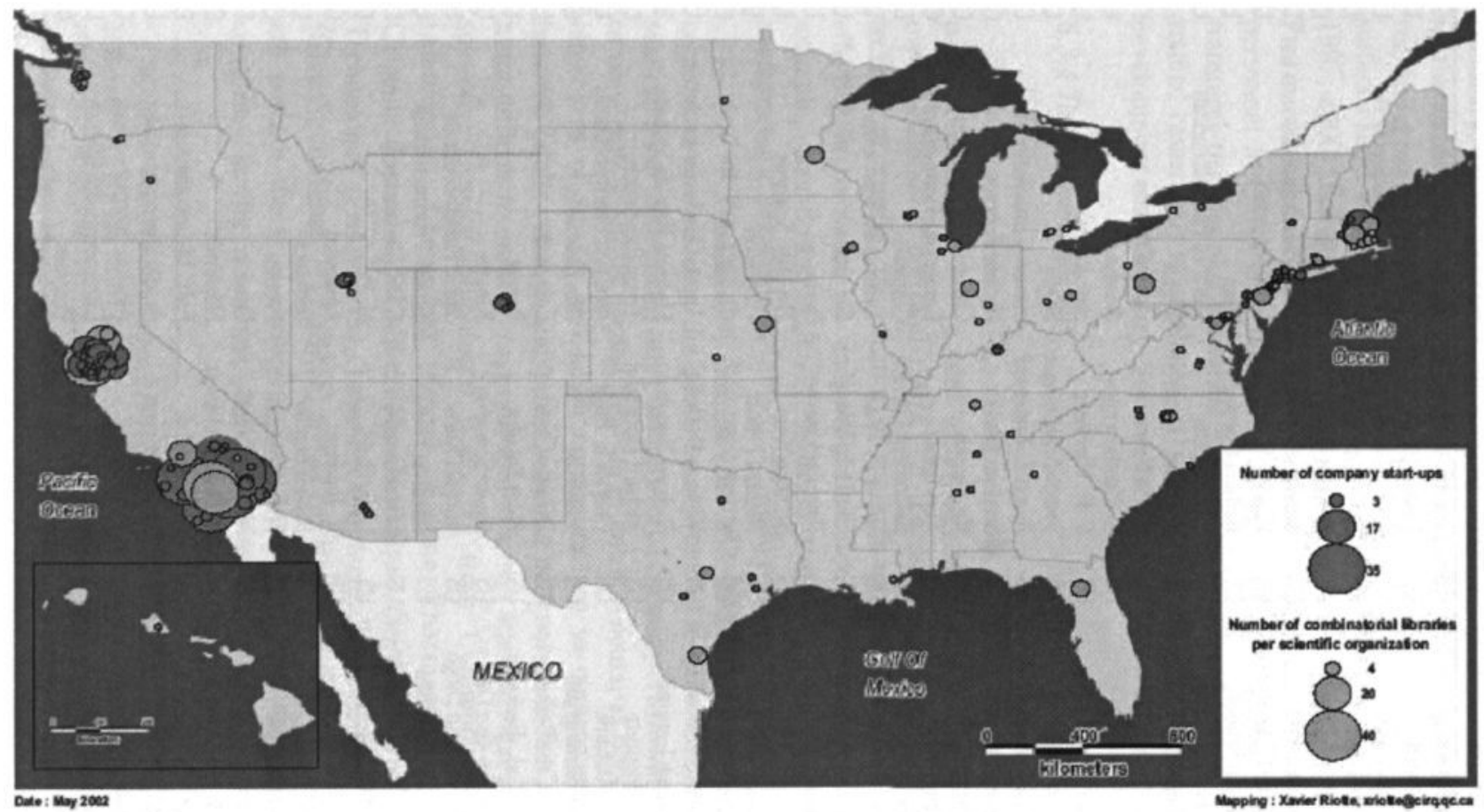

Figure 6.2

Location of start-ups and research output of scientific organizations as of 2000 
laboratories or private, non-profit organizations, most of them highly qualified chemists, helped launched 47 new entrants (see table 6.8). Of these entrepreneurial spin-offs, 35 spun out of American scientific organizations, 9 had their roots in EU-15 ones and 3 from non-EU, non-US ones. These results may suggest that the problem in the Europe Union resides much less in the volume and quality of its research in combinatorialchemistry than a lack of either entrepreneurial culture or venture capital. Yet, in spite of this, EU-15 appears to be improving in terms of firm formation in the second phase of the industrial development. 39.5 percent (or 101) of US-based entrants and 56.1 percent (46) of EU-15 based ones had been founded after 1996. This finding is in consonance with the pattern of growth in the volume of venture capital in recent years across the member states of EU-15. In relative terms, overall venture capital investment in EU-15 has increased three times over 1998 and 200 land seed and start-up investment has increased four times over the same period (COM 2001).

Lastly, it needs to be insisted that spin-offs often neighbor with their parent organization (Rogers et al. 2001). For example, the Association of University Technology Managers (AUTM 2002) reported the foundation of 454 new companies based on an academic discovery in fiscal year 2000, 80 percent of them in the state where the technology originated. The issue of where spin-offs are located becomes crucial, given that closeness to science contributes to ease the transfer of technological know-how. It is, therefore, important to note that California fares better than any other state and even country in terms of firm foundation. Of the American spin-offs, 16 (or 46 percent of the sample) spun out of California-based scientific organizations. As figure 7.1 demonstrates, California saw the foundation of 102 new entrants, of which 59 in the environs of San-Diego and 39 in the environs of San-Francisco Bay. At the same time, scientific organizations from these areas had been responsible to the synthesis of 86 and 58 compound libraries. This contrasts with Massachusetts, which has 42 new entrants and 18 combinatorial libraries. Thus, an important competitive advantage of California-based firms may rest on their ability to better benefit from technology transfer and knowledge spillovers stemming from the most performing scientific organizations in the United States.

\subsection{CONCLUDING REMARKS}

In light of the above discussion, a series of observations can be made about the contribution of scientific organizations to industrial innovations. First of all, combinatorial drug discovery relies heavily on know-why and inventions created in scientific organizations: combinatorial synthesis methods, scientific instruments, identification methods, chemoinformatic tools, combinatorial 
libraries, lead compounds, genomic sciences and so on often have their origins in academia, government laboratories and private, non-for-profit research organizations. The second series of observations is that scientific organizations directly contribute to the dissemination of knowledge supporting drug discovery into entrepreneurial setting, having hundreds of formal and informal linkages with new entrants, offering an increasing number of $\mathrm{Ph} . \mathrm{D}$. studentships, courses, workshops and seminars in the area of combinatorial chemistry, and being the source of dozens of new spin-offs around the world. Formal and informal interorganizational agreements are particularly important for the firm because they may provide a significant impetus for renewing its knowledge base and competences and can help pre-empt rivals in innovations. Last of this series of observations is the fact that the United States has dominated the field in any major respects: firm formation, combinatorial libraries and lead compounds under perclinical and clinical stages. Although the strengths of US-based new entrants is, without doubt, the product of many factors, the number of formal and informal linkages between scientific organizations and the industry and the creation of scientific organization spin-offs, most notably in California, may play an important role in tilting the balance in favor of the United States. 
PART IV: THE PERFORMANCE 



\title{
Determinants of Higher Performance
}

\author{
in a Turbulent Environment
}

Remember that in the field of observation, chance only favours the prepared mind.

Louis Pasteur (1854)

\subsection{INTRODUCTION}

Among the numerous shortcomings with the $\mathrm{I} / \mathrm{O}$ theories is that they ignore the message of chapter 2: firms are heterogeneous with regard to their resources and competences -the elements that explain performance differences in industry. As postulated by the resource-based theory of the firm, the source of superior performance rests "upstream" of product markets, lying on the firm's rare, 
valuable, non-imitable and non-substitutable bundle of resources and competences. While the tenets of resource-based theory of the firm have been given weight by empirical evidence, these arguments do not necessarily hold in a turbulent environment, where demand and technologies are so volatile and competition so intense that resources and competences can rapidly fall into obsolescence. Probing at the case of combinatorial chemistry, the preceding chapters demonstrated that a static emphasis on intangible assets and competences would have proven fatal to most providers of discovery libraries. If anything can shed light on the survival of these new entrants in the context of a competenceenhancing discontinuity, it is their ability to rapidly learn new knowledge from internal and external sources, which enabled them to enhance, expand and renew their competences along the second, third and fourth trajectory.

Still, these firms and diversified, or newly formed, new entrants with a competence in combinatorial chemistry are highly heterogeneous with regard to their learning strategies, accumulated knowledge stocks and historical backgrounds and thereby performance. To improve our general understanding of why some of these companies occupy a high performance position in the markets of chemical-based services and small molecule drugs, section 7.2 will focus on developing 12 different knowledge-based hypotheses. The following sections describe the data (section 7.3) and the results of the correlation and regression analysis (section 7.4). Section 7.5 concludes the thesis by recapitulating on its major themes and by articulating some normative prescriptions.

\subsection{HYPOTHESES}

Creating small molecule drugs and offering chemical-based services are not a oneoff event for new entrants. To survive in a turbulent environment, where technologies, customers demand and competition change rapidly, new entrants must constantly bring about new, or improve old, product and process innovations to maintain or improve their performance. The key input for successful innovations is knowledge, which in turn becomes an output reinforcing the firm's competences in organic synthesis, molecular biology, etc. Learning in $R \& D$ therefore helps new entrants adapt to the evolving external environment and enhances their performance. Thus, the first research proposition is as follows:

Hypothesis 1: New entrants with a higher level of internal learning will perform better than their rivals.

Few, if any new entrant has the scientific, technological and financial capacity to go alone. For one thing, the rapidity, complexity and uncertainty of 
technological change suggest that these firms need to get access to the knowledge and technologies of other smaller companies, most notably genomic firms. For another thing, the costs associated with combinatorial drug discovery and development and the absence of complementary assets in entrepreneurial setting place a premium on collaboration with large incumbents. Yet another thing is that new entrants seeking to achieve fast penetration in pharmaceutical markets can explore new possibilities and renew their knowledge base and competences by linking with scientific organizations. Insofar as membership to the innovation network is paramount for successful performance, one can hypothesise that:

Hypothesis 2: New entrants with a higher level of external learning will perform better than their rivals.

Consistent with the arguments of Cohen and Levinthal $(1989,1990)$, external learning is complementary, rather than supplementary, to internal learning. This is because new entrants must participate in scientific research in order to monitor, absorb and use external know-why in structural biology, chemistry, etc. Thus:

Hypothesis 3: New entrants with a higher level of internal learning will also be those with a higher level of external learning with scientific organizations.

Combinatorial chemistry is a prime example where public research has resulted in ideas that are of economic value. To see this, one only has to mention that the first synthesis, identification and computational methods originated in scientific organizations. Most significantly, genomic research receives considerable attention in academia, private, non-for profit organizations and government laboratories, offering tremendous opportunities for chemical innovations. Against this backdrop, the market for therapeutic products and services is intensely competitive, rapidly evolving and subject to rapid technological change, and there is a clear advantage in being the first in identifying the relevancy of new knowledge and technologies developed in the laboratories of scientific organizations, where they are at their earliest stages. Therefore, the greater a firm's access to know-why and know how from scientific organizations, the higher will be its economic performance. In formal terms:

Hypothesis 4: New entrants with a higher level of external learning with scientific organizations will perform better than their rivals. 
New entrants cannot sit on their laurels and live isolated without branching out to the innovation network. In line with Della Valle and Gambardella (1993), this strategic move should be accompanied by organizational changes: entrepreneurial firms ups must create a stimulating research environment resembling that of Academia. This implies that company scientists, as academic scientists do, be offered the opportunity to attend conferences, communicate with their peers and publish their results. But why would new entrants publish? After all, publishing papers takes time, costs money and could end up "leaking out" valuable knowwhy and know-what into industry. Hicks espouses the following argument: companies "need to participate in the barter-governed exchange of scientific and technical knowledge and ... need to send signals beyond that reflected in prices. Publications signal the existence of tacit knowledge and other unpublishable resources, thus building the credibility needed to find partners in knowledge exchange" (1995:421:422). Thus:

Hypothesis 5: New entrants promoting research "openness" will also be those with a higher level of external learning.

New entrants have often acted upon the belief that size matters, that economies of scale and scope can be achieved if two or more firms from similar, or complementary, backgrounds combine their technology platforms and/or research activities. For these firms, mergers and acquisitions remain a popular vehicle for broadening their knowledge base and competences and thereby creating synergies between chemistry and biology. Most significantly, a merger or acquisition may allow them break the rigidity of a platform technology model, to become fully integrated drug discovery companies. This also often opens the door to the emerging market of small molecule drugs, as opposed to just offering chemical-based or biological-based services to large pharmaceutical companies. Thus:

Hypothesis 6: Learning through acquisitions is an important source of higher performance.

The location of new entrants and research output of scientific organizations were shown in figure 6.2. Of the 256 new US-based entrants with an expertise in combinatorial chemistry, 102 (40 percent) are located either in the San Diego or the San Francisco Bay area. The propensity to set up shop in California is the result of many factors, including the presence of venture capital and the availability of both specialized inputs (e.g. reagents, target receptors, purification tools) and specialized labour. Geographical proximity to the Scripps Research 
Institute, the Torrey Pine Institute for Molecular Studies and the University of California, Berkeley, may also explain why clustering mainly occur in California, as opposed to, say, Utah or Mississippi. Closeness to these scientific organizations not only facilitates the transfer of tacit know-how and codified know-why but also increases the likelihood that knowledge spillovers keep flowing into new entrants. contributing to raise their productivity. To summarize:

Hypothesis 7: New entrants located nearby centres of excellence will perform better than their rivals.

As noted by Sørensen and Stuart (2000), dder companies should have learned from experience and accumulated a larger stock of tacit know-how, and hence, should be more efficient in the way their organizational routines are executed. Due to time compression diseconomies, their head start is also difficult to erase because rivals cannot simply double R\&D expenditures to catch up with the first movers (Dierickx and Cool 1989). In addition, early entrants are more likely to be diversified companies, those with higher sales and/or previous experience in drug discovery. Counterarguments, however, exist. New entrants are competing in a turbulent environment, where technology, demand and competition evolve rapidly. While younger firms begin their operations with a clean slate, often with new technologies licensed from universities, older firms tend to build on previous technological achievements and may find it difficult to match their knowlewdge base and competences with environmental demands (Sørensen and Stuart 2000). In formal terms:

Hypothesis 8: Early entrants perform better than late entrants. Or, inversely, late entrants perform better than early entrants.

Due to the generic nature of chemical sciences, a foot in the pharmaceutical industry did not prevent new entrants from diversifying into new market segments, especially those of new materials, catalysts, phosphors and pesticides. Granted, these firms had to broaden their knowledge base in order to reach these new markets. Still, new entrants capable of meeting both technological opportunities can achieve returns to scope, given that knowledge used in one pharmaceutical-oriented project can be transferred efficiently to a new-materialoriented project. Synergies across disciplines could also be accomplished. For example, the solution to a particular problem in one project could increase productivity of another through knowledge spillovers. Thus:

Hypothesis 9: Diversified firms perform better than their rivals. 
Smaller companies find it easy to focus on technological change. Yet, despite a behaviorial, or learning-based, advantage, smallness can be a liability as far as combinatorial chemistry is concerned. With new threats and opportunities compelling single technology platform firms to become multiple technology platform firms, a great many skills and hence a deeper stock of human capital are needed for moving along the value-added chain of combinatorial research (i.e. lead discovery, lead optimization, structure-based library design, synthesis of new materials, catalysts, etc.). As an empirical matter, it has often been observed that economies of scale are strong in the pharmaceutical industry, thus benefiting larger new entrants from increased specialization of know-why and know-how (e.g. Comanor 1965; Grabowski 1976). Paraphrasing Henderson (2000), I may have to be good in analytical, computational and medicinal chemistry if there are only three of us; I can specialize in medicinal chemistry if there are 20 of us. These ideas can thus be summarized:

Hypothesis 10: Larger entrants will perform better than smaller companies.

Combinatorial chemistry is both research and know-why intensive. Such intensity calls for highly specialized labour, not just technicians and management. Not only these scientists will perform state-of-the-art research but also will be able to better monitor, assess and absorb knowledge carried out in the laboratories of other companies and scientific organizations. This brings us to the eleventh hypothesis:

Hypothesis 11: New entrants with highest number of $\mathrm{PhDs}$ will perform better than their rivals.

As shown in chapter 4 , new entrants may have entered the markets of chemicalbased services and small molecule drugs through diversification, merger or acquisition. The knowledge base of combinatorial drug discovery suggests that these firms, be it biopharmaceutical or rational drug design companies, have not been locked-in with the wrong kind of knowledge and competences. On the contrary, biopharmaceutical or rational drug design companies can use their stock of accumulated knowledge and competences $\mathrm{n}$ molecular biology, $\mathrm{X}$ crystallography, pharmacology and so on and had often made the transition to drug discovery, with many exhibiting revenues from the sales of their products. Underlying this idea is that "history matters": past success in the therapeutic drug market makes it less, rather than more, difficult to cope with the competenceenhancing discontinuity because the accumulation of germane knowledge and the revenues generated by the sales of these drugs enable firms to rapidly and 
efficiently absorb the methods and support research in combinatorial drug discovery. Thus:

Hypothesis 12: New entrants with past success in drug discovery will perform better than their rivals.

\subsection{METHOD:SAMPLE AND MEASURES}

The study began over a population of 90 firms, launched between 1979 and 1998. All had a competence in combinatorial chemistry, and all went public at NASDAQ. However, 20 firms became too large (i.e. more than 1000 employees), went out of business or were acquired by a large incumbent before 2001, and hence, were excluded from the sample. Among the remaining 70 new entrants, one is from Great Britain, 2 are from Canada and 67 are from the United States. The sample has the obvious disadvantage that most firms are USbased, preventing effective comparison across countries. From a strategic point of view, however, the main results should remain valid whether the firm is of American, English or German origins.

\section{The Dependent Variables}

Evaluating the performance of new entrants is bound to be a controversial issue, if only because the concept means different things to different people. Is it profits? Growth? Size? Liquidity? Efficiency? Innovativeness? Market share? Accordingly, performance measures used in entrepreneurship research vary widely, ranging from measures such as returns on assets to respondent assessment (Murphy et al. 1996). As sociologists correctly pointed out, interest groups play a vital role in the choice of these measures (Kanter and Brinkerhoff 1981). Stock market returns are more valuable to shareholders than the growth of employees; ${ }^{95}$ the growth of employees is more valuable to policy makers than returns on sale; etc. Therefore, the relative importance of measurement depends on where you sit. One may also recognize the fact that performance measures are often not consistent or stable over time, often leading to contradictions. For instance, growth measures often require expenditures that are made at the expense of profitability for a time (Fryxell and Barton 1990). Unsurprisingly, there are poor inter-correlations between performance measures (Dubofswki and Varadarajan 1987; Murphy et al. 1996).

95. There is even evidence that stakeholders, which range from labor unions to businessenvironmental groups, have different interests and hence competing demands. See, for example, Savage et al. (1991). 
Yet, in the absence of performance indicators, the knowledge-based theory of superior performance presented in this thesis loses all its relevance. As stated by Chakravarthy: "without a performance referent managers cannot objectively or consistently evaluate the quality of their strategic decisions" (1986:437). While there is no consensus as to how best to measure performance, most scholars agree that research in entrepreneurial settings should consider different performance criteria (Chakravarthy 1986; Murphy et al. 1996). Some potential indicators can be discarded at the outset. Data about market share are simply unavailable for this business. The growth of employees as a barometer for high performance is also a problem considering that new entrants often grow as a result of mergers and acquisitions. Hence, this thesis will use 6 measures commonly used in the strategic management literature to gauge how new entrants perform in a turbulent environment: (1) revenues from services and products per employee (REVEM); (2) returns on equity (ROE); (3) returns on assets (ROA); (4) pricebook ratio (PBR); (5) net profit level (PL); and (6) innovations (PAT).

\section{The Independent Variables}

The data for the sampled population are summarized in Table 7.1. Six variables were used to operationalize technological learning, 4 variables for knowledge assets and one for path dependence. While internal learning could only be measured by R\&D expenditures, 5 different measures were used to assess different dimensions of external learning: (1) external learning (i.e. number of total agreements); (2) external learning with scientific organizations (i.e. number of agreements with universities and non-profit organizations); (3) research "openness" (i.e. number of published libraries); (4) learning through acquisitions (i.e. number of merger and acquisition) and (5) localization effects (i.e. dummy variable set equal to one if the firm is located in California). In this sample, 63 new entrants out of 70 (90 percent) had established linkages with universities, 16 (23 percent) had published libraries and 24 (34 percent) are located in California.

Regarding knowledge assets, four different dimensions were examined using four different measures: (1) age (i.e. the number of years of experience a new entrant accumulated since inception), (2) diversification (i.e. dummy variable set equal to one if the firm is involved in material R\&D); (3) knowledge depth (i.e. number of employees) and (4) size (i.e. number of employees with $\mathrm{Ph} . \mathrm{Ds}$ ). This sample includes 9 firms involved in material R\&D. Finally, the number of marketed drugs, as a measure of past success in drug discovery, captures in an indirect way the fact that firms follow different paths in the course of their life cycle. This is because firms with no drugs in the market are usually de novo entrants, whereas firms with marketed drugs are usually entrants through 
diversification, that is, biotechnology or rational drug discovery firms that have diversified their technology protefolios to include combinatorial chemistry. Thus, 57 firms had no marketed drugs at all, whereas 1 firm had 7 drugs, 2 had 5 drugs, 1 had 4 drugs and 13 had 1 one. Consistent with the theory presented in this thesis, the table shows that new entrants are highly heterogeneous with regard to their learning strategies, knowledge stocks, historical paths and, ultimately, performance. For example, research expenditures vary considerably, from \$ US $\mathrm{O}$ to $\$$ US $231,278,000$. (No research spending was attributed to a firm exiting the industry in 2001). Another example may be found in the fact that a firm held one EPO patent whereas another had 135 patents.

\section{Table 7.1}

Descriptive statistics of new entrants in 2001

\begin{tabular}{|c|c|c|c|c|c|}
\hline \multirow{2}{*}{\multicolumn{2}{|c|}{ Variable }} & \multicolumn{3}{|c|}{ Standard } & \multirow[b]{2}{*}{ Maximum } \\
\hline & & Mean & Deviation & Minimum & \\
\hline & 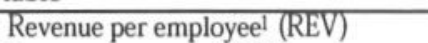 & 89.82 & 73.34 & 0 & 298 \\
\hline & Returns on equity (ROE) & -102.5 & 246.07 & -1592 & 19 \\
\hline & Returns on assets (ROA) & -38.31 & 522.46 & -360.35 & 12.9 \\
\hline 4 & Price book ratio (PBR) & 4.036 & 5.401 & .27 & 35.42 \\
\hline 5 & Profit/Loss ${ }^{1}(\mathrm{PL})$ & $-34,394$ & 35.964 & -224.015 & 34,394 \\
\hline 6 & Number of patents (PAT) & 23.72 & 26.04 & 1 & 135 \\
\hline 7 & $\mathrm{R} \& \mathrm{D}$ expenditures (RD) & 39,915 & 39,960 & 0 & 231.278 \\
\hline 8 & Number of alliances ${ }^{1}$ (ALL) & 25 & 16.73 & 4 & 89 \\
\hline 9 & $\begin{array}{l}\text { Number of alliances with scientific } \\
\text { organizations (SCI) }\end{array}$ & 4.26 & 4.36 & 0 & 24 \\
\hline 10 & Number of published libraries (PUB) & 1.02 & 2.38 & 0 & 15 \\
\hline 11 & Number of acquisitions (M\&A) & 0.65 & 1.01 & 0 & 5 \\
\hline 12 & Localization effects (LOC) & 1.36 & 0.48 & 0 & 1 \\
\hline 13 & Age (AGE) & 12.19 & 6.64 & 4 & 43 \\
\hline 14 & Competence in material $R \& D(N M)$ & 1.15 & 0.36 & 0 & 1 \\
\hline 15 & Number of employees (EMP) & 406 & 374 & 10 & 1000 \\
\hline 16 & Number of PhDs (PHD) & 50 & 20 & 23 & 100 \\
\hline & Number of drugs (DRU) & 0.4023 & 1.166 & 0 & 7 \\
\hline
\end{tabular}

$1=$ in thousands US dollars

Sample: 70 firms

\subsection{Results}

The Pearson correlation results are presented in table 7.2. From it, and consistent with the results of Dubofswki and Varadarajan (1987) and Murphy et al. (1996), one can see that correlation among performance indicators hardly gives positive results. More importantly, returns on equity, returns on assets, price-book ratio and net profit level as a measure of performance prove to be 
unhelpful in our efforts to explain success (or failure). In retrospect, judging new entrants with these indicators is neither fair nor useful. Indeed, paybacks are drawn out over many years: it takes 10 years to bring a drug to market, and the average firm sampled in the analysis is only 12 old. One should also have expected high volatility regarding the financial performance of these new entrants, reflecting the high uncertainty of this sector. ${ }^{96}$ Patent as an indicator of innovativess performs better than financial proxies: they correlate positively with internal learning (i.e. R\&D expenditures), external learning (i.e. number of alliances), research "openness" (i.e. number of published libraries), employees, $\mathrm{PhDs}$ and drugs. However, one should remain cautious about patent counts as a proxy for corporate performance, since patents vary hugely in their technological and economic significance (Pavitt 1988; Griliches 1990). In addition, the results of a linear regression analysis were not statistically significant.

Superior results were obtained for both the correlation and regression analysis when revenues derived from sales and research contracts were used as a proxy for performance. To claim that revenue as an indicator of performance produce positive results, however, is not the same as claiming that all hypotheses have been validated. Neither merger \& acquisition (hypothesis 6) nor age (hypothesis \& made a very large difference in whether the firm received high revenues. Beginning with hypothesis 6 , the empirical test fails to show a strong match between learning through acquisitions and economic performance. Taken at face value, the results may suggest that learning through acquisitions have no impact on revenues. However, the results must be tempered by the fact that this strategic decision is fairly recent: he vast majority of M\&As occured during the last 2 years. To the extent that the integration of knowledge specialists from different location, organizational culture and even scientific background cannot be achieved in such a short time span, the question as to whether M\&As are beneficial to merging or acquiring firms remain open question. Regarding hypothesis 8 , one possible explanation can be put forward for explaining a poor association between age and revenues: younger companies have an advantage over older firms in having access to up-to-date, top-level scientific knowledge while having a disadvantage over older ones regarding the way they execute their organizational routines.

On the other hand, the correlation test reported in table 7.2 confirms

96. Consider the example of Vertex Pharmaceuticals. Recently, Vertex's compounds for failure of chemotherapy, VX-710 and VX-853, have completed Phase II and Phase I, respectively, but aren't currently advancing any further in -house, and have yet to be partnered out. Vertex also announced it had withdrawn one of its lead drugs, VX-745, from clinical trials after observing damage at very high doses in animals. Investors almost instantly knocked 28 percent off the stock price on the news (Goldman 2001). 
hypothesises $1,2,4,7,9,10$ and 12 . Specifically, the correlations seem to indicate that positive association exists between performance and (1) internal learning (2) external learning, (3) external learning with scientific organizations, (4) localization, (3) diversification, (4) size and (5) previous success in drug discovery. Thus R\&D expenditures, the number of total, the number of alliances with scientific organizations, proximity to the best scientific organizations, related diversification into combinatorial material, number of employees, number of $\mathrm{PhDs}$ and number of drugs in the market was strongely correlated with higher performance. Table 7.2 also provides some support for hypothesis 3 and 5 , given that external learning is positively correlated with internal learning and research "openness".

To further substantiate these results, the explanatory power of each dependent variable for which there is no colinearity was examined to provide the best fit model. Several independent variables were indeed so highly correlated that it becames difficult or impossible to distinguish their individual influences on the firm's performance. Consequently, only 5 explanatory variables could be identified, as table 7.3 demonstrates. In this simple model where it is assumed that new entrants overcome the uncertainty, complexity and velocity surrounding drug discovery and development, the results demonstrate that scientific linkages, localization, number of employees, a competence in combinatorial material and marketed drugs increase their expected revenues. The basic model of firm performance is as follows:

$$
\mathrm{REV}=\boldsymbol{\alpha}+B_{1} \mathrm{SCI}+B_{2} \mathrm{LOC}+B_{3} \mathrm{EMP}+B_{4} \mathrm{NM}+B_{5} \mathrm{DRU}
$$

By far the most consistent predictors of superior performance were having competence in new material and having frequent linkages with universities, nonprofit research organizations. Thus these results may suggest that knowledge used in pharmaceutical can efficiently be used in new material R\&D: diversified firms are best positioned to boost revenues. The results also show that new entrants tapping into public research can greatly benefit from know-why created in scientific organizations. The positive effects of external learning with scientific organizations on revenues have an important implication for new entrants in EU15 , the consequence being that these firms, being less connected to the most important source of scientific knowledge, should generate fewer revenues than new entrants in the United States.

There is also evidence suggesting that size and thereby economies of scale can help determine differences in performance. Indeed, successful new entrants use more, not less, employees. As one might have expected, past experience in drug discovery also bestows an advantage as the increase in revenues is directlyई 


\section{Table 7.2}

Intercolleration matrix

\begin{tabular}{|c|c|c|c|c|c|c|c|c|c|c|c|c|c|c|c|c|c|}
\hline Variable & REV & ROE & $\mathrm{ROA}$ & PBR & $\mathrm{PL}$ & PAT & $\mathrm{RD}$ & ALL & $\mathrm{SCl}$ & PUB & $M \& A$ & LOC & AGE & $\mathrm{NM}$ & EMP & PHD & DRU \\
\hline$\overline{\mathrm{REV}}$ & 1 & & & & & & & & & & & & & & & & \\
\hline ROE & .054 & 1 & & & & & & & & & & & & & & & \\
\hline ROA & $.389^{* *}$ & $.313^{*}$ & 1 & & & & & & & & & & & & & & \\
\hline PBR & .102 & $-.513^{* *}$ & * -.158 & 1 & & & & & & & & & & & & & \\
\hline PL & .112 & $.302^{*}$ & .084 & -.003 & 1 & & & & & & & & & & & & \\
\hline PAT & $.275^{*}$ & .141 & .084 & .014 & $-.503^{* *}$ & 1 & & & & & & & & & & & \\
\hline $\mathrm{RD}$ & $.352^{* *}$ & -.064 & .153 & .122 & $-.750^{* *}$ & $.632^{* *}$ & 1 & & & & & & & & & & \\
\hline ALL & $.400^{* *}$ & .024 & .126 & .042 & -.164 & $.437^{* *}$ & $.359^{* *}$ & 1 & & & & & & & & & \\
\hline $\mathrm{SCl}$ & $.377^{* *}$ & -.222 & .067 & .047 & -.072 & .167 & .213 & $.362^{* *}$ & 1 & & & & & & & & \\
\hline PUB & .156 & .121 & .032 & -.083 & -.220 & $.431^{* *}$ & .207 & $.420^{* * *}$ & -.084 & & & & & & & & \\
\hline$M \& A$ & .219 & .203 & .106 & -.166 & .036 & .111 & .072 & $.518^{* *}$ & .198 & .224 & 1 & & & & & & \\
\hline LOC & $.281^{*}$ & .166 & .142 & .155 & .018 & .149 & .175 & .086 & .031 & .156 & .049 & 1 & & & & & \\
\hline AGE & .183 & .044 & .146 & .025 & .060 & .130 & .055 & .098 & .198 & -.108 & .070 & -.115 & 1 & & & & \\
\hline NM & $.325^{* *}$ & .129 & .182 & -.104 & .145 & -.128 & -.056 & .167 & -.087 & .188 & .210 & -.008 & -.169 & 1 & & & \\
\hline EMP & $.504^{* *}$ & .121 & $.293^{*}$ & .047 & $-.401^{* *}$ & $.485^{* *}$ & $.725^{* *}$ & $.589^{* *}$ & .170 & $.326^{* *}$ & $.375^{* *}$ & .149 & .033 & .181 & 1 & & \\
\hline PHD & $.382^{*}$ & .189 & .350 & -.214 & -.118 & $.317^{*}$ & $.459^{* *}$ & $.630^{* *}$ & .144 & $.518^{* *}$ & $.563^{* *}$ & .017 & -.224 & $.456^{* *}$ & $.909^{* *}$ & 1 & \\
\hline DRU & $.415^{* *}$ & .121 & .116 & .160 & $-.432^{* *}$ & $.510^{* *}$ & $.654^{* *}$ & .184 & .102 & .122 & .070 & .184 & .126 & -.097 & $.514^{* *}$ & .175 & 1 \\
\hline
\end{tabular}

${ }^{* *}$ Correlation is significant at the 0.01 level (2-tailed)

- Correlation is significant at the 0.05 level (2-tailed 
attributable to the number of marketed drugs. Finally, the results confirmed the prediction that firms located in California should have higher revenues, though several cautionary notes are necessary. While one has assumed that localization effects derived from closeness to the science base, one could also make the case that California-based new entrants have better access to venture capital, specialized inputs and specialized labour. The data simply cannot distinguish between these factors.

\section{Table 7.3}

$\underline{\text { Regression model with revenue per employee as the dependent variable. }}$

\begin{tabular}{cccccc}
\hline \multicolumn{7}{c}{$\begin{array}{c}\text { Cnstandardized } \\
\text { Coefficients }\end{array}$} & $\begin{array}{c}\text { Standardized } \\
\text { Coefficients } \\
\text { Variable }\end{array}$ & B & Std. Error & Beta & t & Sig. \\
\hline & $-83,297$ & 30,119 & & $-2,766$ &, 007 \\
SCI & 5,360 & 1,423 &, 336 & 3,768 &, 000 \\
LOC & 29,573 & 13,710 &, 192 & 2,157 &, 035 \\
EMP & $6,761 \mathrm{E}-02$ &, 033 &, 221 & 2,056 &, 044 \\
NM & 74,555 & 20,049 &, 341 & 3,719 &, 000 \\
DRU & 15,356 & 6,106 &, 265 & 2,515 &, 014 \\
\hline
\end{tabular}

$\mathrm{R}^{2}=0.514$

$$
\begin{aligned}
& \text { ADJ } R^{2}=0.477 \\
& \mathrm{~F}=13.773 \\
& \mathrm{~N}=70
\end{aligned}
$$

\subsection{CONCLUDING REMARKS}

This thesis started by asking the following question: what conditions separate the winning new entrants from the losers in a turbulent environment? Chapter 3 examined the extent to which knowledge and its creation can improve a firm's competences and thereby its performance position in a turbulent environment. The resulting theory argued that different learning strategies, knowledge stocks and historical paths can explain inter-firm differences in performance. The remainder of the thesis probed at the case of combinatorial chemistry, with chapter 3 beginning the discussion by opening the "black box" of the synthesis methods, chapter 3,4 and 5 assessing the evolving role played in the innovation network by new entrants, large incumbents and scientific organizations and this chapter providing the first insights into the sources of superior performance. Given the complexity of the discussion, it is appropriate for this conclusion to summarize the main findings and ends with some normative prescriptions. 
As demonstrated throughout this thesis, the old screening paradigm is back, if not with a vengeance, then with increased efficiency. However, combinatorial chemistry was not a single, isolated event, since he early methods had been introduced in a "primitive" form by scientific organizations. This is mainly why employees of scientific organizations, new entrants and large incumbents, most commonly scientists from the chemistry profession, had to push the limits of the radical innovation with incremental improvements: small molecule libraries largely replaced peptide libraries; compatible organic reactions for solid phase synthesis were developed; automated instruments took over manual synthesis; etc. By the late eighties-early nineties, "heroic" entrepreneurs in the Schumpeterian mould gave birth to the first new chemical-based entrants. More generally, a new breed of companies, linking the ideas of the pioneering scientists to the market, began performing R\&D contracts and licensing on a non-exclusive basis large random libraries to large pharmaceuticals companies.

But while combinatorial chemistry can be taken to be a competencedestroying discontinuity by the economies of scale it generates, it is really a competence-enhancing process discontinuity in view of the fact that large incumbents had long been familiar with its underlying knowledge base. As a result, and following the predictions of Tushman and Anderson (1986), the introduction of combinatorial chemistry had enhanced, rather than destroyed, the competences of large pharmaceutical companies. By the mid-nineties, every large drug maker was dtermined to develop a competence in the new synthesis field with or without new entrants and scientific organizations. Yet the majority, if not all large incumbents opted to actively learn through acquisitions and/or interfirm cooperation with their smaller cousins. By the late nineties, the transition from the traditional screening method to combinatorial drug discovery was essentially complete, making the market for large collections of compounds less lucrative to new entrants. At the same, large random libraries became less appealing from a technological point of view while competition in the field intensified: the market share of drug-like compounds had to be split among more new entrants, scientific organizations and specialist suppliers, often from Russia and Eastern Europe.

This does not necessarily mean that combinatorial chemistry firms had been doomed from the start. Indeed, recent genomic discoveries about the origin and mechanism of a particular disease open up unprecedented opportunities for screening operations and hence stimulate more combinatorial study and experimentation. There may be as many as 10,000 targets and therefore potential 10,000 niche markets worthy of pursuit, and new entrants willing to crack the market of small molecule drugs know that large pharmaceutical companies will 
not have a stronghold on all of them. Thus, many therapeutic areas are below the radar screen of these drug companies, providing ample technological and commercial opportunities for fast-learning new entrants. Hence, new developments continue at a rapid pace, with scientific organizations, large incumbents and over 390 new entrants engaged in improving both process and product innovations. They have been highly successful. The incremental evolution of the technology, in particular its fruitful fusion with the rational drug design approach, have led to major reductions in discovery and development times. The application of combinatorial chemistry also became more widespread, covering not only pharmaceuticals but also the areas of new materials, catalysts, agro-chemistry, etc. ${ }^{97}$

Very important to recall here is that new entrants willing to leverage synergies between combinatorial chemistry and genomics (or new materials) could no longer simply rely on a single technology platform, given the "commodities" nature of discovery libraries. To the extent that the chemical-based services and combinatorial drug (new materials) discovery approach transcend the discipline of chemistry to include molecular biology, engineering, computational specialists and so on, new entrants have had to create new knowledge and reinforce existing competences and/or developing new ones. However, the business in which these firms are involved is characterized by rapid, complex and uncertain technological change, stiff competition and customer demands change. To cope with such a turbulent environment, top management has been making attempts to integrate their company not only vertically but also horizontally through linkages with other smaller firms. As shown in chapter 4 , these alliances provided a means for learning the knowledge of the other and have been formed with the aim to preempt rivals, to get access to complementary knowledge that would have been too costly to create internally and to reduce risks. Motivated by long-term profits, many if not the majority of new entrants became, or were formed to be, multiple technology platform companies. The logic behind the formation of a multiple technology platform company is the willingness to carve a niche in the small molecule market, though it must be added that the move offers the benefit of introducing a "causal ambiguity" as the reconfiguration of different knowledge streams makes it difficult for rivals to completely understand.

97. One thing that companies also are just coming to appreciate is that combinatorial automation in process development is becoming increasingly important as more drug candidates enter the pipeline (Van Arnum 2000). Additionally, it has also recently been discovered that the combinatorial synthesis approach can be extended to identify and validate targets and thereby probe the whole proteome, giving rise to an entirely new field of research -chemical genomics (Dormán et al. 2001). 
This willingness played a crucial role in stimulating structural changes in the pharmaceutical industry. More precisely, and contrary to the Tushman-Anderson model, de novo entry, along with entry by diversification and entry following mergers and acquisitions, have worked to increase the number of new entrants in the small molecule drug market and will certainly help fill the demand for chemical-based services and products. This further affected the market structures of the pharmaceutical industry, with combinatorial chemistry acting as a catalyst in a new division of labour between large and small firms. The explanation is quite straightforward: large pharmaceutical companies need to plug their innovation gap with small molecule drugs. It follows that a strong complementarity exists between large incumbents and new entrants. In spite of their material advantage, large pharmaceutical firms continue to fall short of expectations regarding the commercialization of therapeutic innovations. In spite of their behavioral advantage, small firms cannot afford to distribute and market their innovations. This dynamic complementarity is apparent in the evolving pattern of relationships between new entrants and large established companies, where an important increase of joint $R \& D$ and licensing agreements has been recorded between 1996 and 2001.

There is, however, a wide variation in revenues per employee across new entrants. If one returns to the theory forwarded in chapter 3 , it can be argued that these inter-firm differences in performance is the outcome of different learning strategies, stocks of accumulated knowledge and historical backgrounds. This clearly suggests that a superior performance position, far from being the outcome of a random process, depends on a firm's ability to learn from external and internal sources, the depth and breath of its knowledge stock and the path it has followed in the course of its history. A turbulent environment, however, confront firms with difficult choices. Which brings us to the initial question: what conditions separate the winning new entrants from the losers in a turbulent environment? This chapter presented results suggesting that performance is associated with (1) external learning with scientific organizations, (2) localization, (3) diversification, (4) size and (5) past successful experience in drug discovery. The support for this claim is that (1) the number of alliances with scientific organizations, (2) location in California, (3) a competence in combinatorial material, (4) number of employees and (5) the number of marketed drugs help determine how much a firm can earn in revenues from sales and contracts per employee.

There is an obvious limitation to all of this, and that arises from the fact that no single combinatorial drug has ever reached the marketplace. It is hard, especially when one is dealing with a product that takes up to ten years to move from 
laboratory to market, to foresee whether a small molecule drug will succeed clinically and economically. The empirical test presented here is also not exempt from problems. The lessons that can be drawn from it must be tempered because the data that are examined only capture financial year 2001, thus amounting to a snapshot of the sampled industry and limiting the scope of the conclusions. The results, clearly, should be further refined by a longitudinal analysis. In addition, performance within firms rests on a blend of factors, which could never be entirely captured by a correlation and regression analysis. Finally, the study should be extended to include performance indicators other that revenues per employee.

Yet few dimensions of a firm's performance are more vital for its survival than revenues derived from sales and inter-firm collaborative agreements. One reason is that new entrants with high revenues per employee are well along the way to generating profits. Another reason is that new entrants concerned about longterm outcome and securing enough revenues can hope to survive until they can develop their own small molecule drug pipeline. The analysis can therefore provide guidance to managers. A first recommendation is that firms seeking to keep abreast of competition must resist the temptation of focusing on a single technology platform and integrate different technologies under the same roof. Grafting knowledge specialists where possible is a convenient way to achieve this objective. Not only would more chemists, biologists and so on enable a firm to serve new markets but also would create scale and scope economies that will ultimately increase revenues. In this respect, it is is important to bear in mind that scale and scope economies cannot be achieved if a company runs its businesses as isolated units: contributions from one business should be able to cross over to the other business (Ghemawat 1986). A second recommendation is that learning, albeit taking place in different places, is especially fruitful with scientific organizations. However, it is important to remark that external collaboration with scientific organizations, while providing a means to renew a firm's knowledge base, can nevertheless fail to internalize important elements of know-why and know-how if not combined with higher levels of internal learning. This leads us to a third and fourth recommendation. On the one hand, and following Cohen and Levinthal (1990), new entrants must increase R\&D expenditures in order to absorb the new knowledge. On the other hand, and following Della Valle and Gambardella (1993), new entrants must encourage "openness" of their research. In concrete terms this should translate into employees publishing scientific papers, participating in conferences and communicating with peers. 


\section{References}

Aaker, D. (1989) Managing assets and skills: the key to sustainable competitive advantage, California Management Journal, Vol. 31, pp. 91-105.

Abramson, N., Encanaçāo, Reid, P., Schoch, U. (1997) Technology Transfer Systems in the United States and Germany, National Academy Press.

Acs, Z., Audretsch, D. (1989) Births and Firm Size, Southern Economic Journal, Vol. 56, No. 2. pp. 467-475.

Adner, R., Levinthal, D. (2001) Demand Heterogeneity and Technology Evolution: Implications for Product and Process Innovation, Management Science, Vol. 47, no. 5. pp. 611-628.

Agrafiotis, D. (1997) Stochastic algorithms for maximizing molecular diversity, Journal of Chem. Inform. Comput. Sc.Vol. 37, pp. 841-851.

Agrafiotis, D., Myslik, J., Salemme, R. (1999) Advances in diversity profiling and combinatorial series design, Molecular Diversity, Vol. 4., No. 1, pp. 1-22.

Aharoni, Y. (1993) In search for the unique: can firm-specific advantage be evaluated? Journal of Management Studies, Vol. 30, pp. 31-49.

Akporiaye, D.E., Dahl, I.M., Karlsson, A., \& Wendelbo, R. (1998) Combinatorial approach to the hydrothermal synthesis of zeolites, Angewandte Chemie International Ed., Vol. 37. pp. 609-611.

Alchian, A.A. (1984) Specificity, specialization and coalitions, Joumal of Institutional and Theoretical Economics, Vol. 140, pp. 34-49.

Amit, R., Livnat, J. (1988) Diversification strategies, business cycles and economic performance, Strategic Management Journal, Vol. 9, pp. 99-110.

Amit, R., Shoemaker, P. (1993) Strategic assets and organizational rent, Strategic Management Journal, Vol. 14, pp. 33-46.

Anand, B., Khanna, T. (2000) Do Companies Learn To Create Value? Strategic Management Journal, Vol. 21 March, pp. 295-316.

Andersen Consulting (1998) Re-Inventing Drug Discovery. The Quest for Innovation and Productivity, Executive Briefing.

Andrews, K. (1971) The Concept of Corporate Strategy, IRWIN, Howood, Illinois.

Antel, J. (1999) Integration of Combinatorial Chemistry and Structure-Based Design. Current Opinion in Drug Discovery and Development, Vol. 2. No. 3, pp. 224-233.

Arora, A., Gambardella, A. (1990) Complementary and external linkages: the strategies of the large firms in biotechnology, Journal of Industrial Economics Vol. 38, pp. 361-481.

Arrow, K (1962a) Economic welfare and the allocation of resources for invention, in R. Nelson, (ed.), The Rate and Direction of Inventive Activity, Princeton.

Arrow, K. (1962b) The economic implication of learnin-by-doing, Review of Economic Studies, no. 29, pp. 155-173.

Arthur, B. (1989) Competing technologies, increasing returns, and lock-in by historical events, The Economic Journal, Vol. 99, pp. 116-131.

Arthur D. Little (2001) The next generation pharmaceutical value chain-Arthur D. Little Industry Forum.

Arundel, A., Van de Pall, G., Soete, L. (1995) Innovation Strategies of Europe's Largest Industrial 
Firms. PACE Report prepared for the SPRINT Programme of the European Commission.

Atkinson, A., Stiglitz, J.E. (1969) A new view of technological change, Economic Journal, Vol. 79, pp. 573-578.

Audretsch, D. (1991) New-firm survival and the technological regime, The Review of Economics and Statistics, Vol. 73 no. 3, pp. 441-450.

Audretsch, D.A., Feldman, M. (1996) R\&D spillovers and the geography of innovation and production, The American Economic Review, Vol. 86, no. 3, pp.630-640.

Audretsch, A (2001) The Dynamic Role of Small Firms: Evidence from the U.S, World Bank, Stock No. 37180.

Augen, J. (2002) The evolving role of information technology in the drug discovery process, Drug Discovery Today, Vol. 7, no. 5, pp. 315-323.

AUTM (Association of University Technology Managers) (2002) FY 2000 Annual AUTM Licensing Survey.

Bailey, D., Brown, D. (2001) High-throughput chemistry and structure-based design: survival of the smartest, Drug Discovery Today, Vol. 6, No. 2, pp. 57-59.

Bain, J.S. (1951) Relation of profit rate to industry concentration: American manufacturing, 1936-1940, Quarterly Journal of Economics, Vol. 65, pp. 293-324.

Bain, J.S. (1954) Economies of scale, concentration, and the condition of entry in twenty manufacturing industries, American Economic Review, Vol. 44, pp. 15-39.

BankBoston (1997) MIT: The Impact of Innovation, prepared by the BankBoston Economics Department.

Barbanti, P., Gambardella, A., Orsenigo, L. (1999) The evolution of collaborative relationships among firms in biotechnology, International Journal of Biotechnology, Vol. 1, No. 1, pp. 10-14.

Barnes, C., Balasubramanian, S. (2000) Recent developments in the encoding and deconvolution of combinatorial libraries, Current Opinion in Chemical Biology, Vol. 4, pp. 346-350.

Barnett, P. (2002) Combinatorial Chemistry: A Guide for Librarians, Issues in Science and Technology Librarianship, No. 33, winter.

Barney, J. (1986) Strategic factor markets: expectations, luck and business strategy. Management Science, Vol. 32, no. 10, pp.1231-1241.

Barney. J. (1991) Firm resources and sustained competitive advantage, Journal of Management, Vol. 17, no. 1, pp. 99-120.

Barney, J. (1992) Integrating organizational behavior and strategy formulation research: a resource-based analysis, Advances in Strategic Management, Vol. 8, pp.39-61.

Barney, J. (1997) Gaining and Sustaining a Competitive Advantage, MA., Addison-Wesley.

Baum. J., Oliver, C. (1991) Institutional linkages and organizational mortality, Administrative Science Quarterly, Vol. 36. pp. 187-218.

Beese, K. (1996) Pharmaceutical Bioprospecting and Synthetic Molecular Diversity, (www.jrc.es/ beese/nat-prod.htm).

Berman, H.M. (1999) The past and future of structure databases, Current Opinion in Biotechnology, Vol. 10, pp. 76-80.

Berman, H.M., Westbrook, J., Feng, Z., Gilliland, G., Bhat, T.N., Weissig, H., Shindyalov, I.N., Bourne, P.E: (2000) The Protein Data Bank, Nucleic Acids Research Vol. 28 pp. 235-242 
Berndt, E., Bui, L., Reily, D., Urban, G. (1994) The Roles of Marketing. Product Quality, and Price Competition in the Growth and Composition of the US Anti-Ulcer Drug Industry, NBER Working Paper 4904.

Bierly, P., Chakrabarti, A. (1996a) Determinants of technology cycle time in the US pharmaceutical industry, R\&D Management, Vol. 26, no. 2, pp. 115-126.

Bierly, P., Chakrabarti, A. (1996b) Generic Knowledge Strategies in the U.S. Pharmaceutical Industry, Strategic Management Journal, Vol. 17, (Winter Special Issue), pp. 123-135.

Biendz-Tadmor, B., DiCerbo, P., Tadmor, G., Lasagna, L. (1992) Biopharmaceuticals and conventional drugs: Clinical Success rates, Bio/Technology, Vol. 10, pp. 521-525.

Blake, J. (2000) Chemoinformatics - predicting the physicochemical properties of 'drug-like' molecules, Current Opinion in Biotechnology, Vol. 11, Issue 1, 2000, pp. 104-107.

Bleeke, J., Ernst, D. (1995) Is Your Strategic Alliance Really a Sale? Harvard Business Review, Vol. 73, no. 1, pp. 97-105.

Blundell, T. (1996) Structure-based drug design, Nature, Vol. 384, Supplement, November 7. pp. 23-26.

Boeker. W. (1989) Strategic change: the effects of founding and history, Academy of Management Journal, Vol. 32, no 3, pp. 489-515.

Böhm, H.J., Stahl, M. (2000) Structure-based library design: molecular modelling merges with combinatorial chemistry, Current Opinion in Chemical Biology, Vol. 4, Issue 3, pp. 283-286.

Borchardt, J. (1998) Combinatorial chemistry: not just for pharmaceuticals, Today's Chemist at Work, Vol. 10, no. 10, pp. 34-35, 37, 39, 41.

Borchardt, J. (2001) Educating for combichem, Today's Chemist at Work, Vol. 10, no. 10, pp. $34-35,37,39,41$.

Borman, S. (1996) Combinatorial chemists focus on small molecules, molecular recognition, and automation. Chemical \& Engineering News Vol. 74, no. 7, pp. 29-54.

Borman, S. (1998) Combinatorial chemistry, Chemical \& Engineering News, Vol. 76, No. 49, pp

Borman, S. (1999) Reducing Time to Drug Discovery, Chemical \& Engineering News, Vol. 77. No. 10, pp.33-48.

Borman, S. (2001) Combinatorial chemistry. Chemical \& Engineering News, Vol. 79, No. 35. pp. $49-58$.

Boswell, C. (2000) High-Throughput Screening Moves to More Refined Libraries, Chemical Market Reporter, August 21.

Brennan, M. (1995) Employment Outlook 1996, Chemical \& Engineering News, October 23.

Brennan, M. (1997) Employment Outlook 1998, Chemical \& Engineering News, Novemnber 3.

Brennan, M. (2000) Employment Outlook 2001, Chemical \& Engineering News, Vol. 78, No. 46.

Brenner, R.A., Lerner, S. (1992) Encoded combinatorial chemistry, Proceedings in National Academy of Science USA, Vol. 89, pp. 5381-5383.

Briceno, G., Chang, H., Sun, X., Schulz, P.G., Xiang, X.D. (1995) A class of cobalt oxide magnetoresistance materials discovered with combinatorial synthesis, Science, Vol. 270 , pp. 273-275.

Brocchini, S., James, K., Tangpasuthadol, V., Kohn,J. (1997); A Combinatorial Approach for Polymer Design, Journal of the American Chemical Society, Vol. 119, no. 19; pp. 45534554.

Brown, K. (1996) Drug, biotech firms beginning to embrace combinatorial chemistry. The 
Scientist, Vol. 10, No. 10, pp. 1-5.

Brown, R.D., Martin, Y.C. (1996) Use of structure-activity data to compare structure-based clustering methods and descriptors for use in compound selection, Journal of Chemical Information and Computer Sciences, Vol. 36, pp. 572-584.

Brown, R.D. (1998) Chemoinformatics: what is it and how does it impact drug discovery, Annual Report of Medicinal Chemistry, Vol. 33, pp. 375-384.

Brown, R.D., Hassan M., Waldman, M. (2000) Combinatorial library design for diversity, cost efficiency, and drug-like character, Journal of Molecular Graphics and Modelling, Vol. 18, Issue 4-5, pp. 427-437.

Bunin, B.A., Ellman, J.A. (1992) A general and expedient method for the solid phase synthesis of 1,4 benzodiazepine derivatives, Journal of American Chemical Society, Vol. 114, pp. 10997-10998.

Burbaum, J. (1998) Miniaturization technologies in HTS: how fast, how small and how soon? Drug Discovery Today, Vol. 3, no. 7, pp. 313-322.

Business Communications Co. Inc. (2001) Combinatorial Chemistry for Materials: What's ahead? Business Communications Publisher.

Caldwell, J. (1998) Patents in comb-space: patent challenges in combinatorial chemistry, Biotechnology and Bioengineering (Combinatorial Chemistry), Vol. 61, No. 1, pp. 69-75.

Callon, M. (1994) Is Science a public good? Science, Technology, and Human Values, Vol. 19. no. 4, pp. 395-424.

Calvert, S., Stewart, F., Swarna, K., Wiseman, J. (1999) The use of informatics and automation to remove bottlenecks in drug discovery, Current Opinion in Drug Discovery and Development, Vol. 2, no. 3, pp. 234-238.

Caruana, C. (2000) Faster growth markets, spur products, projects, Chemical Week; Nov 1.

Carayannis, E.G. (1999) Knowledge transfer through technological hyperlearning in five industries, Technovation, Vol. 19, pp. 141-161.

Carayannis, E.G., Gokes, R. A (1997) Historical analysis of management of technology at

Badische Anilin und Soda Fabrik (BASF) AG, 1865 to 1993: A Case Study, Journal of Engineering and Technology Management, Vol. 14, pp. 175-193.

Caves, R. E., Whinston, M.D., Hurwitz, M. (1991) Patent expiration, entry, and competition in the U.S. pharmaceutical industry, Brookings Papers on Economic Activity Microeconomics, pp. $1-48$.

Chakravarthy, B.S. (1988) Measuring Strategic Performance, Strategic Management Journal, Vol. 7. pp. 110-118.

Chandler, A. (1962) Strategy and Structure, Cambridge, Harvard University Press.

Chatterjee, S., Wernerfelt, B. (1988) Related and unrelated diversifications: a resource-based approach, Academy of Management Proceedings. pp. 7-11.

Chemical Week (1999) DuPont strikes royalty-free deal, June 16.

Chemical Week (2000a) The pesticide hunt. Combinatorial chemistry standard at pesticide labs. August 12.

Chemical Week (2000b) Catalysts: Stepping towards another paradigm, Sept. 13.

Chemical Market Reporter (1998) DSM Teams Up With Cambridge To Use Combinatorial Chemistry, August 31.

Chemical Market Reporter (2001) US-Based Drug Companies Outpaced Most European Counterparts Last Year, March 26.

Chemical Market Reporter (2002) UOP starts up combinatorial catalysis business, August 5. 
Christensen, C. M. (1997) The innovator's dilemma: When new echnologies cause great firms to fail. Boston: Harvard Business School Press.

Coates, W., Hunter, D., MacLachlan, W. (2000) Successful implementation of automation in medicinal chemistry, Drug Discovery Today, Vol. 5, no. 11, pp. 521-527.

Cockburn, I., Henderson, R. (1994) Racing to invest? The dynamics of competition in the ethical drug discovery. Journal of Economics and Management Strategy. Vol. 3, pp. 481519 .

Cockburn, I., Henderson, R. (1998) Absorptive Capacity, Coauthoring Behavior, and the Organization of Research in Drug Discovery, Journal of Industrial Economics. Vol. 46, no. 2. pp. $157-182$

Cockburn, I., Henderson, R., Orsenigo, L., Pisano, G. (1999) Pharmaceuticals and Biotechnology, US Industry in 2000, Studies in Competitive Performance, pp. 363-398.

Coe, D., Storer, R. (1999) Solution-phase combinatorial chemistry, Molecular Diversity, Vol. 4, pp. 31-38.

Cohen, W. M. (1995) Empirical studies of innovative activities, in P. Stoneman (ed). Handbook of the Economics of Innovation and Technological Change, Blackwell Handbooks.

Cohen, W.M, Burkhart, R., Dosi, G., Egidi, M., Marengo, L., Warglien, M., Winter, S. (1996) Routines and other recurring action patterns of organization: contemporary research issues, Industrial and Corporate Change, Vol. 5. pp. 653-699.

Cohen, W. M., Levinthal, D.A. (1989) Innovation and learning: The two faces of R\&D Implications for the analysis of R\&D investment, Economic Journal, Vol. 99, pp. 569596.

Cohen, W.M., Levinthal, D. A. (1990) Absorptive capacity: a new perspective on learning and innovation, Administrative Science Quarterly, Vol. 35, pp. 128-152.

Cohen, W. M., Nelson, R., Walsh, J. (2000) Protecting their Intellectual Assets: Appropriability Conditions and Why US Manufacturing Firms Patent (or Not), NBER Working Paper 7552.

Collins, P.. Wyatt, S. (1988) Citations in patents to the basic research literature, Research Policy, Vol. 17, pp. 65-74.

Collis, D. (1991) A resource-based analysis of global competition: the case of the bearing industry. Strategic Management Journal, Vol. 12, pp. 49-68.

COM (2001) Communication from the Commission to the Council and the European

Parliament on implementation of the risk capital action plan (RCAP), 605 final, Brussels.

Comanor, W. S. (1965) Research and Technical Change in the Pharmaceutical Industry. Review of Economics and Statistics, Vol. 47, pp. 182-190.

Comanor, W.S. (1986) The political economy of the pharmaceutical industry, Journal of Economic Literature, Vol. 24, pp.1178-1217.

Conner, K. (1991) A historical comparison of resource-based theory and five schools of thought within industrial economics: Do we have a new theory of the firm? Journal of Management, Vol. 17, no. 1, pp. 121-154.

Connolly Martin, Y. (1996) Opportunities for Computational Chemists Afforded by the New Strategies in Drug Discovery: An Opinion, Abbott Laboratories (www.netsci.org).

Connolly Martin, Y. (1998) 3D QSAR: current state, scope and limitations, Perspective in Drug Discovery and Design, Vol. 12/13/14, pp. 3-23.

Connolly Martin, Y. (2000) Molecular Diversity: How do we measure it? Has it lived up to its promise? II Farmaco, Vol. 56, pp. 137-139.

Cong P., Dehestani A., Doolen R., Giaquinta D.M., Guan S., Markov V., Poojary D., Self K., 
Turner H., Weinberg W.H. (1999) Combinatorial discovery of oxidative dehydrogenation catalysts within the Mo-V-Nb-O system, Proceedings of the National Academy of Sciences of the United States of America, Vol. 96, Issue 20, pp. 11077-11080.

Cool, K., Schendel, D. (1988) Performance differences among strategic group. Strategic Management Journal, Vol. 9. pp. 207-223.

Copeland, M. (2001) Agouron profits from pharma buyout. A tale of one biotech firm, two corporate parents, and two kinds of autonomy, Red Herring Magazine, March 19.

Cowan, R., Foray, D. (1997) The economics of codification and the diffusion of knowledge, Industrial and Corporate Change, Vol. 6, pp. 595-622.

Cramer, R.D. III, Patterson, D.E., Bunce, J.D. (1988) Comparative molecular field analysis (CoMFA). 1. Effect of shape on binding of steroids to carrier proteins, Journal of American Chemical Society, Vol. 110, pp. 5959-5967.

Current Patents (1999) Special Issue: Combinatorial Chemistry, Current Trend in Pharmaceutical Discovery, Vol. 2, No. 3.

Dagani, R. (1999) A faster route to new materials, Chemical \& Engineering News, March 8, pp. 51-60.

Damms, B., Bains, W. (1995) The cost of delivering drugs without needles, Bio/Technology, Vol. 13, No. 13, pp. 1438-1441.

Danielson, E., Golden, J.H., McFarland, E., Reaves, C., Weinberg, W., Wu, X. (1997) Combinatorial approach to the discovery and optimization of luminescent materials, Nature, Vol. 389, Issue 6654, pp. 944-948.

Dasgupta, P., David, P. (1994) Towards a new economics of science, Research Policy, Vol. 23, pp. 487-521.

David, P. (1975) Technical Choice, Innovation and Economic Growth: Essays on American and British Experience in the Nineteen Century, Cambridge, Cambridge University Press.

David, P. (1993) Knowledge, property, and the system dynamics of technological change, in L. Summer, and S. Sha. (eds), Proceedings of the World Bank Annual Conference on Development Economics 1992, Washington DC. World Bank Press, pp. 215-248.

David, P., Mowery. D., Steinmueller, E. (1992) Analysing the economic pay-offs from basic research, Economics of Innovation and New Technology, Vol. 2, pp. 79-90.

Davis, S. Haltiwanger, J. (1992) Gross job creation, gross job destruction, and employment reallocation, Quarterly Journal of Economiss, August, pp. 819-863.

Davies, K., Upton, R. (1995) 3D pharmacophore searching, Network Science (www.netsci.org).

DeBresson, C., Amesse, F. (1991) Networks of innovators: a review and introduction to the issue, Research Policy, Vol. 20, pp. 363-379.

Deeds, D., De Carolis, D., Coombs, J. (1997) The impact of firm specific capabilities on the amount of capital raised in an initial public offering, Journal of Business Venturing, Vol. 12 . no. 1, pp. 31-46.

Della Valle, F., Gambardella, A. (1993) Biological revolution and strategies for innovation in pharmaceutical companies, R\&D Management, Vol.23, no.4, Cambridge.

Demsetz, H. (1973) Industry structure, market rivalry and public policy, Journal of Law and Economics, pp. 1-9.

Demsetz, H. (1988) The theory of the firm revisited, Journal of Law, Economics, and Organization, Vol. 4, no. 1, pp. 141-161.

Den Hertog, F., Huizenga, E. (2000) The Knowledge Enterprise, Implementation of Intelligent 
Business Strategies, Imperial College Press.

Deprez, B., Williard, X., Bourel, L., Coste, H., Hyafil, F., Tartar, A. (1995) Orthogonal combinatorial chemical libraries, Journal of American Chemical Society, Vol. 117, pp. 5405-5406.

Desrochers, P. (2001) Geographical proximity and the transmission of tacit knowledge. The Review of Austrian Economics, Vol. 14, pp. 25-46.

DeWitt, S.H.H., Kiely, J.K., Stankovic, C.J., Schroeder, M.C., Cody, D.M.R., Pavia, M.R. (1993) Diversomers: An approach to nonpeptide, nonoligomeric chemical diversity, Proceedings in National Academy of Science USA, Vol. 90, pp. 6909-6913.

Dierickx, I., Cool, K. (1989) Asset stock accumulation and sustainability of competitive advantage, Management Science, Vol. 35, no. 12. pp. 1504-1513.

DiMasi, J.S. (2000) New drug innovation and pharmaceutical industry structure: trends in the output of pharmaceutical firms, Drug Information Journal, Vol. 34, no. 4, pp. 1169-1194.

DiMasi, J.S., Graboswski, H.G., Vernon, J. (1995) R\&D costs, innovative output and firm size in the Pharmaceutical Industry, International Journal of the Economics of Business, Vol.2, no. 2, pp. 201-219..

Dodgson, M. (1992) The strategic management of R\&D collaboration, Technology Analysis \& Strategic Management, Vol. 4, No. 3, pp. 227-245.

Dodgson, M. (1991) Technology Learning. Technology Strategy and Competitive Pressures, British Journal of Management, Vol. 2, pp. 133-149.

Dolle, R. (1998a) Comprehensive survey of chemical libraries yielding enzyme inhibitors, receptor agonists and antagonists, and other biologically active agents: 1992 through 1997. Molecular Diversity, Vol. 3, pp. 199-233.

Dolle, R. (1998b) Comprehensive survey of combinatorial libraries with undisclosed biological activity: 1992-1997. Molecular Diversity. Vol. 4, pp. 233-256.

Dolle, R., Nelson. K. (1999) Comprehensive survey of combinatorial library synthesis: 1998. Journal of Combinatorial Chemistry. Vol. 1, No. 4. pp. 235-282.

Dolle, R. (2000) Comprehensive survey of combinatorial library synthesis: 1999, Journal of Combinatorial Chemistry, Vol. 2, No. 5, pp. 383-433.

Dolle. R. (2001) Comprehensive survey of combinatorial library synthesis: 2000, Journal of Combinatorial Chemistry, Vol. 3, No. 6, pp. 1-41.

Dollinger, M. (1999) Entrepreneurship: Strategies and Resources, Prentice-Hall.

Dooley, C.T., Houghten, R.A. (1993) The use of positional scanning synthetic peptide combinatorial libraries for the rapid determination of opioid receptor ligands, Life Sciences, Vol. 52. pp. 1509-1517.

Dosi, G. (1984) Technical Change and Industrial Transformation, London, Macmillan.

Dosi, G. (1988) Sources, procedures and microeconomic effects of innovation, Journal of Economic Literature, Vol. 26, pp. 1120-1171.

Dosi, G., Teece, D., Winter, S. (1992) Toward a Theory of Corporate Coherence: Preliminary Remarks, in G. Dosi, R. Giannetti, and P. A. Toninelli (eds.), Technology and Enterprise in a Historical Perspective Oxford: Clarendon Press, pp. 186- 211.

Dove, A. (1999) Drug screening-beyond the bottleneck, Nature Bio/Technology. Vol. 17. no.13, September, pp. 859-863.

Downs, G.M., Willett, P. (1995) Similarity Searching in Databases of Chemical Structures, Reviews in Computational Chemistry. Vol. 7. pp. 1-66.

Doz, Y., Hamel, G. (1998) Alliance Advantage: The Art of Creating Value Through Partnering. 
Harvard Business School.

Drews, J. (1997) Strategic choice facing the pharmaceutical industry: a case for innovation, Drug Discovery Today, Vo. 2, no. 2, pp. 72-78.

Drews, J., Ryser, S. (1997) Molecular drug targets and genomics sciences, Nature Bio/Technology, Vol. 15, no.13, October, Pullout section.

Drewry, D., Young, S. (1999) Approaches to the design of combinatorial libraries, Chemometrics and Intelligent Laboratory Systems, Volume 48, Issue 1, 14 June 1999, pp. 120.

Dubofswki, P, Varadarajan, P. (1987) Diversification and measures of performance: additional evidence, Academy of Management Journal, Vol. 30, no. 3, pp. 597-608.

Duncan, R. K. (1907) The Chemistry of Commerce. A Simple Interpretation of Some New Chemistry in its Relation to Modern Industry, New York, Harper.

Dunne, T., Roberts, M., Samuelson, L. (1996) The Growth and Failure of U.S. Manufacturing Plants, in Z, Acs (ed), Small Firms and Economic Growth, U.K., Elgar.

Duysters, G. (1996) The Dynamics of Technical Innovation: The Evolution and Development of Information Technology, Cheltenham: Edward Elgar.

Ebers, M. (1997) Explaining Inter-Organisational Network Formation, The Formation of InterOrganisational Networks, edited Mark Ebers, Oxford University Press, pp. 3-40.

Ehrnberg, E. (1995) On the Definition and Measurement of Technological Discontinuities, Technovation, Vol. 15, No.7, pp. 437-452i

Ekins, S.I, Waller, C., Swaan, P., Cruciani, G., Wrighton, S., Wikel, J. (2000) Progress in predicting ADME parameters in silico, Journal of Pharmacological and Toxicological Methods, Vo. 25, pp. 251-272.

Ehrlich, P. (1909) Present status of chemotherapy, Chem. Ber. Vol. 42, pp. 17-47.

Enos, J. (1962) Invention and Innovation in the Petroleum Refining Industry, in The Rate and

Direction of Inventive Activity, ed: Richard Nelson. Princeton: Princeton University Press, pp. 299-322.

Ernst \& Young (1995) Biotech 95. Reform, Restructure, Renewal, Ernst \& Young's Ninth Annual Report on the Biotechnology Industry.

Fairley, P. (1998) Combinatorial chemistry: R\&D power for a price, Chemical Week, August 12.

Fairley, P. (1999) Combinstorial chemistry materials take on Symyx, Chemical Week, August 11.

Fauchere, J.L., Boutin, J.A., Henlin, J.-M., Kucharczyk, N., Ortuno, J.-C. (1998) Combinatorial chemistry for the generation of molecular diversity and the discovery of bioactive leads, Chemometrics and Intelligent Laboratory Systems, Vol. 43, Issue 1-2. September, pp. 43-68

Fecik, R., Frank, K., Gentry, E., Menon, S., Mitsherm, L. Telikepalli, H. (1998) The search for orally medications through combinatorial chemistry, Medical Research Review, Vol. 18, no. 3, pp. 145-185.

Figueiredo, P. (2002) Does technological learning pay off? Inter-firm differences in technological capability-accumulation paths and operational performance improvement, Research Policy, Vol. 31, pp. 73-94.

Fitch, F. (1999) Analytical methods for quality control of combinatorial libraries, Molecular Diversity, Vol. 4, pp. 39-45.

Fitzgerald, J.D. (1992) Technology transfer issues in licensing pharmaceutical products, $R \& D$ 
Management, Vol. 22, no. 3, pp. 199-208.

Flanagan, N. (2001) Firms creating more focused compound libraries, Genetic Engineering News, Vol. 21, No. 20.

Fodor, S.P.A , Leighton, R.J. Pirrung, M. C., Stryer, L. Lu, A. T. Solas, S. (1991) The Light Directed, Spatially Addressable Parallel Chemical Synthesis, Science, Vol. 251, pp. 767-773.

Foss, K., Foss, N. J. (1998) The Knowledge-based Approach: An organizational Economics Perceptive, mimeo.

Foss, N. J., Knudsen, C., Montgomery, C. (1995) An exploration of common ground: integrating evolutionary and strategic theories of the firm, Resource-based and Evolutionary Theories of the Firm, Boston: Kluwer.

Frank, R., Heikens, W., Heisterberg-Moutsis, G., Blocker, H. (1983) A new general approach for the simultaneous chemical of large numbers of oligonucleotides: segmental solid supports, Nucleid Acid Research, Vol. 11, pp. 4365-4377.

Frank, R. (1992) SPOT Synthesis: an easy technique for the positionnaly addressable parallel chemical synthesis on a membrane support, Tetrahedron, Vol. 48, pp. 9217-9232.

Frank, R. (1993) Strategies and techniques in simultaneous solid phase synthesis based on the segmentation of membrane type supports, The Generation of Molecular Diversity, Vol. 3. 425-430.

Freeman, C. (1991), Networks of Innovators: A Synthesis of Research Issues, Research Policy, Vol. 20, No. 5, pp. 499-514.

Freeman, C., Soete, L. (1997) The Economics of Industrial Innovation, Pinter Publication.

Freemantle, M. (1999) Downsizing chemistry, Chemical \& Engineering News, February 22, pp. 27-36.

Fryxell, G.E., Barton, S.L. (1990) Temporal and contextual change in measurement structure of financial performance: implications for strategy research, Journal of Management, Vol. 16. No. 3, pp. 553-569.

Fujimura, J. (1988) The molecular biological bandwagon in cancer research. Social Problems, Vol. 35, no. 3, pp. 261-283.

Furka, À. (1982) Tanulmány, gyógyászatilag hasznositható peptidek szisztematickus felkutasánák lehetöségérôl. Unpublished theoretical study written in Hungarian for internal use. describing the PM synthesis and an iteration strategy for screening of soluble libraries. Notarized on June 15 , file number $36237 / 1982$.

Gallagher, D. (1998) San Diego leads nation in biotech grants, San Diego Daily Transcript, July 21.

Gallop, M., Barrett, R., Dower, W., Fodor, S., Gordon, E. (1994) Applications of combinatorial technologies to drug discovery. 1. Background and peptide combinatorial libraries, Journal of Medicinal Chemistry, Vol.37, No.9. pp.1233-1251.

Gambardella, A. (1992) Competitive advantages from in-house scientific research: The US pharmaceutical industry during in the 1980s, Research Policy, Vol.21, pp.391-407.

Gambardella, A. (1995) Science and Innovation. The US pharmaceutical industry during the 1980s, Cambridge University Press.

Garud, R. (1997) On the distinction between know-how, know-why and know-what, Advances in Strategic Management, Vol. 14, pp. 81-101.

Gelijns, A., Rosenberg, N. (1994) The changing nature of medical technology development, Sources of Medical Technology: Universities and Industry, vol. 5, National Academy Press. 
Gerowski, P.. Jacquemin, A. (1988) The persistence of profits: a European comparison, The Economic Journal, Vol. 98, June, pp. 373-389.

Geysen, H.M., Meloen, R.H., Barteling, S.J. (1984) Use of peptide synthesis to probe viral antigens for epitopes to a resolution of a single amino acid, Proceedings in National Academy of Science USA, Vol. 81, pp. 3998-4002.

Ghose, A., Wendoloski, J. (1998) Pharmacophore Modeling: methods, experimental verification and applications, Perspective in Drug Discovery and Design, Vol. 9/10/11, pp. 253-271.

Gibbons, M., Johnston, R. (1974) The roles of science in technological innovation, Research Policy, Vol.3, pp.220-242.

Gibbons, M., Limoges, C., Nowotny, H., Schartzman, S., Scott, P., Troiw, M. (1994) The new production of knowledge: the dynamics of science and research in contemporary societies, London, SAGE,

Ghemawat, P. (1986) Sustainable Advantage, Harvard Business Review, September-October, pp. 53-58.

Glaser, V. (1995) Drug companies like combinatorial chemistry, Bio/Technology, Vo. 13, pp. 310,311 .

Gille, B. (1978) Histoire des Techniques, Encyclopédie de la Pleiade.

Godin, B. (1996) Research and the practice of publication in industries, Research Policy, Vol. 25. pp. 587-606.

Goldman, B. (2001) The chemical element, Signals Magazine, November 11.

Golebiowski, S., Klopfenstein, R., Portlock, D. (2001) Lead compounds discovered from libraries Adam, Current Opinion in Chemical Biology, Vol. 5, pp. 273-284.

Gorse, D., Lahana, R. (2000) Functional diversity of compound libraries, Current Opinion in Chemical Biology, Vol. 4, Issue 3, pp. 287-294.

Grabowski, H.G., Vernon JM (1982) The Pharmaceutical Industry, Government and Technical Progress. A Cross Industry Analysis, ed. by R.Nelson, Pergamon.

Grabowski, H. G. (1976) Drug Regulation and Innovation, American Enterprise Institute.

Grabowski, H.G., Vernon, J.M (1994) Returns to R\&D on new drug introductions in the 1980s, Journal of Health Economiss, Vol. 13, pp. 383-406.

Grabowski, H.G., Vernon, J.M, DiMasi, J. (2002) Returns on R \&D H. for 1990s New Drug Introductions, Forthcoming in PharmcoEconomics.

Grandstrand, O., Sjolander, S. (1990) The Acquisition of Technology and Small Firms by Large Firms, Journal of Economic Behavior and Organization, Vol. 13, pp. 367-386.

Grant, R. (1991) The resource-based theory of competitive advantage: implications for strategy formulation, California Management Journal, Spring, pp. 114-135.

Grant, R. (1996a) Prospering in dynamically-competitive environments: organizational capability as knowledge integration, Organization Science, Vol. 7, No. 4, pp. 375-387.

Grant, R. (1996b) Towards a knowledge-based theory of the firm. Strategic Management Journal, Vol. 17, pp. 109-122.

Grant, R. (1998) Contemparary Strategy Analysis: Concepts, Techniques, Applications, 3rd ed. Blackwell.

Grant, R., Badder-Fuller, C. (1995) A knowledge-based theory of the inter-firm collaboration, Best Management Paper Proceeding. Academy of Management, pp. 17-21.

Grethe, G. (1999) Reaction information management. Current Opinion in Drug Discovery \& Development, Vol. 2, no. 3, pp. 209-212. 
Griliches, Z. (1990) Patent Statistics as Economic Indicators: A Survey, Journal of Economic Literature, Vol. 28, pp. 1661-1707.

Gulati, R., Nohria, N., Zaheer, A. (2000) Strategic Networks, Strategic Management Journal, Vol. 21, pp. 203-215.

Güner, O., Casher, O. (1999) Role of the Internet in chemoinformatics: recent development, Current Opinion in Drug Discovery \& Development, Vol. 2, no. 3, pp. 204-208.

Gwynne, P. (1999) Focus on careers: Combinatorial chemists on the fast track, Science, March 12, Special advertising supplement.

Hadlington, S. (1999) Faster pace in the hunt for drugs, Financial Times, December 11.

Hagedoorn, J. (1990) Organisational modes of inter-firm cooperation and technology transfer, Technovation, Vol. 10, no. 1, pp. 17-31.

Hagedoorn, J., Schakenraad, J. (1990) Inter-firm partnerships and cooperative strategies in core technologies, in C. Freeman and L. Soete (eds), New Explorations in the Economics of Technical Change, London, Pinter.

Hagedoorn, J. (1993) Understanding the rationale of strategic technology partnering: interorganizational modes of cooperation and sectoral differences, Strategic Management Journal, Vol. 14, pp. 371-385.

Hagedoorn, J., Sadowski, B. (1999) The Transition From Strategic Technology Alliances to Mergers and Acquisitions: An Exploratory, Study, Journal of Management Studies, Vol. 36, no. 1. pp. 87-107.

Hamel, G., Doz., Y. L., Prahalad, C. K. (1989) Collaborate with your competitors - and win, Harvard Business Review, Vol. 67, pp. 133-139.

Hanak, J.J. (1970) The "multiple-sample concept" in materials research: synthesis, compositional analysis and testing of entire multicomponent systems, Joumal of Materials Science, Vol. 5, Issue 964.

Hann, M., Green, R. (1999) Chemoinformatics -a new name for an old problem? Current Opinion in Chemical Biology. Vol. 3, pp. 379-383.

Hannan, M., Freeman, J. (1984) Structural inertia and organizational change, American Sociological Review, Vol. 49, April, pp. 149-164.

Hansch, C., Fujita, T. (1964) [[rho]]-[[sigma]]-[lpi]] Analysis. A Method for the Correlation of Biological Activity and Chemical Structure, Journal of the American Chemical Society, Vol. 86. pp. 1616-1626.

Hansen, G., Wernerfelt, B. (1989) Determinants of firm performance: the relative importance of economic factors, Strategic Management Journal, Vol. 10. pp. 399-411.

Harley, C. (1971) The shift from sailing ships to steamships, 1850-1890: a study h technological change and diffusion, D. McCloskey, ed. Escays on a Mature Economy: Britain after 1840, Methuen, London.

Hegert, M., Morris. D. (1988) Trends in international collaborative agreements, in F. Contractor, and P. Lorange (eds) Cooperative Strategies in International Business, Lexington, Lexington Books.

Henderson, R. (1993) Underinvestment and incompetence as responses to radical innovation: evidence from the photoligraphic alignment equipment industry, RAND Joumal of Economics, Vol. 24, no. 2, pp. 248-270.

Henderson, R. (2000) Drug industry mergers won't necessarily benefit R\&D, Research Technology Management, July/August, pp. 10-11.

Henderson, R., Clark, K. (1990) Architectural innovation: reconfiguration of existing product 
technologies and the failure of large firms, Administrative Science Quarterly, Vol. 35, pp. 9-30.

Henderson, R., Cockburn, I. (1994) Measuring competence? Exploring firm effects in pharmaceutical research, Strategic Management Journal, Vol. 15, pp. 63-84.

Henderson, R. (1994) The evolution of integrative capability: Innovation in cardiovascular drug discovery, Industrial and Corporate Change. Vol. 3, no. 3, pp. 607-629.

Henderson, R., Cockburn, I. (1996) Scale, scope and spillovers: the determinants of research productivity in drug discovery, RAND Journal of Economics, Vol. 27, no. 1, pp. 32-59.

Henry, C. (2000) Employment: Making materials, Chemical \& Engineering News, Vol.78, no. 14, pp. 74-78.

Henry, C. (2001a) Structure-based drug design. Chemical \& Engineering News, Vol. 79, pp.6974.

Henry, C. (2001b) Synthetic chemistry at biotech firms. Industry trend toward smallmolecule therapeutics drives need for organic chemists, Chemical \& Engineering News, Vol. 79, pp.77, 82, 88 .

Hertzberg, R.P., Pope, A.J. (2000) High-throughput screening: New technology for the 21st century, Current Opinion Chemistry and Biology. Vol. 4, pp. 445-451.

Herrera, S. (2002) Knowledge is power, but pills are profit, Red Herring Magazine, May 2.

Hewes, J. (2000) High throughput methodologies for chemical and materials, National Institute for Standards and Technology, Advanced Technology Program, (www.atp.nist.gov).

Hicks, D. (1995) Published Papers, Tacit Competencies and Corporate Management of the Public/Private Character of Knowledge. Industrial and Corporate Change. Vol. 4, pp. 401-424.

Hird, N. (1999) Automated synthesis: new tools for the organic chemist, Drug Discovery Today, Vol. 4, no. 6, pp. 265-274.

Hitt, M., Ireland, R., Lee, H. (2000) Technological learning, knowledge management, firm growth and performance: an introductory essay, Journal of Engineering and Technology Management, Vol. 17, pp. 231-246.

Hodgson, G. H. (1998) Competence and Contract in the Theory of the Firm, Journal of Economic Behavior and Organization, Vol. 35, no. 2, April, pp. 179-201.

Hollander, S. (1965) The Sources of Increased Inefficiency: the Study of DuPont Rayon Plants, MIT Press, Cambridge, Mass.

Holm, A., Myrdal, M. (1989) Multiple column peptide synthesis, In Peptides 1988. Proceedings 20.EPS; Jung, G., Bayer, E. Eds.; Wlater de Gruyter \& Co.P: Berlin, pp. 208-210.

Holzwarth, A., Schmidt, P.W., \& Maier, W.E. (1998) Detection of catalytic activity in combinatorial libraries of heterogeneous catalysts by IR thermography. Angew. Chem. Int. Ed., Vol. 37, pp. 2644-2647.

Holzwarth, A., Denton, P., Zanthoff, H., Mirodatos, C. (2001) Combinatorial approaches to heterogeneous catalysis: strategies and perspectives for academic research, Catalysis Today, Vol. 67, pp. 309-318.

Houghten, R.A., Pinilla, C., Blondelle, S.E., Appel, J.R., Dooley, C.T., Cuervo, J.H. (1991) Generation of and Use of Synthetic Peptide Combinatorial Synthesis for the Basic Research and Drug Discovery, Nature, Vol. 354, pp. 84-86.

Houston, J., Banks, M. (1997) The chemical-biological interface: developments in automated and miniaturized screening technology, Current Opinion in Biotechnology, Vol, 8, pp. 734 
740.

Huber, G. (1991) Organizational learning: the contributing processes and the literatures, Organization Science, Vol. 2, no. 1, pp. 88-115.

Hughes, B.C (1996) The clinical test: human trials, R\&D Directions, March pp. 10-11.

Inkpen, A. (1996) Creating knowledge through collaboration, California Management Review. Vol. 39, Bo. 1, fall, pp. 123-140.

Isaacs, E.D., Marcus, M., Aeppli, G., Xiang, X.D., Sun, X.D., Schultz, P., Kao, H.K., Cargill, G.S., \& Haushalter, R. (1998) Synchrotron X-ray microbeam diagnostics of combinatorial synthesis. Appl. Phys.

Jacobsen, R. (1988) The persistence of abnormal returns, Strategic Management Journal. Vsol. 9. pp. 63-84.

Jaffe, A. (1986) Technological opportunity and spillovers of R\&D, American Economic Review, Vol. 76, pp. 984-1001.

Jaffe, A. (1989) Real Effects of Academic Research. American Economic Review Vol. 79, pp. 957-970.

Jaffe, A., Trajenberg, R., Henderson, R. (1993) Geographic localization of knowledge spillovers as evidence of knowledge spillovers, Quarterly Journal of Economics. Vol. 63. pp. $577-598$.

Jandeleit, B., Schaefer, D., Powers, T., Turner, H., Weinberg. H. (1999) Combinatorial materials science and catalysis, Angewandte Chemie International Edition, Vol. 38, pp. 2494-2532.

Jarvis, L. (2002) Pharma, challenged on innovation, looks to better integrate Biotechnology toolbox, Chemical Market Reporter, May 6.

Jensen, B., McGuckin, R. (1997) Firm performance and evolution: empirical regularities in the US Microdata, Industrial Structure and Dynamics, Vol. 6, No. 1, pp. 25-47.

Jewkes, J.. Sawers, D., Stillerman, R. (1958; 1969) The Sources of Innovation, W.W. Norton \& Company.

Kane, J. (1999) Ultra-High-Throughput Screening Raises the Technology Bar, Chemical Market Reporter, August 16.

Kanter, M., Brinkerhoff, D. (1981) Organizational Performance: Recent Developments in Measurement, Annual Review of Sociology, Vol. 7, pp. 321-349

Karet, G. (1998) Abbott accelerates its combichem efforts, Research and Development Magazine, November, pp. 26-28.

Karet, G. (1999) Are you screening too many compounds? Drug Discovery and Development, November/December, pp. 39-42.

Katz, R., Allen, T. (1982) The Not Invented Here Syndrome (NIH): a look at the performance, tenure and communication patterns of $50 \mathrm{RD}$ project groups. $R \& D$ Management, Vol. 12, No. 1, pp. 7-19.

Keil, T., Laamanen, T. (1995) Technology transfer through technology-driven acquisitions: an exploraitive study, Helsinki University of Technology. Institute of Industrial Management.

Kelly, C. (2000) Rising demand for combinatorial skills, Manufacturing chemist, August, pp. 33-34-

Kelm, K., Narayan, V.K. (1995) Shareholder value creation during R\&D innovation and commercialization stages, Academy of Management Journal, Vol. 38, no.3, pp. 770-786.

Kenney, M. (1986) Biotechnology. The University-Industrial Complex, Yale University Press. 
Kerr, J.M., Banville, S.C., Zuckermann, R.N. (1993) Encoded combinatorial peptide libraries containing non-natural amino acids, Journal of American Chemical Society, Vol. 115, pp. 2529-2531.

Klevorick, A., Levin, R., Nelson, R., Winter, S. (1995) On the Sources and Significance of Interindustry Differences in Technological Opportunities, Research Policy, Vol. 24, pp. 185-205.

Koberstein, W. (2000) Standing on scale, Pharmaceutical Executive, August, pp. 40-54.

Kodama, F. (1986) Japanese innovation in mechatronics technology. Science and Public Policy, Vol. 13, No. 1, pp. 44-51.

Kogut, B., (1988) Joint ventures: theoretical and empirical perspectives, Strategic Management Journal, Vol. 9, pp. 319-332.

Kogut, B. (1989) The Stability of Joint Ventures: Reciprocity and Competitive Rivalry, Journal of Industrial Economics. Vol. 38, no. 2, pp. 183-198.

Kogut, B., Zander, U. (1992) Knowledge of the firm, combinative capabilities and the replication of technology, Organization Science, Vol. 3, no. 3, pp. 383-397.

Kogut, B. (2000). The network as knowledge: Generative rules and the emergence of structure, Strategic Management Journal, Vol. 21, no. 3, pp. 405-425.

Kricka, L. (1998) Revolution on a square centimeter, Nature Bio/Technology, Vol. 16, June.

Krieger. J. (1996) Combinatorial chemistry spawns new software systems to manage flood of information, Chemical \& Engineering News, Vol.57, No.15, February 12.

Krieger, J. (1997) Integration hits software tools, Chemical \& Engineering News, Vol. 75. No.40.

Kubinyi, H. (1997a) QSAR and 3D QSAR in drug design Part 1: methodology, Drug Discovery Today, Vol. 2. Issue 11. November, pp.457-467.

Kubinyi, H. (1997b) QSAR and 3D QSAR in drug design Part 2: applications and problems, Drug Discovery Today, Vol. 2. Issue 12, December 1997, pp. 538-546.

Kubinyi, H. (1998a ) Structure-based design of enzyme inhibitors and receptor ligands, Current Opinion on Drug Discovery and Development, Vol. 1, No. 1, pp. 4-15.

Kubinyi, H. (1998b) Similarity and dissimilarity: a medicinal chemist's view, Perspective in Drug Discovery and Design Vol. 9, no. 10/11, pp. 225-252.

Kubinyi, H. (1998c) Combinatorial and computational approaches in structure-based drug design, Current Opinion in Drug Discovery and Development, Vol. 1, no. 1, pp. 16-127.

Kwavnicki, W. (1994) Knowledge, Innovation and Economy, Oficyna Wydawnicza Politechniki Wroclawskiej. Wroclaw.

Labute, P. (2000) A widely applicable set of descriptors, Journal of Computer Graphics and Modelling, Vol. 18, pp. 464-477.

Lado, A., Boyd, N., Wright, P. (1992) A competitive-based model of sustainable competitive advantage: toward a conceptual integration, Journal of Management, Vol. 18, no. 1, pp. 77-91.

Lahana, R (1999) How many leads from HTS? Editorial, Drug Discovery Today, Vol. 4, Issue 10. pp. 447-448.

Lajiness, M.S. (1997) Dissimilarity-based compound selection techniques, Perspective in Drug Discovery, Vol. 7/8, pp. 65-84.

Lam, K.S., Salmon, S.E., Hersh, E. M., Hruby, V.J., Kazmierski, W. M., Knapp, R. J. (1991) A new type of synthetic peptider library for identifying ligand-binding activity. Nature. Vol. 354, pp. 82-84. 
Langrish, J., Gibbons, M., Evans, W., Jevons, F. (1972) Wealth from Knowledge, MacMillan, London.

Lawson, C., Lorenz, E. (1999) Collective Learning, Tacit Knowledge and Regional Innovative Capacity' Regional Studies, Vol. 33, No. 4, pp. 305-317.

Leach, A., Hann, M. (2000) The in silico world of virtual libraries, Drug Discovery Today, Vol. 5, Issue 8, pp. 326-336.

Learned, E., Christensen, C.R., Andrews, K., Guth, W. (1965) Business Policy: Text and Cases, Homewood, IL, Richard D. Irwin.

Lebl, M. (1998) Parallel personal comments on "classical" papers in combinatorial chemistry. Journal of Combinatorial Chemistry, Vol. 1, No. 1, pp. 3-24.

Lei, D., Hitt, M., Bettis, R. (1996) Dynamic core competences through metalearning and strategic context, Journal of Management, Vol. 222, no. 4, pp. 549-569.

Levin, R., Klevorick, A., Nelson R., Winter, S. (1987) Appropriating the returns from industrial research and development, Brookings Papers on Economic Activity, Vol. 3, pp. 783-820.

Levinthal, D.A., March, J.G. (1993) The Myopia of Learning. Strategic Management Journal, Vol. 14, pp. 95-112.

Levitt, B., March, J. (1988) Organizational learning, Annual Review of Sociology, Vol. 14, pp. 319-340.

Lewis, J. (1990) Partnerships for profit. Structuring and managing strategic alliances, The Free Press.

Li, J., Murray, C., Waszkowycz, B., Young, S. Targeted molecular diversity in drug discovery: integration of structure-based design and combinatorial chemistry (1998) Drug Discovery Today, Vol 3, Issue 3, pp. 105-112.

Lipinsky, A., Lombardo, F., Dominy, B., Feeney, P. (1997) Experimental and computational approaches to estimate solubility and permeability in drug discovery and development settings. Advanced Drug Delivery Revieus, Vol. 23, pp. 3-25.

Liebenau, J. (1985) Innovation in pharmaceutical: industrial R\&D in the eraly twentieth century" in Resacrh Policy, Vol. 14, pp.179-187.

Lieberman, M. (1984) The learning curve and pricing in the chemical industry, Rand Journal of Economics, Vol. 15, pp. 213-228.

Liebeskind, J.P. (1996) Knowledge, strategy and the theory of the firm, Strategic Management Journal, Vol. 17, pp. 93-107.

Liebeskind, J.P., Oliver, A.L., Zucker, L., Brewer, M. (1996) Social networks, learning, and flexibility: sourcing scientific knowledge in new biotechnology companies, Organizational Science, Vol. 7. pp. 428-443.

Lindholm Dahlstrand, A. (1997) Growth and inventiveness in technology-based spin-off firms, Research Policy, Vol. 26, pp. 331-344.

Lippman, S., Rumelt, R. (1982) Uncertain imitability: an analysis of interfirm differences in efficiency under competition, Bell Journal of Economics, Vol. 23, pp. 418-438.

List, F. (1841) The National System of Political Economy, London, Longman.

Lytton, M. (1997) The rise of the platform technology deal, Managing Intellectual Property, issue 71, July/August.

Lu, Z.J., Comanor, W.S, (1998) Strategic Pricing of New Pharmaceuticals, Review of Economics and Statistics, Vol. 80, no. 1, pp. 108-118.

Lundvall, B. (ed) (1992) National Systems of Innovation, London, Pinter. 
Lundvall, B., Johnson, B. (1994) The learning economy, Journal of Industry Studies; Vol. 1, no. 2, December, pp. 23-42.

Lütz, S. (1997) Learning through intermediaries: The case of inter-firm research collaborations, in M. Ebers (ed.) The Formation of Inter-Organziational Networks, Oxford University Press.

McEvily, S.K., Chakravarthy, B. (1999) Resource context and the returns of investments in R\&D, In: Havlovic, S.J. (Ed.) Proceedings of the Academy of Management Meetings 1999.

McKelvey, M. (1996) Discontinuities in genetic engineering for pharmaceuticals? Firm jumps and lock-in in systems of innovation, Technology Analysis \& Strategic Management, Vol. 8, no. 2, pp. 107-115.

McMillan, S., Narin, F., Deeds, D. (2000) An Analysis of the Critical Role of Public Science in Innovation: The Case of Biotechnology, Research Policy, Vol. 29, pp. 1-8.

MaClean, D., Baldwin, J.J., Ivanov, v.T., Kato, Y., Shaw, A., Schneider, P., Gordon, E.M. (1999) Glossary of terms used in combinatorial chemistry, Pure Applied Chemistry, Vol. 71, No. 12, pp. 2349-2365.

Machlup, R.F. (1962) The Production and Distribution of Knowledge in the United States, Princeton University Press.

Mahoney, J., Pandian, R. (1992) The resource-based view within the conversation of strategic management, Strategic Management Journal, Vol. 13, pp. 363-380.

Malo, S., Geuna, A. (2000) Science-Technology Linkages in an Emerging Research Platform: The Case of Combinatorial Chemistry and Biology. Scientometrics, Vol. 47, pp. 303321.

Malerba, F.. Orsenigo, L. (1995) Schumpeterian patterns of innovation, Cambridge Journal of Economics, Vol. 19, pp. 47-65.

Mansfield, E. (1991) Academic research and industrial innovation, Research Policy, Vol.20, pp. $1-12$.

Mansfield, E. (1995) Academic research underlying industrial innovations: sources, characteristics, and financing. The Review of Economics and Statistics, Vol.77, no.1, pp. 55-65.

Mansfield, E., Schwartz, M., Wagner, S. (1981) Imitation costs and patents: an empirical study, The Economic Journal, Vol. 91, pp. 907-918.

March, J. (1991) Exploration and exploitation in organizational learning, Organization Science, Vol. 2, no. 1, pp. 71-87.

Marshall, A. (1920) Industry and Trade, MacMillan, London.

Marshall, A. (1952) Principles of Economics, MacMillan, London.

Mason, E.S. (1957) Economic Concentration and the Monopoly Problem, Cambridge, Harvard University Press.

Mason, E.S. (1966) Introduction. in E.S. Mason (ed) The Corporation in Modern Society. Cambridge, Harvard University Press.

Mathews, J. (2002) A resource-based view of Schumpeterian economic dynamics, Journal of Evolutionary Economics, Vol. 12 Issue 1-2, pp 29-54

Maxwell, R., Eckhard, S. (1990) Drug Discovery: a Case Book and Analysis, Clifton, NK: Humana Press.

Merrifield, R.B. (1965) Automated synthesis of peptides, Science, Vol. 150, pp.178-85.

Merritt, A. (1998) Uptake of new technology in lead optimization for drug discovery, Drug Discovery Today, Vol. 3, Issue 11, pp. 505-510. 
Miller, D., Shamsie, J. (1996) The resource-based view of the firm in two environments: The Hollywood film studios from 1936 to 1965, Academy of Management Journal, Vol. 39 Issue 3, pp.519-543.

Moates, F.C., Somani, M., Annamalai, J., Richardson, J.T., Luss, D., Willson, R.C. (1996) Infrared thermographic screening of combin atorial libraries of heterogeneous catalysts. Ind. Eng. Chem. Res., Vol. 35, pp. 480.

Mody, A. (1993) Learning through alliances, Journal of Economic Behavior and Organization, Vol. 20. pp. 151-170.

Montgomery, C., Wernerfelt, B. (1988) Diversification, Ricardian rents, and Tobin's q, RAND Journal of Economics, Vol. 19, no. 4, pp. 623-632.

Moukheiber, J. (1998) A hail of silver bullets, Forbes Magazine, January 26.

Mooney, G. (2001) Challenges faced by the pharmaceutical industry: training graduates for employment in pharmaceutical R\&D, European Journal of Pharmaceutical Sciences, Vol. 12. pp. 353-359.

Mullis, K. (1990) The unusual origin of the polymerase chain reaction, Scientific American, April.

Murphy, G.B., Trailer, J.F., Hill, R.C. (1996) Measuring performance in entrepreneurship research, Journal of Business Research, Vol. 36, pp. 15-23.

National Science Foundation (2000) Science and Engineering Indicators.

NIHCM (National Institute for Health Care Management) (2002) Changing Pattern of Pharmaceutical Innovation, A report for the National Institute for Health Care Management.

Narin, F., Olivastro D. (1992) Status Report: Linkage Between Technology and Science. Research Policy, Vol. 21, pp. 237-249.

Narin, F., Hamilton, K.S., Olivastro, D. (1997) The increasing linkage between US technology and public science, Research Policy, Vol. 26, pp. 317-330.

Nature Biotechnology (2000) Lead validation platforms, Vol. 18, pp. IT47-IT49..

Nelson, R. (1959) The simple economics of basic scientific research, Jourmal of Political Economy, Vol. 67. pp. 297-306.

Nelson, R. (1989) What is private and what is public about technology? Science, Technology and Human Values, Vol. 14, No. 3, pp. 229-241.

Nelson, R., Winter, S. (1977) In search of a useful theory of innovation, Research Policy, Vol. 6, no. 1, pp. 36-76.

Nelson, R., Winter, S. (1982) An Evolutionary Theory of Economic Change, Cambridge, Belnap Press.

Nelson, R. (1991) Why do firms differ, how should does it matter? Strategic Management Journal, Vol. 12, pp. 61-74.

Nelson, R. (1996) The Evolution of Comparative or Competitive Advantage: A Preliminary Report on a Study, Industrial and Corporate Change, Vol. 5, no.2, pp. 597-617.

New Reporter (2000) Chemical attraction brings in major industrial companies, Volume 17 Issue 13.

Nicolaou, K.C., Xiao, X.Y., Parandoosh, Z., Senyei, A., \& Nova, M.P. (1995) Radiofrequency encoded combinatorial chemistry, Angewandte Chemie International Ed., Vol. 34, pp. 2289-2291.

Nightinghale, P. (2000) Economies of scale in experimentation: knowledge and technology in pharmaceutical R\&D. Industrial and Corporate Change, Vol. 9, No. 2, pp. 315-359.

Nonaka, I. (1991) The knowledge-creating company, Harvard Business Review, November- 
December, pp. 96-104.

NYT (New York Times) (2003) Isis Pharmaceuticals to cut jobs after drug fails test, Section C, p. 4.

OECD (Organisation for Economic Co-operation and Development) (1996) The Knowledge Based Economy, Paris.

OECD (Organisation for Economic Co-operation and Development) (2000) Knowledge Management in the Learning Society, Paris.

Ohlmeyer, M.H.J., Swanson, R.N., Dillard, L.W., Reader, J.C., Asouline, G., Kobayashi, R., Wigler, M., Still, W.C. (1993) Complex synthetic chemical libraries indexed with molecular tags, Proceedings in National Academy of Science USA., Vol. 90, pp. 1092210926.

Oldenburg, K. (1998) Current and future trends in high throughput screening for drug discovery, Annual Reports in Medicinal Chemistry, Vol. 33, pp. 301-311.

Oprea, T., Gottfries, J., Sherbukhin, P., Kühler, T. (2000) Chemical information management in drug discovery: optimizing the computational and combinatorial chemistry interfaces, Journal of Molecular Graphics and Modeling, Vol. 18, Issues 4-5, pp. 512-524.

Olk, P., Young, C. (1997) Why members stay in or leave an R\&D consortium and conditions of membership as determinants of continuity, Strategic Management Journal, Vol. 18, pp. 855-877.

Orsenigo, L. (1989) The Emergence of Biotechnology, Pinter.

OTA (Office of Technology Assessment) (1993) Pharmaceutical $R \& D$ : Costs, Risks and Rewards, OTA-H-522 (Washington DC: US Government Printing Office).

Pammolli, F., Riccaboni, M. (2000) Technological Competencies in Networks of Innovators. The Case of Biopharmaceuticals, Paper presented at the Merck Foundation Conference, EPRIS Program. London.

Papac, D., Shahrokh, Z. (2001) Mass spectrometry innovations in drug discovery and development, Pharmaceutical Research, Vol. 18, No. 2, pp. 131-145.

Parle, E. (1999) Executive Roundtable: Drug Discovery. Chemical Market Reporter, August 16.

Patel, P., Pavitt, K. (1997) The technological competencies of the world's largest firms: complex and path-dependent, but not much variety, Research Policy, Vol. 26, pp.141156.

Patterson, D.E, Cramer, R.D., Ferguson, A.M., Clark, R. D., Weinberger, L. (1996) Neighborhood behavior: a useful concept for validation of "Molecular Diversity" descriptors, Journal of Medical Chemistry, Vol. 39, pp.

Pavia, M.R. (1996) The chemical generation of molecular diversity, Network Science, (www.awod.com/netsci/Science/Combichem/featiure01.html).

Pavitt, K. (1988) Uses and abuses of patent statistics, in Van Raan, (ed), Handbook of Quantitative Studies of Science and Technology, Elsevier Science Publishers.

Pavitt, K. (1992) Some Foundations for a Theory of the Large Innovating Firm, in E.H. David (ed), Industrial Research and Innovation in Business, Edgerton Elgar.

Pearlman, R. S. (1996) Novel Software Tonls for Addressing Chemical Diversity, Laboratory for Molecular Graphics and Theoretical Modeling, College of Pharmacy, University of Texas. Published June/July, 1996

Penrose, E. (1959) The Theory of the Growth of the Firm, Oxford University Press.

Persidis, A. (1998) Combinatorial chemistry, Nature Biotechnology, Volume 16, number 7, pp. 
690-601.

Persidis, A. (1999) Consolidation in biotechnology, Nature Biotechnology, Vol. 17. Supplement, pp. BE3-BE4.

Persidis, A. (2001) Strategies of biotechnology firms towards new, platform technologies, International Journal of Bio Technology. Vol. 3, Nos.1/2, pp. 23-31.

Peteraf, M. (1993) The cornerstones of competitive management: a resource-based view, Strategic Managemert Journal, Vol. 14, pp.179-191.

Pharmaceutical Business News (1997) Laboratories on a chip, December, pp. 17-19.

PHRMA (Pharmaceutical Research and Manufacturers of America) (2001) PHRMA Annual Report 2001-2002.

Plunkett, M.J., Ellman, J.A. (1997) Combinatorial chemistry and new drugs, Scientific American, Vol. 267, pp. 68-73.

Pisano, G., Shan, W., Teece, D. (1988) Joint ventures and collaboration in the biotechnology industry, in D., Mowery (ed), International Collaborative Ventures in US Manufacturing. Cambridge, Ballinger, pp. 183-221.

Polanyi, M. (1958) Personal Knowledge: Towards a Post-Critical Philosophy, New York, Harper Torchbooks.

Polanyi, M. (1966) The logic of tacit inference, Philosophy, Vol. 41, pp. 1-18.

Polinsky. A. (1999) Combichem and Chemoinformatics, Current Opinion in Drug Discovery, Vol. 2, no. 3, pp. 197-203.

Pollack, A. (2002) Drug research yields a decreasing return, The New York Times, Saturday. April 20.

Porter, M. (1979a) How competitive forces shape strategy? Harvard Business Review, Vol. 57. pp. 137-145.

Porter, M. (1979b) The structure within industries and companies performance, Review of Economics and Statistics, May, pp. 214-227.

Porter, M. (1980) Competitive Strategy: Techniques for Analyzing a Business, New York, The Free Press.

Poste, G. (2000) Platform technologies: Second chance at success, Financial Times, October 13.

Powell, W. (1990) Neither market nor hierarchy: networks forms of organization, Research in Organizational Behavior, Vol. 12, pp. 295-336.

Prahalad, C.K., Bettis, R. (1986) The dominant logic: a new linkage between diversity and performance, Strategic Management Journal, Vol. 7, pp. 485-501.

Prevezer, M. (1997) The dynamics of industrial clustering in biotechnology. Small Business Economics, Vol. 9. pp. 255-271.

PR Newswire (2001a) Pharmacopeia and Eos Biotechnology to merge; combination will capitalize on complete drug discovery capabilities, August 22.

PR Newswire (2001b) Combinatorial chemistry puts Dow on the leading edge of materials research, June 13.

Ramesha, C. (2000) How many leads from HTS? - Comment, Drug Discovery Today, Vol. 5. Issue 2, Pages 43-44.

Reed, R., DeFillipi, R. (1990) Causal ambiguity, barriers to imitation, and sustainable competitive advantage, Academy of Management Review, Vol. 15, no. 1, pp. 88-102.

Roberts, E.B., Mizouchi, R. (1989) Inter-firm technological collaboration: the case of Japanese biotechnology, International Journal of Technology Management, Vol. 4, no. 1. 
pp. 43-61.

Roberts, P.W. (1999) Product innovation, product-market competition and persistent profitability in the US pharmaceutical industry, Strategic Management Journal, Vol. 20, pp. 655-670.

Rogers, E., Takegami, S., Yin, J. (2001) Lessons learned about technology transfer, Technovation, Vol. 21, pp. 253-261.

Rosenberg, N. (1976) Perspective on Technology Cambridge, Cambridge University Press.

Rosenberg, N. (1990) Why do firms do basic research with their own money? Research Policy. Vol. 19, no. 2, pp. 165-175.

Rosenberg, N. (1982) Inside the Black Box: Technology and Economics. Cambridge, Cambridge University Press.

Rosenberg, N. (1992) Science and technology in the twentieth century, in G. Dosi, R. Giannetti, and P.A. Toninelli (eds) Technology and Enterprise in a Historical Perspective, Cambridge Press, Oxford.

Rosenberg. N. (1994) Exploring the Black Box: Technology, Economics and History, Cambridge, Cambridge University Press.

Rosenberg, N. (1998) Uncertainty and Technological Change, The Economic Impact of Knowledge, pp. 17-34.

Rosenbloom, R.S., Christensen, C. (1994) Technological discontinuities, organizational capabilities and strategic commitments, Industrial and Corporate Change, Vol.3, No.3, pp.107-126.

Rothwell, R. (1989) Firm size, innovation and industrial change, Small Buisness Economics, Vol. 1 , no. 1, pp. 51-64.

Rothwell, R. (1992) Successful industrial innovation: critical factors for the 1990 s, $R \& D$ Management, Vol. 22, no. 3, pp.

Rothwell, R. (1994) Industrial Innovation: Success, Strategy, Trends, in M. Dodgson and R. Rothwell (eds), The Handbook of Industrial Innovation, Aldershot, U.K. Elgar.

Rothwell, R., Dodgson, M. (1994) Innovation and firm size, in M. Dodgson and R. Rothwell (eds), The Handbook of Industrial Innovation, Aldershot, U.K. Elgar, pp. 310-325.

Rothwell, R., Freeman, C., Horsley, A., Jervis, A.B., Roberston, A.B., Townshend, J. (1974) SAPPHO updated-Project SAPPHO phase II, Research Policy, Vol. 3, pp. 258291.

Rumelt, R. (1982) Diversification, strategy and profitability, Strategic Management Journal, Vol. 3. pp. 359-369.

Rumelt, R. (1984) Towards a strategic theory of the firm, Competitive Strategic Management, B. Lamb (Ed.) Engelwood Cliffs, NJ.

Rumelt, R. P. (1991) How much does industry matter?, Strategic Management Journal, Vol. 12. pp. $167-185$.

Sachwald, F. (1998) Cooperative agreements and the theory of the firm: focusing on barriers to change, Journal of Economic Behaviour \& Organization, Vol. 35, pp. 203-225.

Saftlas, H. (2001) A Drug R\&D Firm Worth Discovering, Business Week, April 2.

Salemme, F.R., Spurlino J., Bone R. (1997) Serendipity meets precision: The integration of structure-based drug design and combinatorial chemistry for efficient drug discovery, Structure, Vol. 5, Issue 3, 1997, pp. 319-324.

Salter, A., Martin, B. (2001) The economic benefits of publicly funded basic research: A critical review, Research Policy, Vol. 30, 509-32. 
Sanson, C. (1999) Dealing with the dilemma of high throughput screening, Scrip Magazine, July/August, pp. 8-9.

Savage, G. T., Nix, T.W., Whitehead, C. J., Blair, J.D (1991) Strategies for Assessing and

Managing Stakeholders, Academy of Management Executive, Vol. 5, no. 2, pp. 61-75.

Saviotti, P.P. (1998) On the dynamics of appropriability of tacit and of codified knowledge, Research Policy, Vol. 26, pp. 843-856.

Saviotti, P.P., Joly, P.B., Estades, J., Ramani, S., De Looze, M.A. (1998) The creation of European dedicated biotechnology firms, in Senker, J. (ed.); Biotechnology and competitive advantage: Europe's firms and the US challenge, Cheltenham, E. Elgar, pp 6888.

Saxenian, A. (1991) The Origins and Dynamics of Production Network in Silicon Valley, Research Policy, Vol. 20, pp. 423-427

Scherer, F. M. (1980). Industrial Market Structure and Economic Performance, second edition. Chicago: Rand-McNally.

Schrader, S. (1991) Informal technology transfer between firms: cooperation through information trading, Research Policy, Vol. 20, pp. 153-170.

Science (1998) Breakthrough of the Year: The Runners-ups Vol. 282, No. 5397, pp. 21572161.

Schmalensee, R. (1985) Markets Differ Much? American Economic Review, Vol. 75 no. 3, pp. 341-51

Schoemaker, P., Amit, R. (1994) Investments in strategic assets: industry and firm-level perspectives, Advances in Strategic Management, Vol. 10A, pp. 3-33.

Schrader, S. (1991) Informal Technology Transfer Between Firms: Cooperation Through Information Trading, Research Policy, Vol. 20, no. 2, pp. 153-170.

Schumpeter, J.A. (1934;1984) The Theory of Economic Development, Cambridge, Maas. Harvard University Press.

Schumpeter, J.A. (1942) Capitalism, Socialism and Democracy, New York, Harper.

Schwartzman, D. (1976) Innovation in the Pharmaceutical Industry, John Hopkins University Press.

Senkan, SM. (1998) High-throughput screening of solid-state catalysts of libraries, Nature. Vol. 384, pp. 350-353.

Senker, J. (1998) Biotechnology: the external environment, Biotechnology and competitive advantage. Europe's firms and the US challenge, ed. By J. Senker, Edward Elgar.

Service, R.F. (1998) Winning combination, Technology Review, May/June, pp.34-41.

Sheridan, R.P., Kearsley, S.K. (1995) Using a genetic algorithm to suggest combinatorial libraries; Journal Chem. Inf. Comput. Sci. Vol. 35, pp. 310-320.

Simmons, S. (1995) Do economies of scale exist in the pharmaceutical industry? Journal of Business and Management, Spring, pp. 96-113.

Simon, H. (1955) A behavioural model of rational choice, Quarterly Journal of Economics, Vol. 69. pp. 99-118.

Smith, A. (1776) The Wealth of Nations, Edwin Cannon, London, Methuen.

Smith, K., Grimm, C., Chen, M., Gannon, M. (1989) Predictors of response time to competitive strategic actions: preliminary theory and evidence, Journal of Business Research Vol. 18, pp. 245-258.

Smith, C. (2002) Cheminformatics: redefining the crucible, The Scientist, Vo. 16, No. 8. pp. 40, Apr. 15. 
Sørensen, J., Stuart, E. T. (2000) Aging, Obsolescence and Organizational Innovation, Administrative Science Quarterly, Vol. 45, pp. 81-112.

Sornette, D. (2002) Economies of scale in innovations with block-busters, Quantitative Finance, Vol. 22, pp. 224-227.

Spencer, R. (1998) High-throughput screening of historic collections: observations on file size, biological targets and file diversity. Biotechnology and Bioengineering (Combinatorial Chemistry), Vol. 61, no. 1, pp. 61-

Spender, J-C. (1993) Competitive advantage from tacit knowledge? Unpacking the concept and its strategic implications, Academy of Management Best Papers Proceedings, pp. 37-41.

Spender, J-C. (1996) Making knowledge the basis of a dynamic theory of the firm. Strategic Management Journal, Vol. 17, pp. 45-62.

Stalk, G. (1988) Time-The next source of competitive advantage, Harvard Business Review, July-August, pp. 41-51.

Stalk, G., Evans, P., Shulman, L. (1992) Competing on capabilities: the rew rules of corporate strategy. Harvard Business Review, March-April, pp. 57-69.

Steensma, K. (1996) Acquiring technological competencies through inter-organizational collaboration: an organizational learning perspective, Journal of Engineering and Technology Management, Vol. 12, pp. 267-286.

Stigler, C.J. (1957) Perfect competition, historically contemplated, Journal of Political Economy, Vol. 65. pp. 1-17.

Still, W.C. (1996) Discovery of sequence-selective peptide binding by synthetic receptors using encoded combinatorial libraries, Account. Chem. Res., Vol. 29, pp. 155-163

Studt, T. (1999) Combinatorial chemistry: collaborations enhance technological strengths, $R \& D$ Magazine, January, pp. 46-48.

Sucholeiki, I. (1999) New developments in solid phase synthesis supports, Molecular Diversity. Vol. 4, pp. 25-30.

Sullivan, M. (1997) Chemistry on the Web: a new approach to chemical discovery. Today's Chemist at Work, Vol. 6, no. 6, pp.13, 15-16.

Sundberg, S.A. (2000) High-throughput and ultra-high-throughput screening: solcution and cell based approaches, Current Opinion in Biotechnology, Vol. 11, pp. 47-53.

Swann, J.P. (1988) Academic Scientists and the Pharmaceutical Industry: Cooperative Research in Twentieth-Century America. Baltimore, Md: Johns Hopkins University Press.

TechKnowledge Associates (1997) Combinatorial chemistry: a business overview, A joint venture of Winifred Halsey \& Associates and Strategic Information Resources.

Teece, D. (1977) Technology transfer by multinational firms: the resource cost of international technology transfer, Economic Journal, vol. 87, pp. 242-261.

Teece, D. (1980) Economies of scope and the scope of the enterprise, Journal of Economic Behavior and Organization, Vol. 1, pp. 223-247.

Teece, D. (1981) The market for know-how and efficient international transfer of technology, Annals of the American Academy of Political and Social Science, Vol. 458, no. 19, pp. 8196.

Teece, D. (1982) Towards an economic theory of the multiproduct firm, Journal of Economic Behavior and Organization, Vol. 3, pp. 39-63.

Teece, D. (1987) Profiting from technological innovation: Implications for integration, licensing and public policy, in D. Teece (ed.) By, The Competitive Challenge, Strategies for Industrial Innovations and Renewal, Ballinger pub. 
Teece, D. (1992) Competition, Cooperation and Innovation, Journal of Economic Behavior and Organization, Vol. 18, no. 1, pp. 1-25.

Teece, D. (1996) Firm Organization, Industrial Structure, and Technological Innovation, Journal of Economic Behavior and Organization, Vol. 31, no. 2, November, pp.193-224.

Teece, D., Pisano, G., Shuen, A. (1997) Dynamic capabilities and strategic management, Strategic Management Journal, Vol. 18, pp. 509-533.

The Economist (1996) The World in 1997, London.

The Economist (1999a) Biotech's Father William, June 26.

The Economist (1999b) Big is beautiful, March 27.

Thayer, A. (1996) Combinatorial chemistry becoming core technology at drug discovery companies, Chemical \& Engineering News, Vol. 57, No. 15, February 12, pp. 57-64.

Thayer, A. (2002) Genomics moves on, Chemical \& Engineering New s, Vol. 80, no. 41, pp. 2536.

Thiel, K. (1999) Suffering from Success: Combinatorial chemistry companies struggle with "commodity" image, www.biospace.com.

Thomke, S., E., Von Hippel, R. Franke (1998) Modes of Experimentation: An Innovation Process -and Competitive- Variable, Research Policy, Vol. 27, pp. 315-332.

Timpane, J. (1996) Six hot careers: biotechnology, pharmaceuticals \& beyond, special advertising supplement, Science, sept. 27.

Toole, A. (2000) The Impact of Public Basic Research on Industrial Innovation: Evidence from the Pharmaceutical Industry, SIEPR Policy paper No. 00-07.

Tripsas, M. (1997) Unravelling the Process of Creative Destruction: Complementary Assets and Incumbent Survival in the Typesetter Industry. Strategic Management Journal Special Issue, Vol. 18, pp.119-142.

Tushman, M., Anderson, P. (1986) Technological discontinuities and organizational environment, Administrative Science Quarterly, Vol. 31, pp. 439-465.

Valler, M., Green, D. (2000) Diversity screening versus focused screening in drug discovery, Drug Discovery Today, Vol. 5, Issue 7, pp. 286-293.

van Arnum, P. (2000) Combinatorial Chemistry in Process Development, Chemical Market

Reporter, Issue: April 24, 2000

van Dover, R.B., Schneemeyer, L.F., Fleming, R.M. (1998) Discovery of a useful thin-film dielectric using a composition spread approach, Nature, Vol. 392, pp. 162-164..

van Hijte, L., Marciniak, G., Froloff, N. (1999) Combinatorial chemistry, automation and molecular diversity: new trends in the pharmaceutical industry, Journal of Chromatography B, Vol. 725, pp. 3-15.

Venton, D., Woodbury, C. (1999) Screening combinatorial chemistry, Chemometrics and Intelligent Labaratory Systems, Vol. 48, pp. 131-150.

Vermeulen, F., Barkema, H. (2001) Learning through acquisitions, Academy of Management Journal, Vol. 44, No. 3, pp. 457-476.

Vernon, J., Gusen, P. (1974) Technical change and firm size: the pharmaceutical industry, Review of Economics and Statistics, Vol. 56, pp. 294-302.

Villar, H., Koehler, R.(2000) Comments on the design of chemical libraries for screening,, Molecular Diversity, Vol. 5, Issue 1, pp. 13-24.

von Hippel, E. (1988) The Source of Innovation, Cambridge: MIT Press.

Walters, P., Matthew T., Stahl, M., Murcko, M. (1998) Virtual screening - an overview, Drug Discovery Today, Vol. 3, Issue 4, April 1998, pp. 160-178. 
Wang, Q., von Tunzelmann, N. (2000) Complexity and the functions of the firm: breadth and depth, Research Policy, pp. 805-818.

Watt, A., Morrison, D. Evans, D. (2000) Approaches to higher-throughput pharmacokinetics (HTPK) in drug discovery, Drug Discovery Today, Vol. 5, Issue 1, pp. 17-24.

Wei, T., Wallace-Freedman, W.G., Schultz, P.G., Xiang. X.-D. (1996) Scanning Tip Microwave Near Field Microscope" Appl. Phys. Lett. Vol. 68, pp. 3506-3508.

Weller, H.N. (1999) Purification of combinatorial libraries, Molecular Diversity, Vol. 4, pp. 47-52.

Wernerfelt, B. (1984) A resource-based view of the firm, Strategic Management Journal, Vol. 5. pp. 171-180.

Wernerfelt, B. (1989) From critical resources to corporate strategy, Journal of General Management, Vol. 14, pp. 4-12.

Wernerfelt, B., Montgomery, C (1988) What is an attractive industry? Management Science, Vol. 3, 1223-1230.

Wertheimer, A., Levy, R., O'Connor, T. (2001) Too many drugs? The clinical and economic value of incremental innovations, Research in Human Capital and Development, Vol. 14. pp. 77-118.

Westphal, L., Kim, L., Dahlman, C. (1985) Reflections on the Republic of Korea's acquisition of technological capability, in N. Rosenberg and C. Frischtak (eds) International Technology Transfer, Prager, New-York.

Wiggins, S. (1981) Product Regulation and New Drug Introductions: Some New Evidence from the 1970s, The Review of Economics and Statistics, Vol. 63, pp. 615-619.

Willett, P. (2000) Chemoinformatics -similarity and diversity in chemical libraries, Current Opinion in Biotechnology, Vol. 11, Issue 1, pp. 85-88.

Wilson, S., Czarnik, A. (1997) Combinatorial chemistry: synthesis and applications, John Wilez \& Sons, Inc.

Windrum, P., Birchenhall, C. (1998) Is product life cycle theory a special case? Dominant designs and the emergence of market niches through coevolutionary-learning, Structural Change and Economic Dynamics, Vol. 9, pp. 109-134.

Winter, S. (1984) Schumpeterian competition in alternative technological regimes, Journal of Economic Behaviour and Organzation, Vol. 5, pp. 287-320.

Winter, S. (1987) Knowledge and competence as strategic assets, The Competitive Challenge, in D. Teece (ed.), Strategies for Industrial Innovations and Renewal, Ballinger pub.

Wood, A. (2000) Combinatorial chemistry picks up speed, Chemical Week, August 9.

Wood, A. (2001) Combinatorial chemistry: reaching commercialization, Chemical Week, July 18.

Wright, T. (1936) Factors affecting the cost of airplanes, Journal of aeronautical Science, Vol. 3 , pp. 122-128.

Xiang, X.D., Sun, X., Briceno, G., Lou, Y., Wang, K.A., Chang, H., Wallace-Freedman, W.G., Chen, S.W., Schultz, P.G. (1995) A combinatorial approach to materials discovery. Science, Vol. 268, pp. 1738-1740.

Zucker, L.G., Darby, M.R., Armstrong. J. (1998) Geographically Localized Knowledge: Spillovers or Markets?, Economic Inquiry, Vol. 6, pp. 65-86.

Zuckermann, R.N., Kerr, J.M., Siani, M.A., Banville, S.C. (1992) Design, construction and application of a fully automated equimolar peptide mixture synthesizer. International Journal of Peptide and Protein Research, Vol. 40, pp. 497-506. 


\section{NEDERLANDSE SAMENVATTING}

Een centraal thema in industriële organisatie $(\mathrm{I} / \mathrm{O})$ is dat externe factoren de winstmogelijkheden van individuele bedrijven vorm geven. Winsten, of het gebrek daaraan, worden bepaald door de industrie en worden voornamelijk gezien als gevolg van marktmacht en sectorstructuur. Deze theorieën hebben uitgewezen behulpzaam te zijn in het economisch onderzoek, maar hebben ook hun keerzijde. Ten eerste hebben deze theorieën de economische wetenschap zo lang gedomineerd dat het verleidelijk is te suggereren dat bedrijven slechts hun prestaties zouden kunnen verbeteren door zich te wenden tot een attractieve sector en/of door zich te wapenen tegen concurrentie. Ten tweede is het $\mathrm{I} / \mathrm{O}$ paradigma niet in staat verschillen in efficiency tussen bedrijven te verklaren in een zelfde industrie of strategische groep van bedrijven. In deze context zal een bedrijf dat de concurrentie achter zich wil laten weinig steun ondervinden van de voornamelijk statische $\mathrm{I} / \mathrm{O}$ literatuur.

Teneinde de problemen met de $\mathrm{I} / \mathrm{O}$ zienswijze het hoofd te bieden, combineert de op kennis gebaseerde theorie van superieure prestaties, die in hoofdstuk 2 wordt ontwikkeld, bijdragen uit de resource-based zienswijze van het bedrijf en de naar voren tredende op kennis gebaseerde theorie van het bedrijf met evolutionaire economie, de economie van de innovatie, organisatorisch leren en de industrie-levenscyclus literatuur. Meer in het bijzonder schrijft de theorie de resource-based zienswijze een manier voor die nauw verbonden is met de bron van comparatief voordeel met betrekking tot de hulpbronnen van het bedrijf. Maar, zoals aanhangers van het dynamische capaciteitsraamwerk snel hebben aangetoond, zal het bezit van hulpbronnen en competenties onvoldoende zijn om welvaart te creëren in roerige omstandigheden. Deze dynamische capaciteitstheorie heeft een belangrijke bijdrage geleverd door erop te wijzen dat "the competitive advantage of firms lies with its managerial and organizational processes, shaped by its (specific) asset position, and the paths available to it" (Teece et al. 1997:518). Dit laatste argument, met betrekking tot de drie dimensies van het bedrijf als determinant van superieure prestaties geeft een goede gelegenheid een model te ontwikkelen dat zich richt op het in kaart brengen van de kenmerken van kennis en de creatie en accumulatie daarvan. In het bijzonder stelt de dissertatie dat het lot van het bedrijf: (1) direct verbonden is aan het technologische leerproces, (2) dat wordt geconditioneerd door de geaccumuleerde hoeveelheid kennis, en (3) wordt gekenmerkt door padafhankelijkheid. Verwant aan Dodgson (1991) wordt het concept van technologisch leren hier gedefinieerd als the process that allows firms to enhance, 
expand and/or renew their competences as a response to changes in technology, competition and demand.

Hoewel de dissertatie zich in essentie bezighoudt met één onderzoeksvraag, namelijk de conditie die winnaars onderscheidt van verliezers in turbulente omstandigheden, zijn de langetermijn gevolgen van twee vormen van technologische discontinuïteit ook van belang: (1) competentievernietigende discontinuïteit, die het gebruik van "new skills, abilities and knowledge in both the development and production of the product" met zich meebrengt, en (2) competentieverhogende innovaties, die "built on existing know-how within a product class" (Tushman 1986:441-442). De implicatie die wordt getrokken uit dit onderscheid is dat het eerste effect de competitieve nadruk verschuift in het voordeel van nieuwe toetreders, terwijl het laatste effect een competitief voordeel verschaft aan bedrijven die reeds in de markt hun plaats hebben verworven.

Om twee redenen levert de combinatorische chemie (of combichem) een interessante achtergrond op om deze gedachten te toetsen. De eerste reden is dat bedrijven in de combichem opereren in een turbulente omgeving waarin technologie, vraag en competenties snel veranderen. Technologisch leren is uiteraard van cruciaal belang. De tweede reden is dat, hoewel combichem wordt gezien als een eenvoudig probleemoplossend proces, een technologisch platform, een general-purpose technologie of een technologie ten behoeve van massaproductie, tevens een competentievẹrhogende proces van discontinuitteit herbergt. De combinatorische aanpak om medicijnen te ontdekken rust op een kennisbasis (i.e., chemie, biologie, geautomatiseerd instrumentarium en informatie technologie) die reeds decennia lang ter beschikking is, al gekend is en wordt gedeeld door wetenschappelijke instellingen en bedrijven, maar die tot vele malen meer verbindingen toelaat te syntheniseren tegen veel lagere kosten dan conventionele methoden. Dit punt kan niet voldoende onder de aandacht worden gebracht, daar de grootste bottleneck in de therapeutische medicijnmarkt niet langer een biologische is, maar veeleer een chemische. Hoewel iedere ontdekking van een medicijn zich traditioneel trachtte te richten op 500 moleculaire doelen (Drews 1997), heeft de explosie van nieuwe doelen die voortkomen uit het Human Genome Project de last van de innovatie op de schouders van de organische chemici gelegd. "We're in a very target-rich but lead-poor post-genomics era for drug discovery", legt Raymond Stevens, onderzoeker aan het Scripps Research Institute en mede-oprichter van Syrrx, uit (Henry 2001:69). Het gebrek aan verbindingen zou echter tot op zeker hoogte teniet moeten worden gedaan door nieuwe toetreders, die 979 moleculen in de pijplijn hebben. 
Hoofdstuk 3 handelt over technologische verandering en de manier waarop combichem een technologische discontinuitteit introduceerde en een basis formeerde voor een groot aantal incrementele innovaties op vier technologische trajecten. De basismethodologie is historisch gericht, waarbij nadruk wordt gelegd op het dynamische patroon van kenniscreatie in combinatorische medicijnontdekking. Sectie 3.2 heeft als doel de grondbeginselen, methodes en onderliggende principes in combichem te identificeren. Sectie 3.3 bestaat uit drie gedeeltes, die ieder de dynamiek van technologische ontwikkelingen in het veld belichten. Sectie 3.3.1 ontleedt de combichemmethode om nieuwe medicijnen te ontdekken in vijf pre-klinische stappen teneinde in staat te zijn de eerste twee technologische trajecten op waarde te schatten: incrementele innovaties die zich bezighouden met: (1) de synthese van compound libraries en (2) de ontdekking en optimalisatie van geleiding. Sectie 3.3.2 richt zich op een samenvatting van het onderzoek dat is uitgevoerd onder de paraplu van de zich op kennis baserende combichem als middel het derde technologische traject inzichtelijk te maken en de verdere integratie met de rationele wijze van medicijnontwikkeling te belichten. Sectie 3.3 .3 beschrijft het vierde traject, dat is, de recente veranderingen die combichem, samen met recente ontwikkelingen in de software en hardware, teweeg heeft gebracht in nieuwe materialen, katalysatoren, pesticiden, etc.

Hoofdstuk 4 draait om het aanpassen van een bedrijf in de context van een turbulente omgeving. Ongeveer 393 nieuwe toetreders hebben tot op heden een bekwaamheid in combichem weten te bewerkstelligen, en slechts 8 bedrijven hebben hun activiteiten stopgezet, hun aandelen verkocht of zijn gestopt vanwege een gebrek aan financiële middelen. De sleutel van deze hoge graad van overleving van nieuwe toetreders ligt in hun behavioural advantage. Liever dan de industrie te verlaten, zijn deze bedrijven geneigd om te gaan met veranderende technologie, concurrentie en vraag door aanpassing. Dat wil zeggen, nieuwe toetreders zijn in staat geweest hun kennisbasis en bekwaamheid door technologisch leren langs het tweede, derde en/of vierde technologische traject te loodsen, waarbij vele, zo niet de meerderheid, zijn verworden tot volledig geïntegreerde pharmaceutische bedrijven die zich richten op het ontdekken van nieuwe medicijnen. Sectie 4.2 is voornamelijk opgenomen om te illustreren hoe de voorwaarden met betrekking tot het betreden van de pharmaceutische industrie en de (agro)chemische industrie zijn veranderd als gevolg van de ontwikkelingen op het gebied van combichem. Sectie 4.3 richt zich op twee fundamentele fases in het proces van industriële ontwikkeling: (1) het bedrijf als verschaffer van compound libraries; (2) het bedrijf als verschaffer van goederen en diensten op chemische grondslag, en dan met name kleine moleculaire 
medicamenten. Daarnaast biedt deze sectie een beschouwing van de bijzondere relatie tussen deze nieuwe, op chemie gebaseerde, toetreders en andere kleine bedrijven, in het bijzonder bedrijfjes die zich bezighouden met genomics. Sectie 4.4 laat zien dat de recente ontwikkelingen met betrekking tot het grote aantal fusies en overnames niet het gevolg lijken te zijn van een op handen zijnde "shakeout", maar veeleer geïnterpreteerd moeten worden als een logische uitkomst van het besef dat rigiditeiten kunnen worden doorbroken en schaalvoordelen kunnen worden behaald indien kennisspecialisten met complementaire vaardigheden worden samengebracht onder hetzelfde dak. Sectie 4.5 besluit dit hoofdstuk en suggereert dat het overleven van nieuwe toetreders mogelijk blijft in een veld met op de achtergrond competentie-verhogende discontinuitteit.

Hoofdstuk 5 gaat nauwgezet in op de reactie van grote pharmaceutische en (agro)chemische bedrijven: (1) in-house ontwikkeling, (2) overname van nieuwe toetreders, (3) leren door allianties aan e gaan met nieuwe toetreders en (4) wetenschappelijke organisaties. Het hoofdstuk laat zien dat het gat tussen kleinere en grotere bedrijven nog nooit zo groot is geweest met betrekking tot de achterstand van grotere bedrijven op de leercurve, en dat de grotere bedrijven voornamelijk de kleinere overtreffen met betrekking tot combinatorial library output. In theorie zou dit de toekomst van de langetermijn ontwikkeling van nieuwe toetreders kunnen overschaduwen. Het voornaamste argument is dat grote pharmaceutische bedrijven, die zich snel de regels van het spel hebben eigengemaakt, het voordeel van hun grootțe kunnen uitbuiten door middel van schaalvoordelen en zo de nieuwe toetreders zullen gaan verdringen. In de praktijk, en dat wordt in het hoofdstuk aangetoond, blijkt het echter moeilijk voor grotere bedrijven om zelfstandig te handelen. Hoewel ze een materieel voordeel hebben ten opzichte van nieuwe toetreders, lijkt het erop dat beide partijen elkaar even hard nodig hebben.

Het tweeledige doel van hoofdstuk 5 is de bijdrage van publiek gefinancierd onderzoek voor industriële innovatie te benadrukken en de volgende puzzel op te lossen: de combinatorische onderzoeksoutput van wetenschappelijke organisaties in de landen van de Europese Unie (EU-15) is goed vergelijkbaar met die van in de Verenigde Staten gelokaliseerde wetenschappelijke instellingen, maar de Amerikaanse private sector lijkt veel gezonder te zijn dan waar ook ter wereld. Het blijkt inderdaad zo te zijn dat Amerikaanse toetreders het goed doen op alle gebieden: (1) het vormen van bedrijven, (2) combinatorial library output, (3) patenten, (4) compounds under preclinical stage, en (5) compounds under clinical stage. Deze dominantie is waarschijnlijk toe te schrijven aan verschillende, gerelateerde factoren, waaronder het verfijnde systeem van durfkapitaal, grotere bedrijven etc. Dit hoofdstuk brengt een engere kijk naar voren met betrekking tot de 
relatie tussen wetenschappelijke organisaties en nieuwe toetreders door te suggereren dat de Verenigde Staten een comparatief voordeel hebben ten opzichte van andere landen dankzij de grotere verspreiding van "publieke" kennis in de Amerikaanse economie.

Het laatste gedeelte van de dissertatie en hoofdstuk 7 keren terug naar de theorie van hoofdstuk 2 en laten een groot aantal van de thema's uit de hoofdstukken $3,4,5$ en 6 de revue passeren. Het laatste hoofdstuk is slechts gericht op een enkele theoretische vraag, namelijk de voorwaarden die de winnaars van de verliezers onderscheiden in een turbulente markt. Een correlatie- en regressieanalyse worden geïntroduceerd om te testen of betere prestaties zijn gerelateerd aan de volgende factoren: niveaus van intern leren, niveaus van leren bij andere organisaties, het leren door overnames, research "openness", locatie, grootte en diversificatie. De resultaten laten het belang zien van (1) extern leren bij wetenschappelijke organisaties, (2) lokalisatie in Californië, (3) het aantal werknemers, (4) bekwaamheid in combichem en (5) vroegere ervaring in de ontwikkeling van medicijnen. Het hoofdstuk en daarmee de dissertatie concluderen met de volgende normatieve voorschriften: bedrijven kunnen hun opbrengsten verhogen door een meervoudig technologisch platform te creëren, door middel van het verhogen van het interne niveau van leren, door het bevorderen van research "openness" en door sterke banden te onderhouden met wetenschappelijke organisaties. 


\section{CURRICULUM VITAE}

Stéphane Malo was born in Montréal on January 21, 1962. He received a BSc in sociology at the Université de Montréal and studied economics at Concordia University. Following this, he completed a MA in sociology at the Université du Québec à Montréal and a MA in Technology Policy and Innovation Management at the Maastricht Economic Research Institute on Innovation and Technology (MERIT), Maastricht University, in the Netherlands. Stéphane then briefly worked at the department of Biology and Society of the Free University of Amsterdam before joining MERIT for a doctorate in economics in 1996, where he carried out his research. He is currently working at the department of Industrial Dynamics at Chalmers University of Technology in Göteborg, Sweden. 
